Final Performance Report

on

\title{
DIMENSIONAL, MICROSTRUCTURAL AND COMPOSITIONAL STABILITY OF METAL FUELS
}

Contract \#DE-FG07-88ER12814

by

\author{
A.A. Solomon and M.A. Dayananda
}

Schools of Nuclear and Materials Engineering

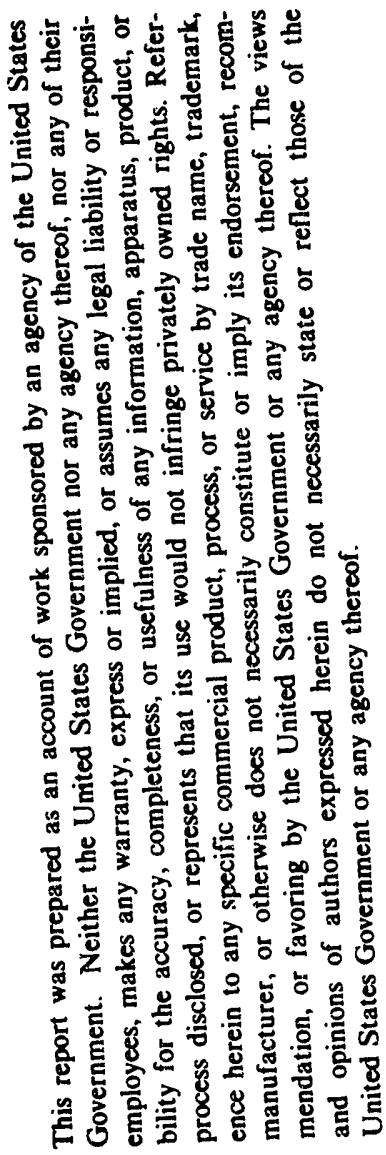

Purdue University

West Lafayette, IN 47907

\section{Submitted to}

Frederick Sienko

U.S. Department of Energy

Chicago Field Office

9800 S. Cass Avenue

RESEIVED

Argonne, II 60439

OSTI

March 15, 1993

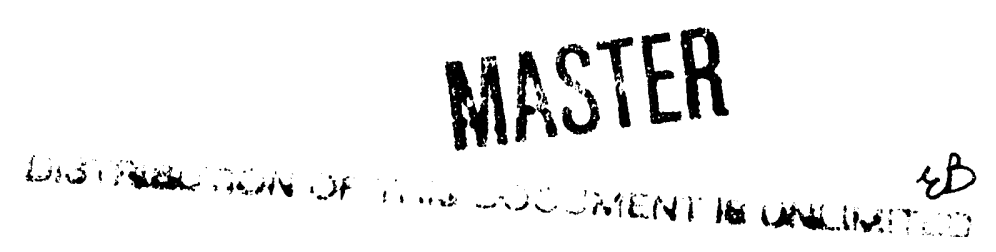




\section{TABLE OF CONTENTS}

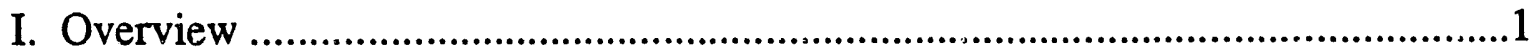

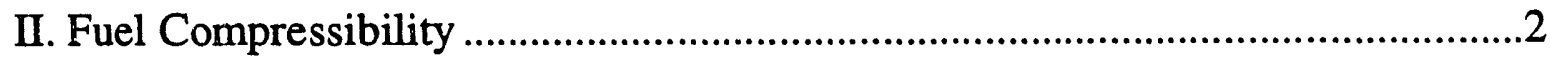

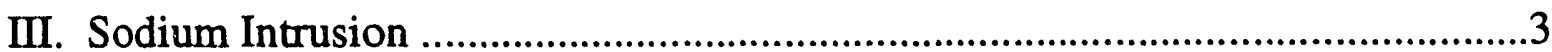

IV. Fuel-Cladding Interdiffusion Studies .............................................................

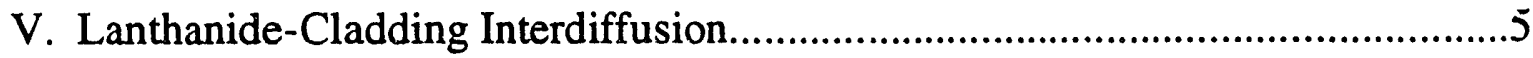

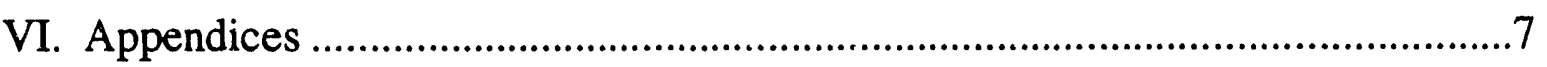

A. Hot Isostatic Pressing of U-10Zr by Coupled Boundary Diffusion/Power-Law Creep Cavitation - Part I

B. Hot Isostatic Pressing of U-10Zr by Coupled Boundary Diffusion/Power-Law Creep Cavitation - Part II

C. Liquid Sodium Intrusion into Porous U-10Zr Fuel Alloy by Differential Capillarity

D. Interdiffusion Between U-Zr Fuel and Selected Fe-Ni-Cr Alloys

E. Interdiffusion Between U-Zr Fuel vs. Selected Cladding Steels

F. Interdiffusion of Cerium in $\mathrm{Fe}$-Base Alloys with $\mathrm{Ni}$ or $\mathrm{Cr}$ 


\section{Overview}

The projects undertaken in this investigation were intended to address two major and traditional areas of concern for metal-fueled fast reactors: (1) the metallurgical compatibility of the fuel and its fission products with the stainless steel cladding, and (2) the effects of the extensive porosity development in the fuel on fuel/cladding interactions, and on sodium penetration in the fuel.

All of these projects have been brought to successful conclusion and have either appeared in archival publications, or are in various stages of publication. In addition, the

work has been presented at the 1990, 1992, and 1993 TMS-AIME meetings, at the 1992 American Nuclear Society meeting, and at the 1992 Powder Metallurgy World Congress. Three Ph.D. students (Sean McDeavitt, Dennis Keiser, and Weijun Liu) and one M.S. student (Peter Tortorici) have completed or are in progress of completing their degrees.

This project has also led to close interactions with colleagues at Argonne National Laboratory involved in the Integral Fast Reactor Program. Both Prof. A.A. Solomon and M.A. Dayananda have participated in annual programmatic review meetings at ANL, and have received ongoing support and the conclusion of the present program.

The technical results ae described in detail in the appendices, and introductory descriptions are given in the following sections. 


\section{Fuel Compressibility}

Metallic nuclear fuels swell primarily by a combination of anisotropic irradiation growth which causes grain boundary "tearing" at low temperatures, and by gaseous fission product precipitation into bubbles at higher temperatures. These phenomena produce a very large swelling component that must be accommodated in the design and performance of the fuel. In the Integral Fast Reactor or IFR fuel design, a large sodium-filled gap is provided between the fuel and cladding that permits heat removal as well as allowing sufficient volume for expansion. The aim is to have the fuel porosity interconnect at about the time the fuel contacts the cladding, so that the gas stabilizing the porosity can be released. Subsequent swelling can then be offset by hot-pressing of the fuel.

To study the ability of porous fuel to hot-press, a special powder metallurgy technique was developed to simulate porous $\mathrm{U}-10 \mathrm{Zr}$ fuels. Hot-pressing experiments were carried out in the $\alpha+\delta$ and $\gamma$ phase fields as described in Appendix A. The results provide the only primary data available on this important phenomenon in metallic fuels, and indicate that the previously assumed models used in fuel modelling codes should be modified. Under the conditions studied, the process appears to follow a coupled mechanism of dislocation motion and vacancy transport as described in Appendix B. However the work raises a cautionary note because the compressibility of $\mathrm{U}-10 \mathrm{Zr}$ fuel appears to be quite restricted especially at low temperatures. The inability of the fuel to compress 1 readily may be even more limited at high burnup when the solid fission products begin to occupy the available porosity. Thus the issue of fuel compressibility is not resolved. 


\section{Sodium Intrusion}

Using our technique of producing porous $\mathrm{U}-10 \mathrm{Zr}$ fuel, we were able to address the considerable uncertainty in fuel thermal conductivity because of the uncertainty of the degree of sodium penetration into the porous fuel. Contrary to previous dissolution experiments conducted at Argonne National Laboratory, our results in Appendix C indicate virtually complete penetration of sodium into the available porosity. A new theory is developed to rationalize the gas release and subsequent penetration of sodium using the notion of "differential capillarity" caused by variations in pore sizes. At sufficiently high temperatures, sodium "wets" U-10Zr causing capillary attraction into all pores. However, when pores are of different sizes, the attraction into small pores is sufficiently strong that sodium as well as the entrapped gas is forced out of the larger pores. The theoretical criterion developed for gas release and the porosity size distributions in the specimens studied determined by mercury intrusion porosimetry are consistent with the amount of sodium that penetrated the specimens. Critical experiments performed on specimens with uniform drilled holes verified that no gas is released when pores are of uniform size.

\section{Fuel-Cladding Interdiffusion Studies}

As part of interdiffusion studies relevant to fuel-cladding compatibility in the Integral Fast Reactors, systematic interdiffusion studies were carried out at $700^{\circ} \mathrm{C}$ with solid-solid diffusion couples assembled with a binary U-23 $\mathrm{Zr}$ (at.\%) alloy fuel bonded to cladding alloys of selected compositions. The composition of the cladding alloys included pure $\mathrm{Fe}$, 
pure Ni, binary $\mathrm{Fe}-20 \mathrm{Cr}, \mathrm{Ni}-16 \mathrm{Cr}$, Fe-10Ni alloys and a ternary Fe-16Ni-10Cr alloy. The couples were examined and analyzed by SEM-EDAX analysis. These studies have identified the formation of several intermetallic phases such as $\mathrm{U}_{2}(\mathrm{Ni}, \mathrm{Fe}), \mathrm{UNi}_{2}, \mathrm{U}_{5} \mathrm{Ni}_{7}$, $(\mathrm{U}, \mathrm{Zr}) \mathrm{Ni}_{2}, \mathrm{U}_{6}(\mathrm{Ni}, \mathrm{Fe}),(\mathrm{Zr}, \mathrm{U})_{4} \mathrm{Ni}_{5},(\mathrm{Zr}, \mathrm{U})_{2} \mathrm{Ni}$ in the diffusion zone of couples with Ni-base cladding alloys. A $\mathrm{Zr}$-rich layer was observed to form as an intermediate diffusion layer in the couple assembled with $\mathrm{Fe}-16 \mathrm{Cr}$ cladding alloy. The major intermetallic phases identified in the $\mathrm{Fe}-16 \mathrm{Ni}-10 \mathrm{Cr} / \mathrm{fuel}$ couple correspond to $\mathrm{U}(\mathrm{Fe}, \mathrm{Ni}, \mathrm{Cr})_{2}$, $(\mathrm{Zr}, \mathrm{U})(\mathrm{Fe}, \mathrm{Ni}, \mathrm{Cr})_{2}, \mathrm{U}_{6}(\mathrm{Fe}, \mathrm{Ni}),(\mathrm{Zr}, \mathrm{U})_{2}(\mathrm{Fe}, \mathrm{Ni})$ and are similar to those that develop in the $\mathrm{Fe}-10 \mathrm{Ni} /$ fuel and $\mathrm{Fe}-20 \mathrm{Cr} / \mathrm{fuel}$ couples. These studies have clearly demonstrated that the diffusion layers that form on the cladding side of the couples are dictated by the interactions of $\mathrm{Ni}, \mathrm{Fe}$ and $\mathrm{Cr}$ with $\mathrm{U}$, while those that develop on the fuel side are governed by the type of intermetallics that can form between $\mathrm{Zr}$ and the cladding elements. The fuel/cladding interdiffusion structures can be understood in the framework of diffusion paths and phase diagrams. Average effective interdiffusion coefficients were also calculated over specific regions of the diffusion zone of selected diffusion couples. The details of this investigation are described in detail in the attached manuscript (Appendiv D) entithed "Interdiffusion between U-Zr Fuel and Selected Fe-Ni-Cr Alloys" which is currently in print in the Journal of Nuclear Materials.

Interdiffusion studies were also made with a second set of diffusion couples assembled with the U-23 Zr fuel and selected commercial cladding steels, such as 316 stainless, D9, and HT9 and annealed at $700^{\circ} \mathrm{C}$ for 4 days. The diffusion layers and phases 
developed in these couples were found to be consistent with those observed for the couples assembled with binary $\mathrm{Fe}-\mathrm{Ni}, \mathrm{Fe}-\mathrm{Cr}, \mathrm{Ni}-\mathrm{Cr}$ and ternary $\mathrm{Fe}-\mathrm{Ni}-\mathrm{Cr}$ alloys. These studies have identified the beneficial role of $\mathrm{Cr}$ and shown that minimal interdiffusion occurs between fuel and cladding in the absence of Ni. HT9 is superior to D9 and 316 in fuelcladding compatibility. The details of this study are presented in the attached manuscript (Appendix E) entitled "Interdiffusion between U-Zr Fuel 
and vs. Selected Cladding Steels". This manuscript is submitted to Metallurgical Transactions for publication.

\section{Lanthanide-Cladding Interdiffusion}

One of the concerns in the IFR program deals with the interdiffusion behavior of lanthanide fission products (Ce,Nd,La,Pr) in the fuel and their interactions with the cladding alloys. At high burn-ups the lanthanide elements interdiffuse toward the fuelcladding interface and interact with cladding alloys such as 316 stainless, D9 and HT9. Since the major components of the cladding alloys are $\mathrm{Fe}, \mathrm{Ni}$ and $\mathrm{Cr}$, the lanthanide interdiffusion into the cladding can develop low meiting diffusion structures containing lanthanide intermetallics and adversely affect the fuel-cladding compatibility and the cladding life.

In order to explore the diffusion structure development as well as to calculate the interdiffusion data for lanthanide/cladding assemblies, two series of interdiffusion experiments were carried out with solid-solid diffusion couples. In the first series (Series I), couples were assembled with disks of $\mathrm{Ce}$ and pure $\mathrm{Ni}$, pure $\mathrm{Fe}$, and binary $\mathrm{Fe}-\mathrm{Ni}, \mathrm{Fe}-\mathrm{Cr}$ and $\mathrm{Ni}-\mathrm{Cr}$ alloys of selected compositions. The concentration of $\mathrm{Ni}$ in the $\mathrm{Fe}$-rich alloys are selected in the range of $10-16$ at.\%, while that of $\mathrm{Cr}$ was in the range of 10-20 at.\%. The alloys were homogenized at $1100^{\circ} \mathrm{C}$ and cut into disks. The second series of couples (Series II) was assembled with disks of pure Ce, and cladding steels, such as 316, D9 and HT9. 
All couples were annealed in evacuated quartz capsules at $425^{\circ} \mathrm{C}$ for 4 days. The annealed couples were examined metallographically and analyzed for concentration profiles and diffusion structure information by SEM-EDAX techniques. Average effective interdiffusion coefficients of the individual components were evaluated over selected regions of the diffusion zones of selected couples. Intrinsic diffusion coefficients were also determined for phases such as $\mathrm{Ni}_{3} \mathrm{Ce}_{7}$ and $\mathrm{Fe}_{2} \mathrm{Ce}$ developed in some of the couples. The diffusion structures were found to be consistent with phase diagrams and described with the aid of diffusion paths. The details of this study are described for selected couples in the attached manuscript (Appendix F) entitled "Interdiffusion of Ce in Fe-base Alloys with $\mathrm{Ni}$ or $\mathrm{Cr} "$. 


\section{APPENDIX A}

Hot Isostatic Pressing of U-10Zr by Coupled Boundary

Diffusion/Power-Law Creep Cavitation - Part I 


\title{
HOT ISOSTATIC PRESSING OF U-10Zr BY COUPLED BOUNDARY DIFFUSION/POWER-LAW CREEP CAVITATION - PART I
}

\author{
Sean M. McDeavitt and A.A. Solomon \\ School of Nuclear Engineering, Purdue University, \\ West Lafayette, IN 47907, USA.
}

\begin{abstract}
$\mathrm{U}-10 \mathrm{Zr}$ is a nuclear fuel proposed for use in the Integral Fast Reactor (IFR). Possible mechanical interaction between the swelling metal fuel and its cladding which may cause cladding failure is a safety and operational issue. Specimens prepared from uranium and zirconium powders (metal and hydride) were sintered in a purified argon atmosphere to entrap gas and simulate fission gas bubbles in irradiated fuel. The specimens were hot isostatically pressed to study the fuels' densification under external pressure. Hot-pressing was not detected at $600^{\circ} \mathrm{C}$, but $\mathrm{U}-10 \mathrm{Zr}$ hot-presses at $700^{\circ} \mathrm{C}$ by a coupled creep/grain boundary diffusion mechanism. The measured stress dependence $(n=3.4 \pm 0.3)$ indicates a dislocation creep mechanism and the measured activation energy $(187 \pm 10 \mathrm{KJ} / \mathrm{mole})$ agrees with the reported value for grain boundary diffusion of $\gamma-\mathrm{U}$. This is contrary to observations for $\mathrm{UO}_{2}$ and cther materials where hot-pressing is controlled by diffusion.
\end{abstract}




\section{Introduction}

Uranium - 10 wt. \% zirconium (U-10Zr) is used as a driver fuel in the Experimental Breeder Reactor-II as part of the Integral Fast Reactor (IFR) program developed by Argonne National Laboratory[1]. Metal nuclear fuels were previously investigated and rejected for breeder reactors due in part to fission gas induced swelling at relatively low burnup which caused severe Fuel-Cladding Mechanical Interaction (FCMI) and cladding rupture under normal operating conditions ${ }^{[1]}$. IFR fuel pins are designed to accommodate swelling and gas release by providing a fuel/cladding gap filled with sodium and an enlarged gas plenum above the fuel which allows the fuel to swell and release its fission gas before coming into contact with the cladding[1]. Swelling in uranium and uranium alloy fuels is generally assumed to be caused by accumulated fission products (primarily gases) and anisotropic irradiation growth which induces "tearing"[2].

After cladding contact, which occurs at 1-2 atom percent burnup [1], the compressibility of the highly porous fuel becomes an important safety issue, since it represents the fuels' ability to relax fuel/cladding contact stresses which arise from continued fuel swelling. Since the target burnup of the IFR exceeds 20 atom percent, this situation is potentially significant over the majority of the fuel's lifetime. FCMI is unavoidably present when fuel swelling is constrained by the current non-swelling cladding materials, and FCMI-induced strains are observed in the U-10Zr fuel rods used in EBR-II after relatively low burnup[2]. Fission product accumulation and precipitation in the available porosity will impair the fuels compressibility at high burnup [2]. Also, rapid temperature rises during reactor transients may generate large contact stresses due to differences in fuel/cladding thermal expansion and gas pressure increases that represent important safety issues.

To address these issues, hot-isostatic pressing (HIP) experiments have been carried out on unirradiated $\mathrm{U}-10 \mathrm{Zr}$ using an experimental procedure previously developed $[3]$ to investigate swelling and $\mathrm{HIP}$ in $\mathrm{UO}_{2}{ }^{[4-6]}$ and other materials[7-9]. The purpose of the experiments was to identify and quantify the rate-controlling HIP mechanism in U-10Zr. Pure, unirradiated material 
was used to avoid ambiguities which could arise from solid fission product accumulation and nonequilibrium defect structures, as well as the difficulties involved with handling irradiated material.

HIP and swelling of porous material at elevated temperatures are stress and temperature dependent phenomena which, to a first approximation, are opposing directions of the same process if they do not involve irreversible fracture. Gas filled pores shrink or grow in response to nonequilibrium pressure conditions. It has been shown that models developed for creep cavitation unde. uniaxial stress are even more appropriate for HIP and swelling where the stress is hydrostatic, and excellent agreement between theory and experiment is obtained if the internal pore pressure and pore surface energy are included[10]. A comprehensive review of several creep cavitation mechanisms has been presented by Svensson and Dunlop ${ }^{[11]}$.

". his present paper will summarize the experimental procedures and HIP results for the sintered U-10Zr specimens. A subsequent paper (Part II) will discuss the comparison of the experimental results with theoretical creep cavitation wodels to identify and quantify the dominant U-10Zr HIP mechanism. These experiments and the results obtained are useful for the development and validation of fuel performance models for metal nuclear fuels, especially in the IFR program.

\subsection{Creep cavitation models}

Creep cavitation models may be classified into two categories based upon the invoked ratecontrolling mechanism: 1) grain boundary diffusion-controlled cavitation, and 2) creep deformation-controlled cavitation.

Hull and Rimmer ${ }^{[12]}$ modeled diffusion-controlled creep cavity growth by defining the ratecontrolling process as the stress-directed motion of vacancies from grain boundaries to cavity surfaces via grain boundary diffusion. The grain boundary is assumed to act as a perfect sink for atoms which move from uniformly sized and spaced cavities and are distributed uniformly over the grain boundary. Diffusion-controlled creep cavitation models have been presented, modified, and 
improved by several authors[11,13-18], with the model of Speight and Beere[15] considered to "best represent" this phenomena[19].

The Speight-Beere formulation ${ }^{[15]}$ for volumetric growth of individual cavities during tensile creep may be written as

$\left(\frac{d V}{d t}\right)_{\text {pore }}=\frac{2 \pi \Omega D_{b} \delta_{b}}{k T f\left(\frac{r_{p}}{\lambda}\right)}\left[\sigma-p+\frac{2 \gamma}{r_{p}}\right]$,

where $D_{b}$ is the boundary diffusion coefficient, $\delta_{b}$ is the boundary width, $N_{v}$ is the pore number density, $\Omega$ is the atomic volume, $\mathrm{k}$ is Boltzman's constant, and $\mathrm{T}$ is temperature. The term in brackets represents the "driving force", F, for the process, where $\sigma$ is the applied tensile load, $p$ is the internal pore pressure, $\gamma$ is the surface energy, and $r_{p}$ is the pore radius. $F$ is related to the stress-induced chemical potential difference between the pore surface and the grain boundary, according to Herring[20]. The geometric "structure" factor, $f\left(\frac{r_{p}}{\lambda}\right)$, is a function of the pore size to spacing ratio given by

$f\left(\frac{r_{p}}{\lambda}\right)=-\left[\ln \left(\frac{r_{p}}{\lambda}\right)+\frac{1}{4}\left(1-\left(\frac{r_{p}}{\lambda}\right)^{2}\right)\left(3-\left(\frac{r_{p}}{\lambda}\right)^{2}\right)\right]$.

where $\lambda$ is the cavity half-spacing itis the pore volume change during HIP, the pore volume rate of change in Equation 1 may be translated to a total linear strain rate according to[10]

$\dot{\varepsilon}=\frac{1}{3} N_{v}\left(\frac{d V}{d t}\right)$

where $N_{V}$ is the cavity number density. Combining Equations 1 and 3, and substituting the external pressure, $\mathrm{P}$, for the applied stress, yields the strain rate for diffusion-controlled HIP as 
$\dot{\varepsilon}_{\text {diffusion }}=\frac{2 \pi}{3} \frac{N_{v} \Omega D_{b} \delta_{b}}{k T f\left(\frac{r_{p}}{\lambda}\right)}\left[P-p+\frac{2 \gamma}{r_{p}}\right]$

Deformation-controlled cavity growth during creep has also been modeled by several authors ${ }^{[21-23]}$. For these models, diffusion is considered unable to relax the applied load because either the grain boundary diffusivity is limited or the cavities do not reside on the grain boundary. The growth rate is therefore controlled by the creep of the material surrounding the cavity. This situation is not commonly observed for nuclear fuels ${ }^{[10]}$.

Beere and Speight ${ }^{21]}$ proposed that both diffusion-controlled and deformation-controlled cavitation mechanisms operate during creep, and that the overall cavitation behavior is defined by the coupling of both mechanisms. A similar mechanism was proposed by Edward and Ashby[24], but their model was applied toward the estimation of the time to failure and not toward the estimation of the cavity growth rate. The model of Beere and Speight ${ }^{[21]}$, Fig. 1, divides the grain boundary into two regions. The unit cell radius is the cavity half-spacing, $\lambda$, and $b$ is the radius of Region I where grain boundary diffusion deposits atoms according to the Hull-Rimmer mechanism. In Region II, grain boundary diffusion is assumed negligible and creep generates compatible strains to maintain compatibility with Region I. Beere and Speight ${ }^{[21]}$ determine $b$ from the solution of a complex system of physical equations, but they avoid the solution of the equations by suggesting that the rate of cavity volume change may be approximated by the direct sum of diffusion-controlled and deformation-controlled limiting solutions. This approximation has been discounted as an over-simplification by several authors $[19,25,26]$.

Chen and Argon ${ }^{[19]}$ derived a simple equation for the coupled cavitation mechanism based upon the displacement induced in Region I by the deposition of atoms. Their formulation matches very well with the cavity growth rate calculations by finite element analysis of Needleman and Rice[26], and the exact solution of Beere and Speight ${ }^{[21]}$ based on the complex system of 
equations ${ }^{[19]}$. The size of the diffusion zone, designated as $\Lambda$ in Fig. 1 , may be directly estimated from the characteristic diffusion length, defined by Rice[25], which is given by

$\Lambda=\left(\frac{\mathrm{D}_{\mathrm{b}} \delta_{\mathrm{b}} \Omega \sigma_{\infty}}{\mathrm{kT} \dot{\varepsilon}_{\infty}}\right)^{1 / 3}$

where $\sigma_{\infty}$ and $\dot{\varepsilon}_{\infty}$ represent the far-field creep stress and creep rate, where $\dot{\varepsilon}_{\infty}$ is equivalent to the material creep behavior, $\dot{\varepsilon}_{\mathrm{c}}$, which has the empirical form

$\dot{\varepsilon}_{c}=\mathrm{B} \sigma^{\mathrm{n}}$

where $B$ is an empirical constant, $\sigma$ is the driving stress for creep, and $n$ is the creep stress dependence. $\Lambda$ may be used to distinguish which cavitation mechanism is dominant ${ }^{[19]}$ using the following criteria: 1) If $\Lambda>\lambda$, then diffusion is uninhibited in the grain boundary and a diffusioncontrolled mechanism dominates, 2) If $\Lambda<r_{p}$, then diffusion is extremely limited and creep deformation dominates cavitation.

The cavity volume change for a coupled mechanism is then given as ${ }^{[19]}$,

$\dot{\varepsilon}_{\text {coupled }}=\frac{2 \pi}{3} \frac{N_{V} \Omega D_{b} \delta_{b}}{k T f\left(\frac{r_{p}}{b}\right)}\left[P-p+\frac{2 \gamma}{r_{p}}\right]$

The difference between Equations 4 and 7 is the structure function. The form of $f\left(\frac{r_{p}}{b}\right)$ is still given by Equation 3, but $b\left(=\Lambda+r_{p}\right)$ is substituted for the cavity spacing, $\lambda$. Because of the strong stress dependence of $\Lambda$, the structure function and Equation 7 also have strong stress dependencies, in contrast to diffusion-controlled models, which have a linear stress dependence.

It should also be pointed out that all of the models described above require the assumption of uniform cavity sizes and spacings so that a single representative volume element can be analyzed. While such models may capture the basic physics, some important interactions are 
omitted if pore sizes and spacings can vary. If sizes vary, diffusional fluxes from cavity to cavity cause coarsening[27] which can greatly increase rupture time. For non-equilibrium cavities or pores $(F \neq 0)$, elastic interactions can give rise to cavity repulsion [27], and for variable spacings, plastic deformation may play an increasing role for widely-spaced pores $[28]$. Thus the simplified models should only be expected to give order-of-magnitude agreement with measurements for most real microstructures.

\subsection{Experimental background}

The technique used for studying the behavior of non-equilibrium pores[3] has been used to study the swelling behavior of $\mathrm{Ni}^{[7]}, \mathrm{ZnO}^{[8]}$, and $\mathrm{UO}_{2}{ }^{[5,6]}$, as well as the $\mathrm{HIP}$ of $\mathrm{UO}_{2}{ }^{[4]}$ and $\mathrm{AlO}_{3}{ }^{[9]}$. Experimental samples are produced by sintering powder compacts under pressure beyond pore closure to entrap gas. By changing the ambient external pressure, a driving force for HIP or swelling may be generated.

In previous studies $[7,8]$, the time-dependent strain rate behavior for HIP and swelling was characterized by the relation

$\dot{\varepsilon} \sim \mathrm{t}^{-\mathrm{m}}$.

where $\mathrm{m}$ is a constant. The $\mathrm{m}$-value for swelling is predicted to be $\mathrm{m}=2 / 5$ using the Hull-Rimmer model[10], assuming that the internal pressure dominated the driving force so the external pressure and surface tension may be neglected. Previous swelling experiments on $\mathrm{Ni}$ and $\mathrm{ZnO}$ exhibit pore interconnection and eventually gas release at high driving forces, but at lower driving forces, the strain rates are observed to decrease with a well-defined time dependence shown to be $[7,8,10]$

$\dot{\varepsilon} \sim \mathrm{t}^{-1 / 3}$,

in reasonable agreement with the above prediction for isolated widely-spaced pores. 
It is evident in Eq. 4 that the HIP and swelling strain rate is linearly dependent upon the driving force for a diffusion-controlled mechanism. The measured driving force dependence, which is designated as $\mathrm{n}$, was close to $\mathrm{n}=1$ for the previous experiments. In nickel, the driving force dependence increased slightly from $n=1$ to $n=2$ as the swelling driving force became large, and it was argued that a coupled cavitation mechanism could be dominant at higher driving forces. The activation energy, $\mathrm{Q}$, was near that for boundary diffusion for both $\mathrm{Ni}$ and $\mathrm{ZnO}$ swelling, which also strongly supports a boundary diffusion-controlled mechanism.

$\mathrm{HIP}$ experiments for $\mathrm{UO}_{2}$ did not exhibit a well-defined time-dependence, unlike the above swelling experiments. There was a continuous decrease in the $\mathrm{m}$-value, indicating that the simplifying assumptions made to predict $m$ for swelling do not apply for HIP. However, the stress dependence was measured to be $\mathrm{n}=1$, indicating diffusion control, but the activation energy was measured to be in agreement with uranium bulk diffusion in $\mathrm{UO}_{2}$. The microstructure indicated that the porosity was predominantly intragranular, and these experiments were concluded to be controlled by a volume diffusion HIP process.

HIP experiments for $\mathrm{Al}_{2} \mathrm{O}_{3}$ were done following a creep test, and not by the previously described procedure. Creep specimens were fabricated by slip-casting an alumina slurry and then sintering to high density[9]. The alumina creep cavitation was observed to agree with the model of Speight and Beere ${ }^{[15]}$ for grain boundary diffusive cavitation. After creep, a specimen was hotpressed using the previously described technique [3], and there was good agreement between the creep cavitation rate and HIP rate. This affirmed the equivalence of creep cavitation and HIP mechanisms.

Une ${ }^{[29]}$ studied swelling in $\mathrm{UO}_{2}$ through the internal oxidation of carbon at $1400^{\circ} \mathrm{C}$ and $1700^{\circ} \mathrm{C}$ to form $\mathrm{CO}$ or $\mathrm{CO}_{2}$ bubbles on the boundary. However, this resulted in a nonhomogeneous microstructure, where the porosity varied from $15 \%$ near the surface to $5 \%$ near the center. Driving force and activation measurements were not made, but the swelling time dependence indicated that grain boundary diffusion was again the most likely rate-controlling mechanism. 


\section{Experimental}

U-10Zr HIP specimens were prepared from powder mixtures of uranium hydride $\left(\mathrm{UH}_{3}\right)$ and zirconium hydride $\left(\mathrm{ZrH}_{2}\right)$ and uranium metal spheres and zirconium metal. The powders are pyrophoric, requiring specimen fabrication to be completed in an inert atmosphere glovebox with a flowing atmosphere of purified argon. The processing methods developed for this study are described in detail in a previous paper [30], but a brief summary will be presented here for clarity.

\subsection{Hydride-derived specimens}

Hydride powders $\left(\mathrm{UH}_{3}{ }^{*}\right.$ and $\left.\mathrm{ZrH}_{2}^{\dagger}\right)$ were chosen to produce alloy specimens because of their fine particle size, compactability, ultimate sinterability, and low temperatures for decomposition to pure metals $[31]$. The hydride-derived specimens were fabricated by mixing the two powders by hand in an alumina mortar to make the final product U-10 wt.\% Zr. The powc mixture was then compacted into a cylindrical pellet of $0.7 \mathrm{~cm}$ diameter at $550 \mathrm{MPa}$ to yield relative green density of over $60 \%$, but relative to the metal alloy theoretical density $\left(16.02 \mathrm{~g} / \mathrm{cm}^{3}[32]\right)$, the decomposed sample has a green density of only $\sim 42 \%$. This is usually too low for effective sintering, but the uranium hydride has a very fine particle size of $\sim 1 \mu \mathrm{m}$ which permitted sintering to $-93 \%$ T.D.

For sintering and HIP, the hydride powder compact is inserted in a thoriated tungsten pressure vessel which is sealed in the glovebox environment and removed to a high pressure, high temperature sintering system, such that the specimen is always under purified argon. The specimen rests between two tungsten slugs, which are relatively inert to uranium and zirconium at the sintering temperatures. A molybdenum rod rests on the upper tungsten slug transmitting specimen length changes to a Linear Variable Differential Transducer (LVDT) above the furnace.

* Courtesy of B. Lambdin, Oak Ridge National Laboratory.

$\dagger$ A.D. Mackay, Inc. 
During the servo-controlled furnace ramp of 1 hour to the sintering temperature of $1100^{\circ} \mathrm{C}$, $\mathrm{UH}_{3}$ decomposes first between $250^{\circ} \mathrm{C}$ and $450^{\circ} \mathrm{C}$ under vacuum, and $\mathrm{ZrH}_{2}$ decomposes between $600^{\circ} \mathrm{C}$ and $900^{\circ} \mathrm{C}$ under vacuum. The decomposition temperature ranges were monitored by a thermocouple vacuum gauge, and back diffusion of air was prevented by maintaining the vacuum above 100 microns during evacuation. After decomposition was complete, $1.7 \mathrm{MPa}$ of purified argon was introduced into the system, and by the time the specimen temperature reached $1100^{\circ} \mathrm{C}$, it had densified from to $\sim 70 \%$ T.D. The process slowed dramatically after the first hour, but after 24 hours, the sintered density was near $93 \%$, and the pores were closed.

The microstructure of the sintered hydride-derived specimens, Fig. 2, indicates the existence of a second phase occupying 25 vol. \%. EDAX analysis showed only $\mathrm{Zr}$ in these phases, and Scanning Auger Microscopy (SAM) showed the presence of significant quantities of carbon, nitrogen, and oxygen[30]. The second phases are uniformly distributed throughout all hydride-derived samples, indicating that manual mixing does not produce heterogeneous samples. Phases of this type are observed in cast IFR fuel rods ${ }^{[2]}$, but they are much more prevalent in the hydride-derived specimens. These phases are generally believed to be interstitial solid solutions which are stable above the melting point of the alloy[2]. In an effort to characterize the source of the contamination, the microstructural evolution of the impurity phase was tracked through the sintering process, as detailed in the previous paper[30]. It was concluded that the starting $\mathrm{UH}_{3}$ powder was the primary source of contamination after all other potential sources (i.e. vacuum leaks, impure sintering environment, etc.) had been eliminated. As described below, the metalderived specimens had a much lower impurity phase content $(5 \mathrm{vol} . \%)$ and this permitted the effect of such phases on HIP to be examined.

\subsection{Metal-derived specimens}

The uranium metal spheres are much larger $(\sim 177 \mu \mathrm{m})$ than the hydride powder particles so sintering is less efficient and requires a higher specimen green density. The original powder had a 
surface oxide layer which acts as a barrier to interdiffusion during sintering. The layer was removed by washing with a $20 \%$ nitric acid bath following Lloyd and Williams[33]. The clean powder is rinsed with water and ethyl alcohol to remove residual acid and then dried in the glovebox by evaporation. This process does contaminate the glovebox atmosphere by releasing vapors, so care must be taken to minimize the duration of exposure to open liquids.

The dry uranium powder is manually mixed in the die, and compressed at $1100 \mathrm{MPa}$, forming a pellet near $80 \%$ T.D. The compaction pressure was twice that used for the hydridederived samples because it is necessary for the zirconium to plastically flow around the uranium spheres to form a coherent network $[30,31]$. After compaction, specimens are transferred to the pressure vessel system, which is evacuated and backfilled with purified argon several times between $100^{\circ} \mathrm{C}$ and $200^{\circ} \mathrm{C}$ to remove adsorbed impurities from the acid-washed powder surface.

The system is pressurized with $3.5 \mathrm{MPa}$ of argon and heated to $1100^{\circ} \mathrm{C}$ in 1 hour, but in contrast with the hydride-derived powders, there is no observable shrinkage during the temperature ramp until the temperature exceeds $\sim 1000^{\circ} \mathrm{C}$. Then, the samples begin to shrink rapidly. Rothman ${ }^{[32]}$ reports that interdiffusion between uranium and zirconium does not occur until both elements are in their body-centered cubic, high temperature phase, which does not occur until $863^{\circ} \mathrm{C}$. Since the specimen temperature lagged the furnace temperature by as much as $120^{\circ} \mathrm{C}$ during the furnace ramp, the above observations are consistent

After 6 hours at $1100^{\circ} \mathrm{C}$, sintering stops and the alloy is well mixed (verified by EDAX spot analysis), but the porosity does not fully close. Because of this, the process was modified to hold the specimens at $1100^{\circ} \mathrm{C}$ for only 30 minutes and then raise the temperature to $1200^{\circ} \mathrm{C}$ for 6 hours. Samples cannot be taken directly to $1200^{\circ} \mathrm{C}$ because it is above the melting point of pure uranium $\left(1132^{\circ} \mathrm{C}\right)$ and time must be allowed for diffusional alloying.

With this method, specimens were sintered to $91 \%$ T.D., but the density was not as homogeneous as in the hydride-derived specimens, due to surface roughness generated during fabrication. Immersion density measurements indicate some open porosity, and specimen microstructures show limited regions of open porosity near the roughness. However, the density 
measurements also indicate significant amounts of closed porosity, and the microstructure, shown in Figure 2, indicates that the interior region of a sintered specimen is closed. There is 5 vol. $\%$ of second-phase impurity particies.

\subsection{HIP procedure}

Following sintering at $1100^{\circ} \mathrm{C}$ and $1200^{\circ} \mathrm{C}$ for the hydride-derived and metal-derived samples, respectively, the temperature was lowered to $700^{\circ} \mathrm{C}$ for hot-pressing. This temperature is in the solid solution, body-centered cubic $\gamma$-phase field of the U-10Zr binary alloy, and is representative of fuel centerline temperatures in the IFR core[1]. The specimens were held at the HIP temperature for 1 hour to verify that no further densification occurs. The ambient external pressure was then raised to induce a HIP driving force and the densification strain was recorded vs. time from the LVDT signal. Various magnitudes of $\Delta \mathrm{P}$ were used to investigate the pressure/driving force dependence of the HIP process, as discussed in the next section.

In order for the HIP experiments to be compared with theoretical models, microstructural information is required from both types of specimens. Porosity and impurity particle size distributions were measured using a Macintosh IIci-based image analysis system which captures digital images from a video camera through an optical microscope[31]. Grain sizes were evaluated from optical micrographs of polished and etched specimens using standard lineal analysis, and this information was used to calculate the average pore spacing.

\section{Results}

\subsection{HIP experiments}

HIP experiments were completed on the hydride-derived specimens with ambient pressure increases $(\Delta \mathrm{P})$ of $3.5,6.9,10.5,13.8$, and $20.7 \mathrm{MPa}$, and the strain rate vs. time results for this 
series are presented in Figure 4 . The specimens densified from $93 \%$ up to $95-97 \%$ relative density, depending on the pressure conditions. Some of the 6.9 and 10.5 MPa transients have been truncated for clarity because of perturbations made to measure the activation energy and stress dependence, as described later. There are two distinct time-dependent regions for the strain rates shown in Figure 3, but the majority of the densification occurs in the first region.

For the tests with $\Delta \mathrm{P}=3.5,6.9,10.5$, and $13.8 \mathrm{MPa}$, the initial hot-pressing strain rate decreases with time as

$\dot{\varepsilon} \sim \mathrm{t}^{-0.32}$.

This is similar to observed time-dependent behavior in previous swelling experiments on $\mathrm{Ni}[7]$ and $\mathrm{ZnO}[8]$, and agrees with the theoretical time-dependence predicted for diffusion-controlled swelling[10]. The experiment with $\Delta P=20.7 \mathrm{MPa}$, however, behaves differently exhibiting a time dependence of

$\dot{\varepsilon} \sim \mathrm{t}^{-0.74}$.

HIP experiments on the metal-derived specimens are presented in Fig. 5, again with some of the transients truncated. Two regions of time-dependent behavior are again evident, but in contrast to the hydride-derived specimens, the time-dependence of the initial HIP strain rate in the metal-derived specimens was

$\dot{\varepsilon} \sim \mathrm{t}^{-0.13}$

for all driving forces. This low time-dependencies has not been seen experimentally before and cannot be explained by the simplified swelling prediction. However, it is reproducible and consistent over the full range of HIP driving forces. 
Two HIP experiments were attempted with the metal-derived samples at $600^{\circ} \mathrm{C}$ with $\Delta \mathrm{P}=17.3 \mathrm{MPa}$ to investigate the behavior of the $\alpha+\delta$ phase mixture, which corresponds to the phases present near the IFR fuel surface[1]. The first experiment was annealed for 6 hours and the second for 50 hours to allow the two phase structure to form. It is reported that "no more than 48 hours" would be required to decompose the $\alpha^{\prime}$ phase into the two-phase structure at this temperature[34]. However, $\delta$ phase was not detected by SEM analysis, even after 50 hours. No HIP strains were detectable in either specimen at this temperature. To verify that the pressure driving force and closed porosity were typical of the previous specimens, 1 hour after the initial $\Delta \mathrm{P}$, the temperature of the first sample was raised to $700^{\circ} \mathrm{C}$, and it began to hot-press very rapidly, indicating that the porosity was closed.

\subsection{Specimen microstructure}

Figures 6 and 7 show normalized frequency distributions for pore size and particle size in the metal-derived and hydride-derived samples, respectively. The distributions were measured from several representative, digital images of post-HIP samples using area analysis methods. The porosity has a log-normal distribution with modal pore diameters of $2.5 \pm 0.1 \mu \mathrm{m}$ and $1.7 \pm 0.1 \mu \mathrm{m}$ for the hydride and metal derived samples, respectively. The hydride-derived specimens are found to have slightly more porosity, with a total number density of $9.3 \times 10^{14} \mathrm{~m}^{-3}$ and a volume fraction of $6.4 \%$ compared to $5.5 \times 10^{14} \mathrm{~m}^{-3}$ and $4.2 \%$ in the metal-derived specimens.

The impurity particle distributions for both materials are similar, having a bi-modal distribution with an upper mode of $4.5 \mu \mathrm{m}$ for both materials. However, the hydride-derived material has a much higher particle density of $5.0 \times 10^{15} \mathrm{~m}^{-3}$ and a volume fraction of $25 \%$ versus $3.9 \times 10^{14} \mathrm{~m}^{-3}$ and $4.8 \%$ for the metal-derived specimens. Because there are fewer impurities in the

metal-derived specimens, the zirconium content in solution should be higher. This was verified by EDAX chemical analysis, which showed that the matrix compositions were 4.7 and 9.4 weight \% $\mathrm{Zr}(11.5$ and 21.3 atom \%) for the hydride and metal-derived samples, respectively. 
Using lineal analysis to measure the mean intercept length, and assuming the grain shape to be a space-filling tetrakaidecahedron (truncated octahedron)[35], the average grain size is found to be $34 \pm 4$ and $114 \pm 12 \mu \mathrm{m}$ for the hydride and metal derived specimens, respectively. Based upon the grain size and number densities, the pore spacings were calculated to be 10 and $7 \mu \mathrm{m}( \pm 10 \%)$ and the particle spacings were calculated to be 4 and $8 \mu \mathrm{m}( \pm 10 \%)$ for the hydride and metal derived specimens assuming all pores and particles are on grain boundaries.

\subsection{HIP driving force dependence}

The measured HIP strain rates shown in Figs. 4 and 5 were extrapolated in time to 1 minute to approximate the initial strain rate response to the HIP driving force. The extrapolated rates are shown vs. the initial diffusional driving force, F, in Fig. 8. The experimental parameter $\Delta P$, used to characterize the transients in section 3.1, is not the same as the driving force $F(=P-p$ $-2 \gamma / r$ ). The driving force is calculated based on the known external pressure and estimated values of the internal pressure and surface energy. The internal pore pressure is calculated from the estimated gas content in the pore at the end of sintering, adjusted for temperature and pore size changes. The $\mathrm{U}-\mathrm{Zr}$ surface tension is taken as $1.5 \mathrm{~J} / \mathrm{m}^{2}$, based upon data for pure $\mathrm{U}$ and $\mathrm{Zr}[30]$.

It is evident from the data in Figure 8 that the driving force dependence is non-linear $(n \neq 1)$ and that the metal-derived specimens HIP at a lower rate than the hydride-derived specimens.. A power-law curve fit of the data yields a driving force dependence of $n=3.7 \pm 0.2$ for both the hydride-derived and metal-derived materials. This high $\mathrm{n}$-value is not in agreement with the model predictions for grain boundary diffusion-controlled HIP.

A second measure of the driving force dependence is calculated from strain rate changes due to step changes in the external pressure during hot-pressing transients. Even though the structure in the specimen is evolving during a transient, by extrapolating the strain rate from before and after the step change to the time when the change is induced, the structure can be assumed to be constant and $n$ may be evaluated from the relation $[30,31]$ 
$\mathrm{n}=\frac{\ln \left(\frac{\dot{\varepsilon}_{1}}{\dot{\varepsilon}_{2}}\right)}{\ln \left(\frac{\mathrm{F}_{1}}{\mathrm{~F}_{2}}\right)}$

where the subscripts 1 and 2 indicate the strain rate and driving force conditions before and after the induced changes.

Two of each type of specimen were exposed to incremental $\triangle \mathrm{P}$ steps of 1-3 MPa following initial $\triangle \mathrm{P}$ 's of 10.5 and $13.8 \mathrm{MPa}$. The initial $\mathrm{HIP}$ transients before the $\triangle \mathrm{P}$ steps are represented by the truncated curves in Figs. 4 and 5, and the full transients are shown in Figs. 9-12. $F_{1}$ and $\mathrm{F}_{2}$ for the $\Delta \mathrm{P}$ 's were calculated for use in Eq. 14 vsing the method described above applied to the point of pressure application instead of the beginning of the HIP transient.

The first hydride-derived specimen, Fig. 9, was exposed to four $\triangle \mathrm{P}$ steps of $\pm 2.4 \mathrm{MPa}$, but there were unexpected large loading and unloading transients which caused an overestimation of the $\mathrm{n}$-value. Such loading transients are typical for dislocation controlled processes in which a stress increase causes blocked dislocations to break free and a stress decrease causes dislocations to become blocked until their density can be reduced by recovery[36]. Therefore, the second hydride-derived $\Delta \mathrm{P}$ test was done with a single step of $+1.9 \mathrm{MPa}$, Fig. 10, to allow the transient to dissipate, which yielded a driving force dependence of $n=3.2 \pm 0.5$.

The first metal-derived $\Delta \mathrm{P}$ test, Fig. 11 had a single step of $+0.7 \mathrm{MPa}$. There was a slight loading transient with this experiment, but it was much smaller in magnitude and duration than the hydride-derived transients. Since the "dislocation" transients were less significant in the metalderived samples, a second test was done with several $\Delta \mathrm{P}$ increases of $+1.7 \mathrm{MPa}$, Fig. 12. The driving force dependence is found to be $n=3.5 \pm 0.5$ from the first test and $n=3.8 \pm 0.6,3.1 \pm 0.5$, and $3.2 \pm 0.5$ from the $\Delta \mathrm{P}$ steps in the second test, yielding a mean value of $3.4 \pm 0.3$ for the metal derived specimens. The measured $\mathrm{n}$-values show that both the hydride-derived and metal-derived 
materials have essentially identical driving force dependencies, which deviate from the previously observed diffusional behavior.

\subsection{HIP activation energy}

The activation energy, $Q$, is calculated for $\mathrm{U}-10 \mathrm{Zr}$ from $\mathrm{HIP}$ strain rate changes resulting from controlled temperature steps using the relation $[30,31]$

$\mathrm{Q}=\frac{-\mathrm{R}}{\frac{1}{\mathrm{~T}_{\mathrm{i}}}-\frac{1}{\mathrm{~T}_{2}}}\left[\ln \left(\frac{\dot{\varepsilon}_{1}}{\dot{\varepsilon}_{2}}\right)-\mathrm{n} \ln \left(\frac{\mathrm{F}_{1}}{\mathrm{~F}_{2}}\right)\right] \mathrm{kJ} / \mathrm{mole}$,

where $\mathrm{R}$ is the gas constant $\left(\mathrm{kJ} /{ }^{\circ} \mathrm{K}\right.$ mole), $\mathrm{T}$ is temperature $\left({ }^{\circ} \mathrm{K}\right), \dot{\varepsilon}$ is the linear strain rate $\left(\mathrm{s}^{-1}\right), \mathrm{F}$ is the driving force (MPa), subscripts 1 and 2 indicate the before and after conditions, and $n$ is the driving force $\mathrm{c}$. ponent from the previous siction. The second term in the brackets is a correctio for the change in the driving force due to the change in internal pore pressure with temperature, where $F_{1}$ and $F_{2}$ are calculated as before.

The change in strain rate due to the $\Delta \mathrm{T}$ was found by extrapolation in time as done in the previous section for the driving force dependence, as shown in Figs. 13-15. Two hydride-derived specimens and one metal-derived specimen werc subjected to incremental $\Delta \mathrm{T}$ changes of $\pm 25^{\circ} \mathrm{C}$ during HIP. Assuming $n \approx 3$, Eq. 15 yields activation energies of $200 \pm 14 \mathrm{~kJ} / \mathrm{mole}$ (Fig. 13) and $181 \pm 13$ and $i 81 \pm 13 \mathrm{kj} /$ mole (Fig. 14) for the bydride-derived transients and $180 \pm 13$ and $182 \pm 13$ $\mathrm{kJ} / \mathrm{mole}$ (Fig. 15) for the metal-derived transients. The mean $\mathrm{Q}$ from all experiments is $187 \pm 10$ $\mathrm{kJ} / \mathrm{mole}$.

Although not many measurements were made, there is apparently no significant difference in the HIP kinetics between the two types of alloy specimens. The measured astivation energies for hot-pressing are significantly higher than the repcrted value of $112 \mathrm{~kJ} / \mathrm{mole}$ for bulk diffusion

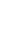


in $\gamma(\mathrm{U}-10 \mathrm{Zr})^{[32]}$, but agrees well with the reported value of $186.6 \mathrm{~kJ} / \mathrm{mole}$ for boundary diffusion of uranium in $\gamma-\mathrm{U}^{[37]}$.

\section{Discussion}

The results of the HIP experiments may be compared to the existing cavitation models to determine the dominant mechanism of pore shrinkage. If the U-10Zr specimens hot-press by a boundary diffusion-controlled mechanism, then the stress-dependent strain rates in Fig. 8 should he well represented by the Speight-Beere model, Eq. 4. The diffusion-controlled models predict a stress dependence of $n=1$, as seen experimentally for HIP and swelling in several materials ${ }^{[4-10]}$, but the measured stress dependence of $n \approx 3$ for $U-10 Z r$ is reproducible and was determined through two independent measures. However, there is excellent agreement between the measured activation energy $(187 \pm 10 \mathrm{~kJ} / \mathrm{mole})$ and the reported value for grain boundary diffusion (186.6 $\mathrm{kJ} / \mathrm{mole}$ ). The agreement in activation energy implies that grain boundary diffusion is significant in the HIP of $\mathrm{U}-10 \mathrm{Zr}$, but the poor agreement in the $\mathrm{n}$-value and the predicted strain rates indicates that a diffusion-controlled mechanism does not dominate the HIP process. Also, the observance of the loading and unloading transients in Figs. 9-12 indicate that a dislocation-controlled process is involved in the HIP of U-10Zr.

We earlier suggested a modification of the diffusion-controlled mechanism[30,38], based upon the model of Ashby[39] and Arzt, et al. ${ }^{[40]}$ which introduces effects of interface control by solute drag and second phase particle pinning effects on the grain boundary dislocations to rationalize the dislocation-control behavior and the high $n$-value. The presence of both zirconium as a solute and the impurity particles on the grain boundary are qualitatively consistent with this model. However, the second phase particles would have to generate a "threshold" stress of $\sim 5$ $\mathrm{MPa}$ and lower the measured driving force dependence down to the models predicted $\mathrm{n}$-value of $n=2[30,31]$. 
Using the model of Arzt, et al. ${ }^{[40]}$ and the microstructural information reported in section 3.2, the maximum threshold stress generated by the impurity particles would be 0.2 and $0.5 \mathrm{MPa}$ for the metal-derived and hydride-derived specimens, respectively. These values are less than the $\pm 1 \mathrm{MPa}$ uncertainty in the calculated driving forces, and much lower than the required value of 5 $\mathrm{MPa}$. Also, the measured activation energy for this mechanism should agree with the activation energy for $\mathrm{Zr}$ solute diffusion, $\mathrm{Q}_{\mathrm{S}}$, which is composition dependent and ranges from 113 to 134 $\mathrm{kJ} / \mathrm{mole}^{[32]}$, and the measured activation energy for $\mathrm{U}-10 \mathrm{Zr}$ HIP was consistent for both types of specimens, despite differences in the matrix $\mathrm{Zr}$ content. Therefore, interface controlled grain boundary diffusion is unlikely.

The lack of full agreement between the experimental results and the grain boundary diffusion-controlled models or the interface-controlled model described above implies that some other mechanism must be operating. Since cavitation by creep alone under hydrostatic stress is not expected for low stresses, a coupled grain boundary diffusion/power-law creep mechanism is likely, such as the one defined by Beere and Speight $[21]$. The analysis of the various models for cavitation, as applied to the U-10Zr HIP conditions, will be presented in Part II of this study to quantitatively model the present experiments and determine the dominant HIP mechanism.

The results reported above have direct implications on fuel performance modeling for metal fueled reactors such as the IFR. Performance codes such as LIFE-METAL[41] and FASTGRASS ${ }^{[42]}$ (developed at ANL) attempt to model the detailed physical phenomena of reactor fuel in the complex reactor environment. Both codes utilize HIP/swelling model which have a linear stress dependence, in contrast to the above observations. Although HIP is only one of many phenomena taking place in the fuel during irradiation, but the proper physics should be in place to provide accurate modeling of the process. It is apparent from the HIP experiments on U-10Zr presented above that the assumption of a diffusion-controlled mechanism for HIP and swelling of the high temperature $\gamma$-phases is inappropriate under the experimental conditions, especially at high driving forces. 


\section{Summary}

$\mathrm{UH}_{3}$ and $\mathrm{ZrH}_{2}$ powders were compressed, decomposed under vacuum, and sintered at $1100^{\circ} \mathrm{C}$ for 24 hours under purified argon to a relative density of $\sim 93 \%$ T.D. Approximately $50 \%$ of the zirconium was stabilized into an interstitial solution with carbon, nitrogen, and oxygen present in the starting $\mathrm{UH}_{3}$ powders, forming second phase particles on the grain boundaries which occupied $\sim 25$ vol. \% of each sample. Pure uranium and zirconium metal powders were then used to fabricate and sinter HIP specimens. The uranium metal was washed with nitric acid to remove surface oxidation. The powders were compressed and sintered under purified argon to a relative density of $\sim 92 \%$ T.D. Second phase impurity particles were again found on the boundaries, but their presence was greatly reduced to $\sim 5$ vol. $\%$.

The hydride and metal-derived samples were successfully HIPed at $700^{\circ} \mathrm{C}$ in a highpressure sintering system. The driving force dependence of $\mathrm{U}-10 \mathrm{Zr}$ was found by stress change experiments to be $n=3.4 \pm 0.3$ for the metal-derived specimens and $3.2 \pm 0.5$ for the hydride-derived specimens. The driving force dependence was also found to be $3.7 \pm 0.2$ for both materials based upon the variation of the initial HIP rates with driving force. An average activation energy of $187 \pm 10 \mathrm{KJ} /$ mole was measured for both types of specimen by temperature cycling. The driving force dependence suggests power-law creep controlled cavitation, but the activation energy is consistent with boundary diffusion controlled cavitation. Both $\mathrm{n}$ and $\mathrm{Q}$ indicate that the hydrideand metal-derived specimens exhibit the same HIP mechanism.

The expected Hull-Rimmer boundary diffusion mechanism was rejected because the observed strain rates had a non-linear driving force dependence, and loading transients were observed during $\triangle \mathrm{P}$ steps in the middle of the HIP experiments. The second phase particles on the boundary and solute $\mathrm{Zr}$ atoms in the matrix suggested that interfacial control of grain boundary diffusion might be a dominant feature, but it was shown that these phenomena could not dominate under the experimental conditions. Part II of this study will report on the further analysis of the 
experimental results using creep cavitation models, especially in relation to nuclear reactor fuel performance. 


\section{References}

[1] Walters, L.C.,Seidel, B.R., and Kittel, J.H., Nuclear Technology, v65, 1984, 202.

[2] Hofman, G.L., Pahl, R.G., Lahm, C.E. and Porter, D.L., Metallurgical Transactions A, v21A, 1990, 517.

[3] Abbott, R.C. and Solomon, A.A., Bull. of the Am. Cer. Soc., v58, 1979,128.

[4] Solomon, A.A., Cochran, K.M., and Habermeyer, J.A., NUREG/CR-2023, PUR-101, 1981.

[5] Solomon, A.A., Casagranda, A., and Rest, J., Journal of Nuclear Materials, v154, 1988, 332.

[6] Xu, A. and Solomon, A.A., in Ceramic Microstructures '86: Role of interfaces, Ed. Pask,J., 1986.

[7] Hsu, F. and Solomon, A.A., Acta Metallurgica, v31, 1983, 453.

[8] Solomon, A.A. and Hsu, F., J.Am.Cer.Soc.,63,1981,467.

[9] Xu, A. and Solomon, A.A., J. American Ceramic Society, v75, 1992, 985.

[10] Solomon, A.A., and Hsu, F., Sintering Processes, ed. Kuczyinski, Plenum Press, 1980, 485.

[11] Svensson, L.-E. and Dunlop, G.L., International Metal Reviews, v2, 1981, 109.

[12] Hull, D. and Rimmer, D.E., Philosophical Magazine, v4, 1959, 673.

[13] Speight, M.V. and Harris, J.E., Metal Science Journal, v1, 1967, 83.

[14] Weertman, J., Scripta METALLURGICA, v7, 1973, 1129.

[15] Speight, M.V. and Beere, W., Metal Science, v9, 1975, 190.

[16] Vitovec, F.H., Journal of Material Science, v7, 1972, 615.

[17] Raj, R. and Ashby, M.F., Acta Metallurgica, v23, 1975, 653.

[18] Raj, R., Shih, H.M., and Johnson, H.H., Scripta METALLURGICA, v11, 1979, 265.

[19] Chen, I.W. and Argon, A.S., Acta Metallurgica, v29, 1981, 1759.

[20] Herring, C. Journal of Applied Physics, v21, 1950, 437.

[21] Beere, W. and Speight, M.V., Metal Science, April, 1978, 172.

[22] Wilkinson, D.S. and Ashby, M.F., University of Cambridge Report, CUED/C-Mats/TR.22, 1975.

[23] Hancock, J.W., Metal Science, v10, 1976, 319. 
[24] Edward, G.H. and Ashby, M.F., Acta Metallurgica, v27, 1979, 1505.

[25] Rice, J.R., Time-Dependent Fracture of Materials at Elevated Temperature, Ed. S.Wolf, USDOE report, CONF 790236 UC-25, Germantown MD, 1979, p. 130.

[26] Needleman, A. and Rice, J.R., Acta Metallurgica, v28, 1980, 1315.

[27] Davanas, K. and Solomon, A.A., Acta Metall. Mater., v38, 1990, 1905.

[28] Dyson, B.F., Metals Science, v10, 1976, 349.

[29] Une, K., Journal of Nuclear Materials, v158, 1988, 188.

[30] McDeavitt, S.M. and Solomon, A.A., World Congress of Powder Metallurgy, v.6, Proceedings, San Francisco, June 1992.

[31] McDeavitt, S.M., Ph.D. Thesis, Purdue University, Dec. 1992.

[32] Rothman, S.J.., "Diffusion in Uranium, Its Alloys, and Compounds," ANL-5700, Part C, Argonne National Laboratory, 1961.

[33] Lloyd, H. and Williams J., Metallurgy and Fuels, v.3, Finniston, H.M. and Howe, J.P., ed., Pergamon Press, 1961.

[34] Hansen, M. and Anderko, K., Constitution of Binary Alloys, McGraw-Hill, 1958, p.1250.

[35] Mendelson, M.I., J. American Ceramic Society, v 52, 1969, 1269.

[36] Solomon, A.A. and Nix, W.D., Acta Metallurgica, v18, 1970, 863.

[37] Kaur, I, Gust, W., and Kozma, L., Handbook of Grain and Interphase Boundary Diffusion Data, v.2, Ziegler Press, Stutgart, 1989, p.1345.

[38] McDeavitt, S.M. and Solomon, A.A., ANS Transactions, v66, 1992, 189.

[39] Ashby, M.F., Scripta METALLURGICA, v3, 1969,837.

[40] Arzt, E., Ashby, M.F., and Verrall, R.A. Acta Metallurgica., v31, 1983, 1977.

[41] Billone, M.C., Argonne National Laboratory, private communication

[42] Rest, J., Journal of Nuclear Materials, v120, 1984, 195.

\section{ACKNOWLEDGEMENTS}

The authors express their appreciation to Nuclear Metals, Inc. for providing the uranium powder, to Oak Ridge National Laboratory for providing the uranium hydride powder, and to the U.S. Department of Energy for financial support under contract \#DE-FG07-88ER12814. 


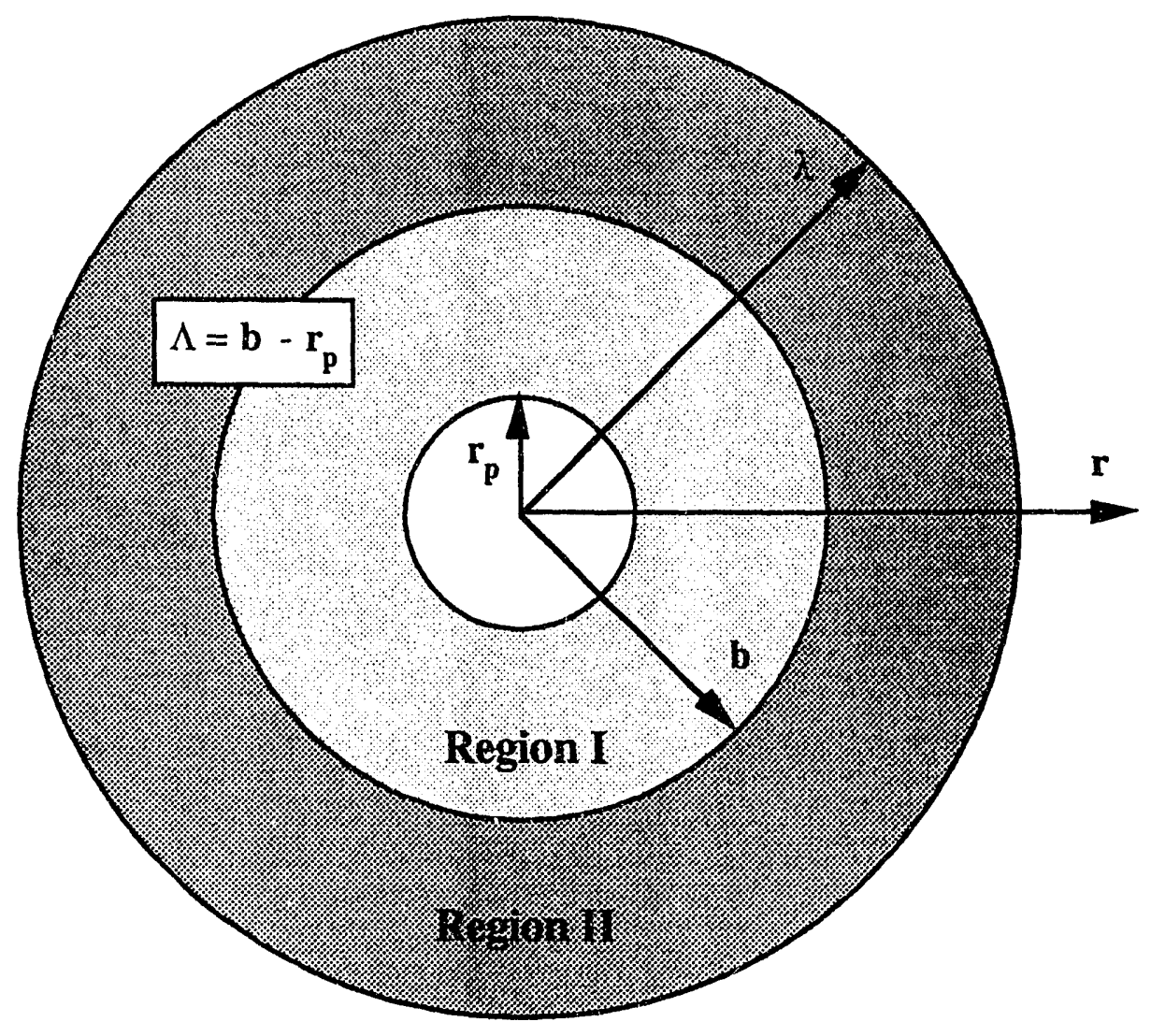

Figure 1. Beere-Speight model geometry. 


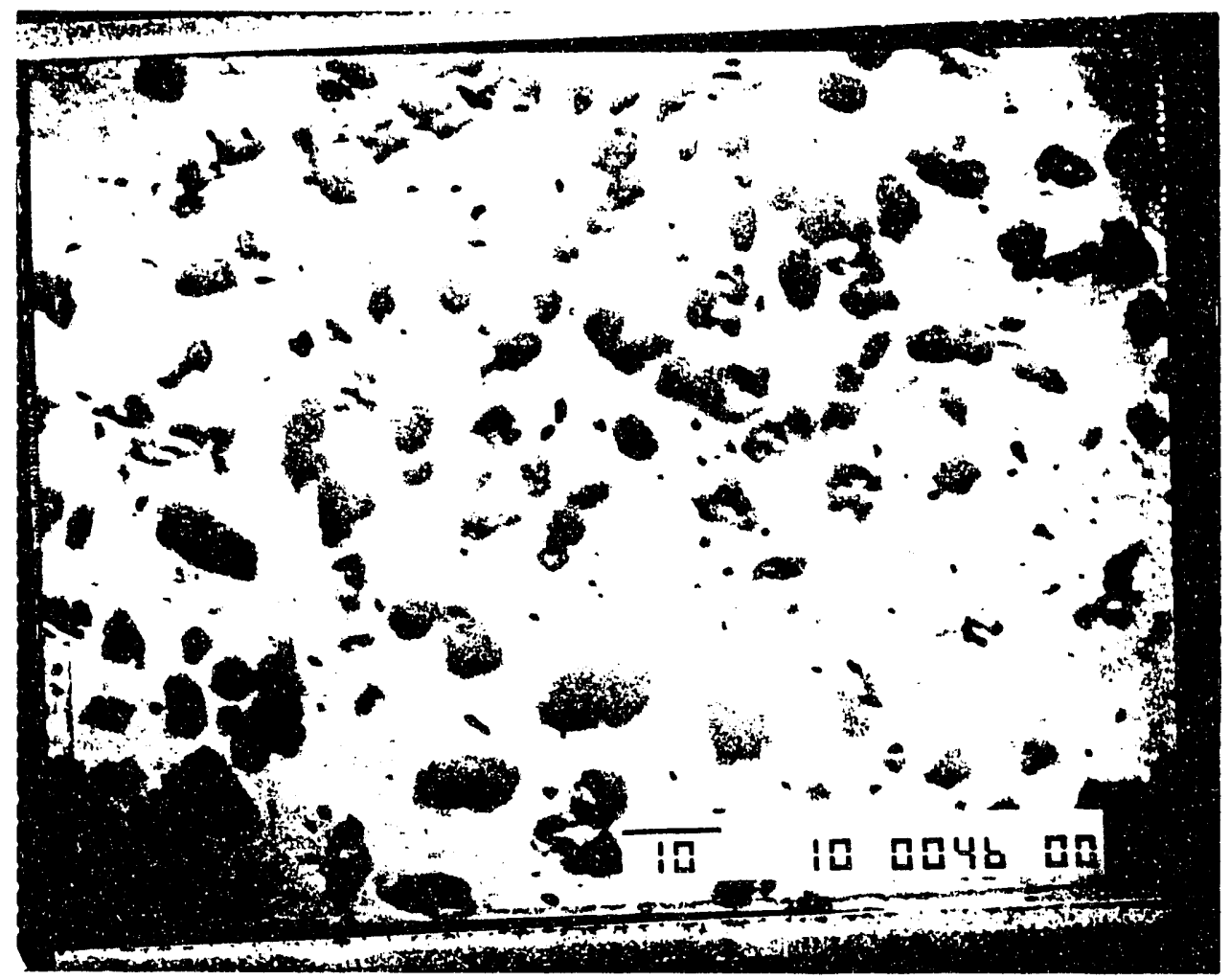

Figure 2. SEM backscatter image of hydride-derived $U-10 \mathrm{Zr}$ sintered for 24 hours at $1100^{\circ} \mathrm{C}(1000 \mathrm{x})$.

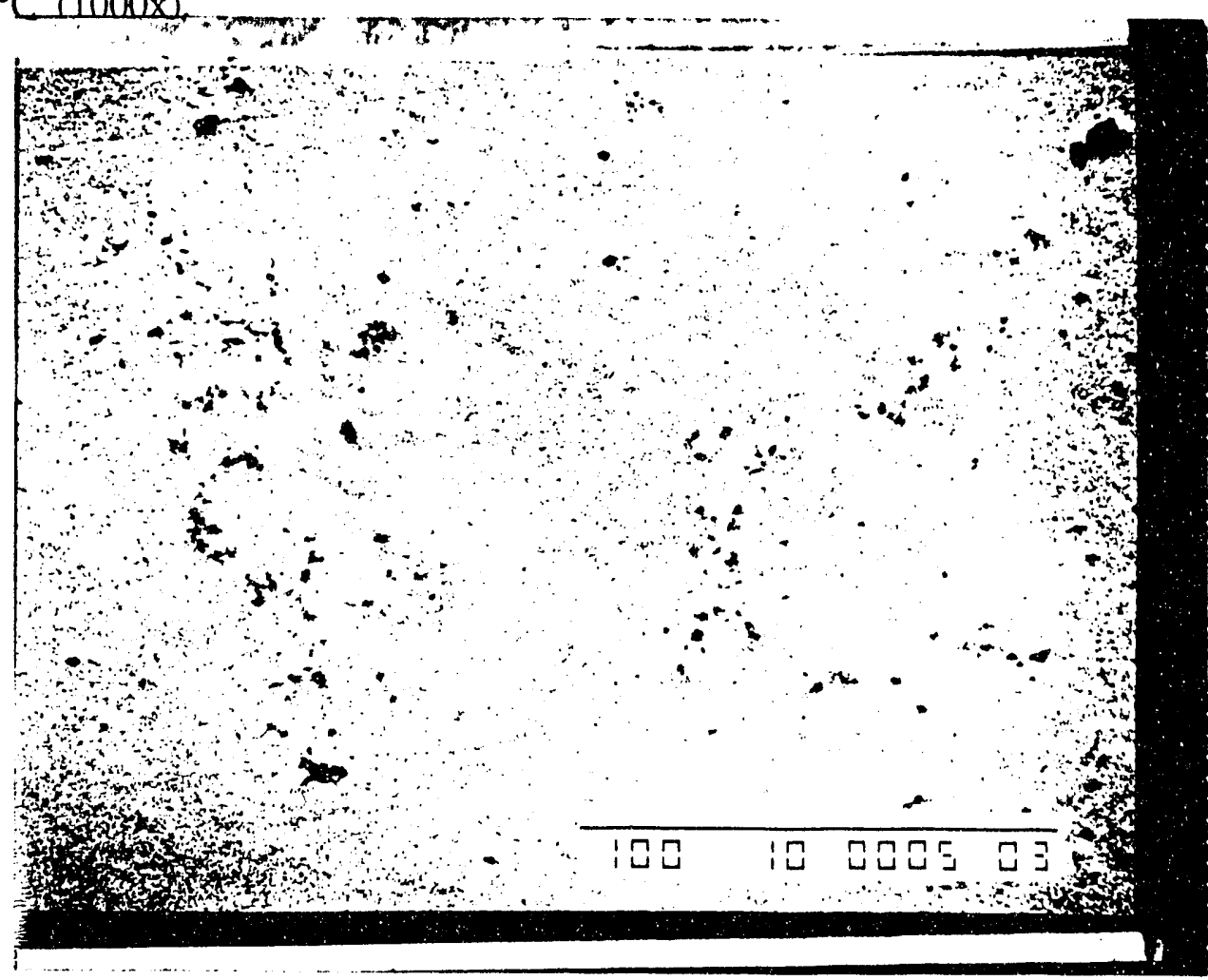

Figure 3. SEM backscatter image of sintered $U-10 Z r$ specimen produced from metal powders $(500 \mathrm{x})$. 


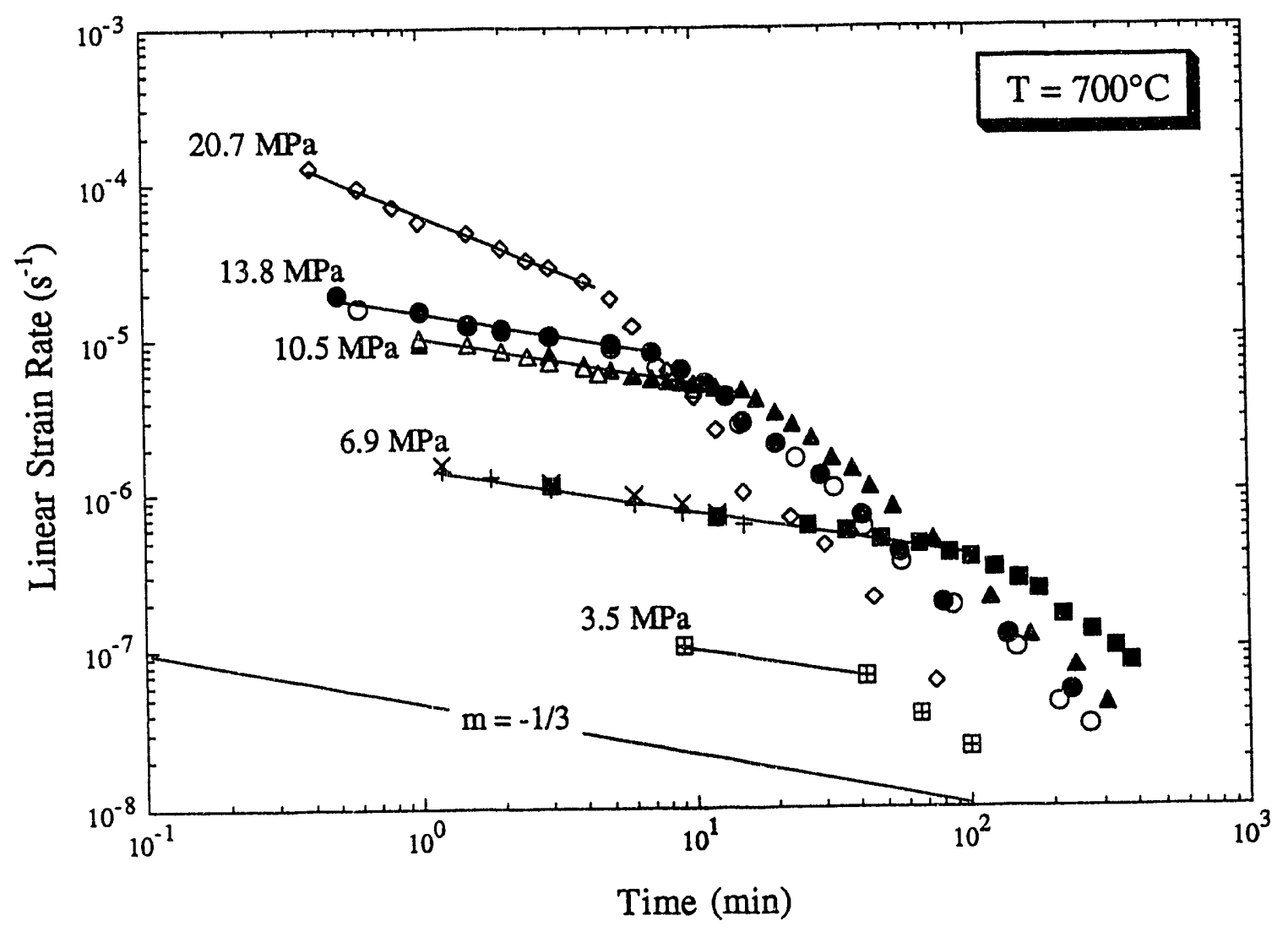

Figure 4. HIP results at $700^{\circ} \mathrm{C}$ for hydride-derived U-10Zr specimens. Points lying on same curve indicate duplicate experiments. 


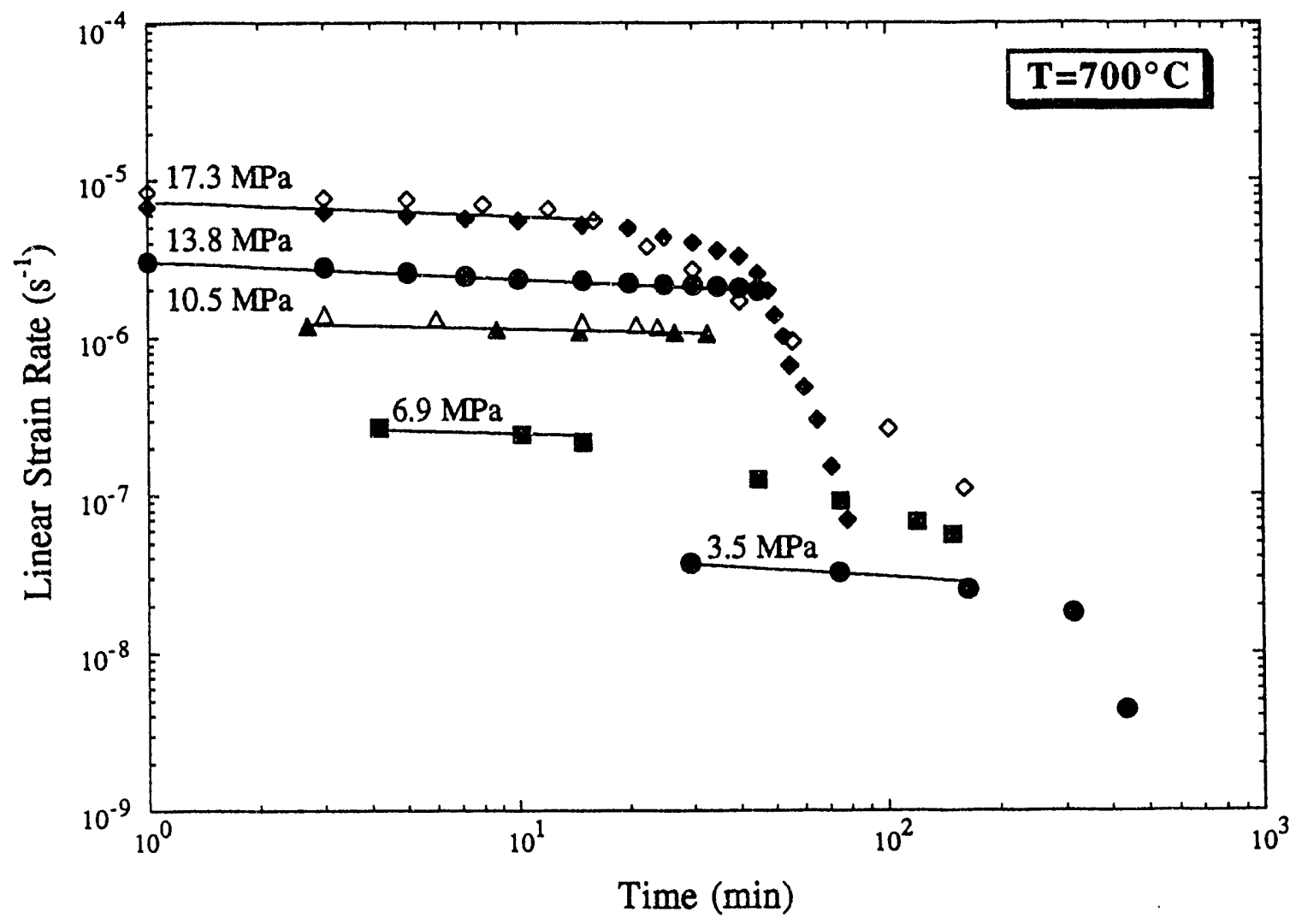

Figure 5. HIP strain rates vs. time at $700^{\circ} \mathrm{C}$ for metal-derived $\mathrm{U}-10 \mathrm{Zr}$ specimens. Points lying on same curve indicate duplicate experiments. 


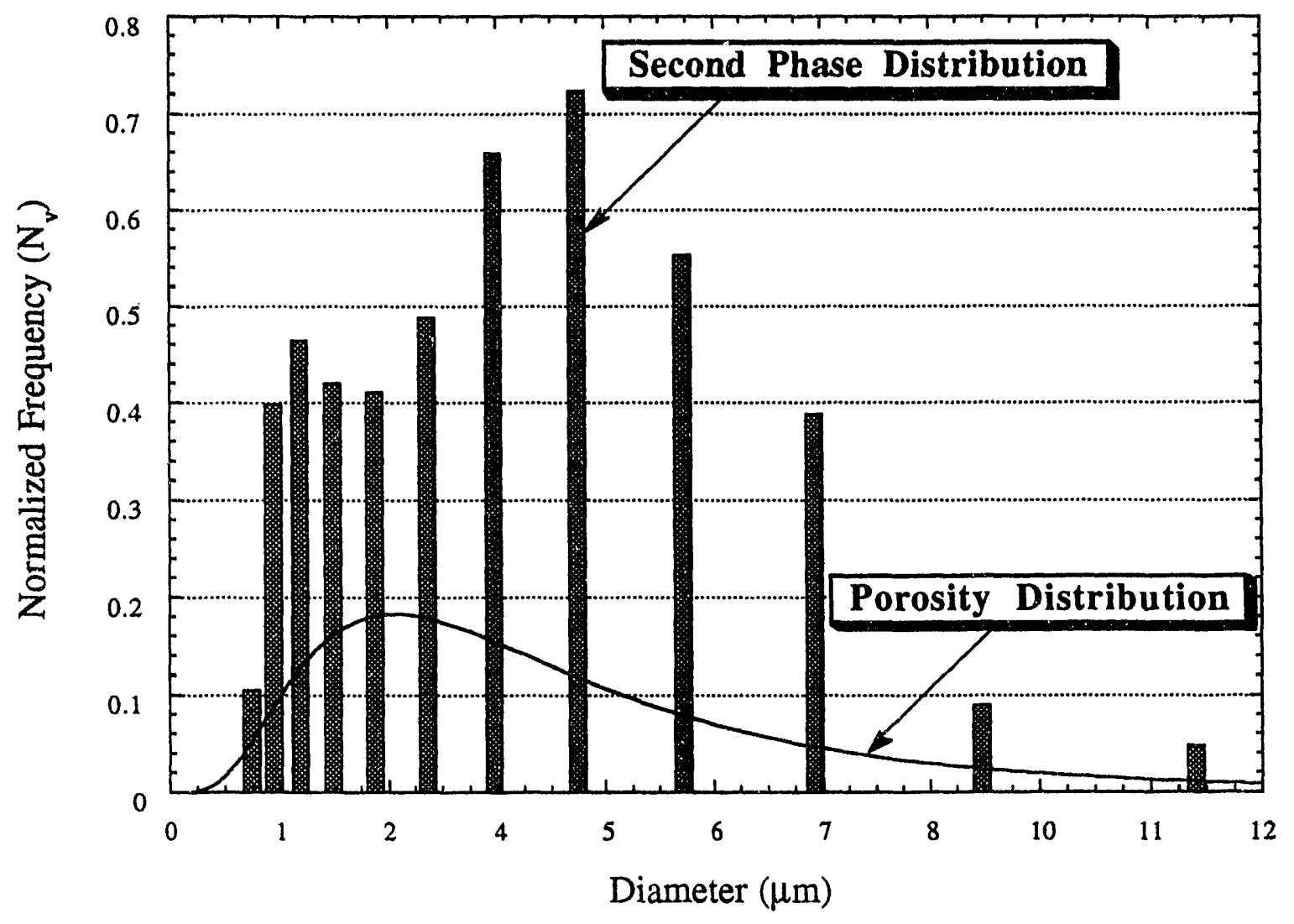

Figure 6. Normalized porosity and particle size distributions in the hydride-derived samples. 


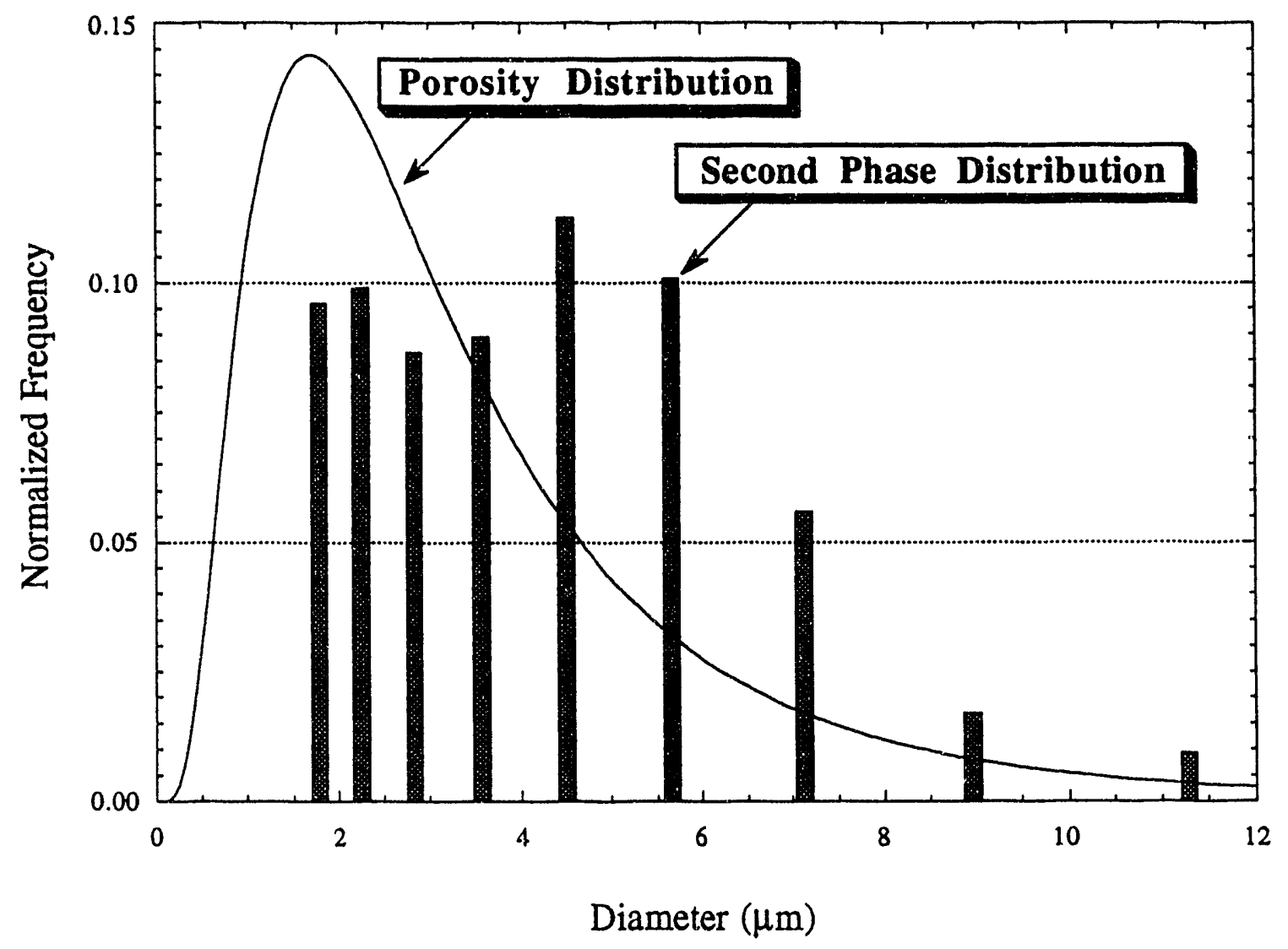

Figure 7. Normalized porosity and particle size distributions in the metal-derived samples. 


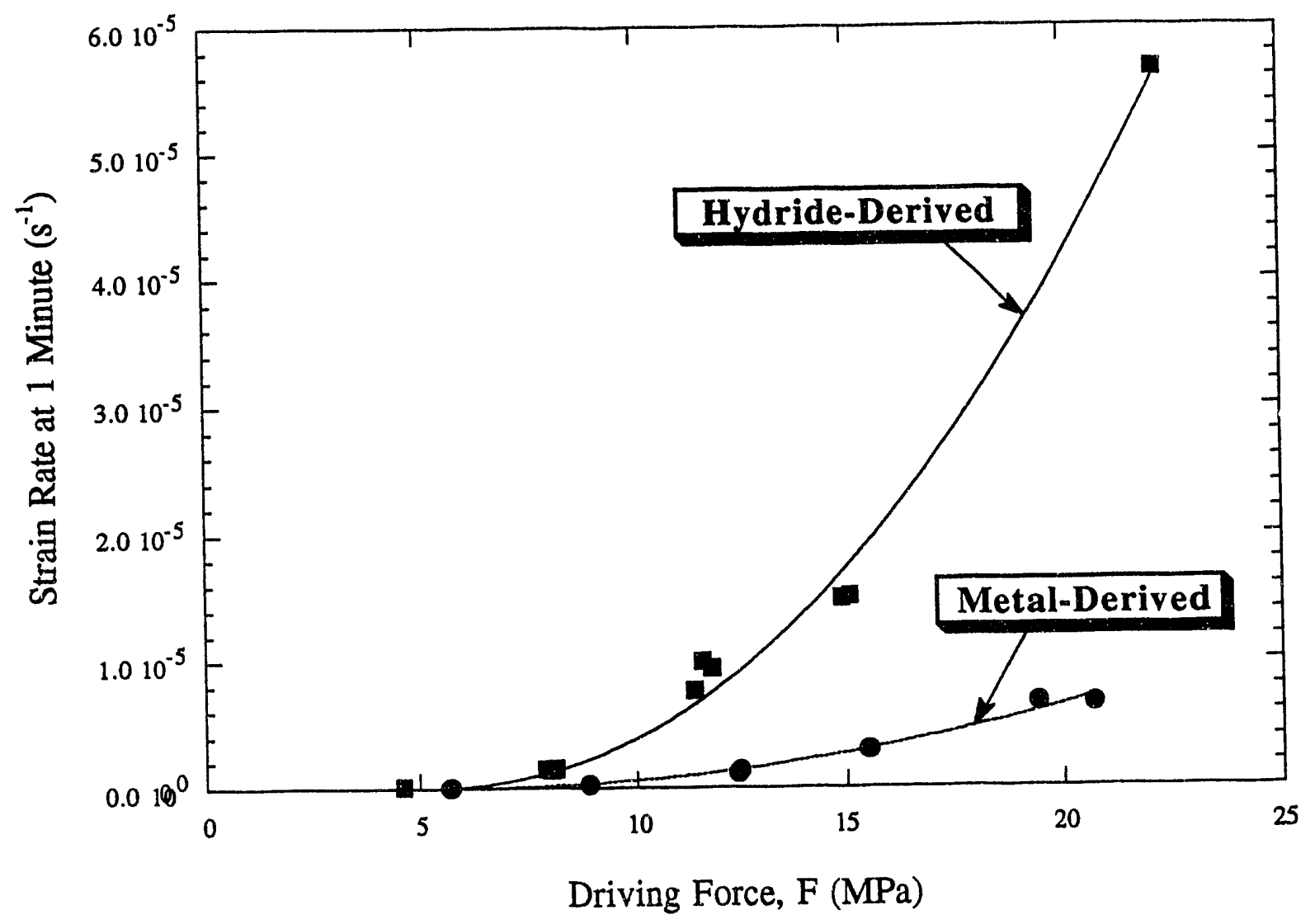

Figure 8. Extrapolated strain rates at 1 minute vs. the initial driving force. 


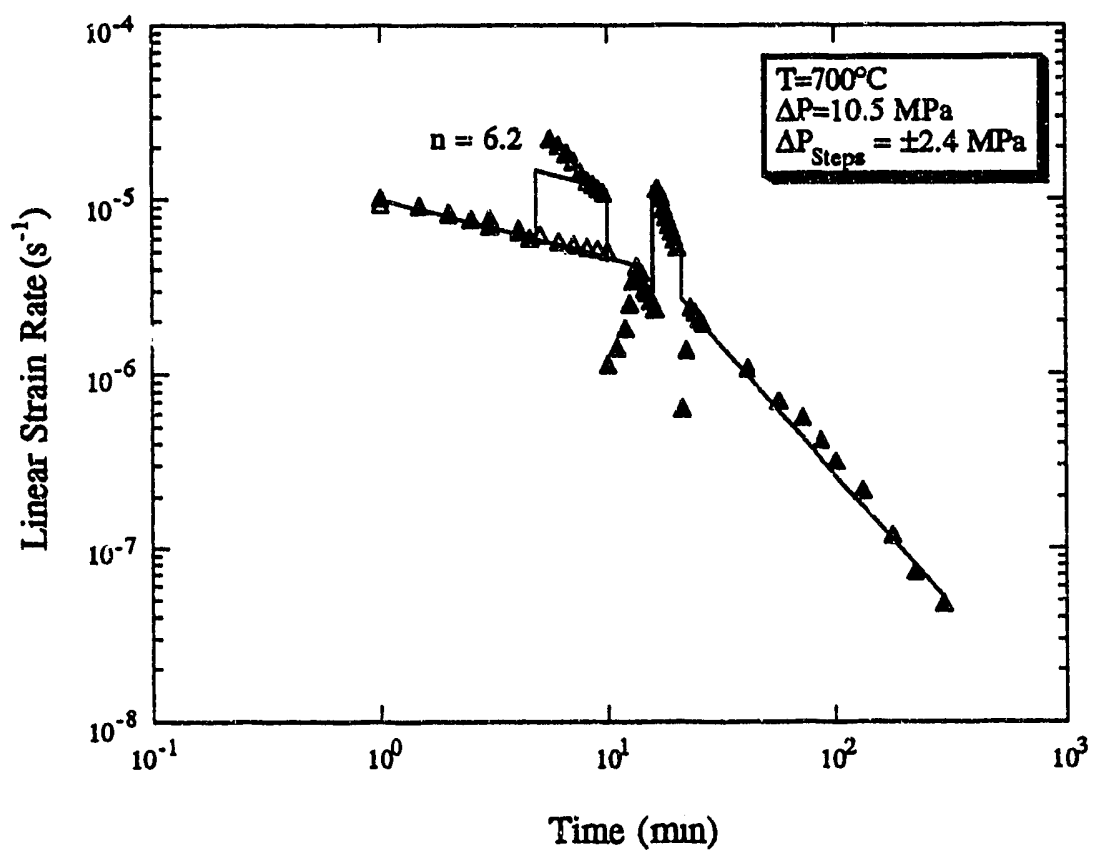

Figure 9. Hydride-derived specimen strain rate vs. time with $\triangle \mathrm{P}$ steps of $+2.4 \mathrm{MPa}$. 


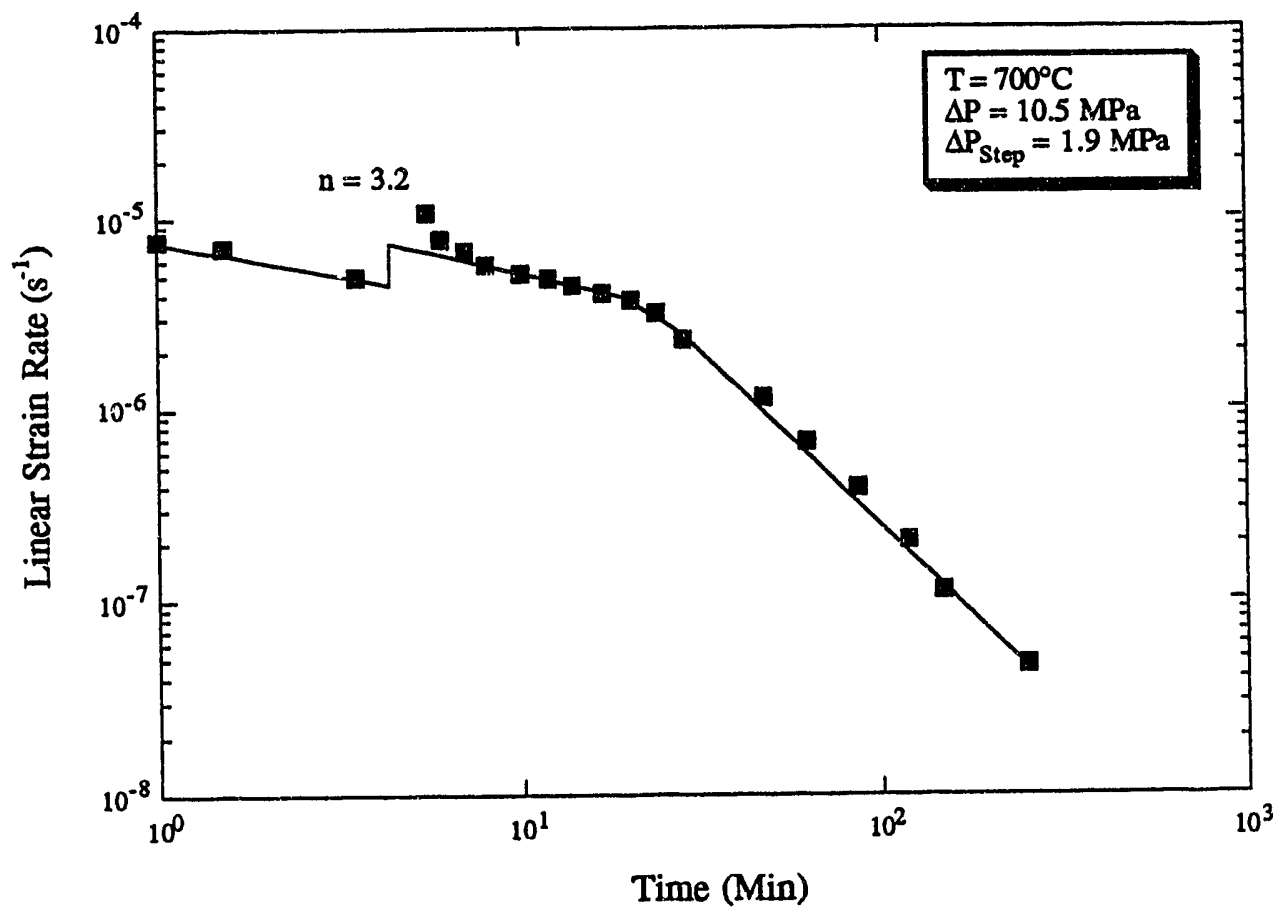

Figure 10. Hydride-derived specimen strain rate vs. time with a single $\triangle \mathrm{P}$ step of $1.9 \mathrm{MP}$. 


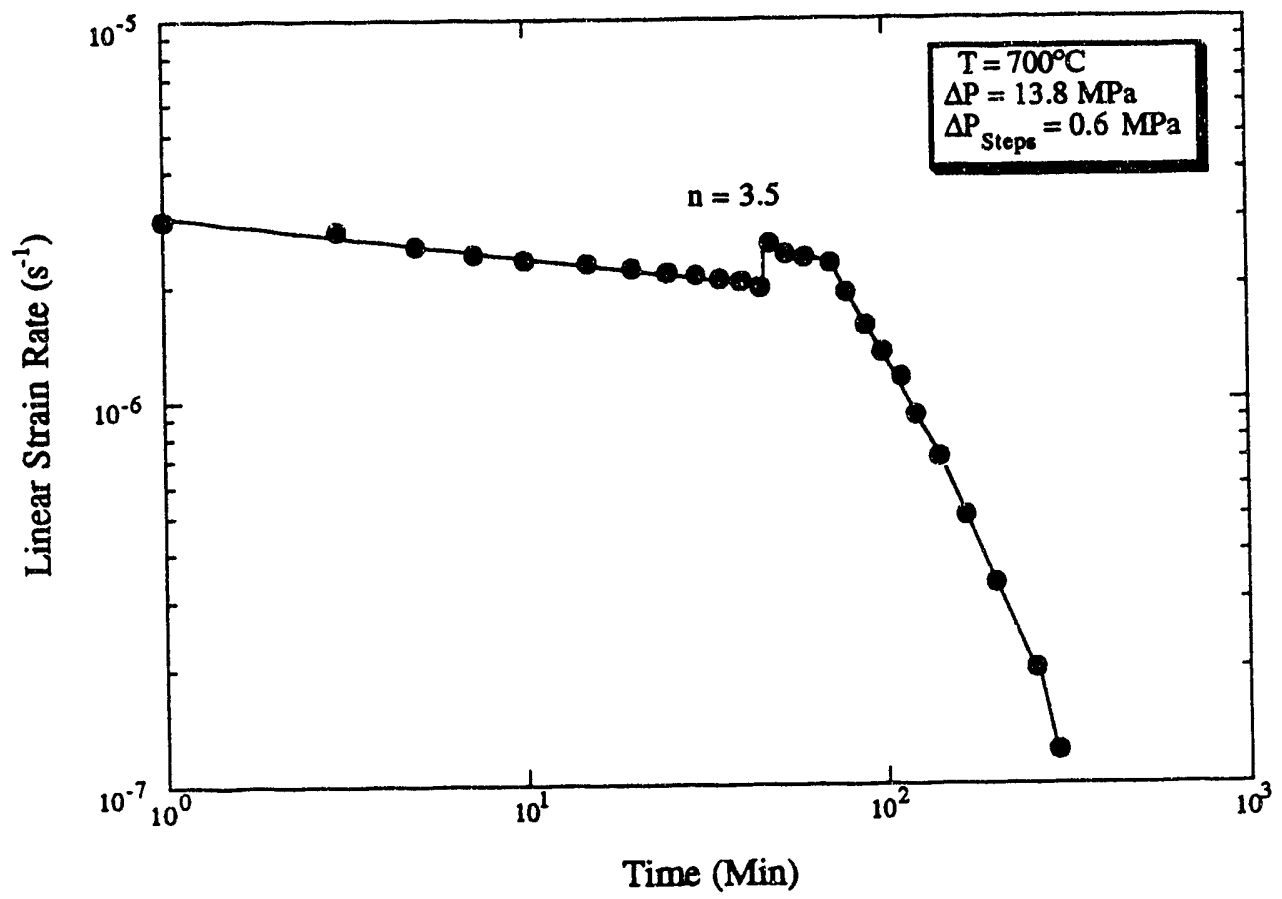

Figure 11. Metal-derived specimen strain rate vs. time with a single $\Delta \mathrm{P}$ step of $0.6 \mathrm{MPa}$. 


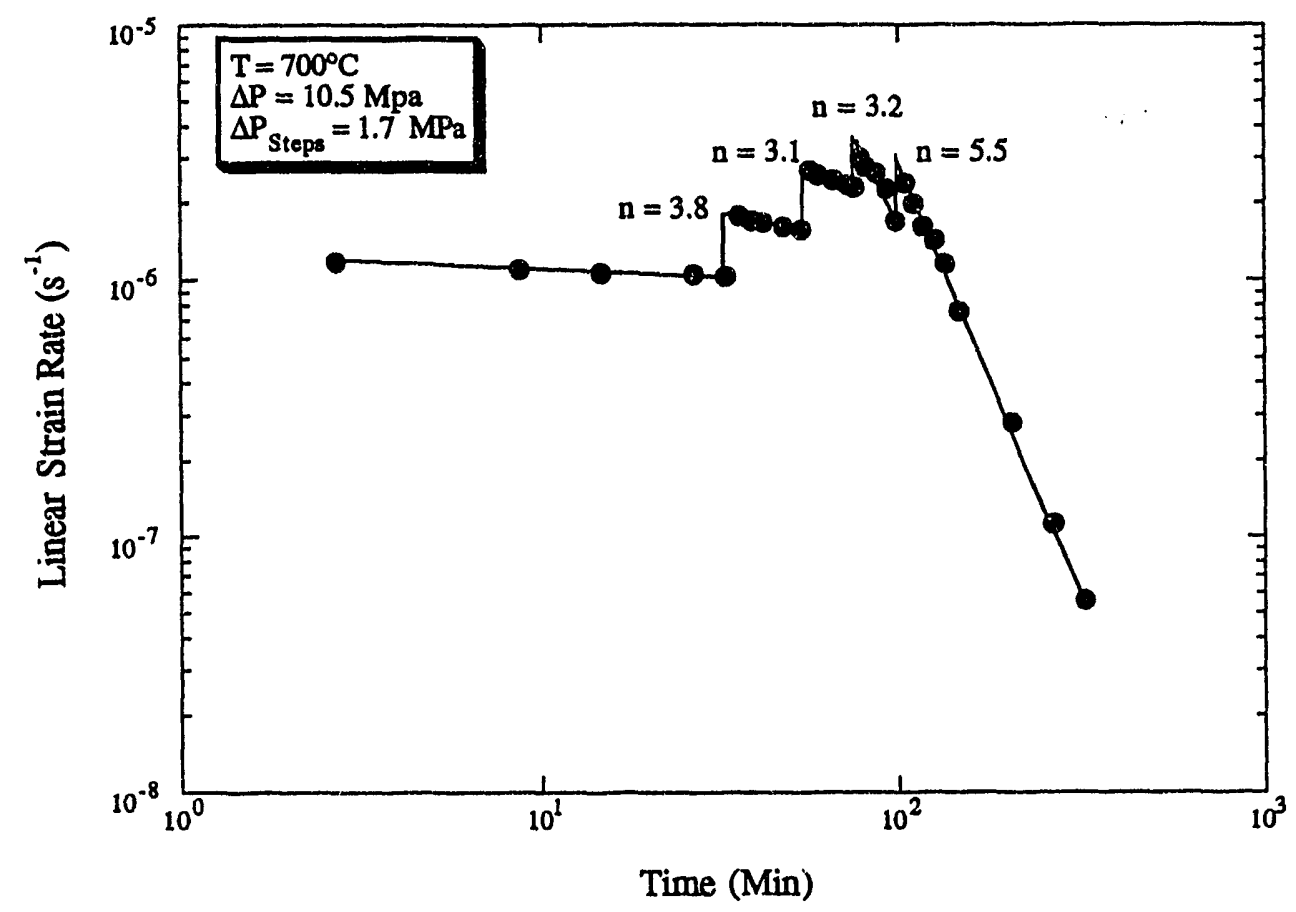

Figure 12. Metal-derived specimen strain rates vs. time with $\Delta \mathrm{P}$ steps of $+1.7 \mathrm{MPa}$. 


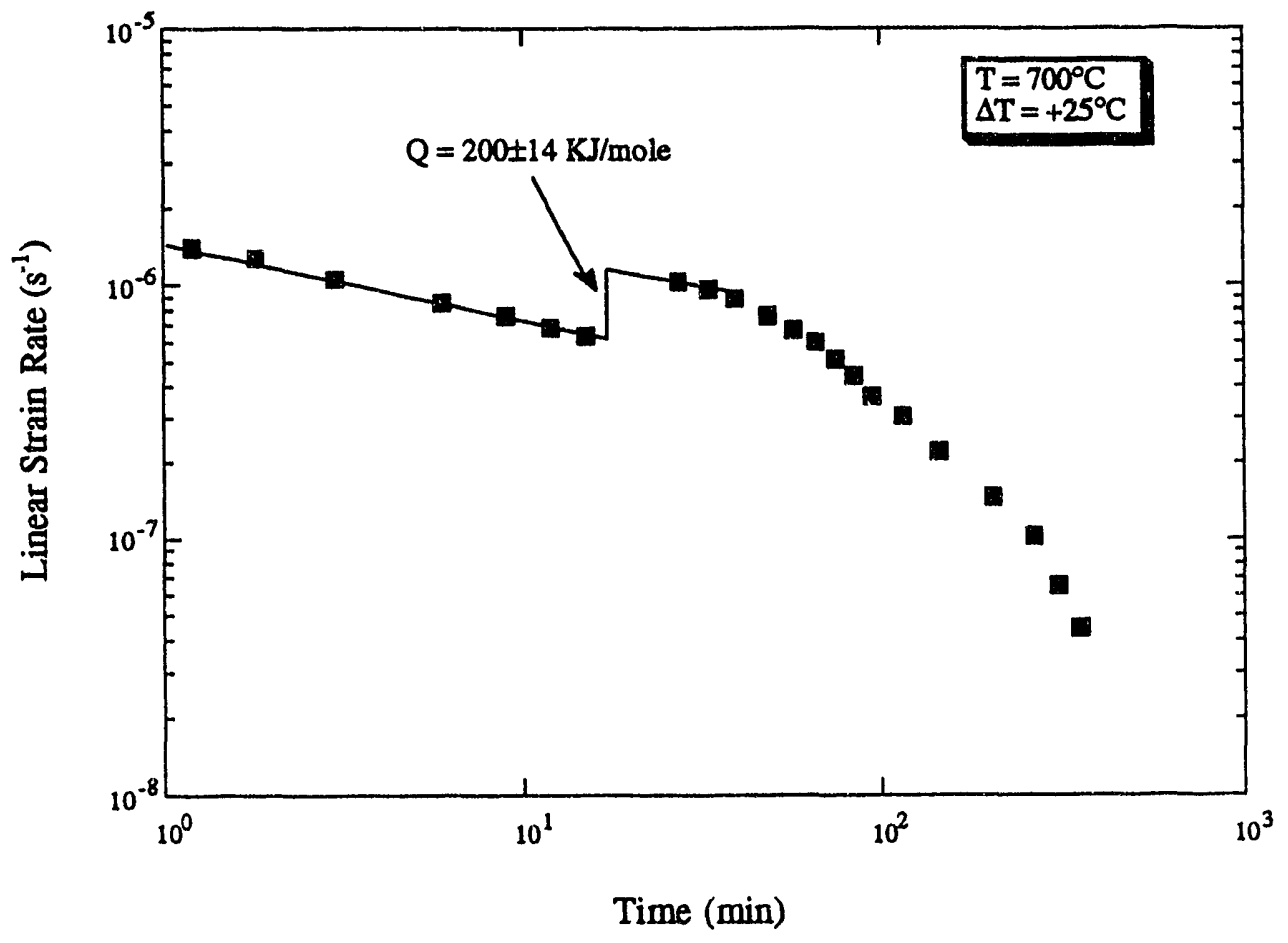

Figure 13. Hydride-derived sample strain rate vs. time with a single $\Delta \mathrm{T}$ transient of $+25^{\circ} \mathrm{C}$. 


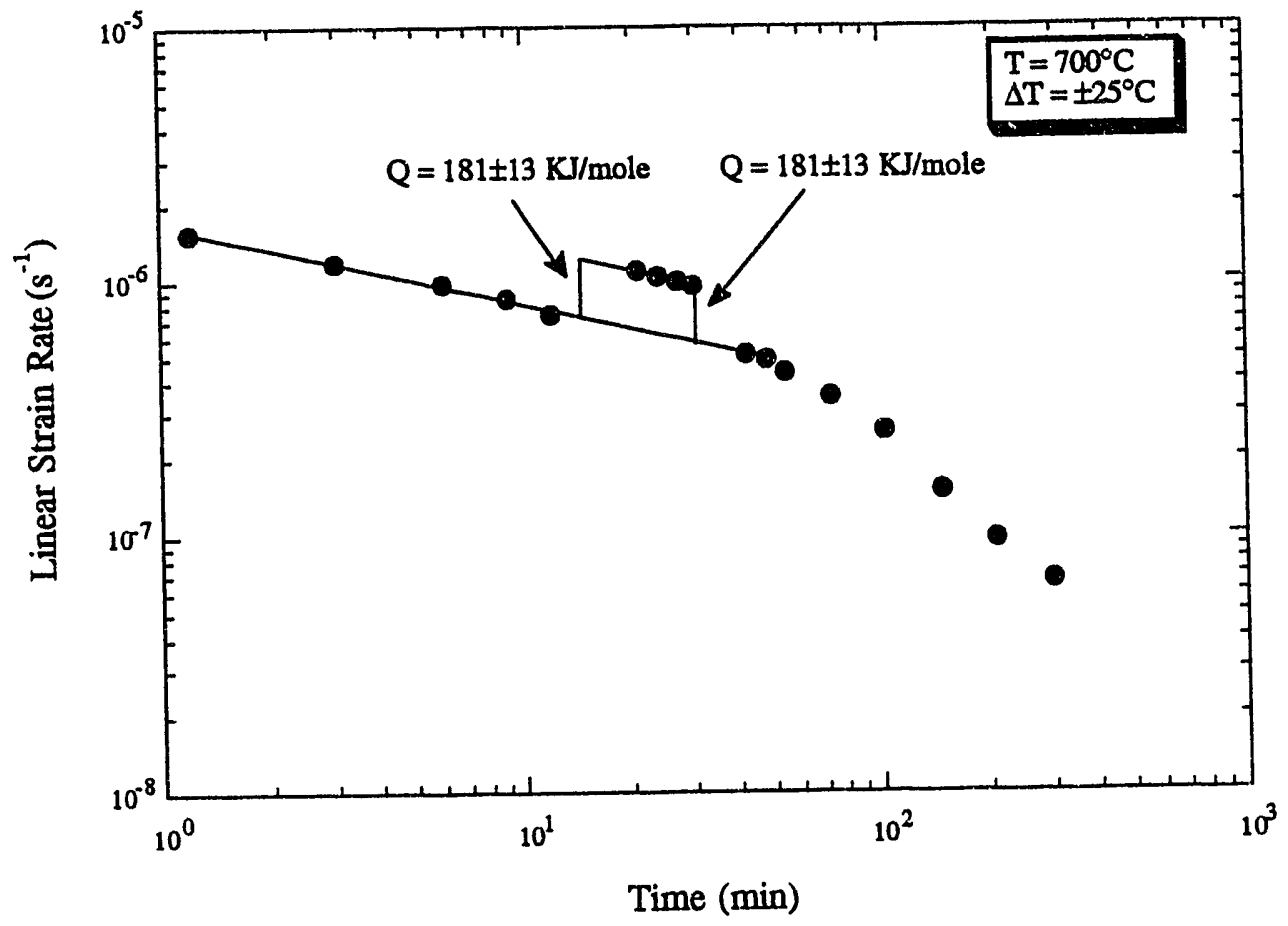

Figure 14. Hydride-derived sample strain rate vs. time with $\Delta \mathrm{T}$ transients of $\pm 25^{\circ} \mathrm{C}$. 


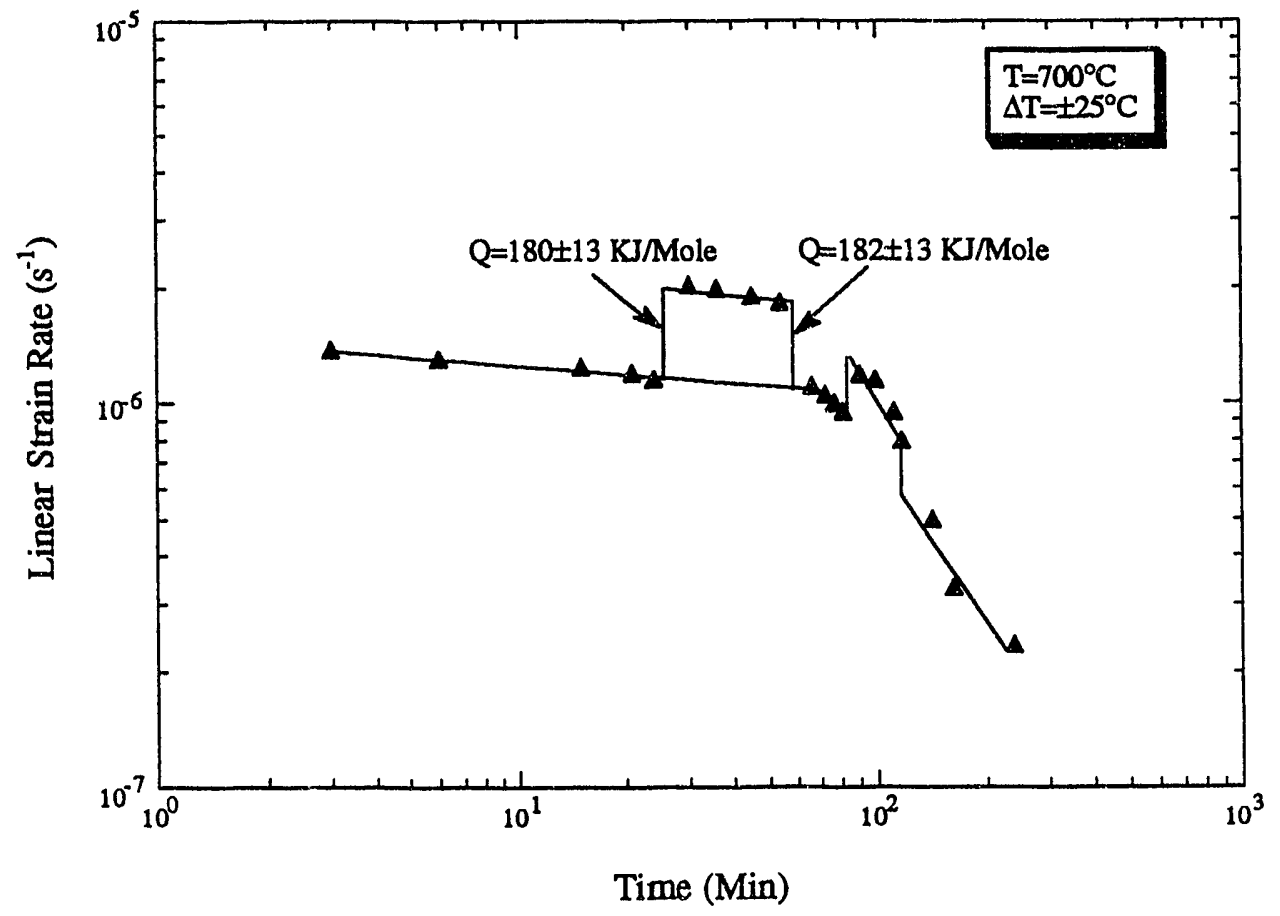

Figure 15. Metal-derived sample strain rate vs. time with $\Delta \mathrm{T}$ transients of $\pm 25^{\circ} \mathrm{C}$. 


\section{APPENDIX B}

Hot Isostatic Pressing of U-10Zr by Coupled Boundary

Diffusion/Power-Law Creep Cavitation - Part II 


\title{
HOT ISOSTATIC PRESSING OF U-10Zr BY COUPLED BOUNDARY DIFFUSION/POWER-LAW CREEP CAVITATION - PART II
}

\author{
Sean M. McDeavitt and A.A. Solomon \\ School of Nuclear Engineering, Purdue University, \\ West Lafayette, IN 47907, USA.
}

\begin{abstract}
$\mathrm{HIP}$ experiments performed on porous $\mathrm{U}-10 \mathrm{Zr}$ nuclear fuel at $700^{\circ} \mathrm{C}$ are compared with theoretical creep cavitation models. The coupled cavitation model of Chen and Argon shows quantitative agreement with the measured $\mathrm{HIP}$ rates. This model also predicts, for the first time, an asymmetry in HIP and swelling for identical driving forces due to differences in grain boundary stress. A calculation of the time-dependent HIP behavior was made which shows a varying time dependence that is consistent with the observed HIP rates. The compressibility of $\mathrm{U}-10 \mathrm{Zr}$ is different from previously studied ceramics and metals and is significantly lower than U-5Fs, which appears to HIP by diffusive transport only. The differences could be due to higher grain boundary diffusivity and/or larger pore size-to-spacing ratios in U-5Fs causing diffusional growth to be rapid and dominant. The lack of detectable compressibility of $U-10 \mathrm{Zr}$ in both the $\alpha^{\prime}$ and $\alpha+\delta$ phases may lead to fue $/$ cladding mechanical interactions during normal and off-normal conditions, especially at high burnup when solid fission products occupy available porosity.
\end{abstract}




\section{Introduction}

Uranium - 10 wt. \% zirconium (U-10Zr) is a driver fuel for the Experimental Breeder Reactor - II (EBR-II), which is being modified to operate as an Integral Fast Reactor (IFR); a fast reactor plant design developed by Argonne National Laboratory[1]. The metal-fueled IFR has passive safety features which will prevent severe nuclear accidents under conditions which would normally be devastating for the standard pressurized water reactors $[2]$. Metal alloys of uranium are attractive nuclear fuels because of their high thermal conductivity and high fissile atom density, but they were previously rejected due in part to fission gas induced swelling which caused FuelCladding Mechanical Interaction (FCMI) and cladding rupture under normal operating conditions ${ }^{[1]}$.

IFR fuel pins are designed to accommodate swelling and gas release by providing a fuel/cladding gap filled with sodium and an enlarged gas plenum which will allow the fuel to swell and release its fission gas before it comes in contact with the cladding ${ }^{[1]}$. After cladding contact at 1-2 atom \% burnup, FCMI is unavoidably present because fuel swelling is constrained by the current non-swelling cladding materials. Also, solid fission product accumulation in available porosity will impair the fuels compressibility at high burnup ${ }^{[3]}$, and rapid temperature rises during reactor transients could generate large contact stresses due to differences in fuel/cladding thermal expansion and plenum pressure increases.

To address these issues, hot-isostatic pressing (HIP) experiments ware carried out on unirradiated U-10Zr, as described in Part I of this reported work [4]. U-10Zr HIP specimens were prepared in an inert atmosphere glovebox from powder mixtures of uranium metal spheres with zirconium metal powder and uranium hydride $\left(\mathrm{UH}_{3}\right)$ with zirconium hydride $\left(\mathrm{ZrH}_{2}\right)$ powders. The processing methods developed for this study are described in detail in elsewhere[4-6]. The purpose of these experiments was to identify and quantify the rate-controlling HIP mechanism in U-10Zr using pure, unirradiated material to eliminate ambiguities from solid fission products, nonequilibrium defect structures, and other irradiation effects. 
The hydride- and metal-derived samples were sintered in a purified argon atmosphere beyond the point of pore closure at $1100^{\circ} \mathrm{C}$ and $1200^{\circ} \mathrm{C}$, respectively, to generate gas bubbles on the grain boundaries $[4]$. Both types of specimens were successfully HIPed at $700^{\circ} \mathrm{C}$, which is in the $\gamma$-phase field, using a high-pressure sintering system described elsewhere[7]. Hot-pressing was attempted at $600^{\circ} \mathrm{C}$, in the $\alpha+\delta$ phase field, but no densification was observed. HIP was accomplished through raising the external ambient pressure to create a driving force for densification. The HIP strains were monitored in situ, and the initial HIP rates are shown in Fig. 1 vs. the initial pressure driving force. The hydride-derived specimens HIPed at relatively higher strain rates, as compared to the metal-derived specimens.

It is apparent from the data in Fig. 1 that the driving force dependence of the HIP rate, which is denoted by the variable $\mathrm{n}$, is non-linear. The $\mathrm{n}$-value for both materials was found to be $3.7 \pm 0.2$, based upon the variation of the initial rates with driving force[4,6]. An independent measure of $\mathrm{n}$ was also made through small pressure perturbations during the HIP experiments, and the driving force dependence was found to be $n=3.4 \pm 0.3$ for the metal-derived specimens and $3.2 \pm 0.5$ for the hydride-derived specimens $[4,6$. This non-linear driving force dependence was not seen previously in other HIP and swelling experiments on other materials [8-14], and it suggests the possibility that power-law creep dominates the HIP process.

To quantify the kinetic behavior of the process, the HIP activation energy (Q) was measured for both types of specimen through temperature cycling during hot-pressing transients. Although relatively few data were generated, there was good agreement between the Q-values measured for the hydride- and metal-derived materials, with an overall mean Q-value of $187 \pm 10$ $\mathrm{KJ} /$ mole $(45 \pm 3 \mathrm{kcal} / \mathrm{mole})[4,6]$. This value is consistent with the reported activation energy of $186.6 \mathrm{~kJ} / \mathrm{mole}$ ( $44.6 \mathrm{kcal} / \mathrm{mole})$ for grain boundary diffusion in uranium [15], which suggests the possibility that grain boundary diffusion dominates the HIP process.

Despite the different implications of the measured $\mathrm{n}$ and $\mathrm{Q}$ values, the agreement between the hydride- and metal-derived data strongly supports the idea that both specimens exhibit the same HIP mechanism. The purpose of this paper is to consider the proposed HIP mechanisms and 
rationalize the differences and similarities in the data through quantitative analysis using previously derived models. It has been established that the phenomena of HIP and swelling of porous material at elevated temperatures are well described by models developed for creep cavitation[14]. The following sections will review the mechanistic models for creep cavitation and then apply them to simulate the conditions of the U-10Zr experiments presented in Part I in order to quantitatively determine the dominant HIP mechanism.

\section{Creep Cavitation Models}

\subsection{Grain Boundary Diffusion Controlled Cavitation}

Hull and Rimmer ${ }^{[16]}$ were the first to analyze grain boundary creep cavity growth by vacancy diffusion in response to a tensile stress. Cavities are assumed to reside on grain boundaries which are perpendicular to the applied tensile load. The stress-induced potential difference between the grain boundary and the cavity surface creates a driving force for vacancy diffusion from the boundary to the cavity surface, inducing cavity growth. Diffusion on the pore surface is assumed to be much more rapid than in the grain boundary, such that grain boundary diffusion is the rate-limiting cavity growth phenomena. It is also assumed that the grain boundary is a perfect sink for atoms which are deposited uniformly over the entire boundary to minimize lattice strains.

The original model from Hull-Rimmer has been modified by several authors[17-22], but the fundamental concept has not changed. Important modifications have been made to the model geometry[17-20] and the physical boundary conditions[21,22]. A similar diffusive model was developed by Chuang, et al. $[23,24]$ for crack like cavity growth during creep when the pore surface

diffusion is the rate limiting phenomenon. However, this model will be neglected because this type of cavity growth is not observed for HIP and swelling situations[14]. 
Chen and Argon ${ }^{[25]}$ suggest that the diffusion-controlled model presented by Speight and Beere ${ }^{[22]}$ provides the most accurate and complete formulation. Fig. 2 shows a top view of the Speight-Beere model unit cell geometry for a planar grain boundary, which consists of a pore of radius $\mathrm{r}_{\mathrm{p}}$ in a circular cell with radius $\lambda$. Physically, $\lambda$ represents the pore half-spacing for equispaced, equi-sized cavities in the grain boundary. Assuming spherical cavities and including internal pore pressure, the Speight-Beere expression for the rate of cavity volume change under HIP or swelling conditions is given as[20]

$\left(\frac{d V}{d t}\right)_{\text {diffusion }}=\frac{2 \pi \Omega D_{b} \delta_{b}}{k T f\left(\frac{r_{p}}{\lambda}\right)}\left[\mathrm{P}-\mathrm{p}+\frac{2 \gamma}{r_{p}}\right]$,

where $P$ is the external pressure, $p$ is the cavity internal pressure, $\gamma$ is the cavity surface energy, $D_{b}$ is the grain boundary diffusion coefficient, $\delta_{\mathrm{b}}$ is the effective width of the boundary, $\Omega$ is the atomic volume, $\mathrm{k}$ and $\mathrm{T}$ have their usual meanings, and $f\left(\frac{r_{p}}{\lambda}\right)$ is a geometric function given by[20]

$f\left(\frac{r_{p}}{\lambda}\right)=-\left[\ln \left(\frac{r_{p}}{\lambda}\right)+\frac{1}{4}\left(1-\frac{r_{p}^{2}}{\lambda}\right)\left(3-\left(\frac{r_{p}}{\lambda}\right)^{2}\right)\right]$.

\subsection{Power-law Creep Deformation Controlled Cavitation}

In the above diffusion-controlled models, it is assumed that the grains do not deform plastically (which is always true for HIP and swelling, but not for creep) and that diffusion occurs over the entire grain boundary. In practice, it is possible that diffusion only dominates the portion of the grain boundary adjacent to the pore and that dislocation creep is the dominant deformation mechanism over the remainder of the boundary [5]. In the extreme situation where grain boundary diffusion is limited, creep deformation can control cavity growth . 
This section will discuss two models for creep cavitation which are governed by plastic deformation[26,27]. Both models assume that the material surrounding the cavity creeps according to the constitutive relation

$\dot{\varepsilon}_{\mathrm{c}}=\mathrm{B} \sigma_{\mathrm{e}}^{\mathrm{n}}$

where $\mathrm{B}$ and $\mathrm{n}$ are constants and $\sigma_{\mathrm{e}}$ is an effective stress.

Beere and Speight[26] consider the creep of a thin shell of material around the boundary which is approximately as thick as the pore diameter. They consider this effect to be in addition to the creep of the bulk, intragranular material. Although creep is a constant volume process, the deformation of the cavity as the surrounding material creeps is not. The pore growth rate due to the creep of the boundary shell is given by

$$
\left(\frac{\mathrm{dV}}{\mathrm{dt}}\right)_{\text {creep }}=2 \pi \mathrm{r}_{\mathrm{p}}^{3} \dot{\varepsilon}_{\mathrm{c}}
$$

where $\dot{\varepsilon}_{\mathrm{c}}$ is the creep response to the stress acting on the boundary. This expression is derived by assuming a shell depth of $2 r_{p}$ and a creeping pore volume of $\left(2 r_{p} \cdot \pi r_{p}^{2}\right)$. This is effectively a cylindrical pore, but the model is limited because of the planar geometry.

A general creep-controlled HIP model was derived by Wilkinson and Ashby[27] based upon the models of Murray, et al. [28], Mackenzie and Shuttleworth [29], and Wolfe[30]. The model describes a 3 -dimensional, even distribution of equisized pores with the unit cell geometry defined as a spherical pore in the center of a creeping spherical shell. Wilkinson and Ashby derive the stress field within the shell to estimate the effective stress, assuming an external hydrostatic pressure an internal pore pressure. They neglect the pressure effect of the surface energy of the pore, but this model was specifically derived for HIP conditions. They derive an expression for the rate of density change due to pore shrinkage which is given as [27] 
$\dot{\rho}=\frac{3 B}{2} \frac{\rho(1-\rho)}{\left[1-(1-\rho)^{1 / n}\right]^{n}}\left(\frac{3}{2 n}(\Delta P)\right)^{n}$

whene $\rho$ is the relative density of the material, $\Delta P$ represents the difference between the internal and external pressures, $\mathrm{n}$ is the creep stress dependence from Eq. 3 , and $\mathrm{B}$ is a constant.

\subsection{Coupled Grain Boundary Diffusion/Power-law Creep Controlled Cavitation}

Several authors have considered coupled operation of creep and grain boundary diffusion, and the models are referred to as: i) "constrained" cavitation, and 2) "enhanced" cavitation. The first case occurs when pores are isolated on a boundary surrounded by adjacent boundaries having no porosity. The growth of cavities under a tensile load requires long-range diffusion unless the material far from the cavities can creep[31-33]. The surrounding material is considered to act as a "constraint" to diffusive cavitation and creep can relax this constraint. This case is equivalent to diffusional cavitation under variable pore spacing as described by Davanas and Solomon[34]. These models will not be considered furth $r$ for this study because the porosity generated in the U$10 \mathrm{Zr}$ samples is evenly distributed over all grain boundaries[4,6].

The sec and case is equivalent to coupled grain boundary diffusion and power-law creep controlled cavitation $[25,26,35-37]$. Beere and Speight ${ }^{[20]}$ considered this coupled mechanism for tensile loading by assuming that vacancy creation occurs predominantly near the cavity and negligibly over the rest of the boundary. The cavity growth rate is "enhanced" because the diffusional path length is shorter, as vacancies are created in the boundary closer to the cavity. The authors simplify the situation by assuming the boundary may be divided into two regions, as indicated in Figure 3(a). The unit cell of the model is circular for symmetry, where $\mathrm{r}_{\mathrm{p}}$ is the pore radius, $\lambda$ is the pore half-spacing, and $b$ is the radius of the division between Regions I and II.

During diffusive cavity growth, the rigid grains move apart due to the platin; of atoms on the grain boundary, and this process is called "jacking"[22]. For the coupled model, jacking is 
restricted to Region I, near the cavity, as indicated by the side view in Figure 3(b). The cell boundary displacement far from the cavity in Region II matches the jacking displacement through dislocation creep to maintain continuity. The vertical depth of the model is taken as $2 b$, which is equivalent to assuming a hole exists in the material the size of the diffusion zone because all stresses are relaxed by diffusion and creep deformation does not occur.

The displacements in Region I due to jacking are matched by dislocation creep in Region II to maintain continuity. Beere and Speight derived a system of three equations to physically represent the situation, which may be used to calculate the parameters $b, \sigma_{1}$ and $\sigma_{I}$, where $\sigma_{\mathrm{I}}$ is the average stress over region I (including the cavity) and $\sigma_{\text {II }}$ is the stress on the boundary in Region II. Because the system of equations is complex, Beere and Speight presented an approximation for the pore rate of volume change by summing the two limiting cases where only diffusion $(b \geq \lambda)$ or only creep $\left(b \leq r_{p}\right)$ is dominant in the grain boundary. This approximation was later rejected as ... oversimplification by several authors ${ }^{[25,35-37]}$.

A significant improvement to the coupled model came from Chen and Argon[25], who advanced a similar, but more elegant, model and extended it to include non-equilibrium, crack-like pores, similar to the model of Chuang et al.[23-24]. The complex system of equations presented above become unnecessary because the size of the diffusion zone, $b$, may be directly calculated from the "diffusion distance" or "characteristic length" in a creeping materiai darived by Rice[36] as

$\Lambda=\left(\frac{D_{b} \delta_{b} \Omega \sigma_{\infty}}{k T \dot{\varepsilon}_{\infty}}\right)^{1 / 3}$,

where $\sigma_{\infty}$ and $\varepsilon_{\infty}$ represent the far-field creep stress and creep rate. Chen and Argon ${ }^{[25]}$ estimate the diffusion zone radius, by $b=r_{p}+\Lambda$, and then calculate the pore growth rate due to the jacking of Region I. Therefore, the pore growth rate may be directly calculated from 
$\left(\frac{\mathrm{dV}}{\mathrm{dt}}\right)_{\text {diffusion }}=\frac{2 \pi \Omega \mathrm{D}_{\mathrm{b}} \delta_{\mathrm{b}}}{\mathrm{kT} f\left(\frac{\mathrm{r}_{\mathrm{p}}}{\mathrm{b}}\right)}\left[\mathrm{P}-\mathrm{p}+\frac{2 \gamma}{\mathrm{r}_{\mathrm{p}}}\right]$

which is equivalent to Equation 1, substituting $b$ for $\lambda$. The structure function $f\left(\frac{r_{p}}{b}\right)$ is strongly stress dependent, which raises the stress dependence of the model from $n=1$ at low stresses to the creep exponent of the material at very high stresses. Chen and Argon compare their model with the exact calculation of Needleman and Rice and an exact solution of the system of equations derived by Beere and Speight, and show excellent agreement with both.

\section{Comparison of Data with Theoretical Models}

The above models will now be used to calculate the predicted HIP behavior for U-10Zr for each of the described models. The expressions presented for the rate pore volume change may be translated to an overall linear specimen HIP or swelling rate according to Solomon and Hsu[14] using

$\dot{\varepsilon}=\frac{1}{3} \mathrm{~N}_{\mathrm{v}}\left(\frac{\mathrm{dV}}{\mathrm{dt}}\right)$.

Spherical pores are assumed for this study, consistent microstructural observation of the $U-10 \mathrm{Zr}$ samples $[4,6$. The measured values and physical parameters assumed for $\mathrm{U}-10 \mathrm{Zr}$ which were used in the models to calculate HIP behavior are summarized in Table 1.

\subsection{Grain Boundary Diffusion Controlled HIP of U-10Zr}

The Speight-Beere model (Equation 1) for grain boundary diffusion controlled cavity growth becomes 


$$
\dot{\varepsilon}_{\text {diffusion }}=\frac{2 \pi}{3} \frac{\mathrm{N}_{\mathrm{v}} \Omega \mathrm{D}_{\mathrm{b}} \delta_{\mathrm{b}}}{\mathrm{kT} f\left(\frac{\mathrm{r}_{\mathrm{p}}}{\lambda}\right)}\left[\mathrm{P}-\mathrm{p}+\frac{2 \gamma}{\mathrm{r}_{\mathrm{p}}}\right]
$$

when combined with Equation 8. The predicted driving force dependence of $n=1$ does not agree with the experimental values of 3 to $3.5[4,6]$.

Figure 4 shows the predicted diffusion-controlled $\mathrm{HIP}$ behavior of $\mathrm{U}-10 \mathrm{Zr}$ as compared with the initial HIP rates shown in Figure 1 for the metal- and hydride-derived materials. Theses comparisons show the significance of the driving force dependence to the accuracy of model predictions. Although the model prediction and the measured HIP rates are within one order of magnitude at low driving forces, a change in the driving force from 5 to $30 \mathrm{MPa}$ shifts the difference between the model and the data to almost 3 orders of magnitude. Therefore, a diffusioncontrolled cavitation model does not adequately predict the HIP rates for $\mathrm{U}-10 \mathrm{Zr}$ under the observed conditions in spite of the excellent agreement between the measured activation energy $(187 \pm 10 \mathrm{~kJ} / \mathrm{mole})$ with the reported value for grain boundary diffusion $(186.6 \mathrm{~kJ} / \mathrm{mole})$.

\subsection{Power-law Creep Controlled HIP of U-10Zr}

Before the creep-controlled cavitation models were applied to U-10Zr HIP conditions, an appropriate constitutive creep expression of the form given by Equation 3 was determined. The expression was determined using the empirical method of Stocker and Ashby[38] and Derby and Ashby [39], and the relation is given as

$\dot{\varepsilon}_{c}=\left(4 \times 10^{-10}\right) \sigma^{5} \mathrm{~s}^{-1}$.

The use of this expression is justified elsewhere[ $[$, but this justification is beyond the scope of this paper. 
The Beere-Speight cavitation model is derived to represent the rate of pore volume change so it may also be translated to a HIP strain rate using Equation 8 to yield

$\dot{\varepsilon}_{\text {creep }}=\left[\frac{2 \pi \pi_{p}^{3}}{3} N_{v}\right] \dot{\varepsilon}_{d}\left(\sigma_{a v}\right)$

where $\dot{\varepsilon}_{\mathrm{c}}$ is given by Equation 10 and $\sigma_{\mathrm{av}}$ is the average stress acting on the creeping boundary shell. To use this expression, an approximation for $\sigma_{\mathrm{av}}$ must be made, and based upon the freebody diagram in Figure 5, the average stress on the boundary may be written as

$\sigma_{\mathrm{av}}=\frac{\mathrm{P} \lambda^{2}+\left(\frac{2 \gamma}{r_{\mathrm{p}}}-\mathrm{p}\right) \mathrm{r}_{\mathrm{p}}^{2}}{\left(\lambda^{2}-\mathrm{r}_{\mathrm{p}}^{2}\right)}$

The model of Wilkinson and Ashby does not require this approximation for $\sigma_{\mathrm{av}}$, since it was derived for HIP stress conditions. However, the model must be modified because it considers intragranular porosity homogeneously distributed throughout a material. The model predicts the rate of density change for a spherical unit cell, which may be translated to a HIP strain rate by considering the combined contribution of all pores to the density change, which yields a linear strain rate according to

$\dot{\varepsilon}=\frac{N_{v}}{3}\left(\frac{d V}{d t}\right)_{\substack{\text { ugiat } \\ \text { codi }}}=\frac{N_{v}}{3}\left(\frac{V}{\rho}\right)_{\substack{\text { cajit } \\ \text { cad }}} \dot{\rho}$

This may be combined with the model in Equation 5 to yield

$\dot{\varepsilon}_{\text {creep }}=\frac{\mathrm{BN}_{\mathrm{V}} \mathrm{V}}{2} \frac{(1-p)}{\left[1-(1-p)^{1 / \mathrm{p}}\right]^{\mathrm{n}}}\left(\frac{3}{2 \mathrm{n}}\right)^{\mathrm{a}}\left[\mathrm{P}-\mathrm{p}+\frac{2 \gamma}{\mathrm{r}_{\mathrm{p}}}\right]^{\mathrm{n}}$ 
where $B$ is the coefficient of the creep correlation in Equation 3, and V is the volume of the model unit cell which is $(4 / 3) \pi \lambda^{3}$. The density, $\rho$, represents the relative unit cell density, not the relative material density, and it is given by $[27]$

$\rho=1-\left(\frac{r_{p}}{\lambda}\right)^{3}$

Equation 15 is therefore applicable to HIP of grain boundary cavities if the unit cell densification is associated with the grain boundary pores. This effectively implies a "shell-like" layer of deforming material surrounding the grain boundaries, just as in the Beere-Speight model.

The power-law creep controlled cavitation models described above are both completely defined and may be evaluated for the HIP of U-10Zr using the data in Table 1. Figure 6 and compares the calculated HIP rates with the experimental data. The upper data set for each pair of curves represents the hydride-derived information, whereas the lower data set for each pair represents the metal-derived information. It is apparent that the Wilkinson-Ashby prediction is orders of magnitude lower than both the experimental data and the Beere-Speight model prediction.

Although it is evident that the Beere-Speight creep cavitation model provides the better prediction of HIP strain rate, it is not clear that this model best represents the HIP of U-10Zr. A network of creeping material around rigid grains, such as that proposed by a creeping shell model, will not maintain continuity. If the creeping shell decreases in volume under a HIP driving force, there would be a tendency for cavities to form within the grain unless the "rigid" interior of the grain accommodates the shell defornation. Therefore, deformation within the grain must occur to maintain continuity, and this is inconsistent with the hydrostatic nature of the HIP pressure driving force.

The above cavitation models are also inconsistent with the measured HIP activation energy of $187 \pm 10 \mathrm{~kJ} / \mathrm{mole}$ which matches well with the activation energy for grain boundary diffusion in uranium (186.6 KJ/mole). The activation energy for dislocation creep, equivalent to that for 
volume diffusion, would be a combination of the activation energies for uranium and zirconium bulk diffusion. From the data in Table $1, Q$ for the above models should lie within $112<Q<134$ $\mathrm{kJ} /$ mole, dependent upon the zirconium concentration. All of the above factors imply that creep does not control the HIP mechanism in the U-10Zr experiments.

\subsection{Coupled diffusion/power-law creep controlled HIP}

The lack of full agreement between the U-10Zr HIP results and either the grain boundary diffusion controlled cavitation models or the power-law creep controlled cavitation models implies that a coupling of the two mechanisms is possible. This section will compare the coupled cavitation model of Chen and Argon ${ }^{[28]}$ with the experimental results. The coupled model may also be translated to a HIP strain rate using Equation 8, as done for the other pore growth models, with a resulting expression given as

$\dot{\varepsilon}_{\text {coupled }}=\frac{2 \pi}{3} \frac{\mathrm{N}_{\mathrm{v}} \Omega \mathrm{D}_{\mathrm{b}} \delta_{\mathrm{b}}}{\mathrm{kT} f\left(\frac{\mathrm{r}_{\mathrm{p}}}{\mathrm{b}}\right)}\left(\mathrm{p}-\mathrm{p}+\frac{2 \gamma}{\mathrm{r}_{\mathrm{p}}}\right)$.

The structure function, $f\left(\frac{r_{p}}{b}\right)$, is the only difference between this equation and the diffusion controlled model described by Equation 9, but the calculation of the diffusion zone radius, b, requires several assumptions. First, the characteristic length, $\Lambda$, defined in Equation 6 must be evaluated. Using the parameters in Table 1 for $\mathrm{U}-10 \mathrm{Zr}$ at $700^{\circ} \mathrm{C}$, Equation 6 becomes

$\Lambda=18.9 \sigma_{\infty}^{-4 / 3} \mu \mathrm{m}$

when $\sigma_{\infty}$ is given in MPa. For the calculation of the HIP rate in the $U-10 Z r$ specimens, $\sigma_{\infty}$ was taken to be $\sigma_{\mathrm{av}}$, as defined by Equation 13. As stated previously, $\mathrm{b}$ is calculated as the sum of the pore radius and the characteristic length. 
The variation of the diffusion zone radius, $b$, with external HIP pressure is shown in Figure 7 for the two types of $U-10 Z r$ specimens. The pore radii $\left(r_{p}\right)$ and pore half-spacings $(\lambda)$ are indicated along the vertical axis for reference. This calculation of $b$ implies that a strongly coupled mechanism is likely for both types of $U-10 Z$ r specimens between external pressures of approximately 5 to $30 \mathrm{MPa}$. Below $5 \mathrm{MPa}$, b becomes greater than $\lambda$, indicating that the diffusion length is large enough for diffusion-controlled cavitation to dominates $\mathrm{HIP}$. Above $30 \mathrm{MPa}, \mathrm{b}$ is nearly equivalent to $r_{p}$, indicating that the diffusion length is small and creep-controlled cavitation dominates HIIP.

Figure 8 shows the comparison of the coupled model prediction vs. the experimental HIP data, indicating good agreement between model predictions and the data. Although the prediction of the magnitude of the strain rate is not as important as the prediction of the proper trends, the data and model do agree well in magnitude. The model predicts a variation in the stress dependence from $n=1$ to $n=5$ as the diffusion zone shrinks from $b \approx \lambda$ down to $b \approx r_{p}$. The $U-10 Z$ r HIP results were all generated between 5 and $30 \mathrm{MPa}$ where the predicted n-value is between the two extremes[4,6]. For the calculated HIP rates between 5 and $30 \mathrm{MPa}$, the predicted $\mathrm{n}$-values are $\mathrm{n}=3.6$ and $\mathrm{n}=3.8$ for the metal and hydride-derived materials. This agrees well with the measured n-values reported earlier[4,6].

The HIP activation energy should show a similar transition, as boundary diffusion becomes less dominant and power-law creep becomes dominant. All of the experimental measurements for $\mathrm{Q}$ were made at lower driving forces ( 8 MPa) where diffusion is significant $[4,0$. Therefore the apparent agreement between the measured activation energy and the activation energy is consistent with the model. It should be noted, however, that according to Figure 7 , the portion of the boundary which is deforming by creep is significant at the HIP pressures where $Q$ was measured. It would therefore seem to indicate that the measured $Q$-values should be slightly lower under the conditions where the data were generated.

An important consequence of the coupled model and the assumptions described above is the prediction of asymmetrical HIP and swelling behavior for similar driving forces. The average 
stress on the boundary, which is used to evaluate $\Lambda$, is dramatically different for HIP as compared to swelling. It is feasible for HIP to be controlled by a coupled mechanism because of the high stresses in the grain boundary while a similar driving force for swelling would be in the diffusioncontrolled regime because $\sigma_{a v}$ is small and $\Lambda$ is large. Evidence for this effect was not available from this present study, but there are indications that this does occur in the post-irradiation experiments discussed later. Considering the good agreement with the measured n-values and the qualified agreement with the measured Q-values, it can be concluded that the HIP of U-10Zr is best modeled by a coupled boundary diffusion/dislocation creep mechanism.

\section{Discussion}

\subsection{Time dependence of the coupled HIP model}

The model vs. data comparisons discussed above only consider the initial HIP rates vs. the initial pressure driving force. The pressure driving force for HIP will decrease with time as the pressure-filled cavity volume changes. Eventually, a new pressure equilibrium is achieved and HIP induced densification stops. This is also true for swelling, except when the driving force is so great that cavity interconnection and gas release occur before the new equilibrium is established. The HIP/swelling strain rate will therefore decrease with time.

In swelling experiments on other materials $[11,12]$, the strain rate was observed to follow

$\varepsilon \sim t^{-m}$

where $m$ is the time dependence which was experimentally determined to be $m=1 / 3$. This is in good agreement with the theoretical prediction of $m=2 / 5[14]$, which was made assuming that internal gas pressure and surface energy effects on the pressure driving force are negligible for swelling. However, these parameters should be very significant for HIP in establishing the new 
equilibrium required to halt densification. The U-10Zr HIP results reported in Part $\mathrm{I}^{[4]}$ indicate that the $\mathrm{m}$-value for HIP varies from as low as 0.1 up to 0.8 , depending upon the HIP conditions.

To rationalize this difference, the coupled model of Chen and Argon was used to predict the time dependent HIP behavior of U-10Zr using a simple numerical integration method. A simple loop calculation is used to evaluate the specimen strain rate vs. time. The pore radius is decreased after a finite time step, $\Delta t$, by a linear first order approximation given by

$\left(r_{p}\right)_{i+1}=\left(r_{p}\right)_{i}-\left(\frac{d r_{p}}{d t}\right)_{i} \Delta t$

where the radial shrinkage rate is calculated from the volume rate of change generated by the cavitation model. Equation 6 was used to calculate the characteristic length for each time step, $\Lambda_{\mathrm{i}}$, which increases as the transient progresses and the pressure driving force decreases. When the calculated diffusion zone radius, $b_{\mathfrak{i}}$, exceeds the unit cell radius, $\lambda$, as the diffusion zone increases, the diffusion model of Speight and Beere ${ }^{[22]}$ was used for the remainder of the calculated transient.

Calculated HIP transients are shown in Figure 9. The calculations were made using the hydride-derived specimen parameters in Table 1, external pressure changes $(\Delta \mathrm{P})$ of $5,10,15$, and $20 \mathrm{MPa}$, and time step intervals $(\Delta \mathrm{t})$ of 10 seconds. The transients agree well in magnitude, duration, and initial m-value with the experimental HIP transients discussed in Part $\mathrm{I}$, although they do slightly under predict the HIP rates by a factor of $\sim 3$. This underprediction is consistent with the data in Figure 8, which shows a similar underprediction for the initial rates.

There is a continuous change with time-dependence (m) of the calculated strain rates, in contrast to the data, where two apparently distinct regions of constant time dependence are observed. It is therefore apparent that a single definitive $m$-value does not exist for HIP transients. The difference between model and experiment is likely due to an over-interpretation of the experimental data and not an error in the theoretical model.

To verify this, HIP conditions for a specific hydride-derived $\mathrm{HIP}$ transient $(\mathrm{P}=12.7 \mathrm{MPa})$ were duplicated using the above methodology, and the result is compared with the data in Figure 
10. The calculated strain rates were again -3 times lower than the measured strain rates, as expected, so the result was normalized to match the initial measured HIP rate. Despite potential inaccuracies in the boundary stress assumption and the calculation of $\Lambda$ and $b$, this time-dependent calculation reproduces the HIP transient with reasonable accuracy. The calculated transient mirrors the experimental HIP transient through most of the test, but it drops off dramatically at extended time as the calculated driving force approaches $1 \mathrm{MPa}$. Below $1 \mathrm{MPa}$, the strain rates are low (approaching the resolution limit of the LVDT) and little specimen strain occurs. The overall calculated strain $(1.31 \%)$ is similar to the measured strain for this particular sarsple (1.33\%). The decrease in the calculated strain rate is due solely to the changing driving force from the rise of the internal gas pressure as the calculated pore radius decreases. The ability of this model to so accurately predict the time-dependent HIP behavior of $U-10 Z r$ has significant implications on the modeling of nuclear fuel behavior.

\subsection{Irradiated metal fuel performance and modeling}

A limited number of HIP and swelling experiments have been performed[40] and analyzed $[6,40]$ on irradiated $U-5 F s$ and $U-10 \mathrm{Zr}$ nuclear fuels. The data is very limited, but estimates of $n$ and $Q$ for the two materials imply that HIP and swelling in irradiated U-5Fs is controlled by a grain boundary diffusion mechanism, whereas irradiated $U-10 \mathrm{Zr}$ is controlled by a coupled mechanism, as found in this present study.

Figure 11 shows U-5Fs and U-10Zr post-irradiation transients along with present data for hydride- and metal-derived specimens at $700^{\circ} \mathrm{C}$ and $\triangle \mathrm{P}=6.9 \mathrm{MPa}(1000 \mathrm{psi})$. The irradiated U-5Fs swelling data were generated at $600^{\circ} \mathrm{C}$ and has been adjusted for comparison at $700^{\circ} \mathrm{C}[0]$. HIP data were unavailable, but HIP and swelling were found to be reversible phenomena for U-5Fs [40], so the comparison to the U-10Zr HIP results is valid. The irradiated U-10Zr FIIP and swelling data were generated from Figure 5.11 for $\Delta \mathrm{P}=33.8 \mathrm{MPa}$ for both cases. Both transients were adjusted for comparison at $6.9 \mathrm{MPa}$ using $n=3.4$, based upon the present results. The asymmetry in the 
HIP and swelling rates is consistent with the coupled model discussed above. Quantitative microstructural information was not available for either irradiated material[ $[$ ].

It is apparent that U-5Fs and U-10Zr do not exhibit similar HIP/swelling behavior. It would therefore be appropriate to investigate the reason this coupled mechanism is dominant in one uranium alloy and not the other, and also to examine pure uranium and other metal fuel alloys and the effect of fission products on $U-10 Z$ r. An estimation of $\Lambda$ for both materials would aid in defining the difference between the two materials, but accurate microstructural, diffusion, and creep data would be required for both alloys, and such data is not available at this time. The difference between the hydride- and metal-derived HIP rates may be rationalized rationalized due to the differences in specimen microstructure. The difference in rates between the present experiments and the irradiated $\mathrm{U}-10 \mathrm{Zr} \mathrm{HIP}$ rates could be the result of either microstructural differences, irradiation, or a combination of both, but such a determination is not possible without more information. It is evident that the microstructure has a strong effect on HIP or swelling rates.

The experimental and calculational results have direct implications on fuel performance modeling for metal fueled reactors such as the IFR. Performance codes such as LIFE-METAL[41] and FASTGRASS ${ }^{[42]}$ attempt to model the detailed physical phenomena of fissioning reactor fuel in the complex reactor environment. Both codes assume a HIP/swelling model based on out-ofpile, diffusion-controlled growth formulations for non-equilibrium pores which have a linear stress dependence, in contrast to the present observations.

HIP is one of many phenomena taking place in the fuel during irradiation, but the proper physics should be in place to provide accurate modeling of the process. It is apparent from the HIP experiments on $\mathrm{U}-10 \mathrm{Zr}$ presented above that the assumption of a boundary diffusion mechanism for HIP and swelling is inappropriate for $\mathrm{U}-10 \mathrm{Zr}$, in spite of the strong evidence from previous observations on $\mathrm{UO}_{2}, \mathrm{U}-5 \mathrm{Fs}$, and other materials. This is important because the coupled mechanism predicts initial strain rates which are orders of magnitude higher than the diffusioncontrolled models, especially at high stresses, and has an inherent asymmetry in the HIP/swelling predictions. 


\subsection{Relevance of ex-reactor models and experiments to nuclear fuels}

Despite all the previous assumptions concerning the relevance of ex-reactor models to inreactor hot-pressing, the question of unique in reactor phenomena does exist. During irradiation, a supersaturation of vacancies and interstitials exists in the fuel which enhances atom mobility. However, if local equilibrium is maintained at the pore surfaces and the grain boundary sinks, then, as argued for radiation-induced creep ${ }^{[44]}$ and fission-induced densification $[45]$, enhanced diffusion cannot affect the de-cavitation (HIP) rate since the net flux of vacancies from source to sink is unchanged. However, as argued elsewhere [45], if local equilibrium cannot be maintained under irradiation, effects of interface control may occur. There is also the possibility that the creep component could be enhanced by radiation ${ }^{[44]}$ causing an acceleration at high stresses and low temperatures, but there are no data available on the magnitude of this enhancernent. For the outer region of the fuel which hot-presses very sluggishly, a radiation enhanced creep component could have an important effect on FCMI.

Another potential effect from vacancy and interstitial supersaturation during irradiation is the direct deposition of vacancies and atoms on grain boundary and pore surfaces from the matrix in response to a driving force for densification. It can be assumed that during steady state irradiation, the point defects are continuously moving to all available sinks, such as the grain boundaries. For a HIP or swelling transient, any biased defect diffusion to sinks due to the changes in the chemical potential of the pore surface or the grain boundary would be in competition with the presently proposed boundary de-cavitation mechanism.

If a HIP transient were generated by a rise in temperature in a fuel rod after fuel-cladding contact has occurred, the local chemical potentials for vacancies would rise on grain boundaries due to FCMI thermal contact stresses (grain jacking induced densification) and on pore surfaces due to internal pore pressure increases with temperature (pressure-induced swelling), whereas the local chemical potentials for interstitials will decrease on both the grain boundaries and pore 
surfaces. This implies that supersaturated vacancy fluxes should dominate the transient. At the same time, the relative difference in chemical potentials will drive vacancies from pore surfaces to grain boundaries if the FCMII-induced potential difference in the boundaries is greater than the pressure-induced potential difference on the pore surfaces.

Thus, the de-cavitation mechanism proposed for HIP would be in competition with the bulk diffusion of vacancies toward sinks. The analysis of the irradiation-induced process would require a detailed kinetic calculation, but since vacancy diffusion is not enhanced by irradiation, it would appear that the kinetics of vacancy and atom transport along the grain boundaries would be more rapid than bulk diffusion. Also, the loss of vacancies to recombination and possible depletion near the grain boundary sinks during a transient lend more credence to the proposed mechanism. It is perhaps relevant that in-reactor densification can be accurately represented by exreactor sintering behavior[45] which supports the relevance of ex-reactor densification measurements.

\section{Summary}

The results from hot Isostatic pressing experiments performed on sintered hydride- and metal-derived U-10Zr samples were analyzed to quantitatively determine the dominant HIP mechanism. It was found that the specimen hot-pressing behavior agreed with the model predictions of Chen and Argon[22] for coupled grain boundary diffusion and power-law creep controlled cavitation. It was found that the coupled model predicts an asymmetry between HIP and swelling rates which were previously assumed to be completely reversible phenomena. The differences in HIP behavior between the hydride- and metal-derived samples could be rationalized from the differences in pore size-to-spacing ratios.

The model of Chen and Argon was used to predict the time-dependent HIP behavior of U$10 \mathrm{Z} r$ using numerical integration. The result showed that HIP should not exhibit a characteristic time-dependence, in contrast to swelling where an exponential time dependence of $m=2 / 5$ is 
predicted. Comparison of a calculated HIP transient with a hydride-derived HIP experiment showed good agreement between the calculated HIP rates and the measured HIIP rates over most of the experimental transient.

The present HIP experiments were compared with similar post-i.radiation HIP/swelling experiments on $U-10 Z r$ and $U-5 F s$. The U-5Fs hot-pressed and swelled much more rapidly than the U-10Zr under similar conditions. Therefore, the experience gained with U-5Fs transient - response may not be appropriate for U-10Zr. Fuel performance codes should be modified to reflect the coupled diffusion/creep mechanism using the diffusion length calculation, but accurate knowledge of the fuel micrc:-mucture is necessary to differentiate between the diffusion-only and coupled rate-controlling mechanisms.

\section{References}

[1] Walters, L.C.,Seidel, B.R., and Kittel, J.H., Nuclear Technology, v65, 1984, 202.

[2] Till, C., Nuclear Engineering International, v30, 1985, 20.

[3] Hofman, G.L., Pahl, R.G., Lahm, C.E. and Porter, D.L., Metallurgical Transactions A. v21A, 1990, 517.

[4] McDeavitt, S.M. and Solomon, A.A., to be published.

[5] McDeavitt, S.M. and Solomon, A.A., World Congress of Powder Metallurgy, 1992.

[6] McDeavitt, S.M., Ph.D. Thesis, Purdue University, Dec. 1992.

[7] Abbott, R.C. and Solomon, A.A., Bull, of the Am. Cer. Soc., v58, 1979,128.

[8] Solomon, A.A., Cochran, K.M., and Habermeyer, J.A., NUREG/CR-2023, PUR-101, 1981.

[9] Solomon, A.A., Casagranda, A., and Rest, J., I. of Nuclear Materials v154, 1988, 332.

[10] Xu, A. and Solomon, A.A., in Ceramic Microstructures '86: Role of interfaces, Ed. Pask, J., 1986.

[11] Hsu, F. and Solomon, A.A., Acta Metallurgica, v31, 1983, 453.

[12] Solumon, A.A. and Hsu, F., J.American Ceramic Society v63, 1981, 467. 
[13] Xu, A. and Solomon, A.A., J.American Ceramic Society, v75, 1992, 985.

[14] Solomon, A.A. and Hsu, F., Sintering Processes, ed. Kuczyinski, Plenum Press, 1980, 485.

[15] Kaur, I, Gust, W., and Kozma, L., Handbook of Grain and Interphase Boundary Diffusion Data. v.2, Ziegler Press, Stutgart, 1989, p.1345.

[16] Hull, D. and Rimmer, D.E., Philosophical Magazine, v4, 1959, 673.

[17] Speight, M.V. and Harris, J.E., Metal Science Journal, v1, 1967, 83.

[18] Vitovec, F.H., J. of Material Science, v7, 1972, 615.

[19] Raj, R. and Ashby, M.F., Acta Metallurgica, v23, 1975, 653.

[20] Raj, R., Shih, H.M., and Johnson, H.H., Scripta METALLURGICA, v11, 1979, 265.

[21] Weertman, J., Scripta METALLURGICA, v7, 1973, 1129.

[22] Speight, M.V. and Beere, W., Metal Science, v9, 1975, 190.

[23] Chuang, T.J. and Rice, J.R., Acta Metallurgica, v21, 1973, 1625.

[24] Chuang, T.J., Kagawa, K.I., Rice, J.R., and Sills, L.B., Acta Metallurgica, v27, 1979, 265.

[25] Chen, I.W. and Argon, A.S., Acta Metallurgica, v29, 1981, 1759.

[26] Beere, W. and Speight, M.V., Metal Science, April, 1978, 172.

[27] Wilkinson, D.S. and Ashby, M.F., University of Cambridge Report, CUED/CMats/TR.22, 1975.

[28] Murray, P., Rodgers, E.P., and Williams, A.E., Trans. Brit. Ceram Soc. v53, 1954, 474.

[29] Mackenzie, J.K. and Shuttleworth, R., Proc. Roy. Soc. B, v62, 1949, 833.

[30] Wolfe, R.A., Bettis Atomic Laboratory Report, WAPD-T-2021, 1967.

[31] Dyson, B.F., Metals Science, v10, 1976, 349.

[32] Rice, J.R., Acta Metallurgica, v29, 1981, 675.

[33] Anderson, P.M. and Rice, J.R., Acta Metallurgica, v33, 1985, 409.

[34] Davanas, K. and Solomon, A.A., Acta Metall, Mater., v38, 1990, 1905.

[35] Edward, G.H. and Ashby, M.F., Acta Metallurgica, v27, 1979, 1505.

[36] Rice, J.R., Time-Deneñdent Fractiue of Materials at Elevated Temperature Ed. S.Wolf, USDOE report, CONF 790236 UC-25, Germantown MD, 1979, p. 130. 
[37] Needleman, A. and Rice, J.R., Acta Metallurgica, v28, 1980, 1315.

[38] Stocker, R.L. and Ashby, M.F., Scripta METALLURGICA, v7, 1973, 115.

[39] Derby,B. and Ashby, M.F., Scripta METALLURGICA, v18, 1984, 1079.

[40] Solomon,A.A., Hofman,G.L., and McDeavitt,S.M., to be submitted for publication.

[41] Billone, M.C., Argonne National Laboratory, private communication

[42] Rest, J., Journal of Nuclear Materials, v120, 1984, 195.

[44] Hesketh, R.V., Journal of Nuclear Materials, v35, 1970, 253.

[45] Solomon, A.A., Journal of Nuclear Materials, v102, 1981, 346.

[46] Rothman, S.J.., "Diffusion in Uranium, Its Alloys, and Compounds," ANL-5700, Part C, Argonne National Laboratory, 1961.

\section{ACKNOWLEDGEMENTS}

The authors express their appreciation to Nuclear Metals, Inc. for providing the uranium powder, to Oak Ridge National Laboratory for providing the uranium hydride powder, and to the U.S.Department of Energy for financial support under contract \#DE-FG07-88ER12814. 


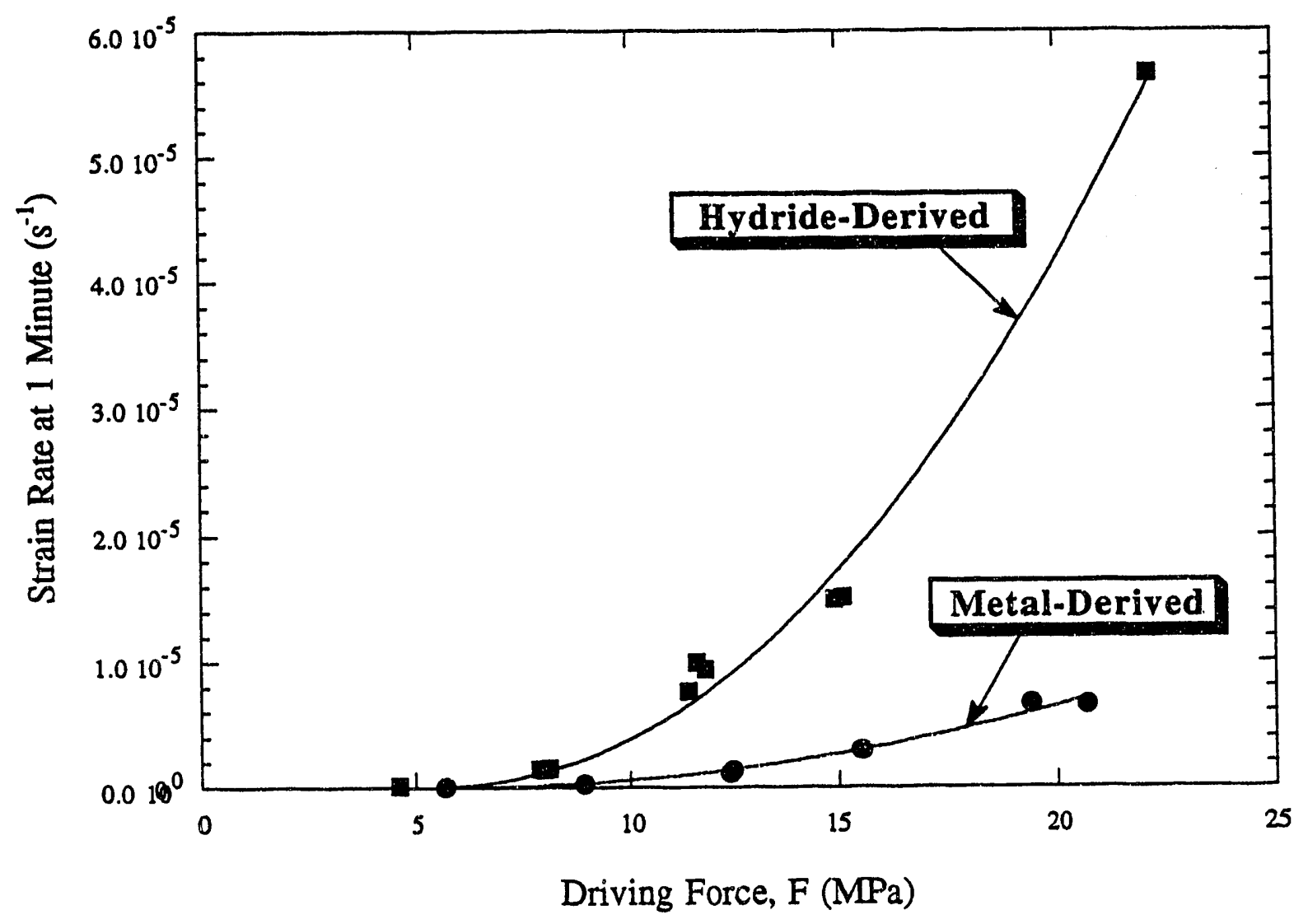

Figure 1. Initial HIP strain rates at 1 minute vs. the initial pressure driving force. 


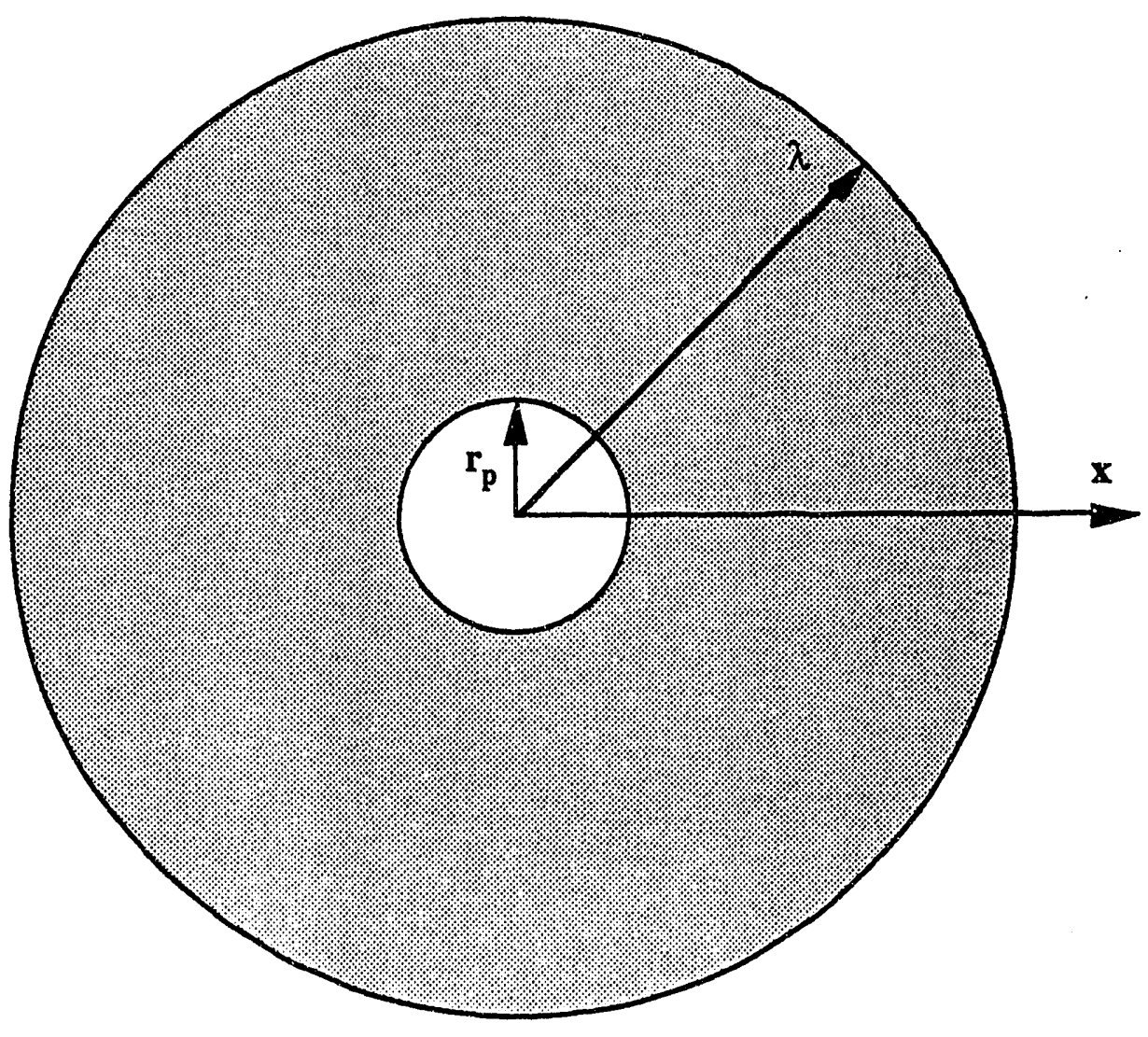

Figure 2. Speight-Beere model geometry. 


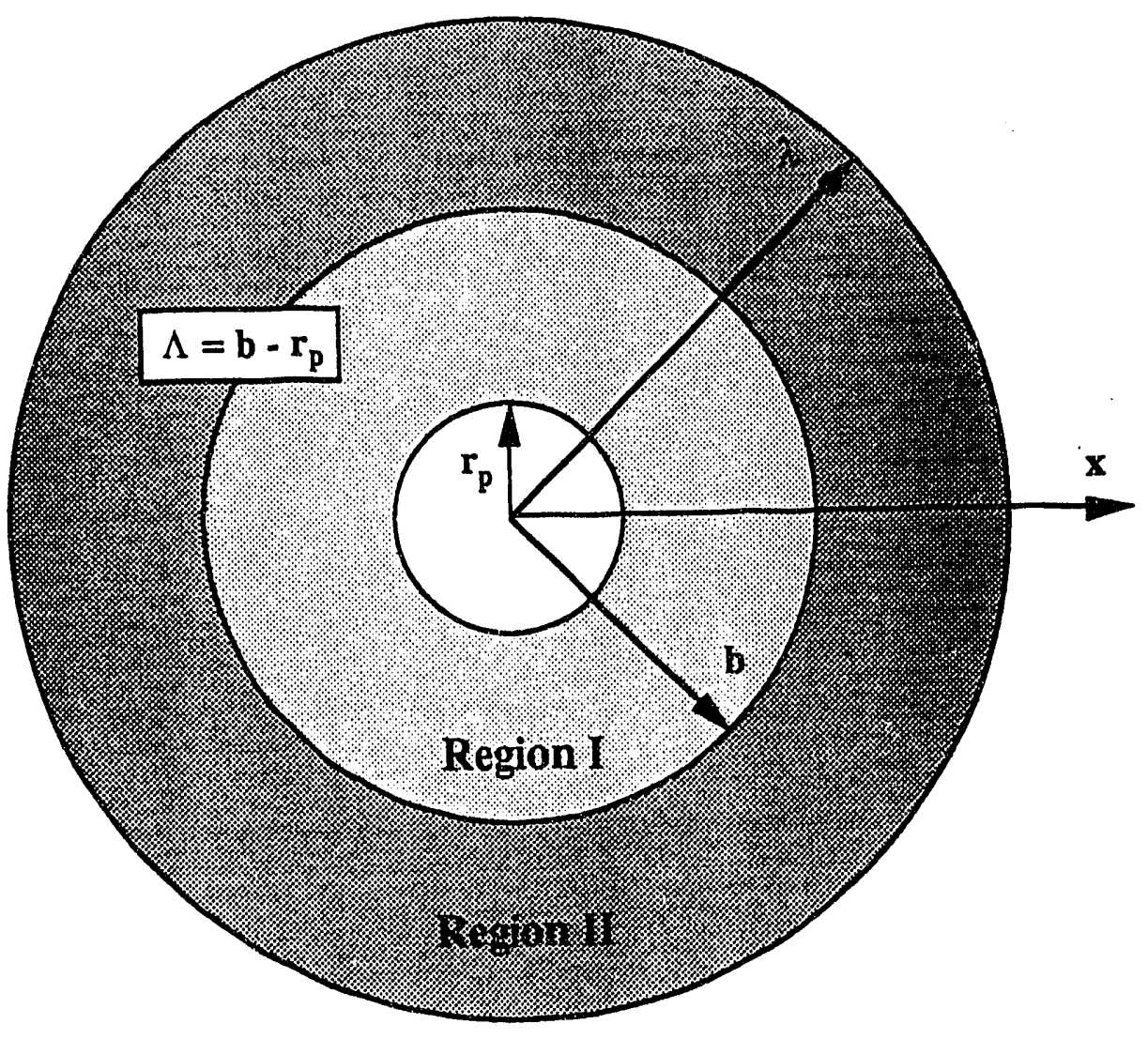

(a) Top view of Beere-Speight geometry. Region I is the diffusion zone, and Region II is the creep-dominated zone.

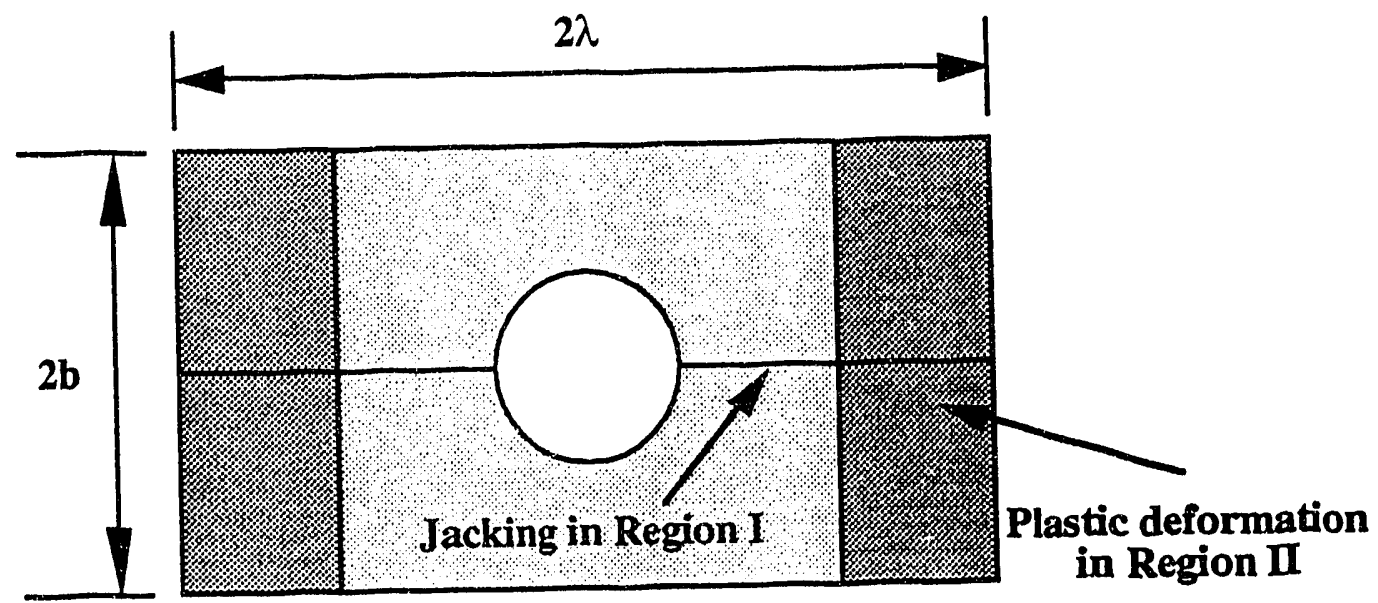

(b) Side view of Beere-Speight geometry.

Figure 3. Beere-Speight model geometry. 


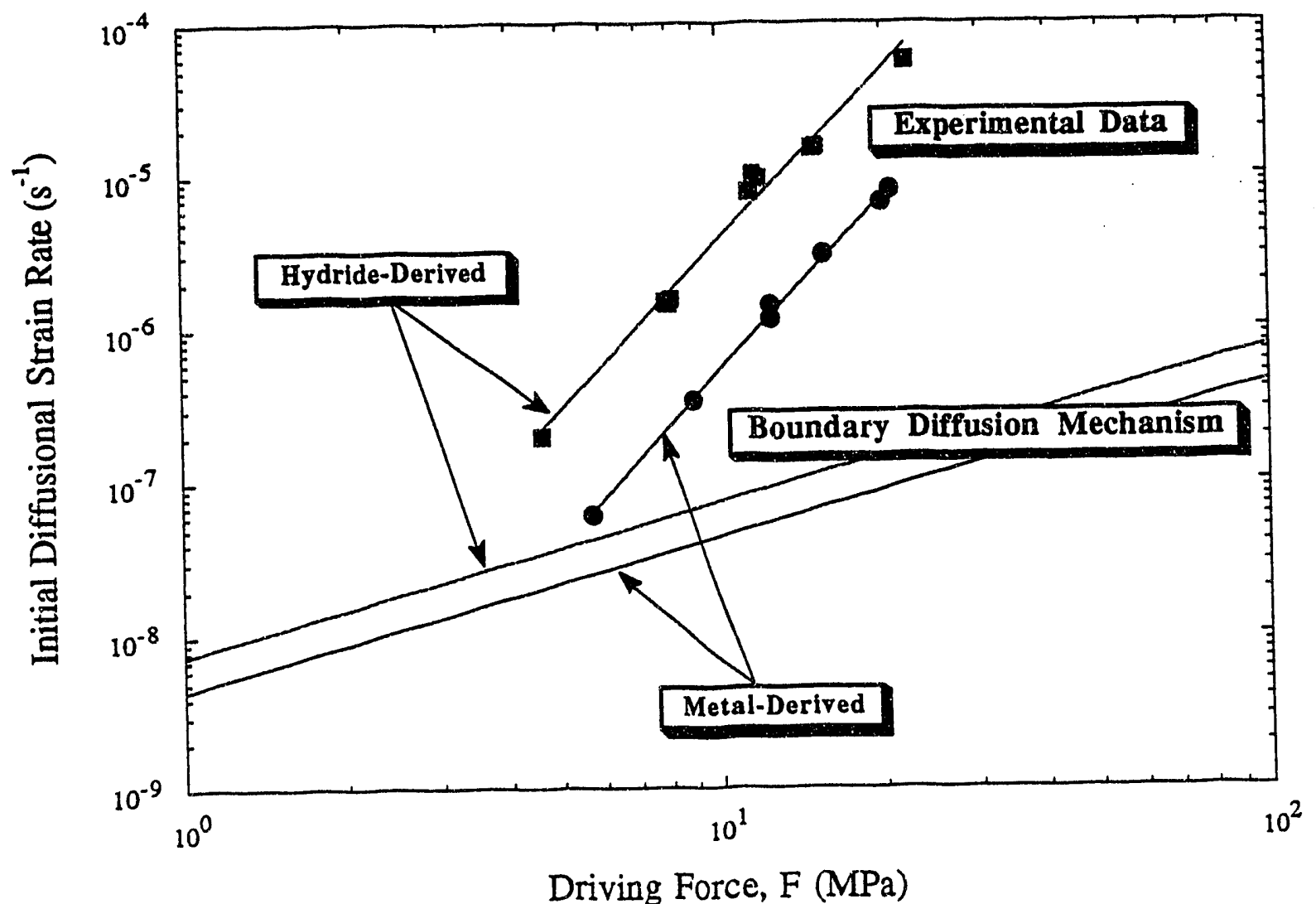

Figure 4. Comparison of diffusion-controlled cavitation model with U-10Zr HIP rates. 


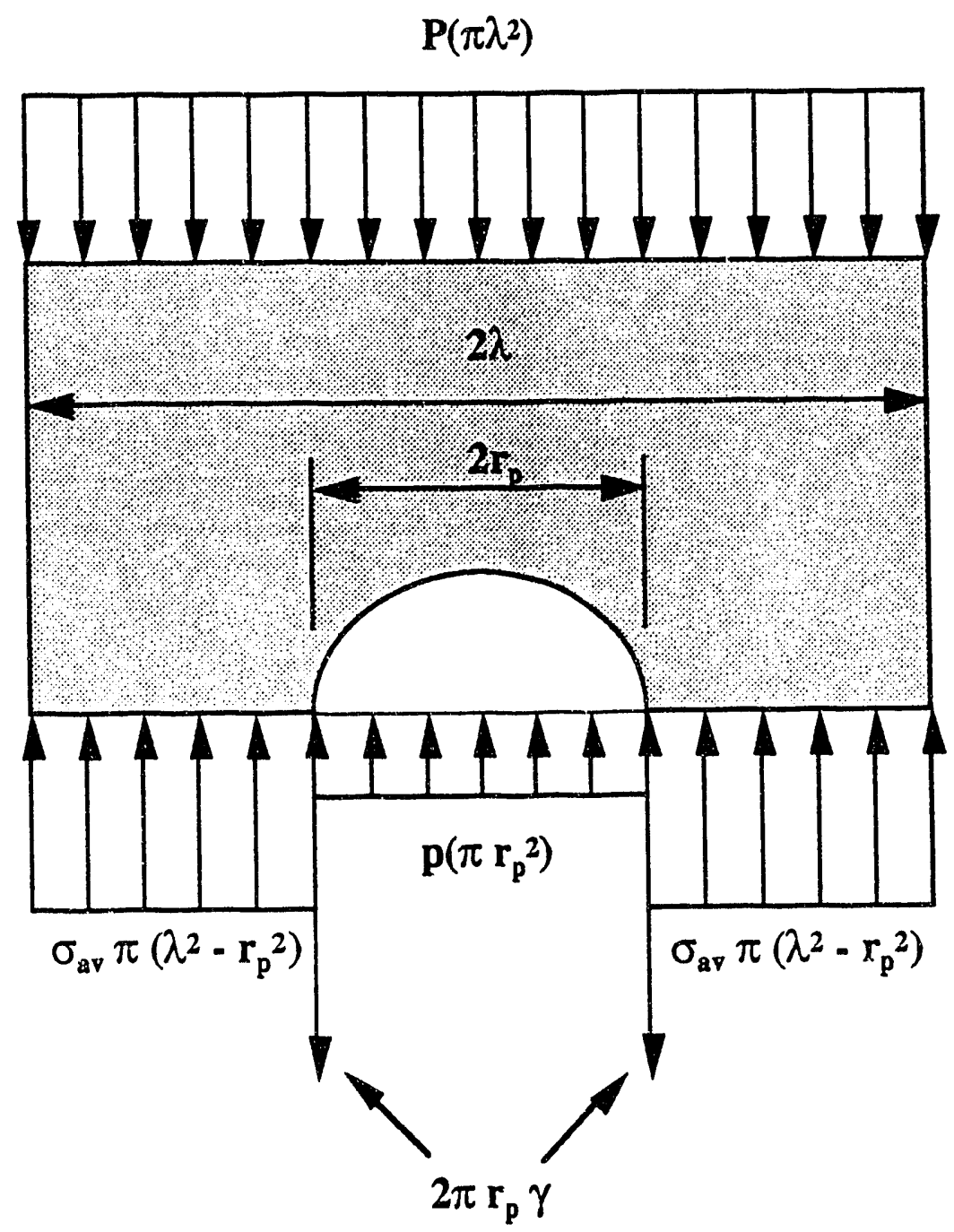

Figure 5. Free-body diagram grain boundary stresses during HIP. 


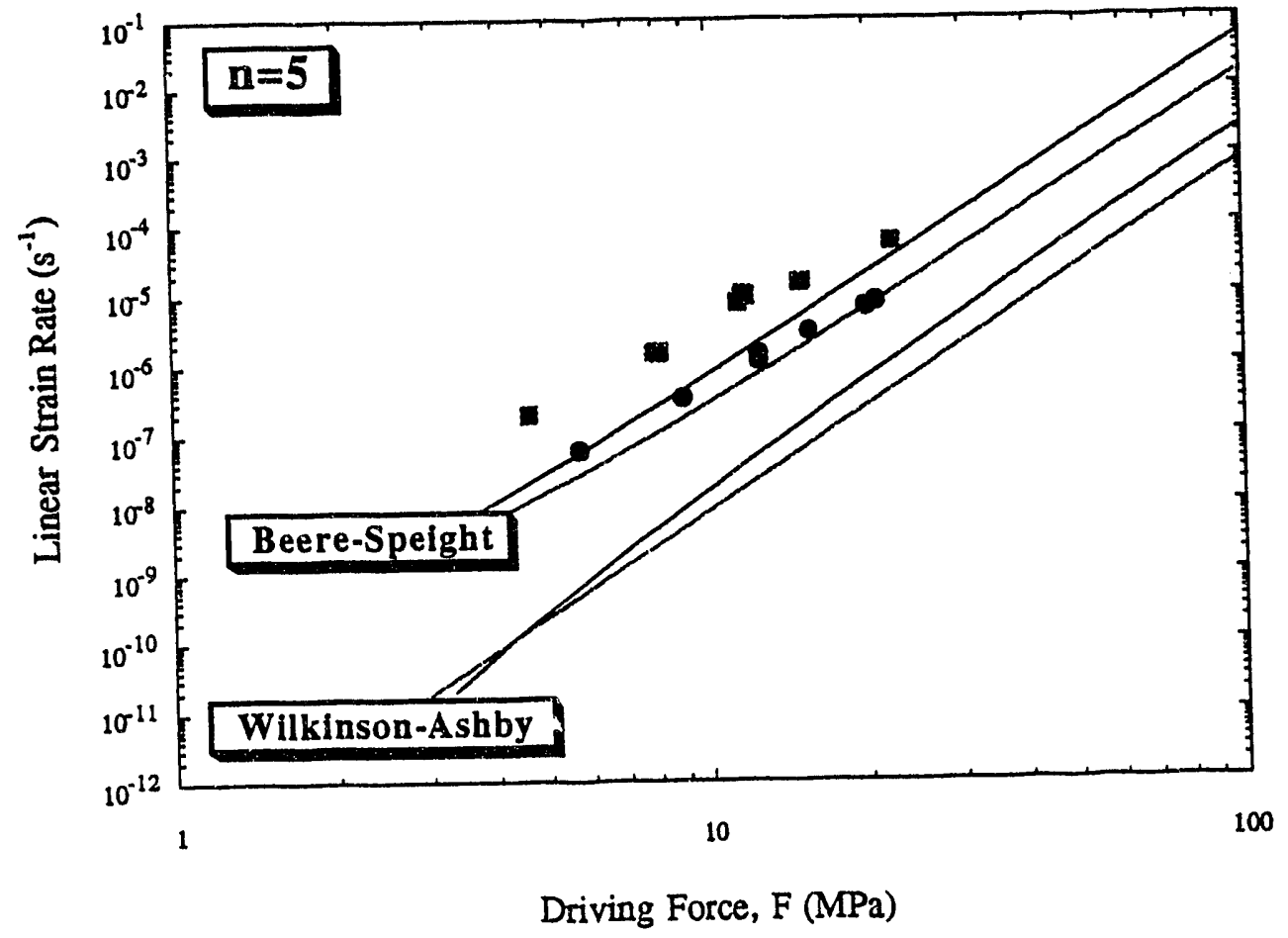

Figure 6. Comparison of creep-controlled cavitation models with U-10Zr HIP rates. 


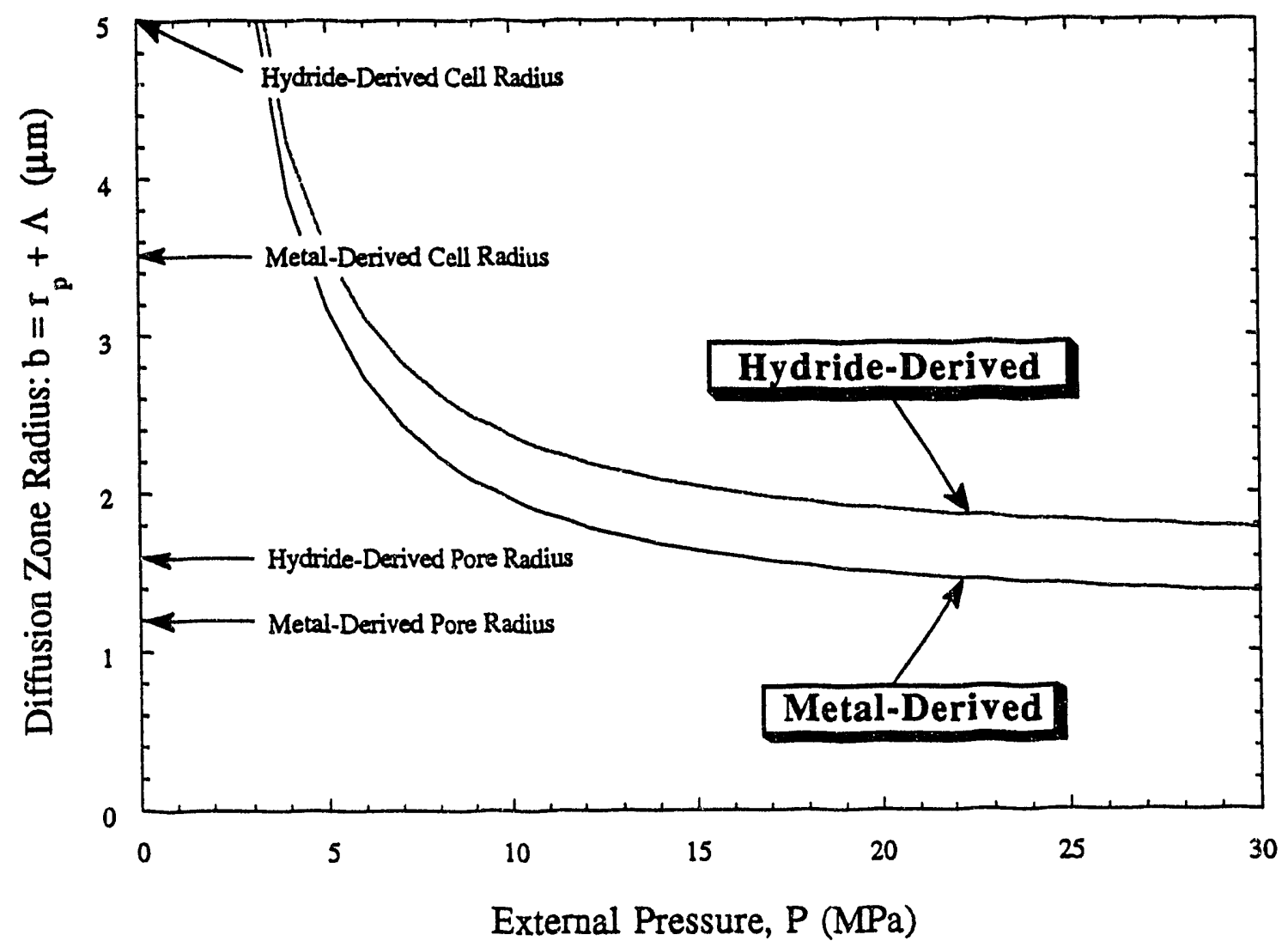

Figure 7. Variation of the diffusion zone radius with external pressure. 


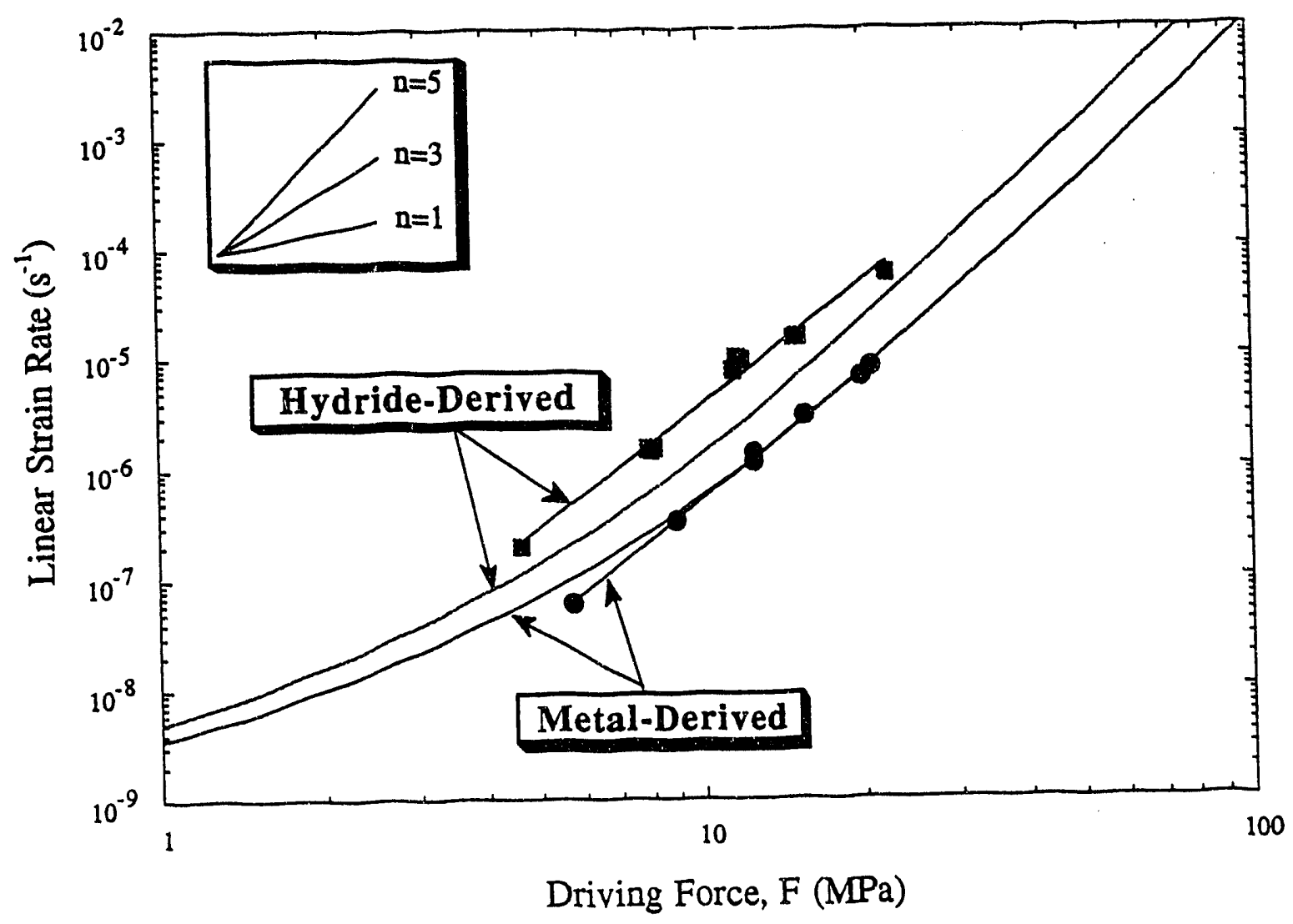

Figure 8. Comparison of coupled cavitation model of Chen and Argon with U-10Zr HIP rates. 


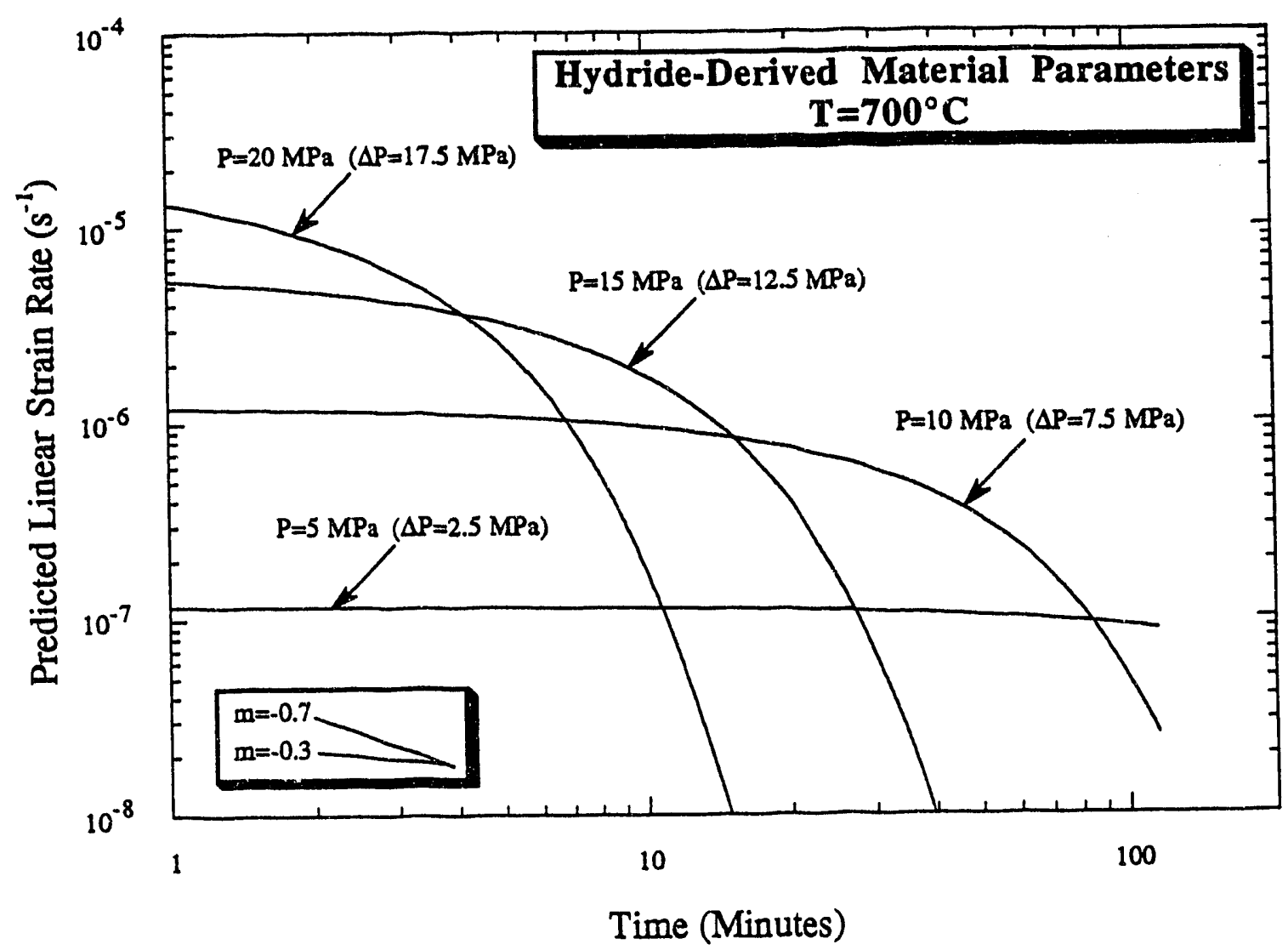

Figure 9. Calculated time-dependence of hydride-derived U-10Zr HIP transients using the coupled model of Chen and Argon. 


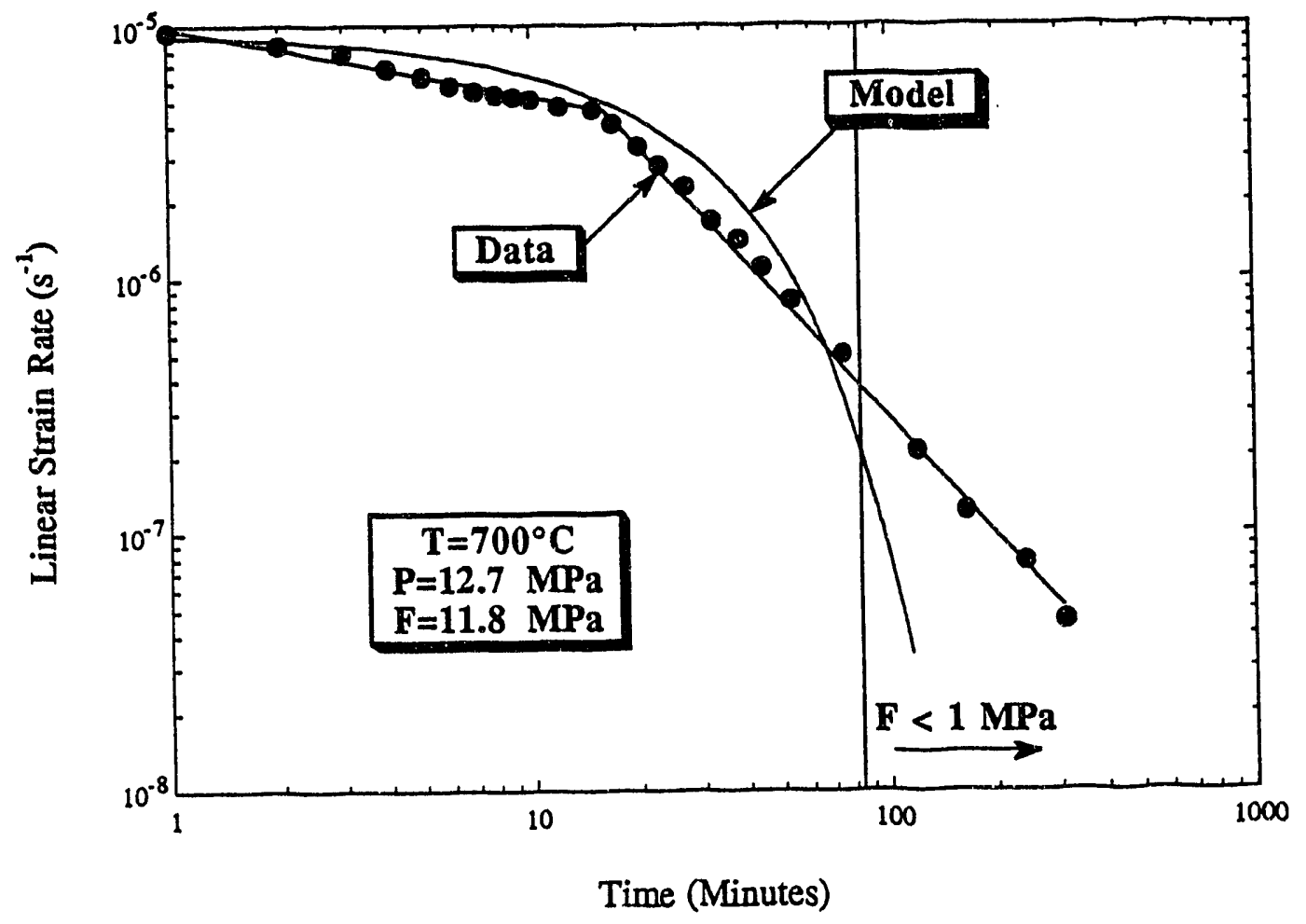

Figure 10. Comparison of a single hydride-derived HIP transient and a
comparable, calculated HIP transient based upon identical conditions. 


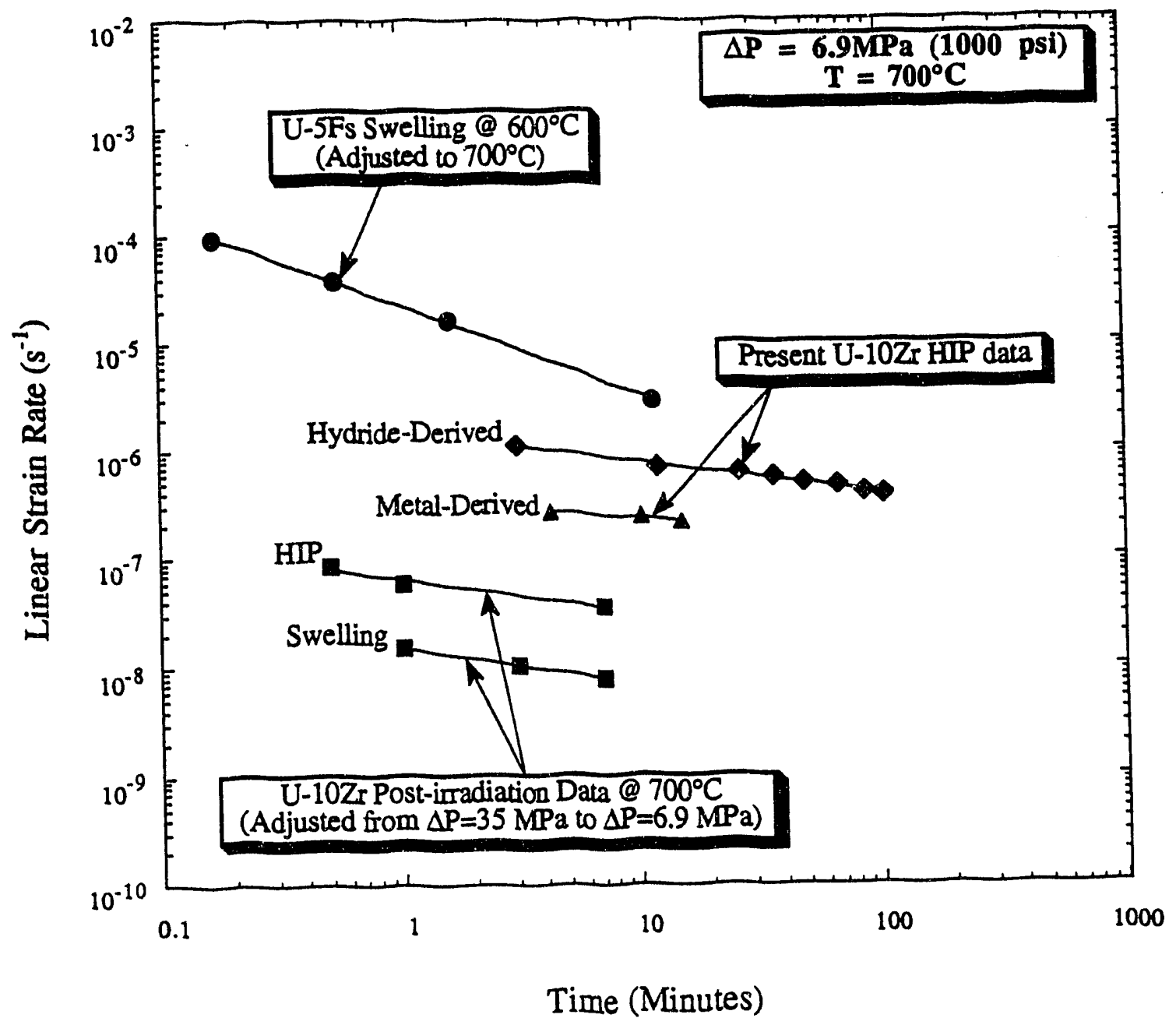

Figure 11. Comparison of U-5Fs and U-10Zr post-irradiation swelling rates with sintered U-10Zr HIP rates $\left(700^{\circ} \mathrm{C}\right)$. 
Table 1. Material properties of $U, Z r$, and $U-Z r$.

\begin{tabular}{|c|c|c|}
\hline Property & Data & Source \\
\hline \multicolumn{3}{|l|}{ Hydride-Derived: } \\
\hline Cavity density, $\mathrm{Nv}\left(\mathrm{m}^{-3}\right)$ & $9.3 \times 10^{14}$ & McDeavitt[6] \\
\hline Modal diameter, $\mathrm{I}_{\mathrm{p}}(\mu \mathrm{m})$ & $1.6 \pm 0.1 \dagger$ & McDeavitt[6] \\
\hline Avg. Spacing, $\lambda(\mu \mathrm{m})$ & 10 & McDeavitt[] \\
\hline Grain Size $(\mu \mathrm{m})$ & 34 & McDeavitt[6] \\
\hline Internal pressure, $\mathrm{p}(\mathrm{MPa})$ & $1.7^{\dagger}$ & McDeavitt[6] \\
\hline \multicolumn{3}{|l|}{ Metal-Derived: } \\
\hline Cavity density, $\mathrm{Nv}\left(\mathrm{m}^{-3}\right)$ & $5.8 \times 10^{14}$ & McDeavitt[] \\
\hline Modal diameter, $r_{p}(\mu \mathrm{m})$ & $1.3 \pm 0.1 \dagger$ & McDeavitt[6] \\
\hline Avg. Spacing, $\lambda(\mu \mathrm{m})$ & 7 & McDeavitt[ \\
\hline Grain Size $(\mu \mathrm{m})$ & 114 & McDeavitt[6] \\
\hline Internal pressure, $\mathrm{p}(\mathrm{MPa})$ & $1.2 \dagger$ & McDeavitt[6] \\
\hline \multicolumn{3}{|l|}{$\gamma-\circlearrowright$ U Boundary Diff.: } \\
\hline $\begin{array}{r}\text { Pre-exp, }\left(D_{b} \delta_{b}\right)_{o}\left(\mathrm{~m}^{3} / \mathrm{s}\right) \\
\text { Act. Energy, } Q(Y \mathrm{~F} / \mathrm{mole})\end{array}$ & $\begin{array}{c}3.24 \times 10^{-11} \\
186.6\end{array}$ & $\begin{array}{l}\text { Kaur,Gust,and Kozma[15] } \\
\text { Kaur,Gust,and Kozma[15] }\end{array}$ \\
\hline $\mathrm{D}_{\mathrm{b}} \delta_{\mathrm{b}} @ 700^{\circ} \mathrm{C}\left(\mathrm{m}^{3} / \mathrm{s}\right)$ & $3.1 \times 10^{-21}$ & $D_{b} \delta_{b}=\left(D_{b} \delta_{b}\right)_{0}{ }^{*} \exp (-Q / R T)$ \\
\hline \multicolumn{3}{|l|}{$\gamma-\mathrm{U}$ Volume Diff.: } \\
\hline $\begin{array}{r}\text { Pre-exp, }\left(\mathrm{D}_{\mathrm{y}}\right)_{\mathrm{O}}\left(\mathrm{m}^{2} / \mathrm{s}\right) \\
\text { Act. Energy, } \mathrm{Q}(\mathrm{KJ} / \mathrm{mole})\end{array}$ & $\begin{array}{c}1.12 \times 0-7 \\
112\end{array}$ & $\begin{array}{l}\text { Rothman[46] } \\
\text { Rothman[46] }\end{array}$ \\
\hline $\mathrm{D}_{\mathrm{v}} @ 700^{\circ} \mathrm{C}\left(\mathrm{m}^{2} / \mathrm{s}\right)$ & $1.2 \times 10^{-13}$ & $D_{\mathrm{v}}=\left(\mathrm{D}_{\mathrm{v}}\right)_{0} * \exp (-\mathrm{Q} / \mathrm{RT})$ \\
\hline \multicolumn{3}{|l|}{$\mathrm{D}_{\mathrm{v}}(\mathrm{Zr})$ in $\mathrm{U}-\mathrm{Zr}$ alloys: } \\
\hline $\begin{array}{l}20 \text { at. \% Zr: } \\
\text { Pre-exp, }\left(\mathrm{D}_{\mathrm{v}}\right)_{0}\left(\mathrm{~m}^{2} / \mathrm{s}\right) \\
\text { Act. Energy, } \mathrm{Q}(\mathrm{KJ} / \mathrm{mole})\end{array}$ & $\begin{array}{l}10^{-8} \\
113\end{array}$ & $\begin{array}{l}\text { Rochman[46] } \\
\text { Rothman[46] }\end{array}$ \\
\hline $\mathrm{D}_{\mathrm{v}} @ 700^{\circ} \mathrm{C}\left(\mathrm{m}^{2} / \mathrm{s}\right)$ & $8.6 \times 10^{-15}$ & $D_{\mathrm{v}}=\left(\mathrm{D}_{\mathrm{v}}\right)_{0} * \exp (-\mathrm{Q} / \mathrm{RT})$ \\
\hline $\begin{array}{l}10 \text { at. } \% \mathrm{Zr}: \\
\text { Pre-exp, }\left(\mathrm{D}_{\mathrm{V}}\right)_{0}\left(\mathrm{~m}^{2} / \mathrm{s}\right) \\
\text { Act. Energy, } \mathrm{Q}(\mathrm{KJ} / \mathrm{mole})\end{array}$ & $\begin{array}{l}10^{-7} \\
134\end{array}$ & $\begin{array}{l}\text { Rothman[46] } \\
\text { Rothman[46] }\end{array}$ \\
\hline$D_{v} @ 700^{\circ} \mathrm{C}\left(\mathrm{m}^{2} / \mathrm{s}\right)$ & $6.5 \times 10^{-15}$ & $\mathrm{D}_{\mathrm{v}}=\left(\mathrm{D}_{\mathrm{v}}\right)_{0} * \exp (-\mathrm{Q} / \mathrm{RT})$ \\
\hline
\end{tabular}

$\dagger$ denotes post-sintering values prior $\omega \mathrm{HIP} @ 700^{\circ} \mathrm{C}$ 


\section{APPENDIX C}

Liquid Sodium Intrusion into Porous U-10Zr Fuel Alloy by Differential Capillarity 


\section{Final Report on}

\section{Liquid Sodium Intrusion into Porous $\mathcal{U}$-10Zr Fuel Alloy by Differential Capillarity}

by Weijun Liu and Alvin A. Solomon

School of Nuclear Engineering

Purdue University

December, 1992 


\section{ABSTRACT}

The objective of this study was to simulate the intrusion behavior of liquid sodium into porous irradiated metal fuel, using sintered $\mathrm{U}-10 \mathrm{Zr}$ alloy specimens. Specimens were fabricated with about $\sim 30 \%$ open porosiiy, and an average pore diameter of $2 \mu \mathrm{m}$ to simulate the condition of bubble and tear interconnection at low burnup. The intrusion volumes determined from weight-gain measurement were measured at $150^{\circ} \mathrm{C}$ and $400^{\circ} \mathrm{C}$ in a pressure range of 20 to 800 psig. Sodium extrusion from pressurized pores was also measured to verify the existence of retained gases as a function of their pressure.

The intrusion results showed essentially complete gas release and intrusion for low pressures, but gas retention at the highest gas pressure within the pores. It is argued that the highest pressure test may be rationalized such that complete intrusion was likely for all specimens. A model for gas-release in wetting systems is developed based on capillary attraction into small pores and gas release from larger pores, a mechanism we call Differential Capillarity. The criterion for gas release is a function of the pore diameters and wetting angle. To test the model, two specimens made of fully-dense Brass and U-10Zr alloy with drilled holes were intruded at low pressure by Dioctyl phthalate (at $20^{\circ} \mathrm{C}$ ) and sodium (at $400^{\circ} \mathrm{C}$ ), respectively. The holes in the $\mathrm{U}-10 \mathrm{Zr}$ were tapered which permitted intrusion to occur as predicted, while the holes in the brass were of uniform diameter and no penetration was measured. 


\section{INTRODUCTION}

\subsection{BACKGROUND}

Uranium-based nuclear fuels have historically been saddled with the problem of swelling caused primarily by the accumulated gaseous fission products and by anisotropic irradiation growth which leads to "tearing" or fracture at the grain boundaries. In the Integral Fast Reactor, IFR, fuel design, these inherent problems are addressed by providing a large, sodium-filled gap between the fuel and cladding which allows the fuel to swell $\sim 25 \%$ and develop a network of interconnected open porosity at approximately the time the fuel contacts the cladding. Ideally, this network then either allows easy pathways for gas release, or provides a deformable structure to accommodate subsequent swelling caused by fission product accumulation. One major issue in this scenario is the significant decrease in fuel thermal conductivity with the development of the high porosity. The present investigation was undertaken to determine the extent to which sodium intrusion into the open porosity can ameliorate the loss in conductivity.

There is anecdotal, experimental and inferential evidence that sodium penetrates the fuel to some degiee. Instrumented irradiations have shown a significant decrease in fuel temperature after pores ir rerconnect and open ${ }^{[1]}$. A decrease in sodium level is also observed ${ }^{[2]}$ and sodium is found present during sectioning of the fuel[2]. Also, fuel temperatures inferred from post-irradiation microstructures suggest rather complete penetration of the $\mathrm{Na}$ at least into the outer regions of the fuel[ ${ }^{[3]}$.

In the only previous attempt to quantify the sodium penetration, Villarreal, measured the $\mathrm{Na}$ remaining in irradiated $\mathrm{U}-10 \mathrm{Zr}, \mathrm{U}-8 \mathrm{Pu}-\mathrm{Zr}$ and $\mathrm{U}-19 \mathrm{Pu}-\mathrm{Zr}$ fuels after 10 
to $12 \%$ burnup by dissolution of fuel segments in acid[4]. There is some ambiguity in the results because he attempted to separate the sodium in the "gap" from the $\mathrm{Na}$ in the fuel by reauting and "washing off" the surface layer of $\mathrm{Na}$ and found for $\mathrm{U}-10 \mathrm{Zr}$, a little less than half of the $\mathrm{Na}$ was in the gap. It is not clear how much of this should have properly been included in the fuel. If none of this sodium is included in the fuel, approximately 6 to 25 vol\% of the porosity (calculated as volume increase) is occupied by sodium, and almost double that percentage if all the "gap" $\mathrm{Na}$ is included in the fuel. Thus, there is considerable uncertainty and scatter in the results, but at a maximum, $50 \mathrm{vol} \%$ of the pores are predicted to be filled with sodium.

It can be assumed that early-on in the irradiation, when the irradiation tears and gas bubbles interconnect, all of the porosity is measured to be interconnected and therefore accessible to sodium penetration. In face, this penetration may prevent re-sintering of the porosity after gas release as measured in other systems ${ }^{[5]}$. Therefore the present investigation focused on the critical event of pore interconnection, gas release and sodium penetration at low burnup. Simulated porous $\mathrm{U}-10 \mathrm{Zr}$ fuel was produced by sintering and penetration was examined as a function of temperature and ambient pressure. At high retained gas pressure, sodium was also extruded from the pores if the sodium was melted and the external pressure were reduced.

\subsection{THEORY}

Various studies have revealed that the penetration of a liquid into a porous solid dipends on the pore structure, surface energies of all interfaces and external pressure applied to the liquid[6]. In order to intrude gas-filled pores, the liquid/gas interface must come into mechanical equilibrium with the gas pressure, with the help or resistance of capillary force. Mechanical equilibrium requires that the pressure difference between the 
penetrating liquid and gas be balanced by the surface tension of the curved liquid/gas interface. As shown in Fig.1, for a cylindrical pore with radius $r$, equilibrium can be established under the following condition [7]:

$$
\Delta P=2 \gamma_{\lg } / \frac{r}{\cos \theta}
$$

or

$$
P_{1}=P_{g}-2 \gamma_{1 g} / \frac{r}{\cos \theta}
$$

where $P_{g}$ and $P_{1}$ are the pressures of gas and liquid, respectively; $r / \cos \theta$ is the radius of curvature of the liquid/gas interface; $\gamma_{\mathrm{lg}}$ is surface tension of the interface and $\theta$ has the definition shown in Fig.1. It is necessary for a liquid to have a pressure higher than the $\mathrm{P}_{1}$ predicted from $\mathrm{Eq}(2)$ to intrude into the pores spontaneously. If the gas is trapped within the specimen, intrusion will stop when $\mathrm{P}_{\mathrm{g}}$ has increased to satisfy $\mathrm{Eq}(2)$.

It should be noticed that $\gamma_{1 \mathrm{~g}}$ and $r$ are positive, therefore, the sign of $\Delta \mathrm{P}$ is determined only by the value of $\cos \theta$. For poorly wetting conditions $\cos \theta<0$ (or $\theta>90^{\circ}$ ), we have $\Delta \mathrm{P}<0$ or $\mathrm{Pl}_{\mathrm{l}}>\mathrm{P}_{\mathrm{g}}$, and an external pressure must be applied on the liquid to penetrate into the pores. For well-wetted conditions $\cos \theta>0\left(\right.$ or $\left.\theta<90^{\circ}\right), \mathrm{Eq}(2)$ gives the equilibrium pressures $\mathrm{P}_{1}<\mathrm{P}_{\mathrm{g}}$. In this case, the capillary force induces intrusion of the liquid into the porous solid without additional external pressure.

The contact angle $\theta$ is related to the three surface tensions by the well-known Young's equation [8]:

$$
\gamma_{\text {lg }} \cos \theta=\gamma_{\text {sg }}-\gamma_{\text {sI }}
$$


where $\gamma_{\mathrm{sg}}, \gamma_{\mathrm{sl}}$ and $\gamma_{\mathrm{lg}}$ are the surface tensions of the solid-gas, solid-liquid and liquid-gas interfaces, respectively, and can be measured through simple experiments ${ }^{[9]}$. Obviously, $\theta$ depends on the surface chemical composition of the three phases in the system as well as temperature. For liquid metals on solid metals with very low mutual solubility, it has been found that the equilibrium $\theta$ at the melting point of the liquid follows the empirical relation[10]:

$$
1-\cos \theta=\mathrm{K}\left(\mathrm{T}_{\mathrm{m} 1} / \mathrm{T}_{\mathrm{m} 2}-1\right)
$$

where $T_{m 1}$ and $T_{m 2}$ are the melting temperatures of the solid and liquid, respectively, and $\mathrm{K}$ is a constant, whose theoretical value is $0.28^{[11]}$, and the experimental value is $0.36^{[10]}$. By applying $\mathrm{Eq}(4)$ to the $\mathrm{Na} / \mathrm{U}-10 \mathrm{Zr}$ system in which $\mathrm{T}_{\mathrm{m} 1}$ and $\mathrm{T}_{\mathrm{m} 2}$ are $1396 \mathrm{~K}$ and $372 \mathrm{~K}$, respectively, we obtain $\theta=91^{\circ}$ at the melting point of sodium. This result, which means that liquid $\mathrm{Na}$ does not wet $\mathrm{U}-10 \mathrm{Zr}$ at about $100^{\circ} \mathrm{C}$, is accordant with experimental observations ${ }^{[12]}$ and probably results from a presumably low solubility of oxide layers on $\mathrm{U}-10 \mathrm{Zr}$ in $\mathrm{Na}$ at low temperature.

Both temperature and time play important roles in the onset of wetting. Sodium has been found to not wet $\mathrm{U}-10 \mathrm{Zr}$ alloy when the temperature is lower than $200^{\circ} \mathrm{C}$, but at $370^{\circ} \mathrm{C}$ and $400^{\circ} \mathrm{C}$ it appears to wet the alloy after 8 hours and 1 hour, respectively[12]. Austenetic stainless steels exhibit a similar time/temperature dependence for wetting by $\mathrm{Na}[13][14]$. The observed time required for wetting suggests that wetting is a kinetic process involving the removal or dissolution of the oxide surface layers on the solid.

The temperature dependence of the contact angle has been found to be negligible after wetting has occurred in some sodium/metal and sodium/oxide systems ${ }^{[14]}$. This result implies that, after the surface layer is removed and the liquid wets the solid, the 
composition of the surface remains relatively stable with temperature and surface energies and contact angles do not change dramatically with temperature. Therefore, de-wetting in a clean (non-oxidizing) system is assumed not to occur when the temperature is subsequently reduced below the "wetting" temperature.

Unfortunately, contact angles are not available for the $\mathrm{Na} / \mathrm{U}-10 \mathrm{Zr}$ system as a function of temperature. Dodds and Henslee ${ }^{[11]}$ estimated the contact angle to be $20^{\circ}$, which is the typical value for most metal(s)/metal(1) systems under wetting conditions[15]. However, Bader and Busse ${ }^{[14]}$ showed that the contact angles for sodium on different pure metals (Ni, Ta, Nb, Mo, W), alloys (ss 304I, Inconel 600, RTG 36, and TZM) and oxides $\left(\mathrm{Al}_{2} \mathrm{O}_{3}\right.$, sapphire, $\left.\mathrm{ZrO}_{2}, \mathrm{Y}_{2} \mathrm{O}_{3}\right)$ ranged from $<1.0^{\circ}$ to $7.3^{\circ}$ between $520^{\circ} \mathrm{C}$ and $720^{\circ} \mathrm{C}$. In the absence of primary data, we have assumed a temperature-independent contact angle of $10^{\circ}$ for $\mathrm{Na} / \mathrm{U}-10 \mathrm{Zr}$ after wetting was achieved at $400^{\circ} \mathrm{C}$ for 1 hour.

The surface energy $\gamma_{\mathrm{lg}}$ may be different from $\gamma_{\mathrm{lv}}$ which is the surface energy of a liquid/vacuum interface. For active gases, the difference between $\gamma_{\mathrm{lg}}$ and $\gamma_{\mathrm{lv}}$ may be very great because the chemical reactions between the gas and liquid can change the composition of the liquid near the interface ${ }^{[16]}$. However, for inert gases, it is expected that the difference is small especially when the gas pressure is low.

Several methods have been developed for measuring $\gamma_{1 v}[17]$, and data on liquid metals at the melting temperature are available[18]. Some empirical rules have been established relating the surface tension $\gamma_{1 v}$ to other properties of the metals. Skapski[19] suggested that $\gamma_{\mathrm{lv}}$ (in J/m²) and the heat of vaporization of the liquid metal $\Delta \mathrm{H}_{\mathrm{v}}$ (in J/mol) follow a linear relation:

$$
\gamma_{\mathrm{lv}}=\mathrm{K}^{\prime} \Delta \mathrm{H}_{\mathrm{v}}
$$


where $\mathrm{K}^{\prime}$ is a proportionality constant with an experimental value of 0.15 to 0.16 . Another relation was proposed by Allen ${ }^{[18]}$ who showed that the surface tension of pure liquids could be described by:

$$
\gamma_{\mathrm{lv}}=\mathrm{K}^{\prime \prime} \mathrm{T}_{\mathrm{m}}(\mathrm{M} / \mathrm{p})^{-2 / 3}
$$

where $T_{m}(K)$ is the melting temperature and $M(g)$ and $\rho\left(g / \mathrm{cm}^{3}\right)$ are the molecular weight and density of the liquid, respectively, and $\mathrm{K}^{\prime \prime}=3.6 \times 10^{-7} \mathrm{~J} / \mathrm{K}$. For liquid sodium in which $T_{m}=371 \mathrm{~K}, M=23 \mathrm{~g}$ and $\rho=0.97 \mathrm{~g} / \mathrm{cm}^{3}, \mathrm{Eq}(6)$ yields $\gamma_{\mathrm{Iv}}$ at the melting temperature of 0.162 $\mathrm{J} / \mathrm{m}^{2}$. This value is relatively close to the $\gamma_{\mathrm{lg}}$ of $\mathrm{Na}(\mathrm{l})-\mathrm{Ar}_{(\mathrm{g})}$ interface that is measured as $0.210 \mathrm{~J} / \mathrm{m}^{2[20]}$. The $\gamma_{1 v}$ of $\mathrm{Na}, \mathrm{K}, \mathrm{Rb}$ and $\mathrm{Cs}$ were found to decrease linearly with temperature. This trend for those liquid metals is in agreement with an analytical model of $\gamma_{\mathrm{lv}}$ for liquid metals by Lukabov[21].

Time may still play an important role in the penetration process even when the surfaces are chemically stable because it takes time for a liquid to flow into a porous body. The flow resistance caused by the viscosity $\eta$ of a liquid may be examined using a model by Semlak (1958). The distance $x$ traveled by the liquid through a capillary of radius $r$ after a time $t$ under fixed $\Delta \mathrm{P}$ can be estimated by the following equation[22]:

$$
4 \eta x^{2}=r^{2} t\left(\Delta P+2 \gamma_{1 g} \cos \theta / r\right)
$$

For liquid sodium at $\mathrm{T}=400^{\circ} \mathrm{C}$ in $\mathrm{Ar}$, the viscosity $\eta$ and the surface tension $\gamma_{\mathrm{gg}}$ are 0.0284 $\mathrm{N}-\mathrm{s} / \mathrm{m}^{2}$ and $0.179 \mathrm{~J} / \mathrm{m}^{2}$, respectively[20]. Assuming $\Delta \mathrm{P}=0$ for minimum $x, \mathrm{r}=10^{-6} \mathrm{~m}$ $(1 \mu \mathrm{m})$ and $\theta=20^{\circ}$, we can estimate from $\mathrm{Eq}(7)$ that molten sodium will travel $13.3 \mathrm{~mm}$ after 
1 minute, which makes viscous flow not an issue in the $5 \mathrm{~mm}$ diameter specimens used in the present investigation.

\section{GAS RELEASE CRITERION}

The equilibrium pressure difference $\Delta \mathrm{P}$ between liquid and solid in both sides of the interface are determined only by the pore radius for a given system. From $\mathrm{Eq}(1)$ we can see that the smaller the radius, the larger is $\Delta \mathrm{P}$. For relatively small bubbles, the pressure head due to gravity is negligible. A porous body $10 \mathrm{~cm}$ high immersed in sodium $\left(\rho=0.97 \mathrm{~g} / \mathrm{cm}^{3}\right.$ ) has a pressure head of less than $0.1 \mathrm{psi}$, which is very small compared to the pressure differential ( $\sim 270 \mathrm{psi}$ ) caused by the pore size difference in the present specimens, and can not explain how the entrapped gases are released. .

If we rapidly immerse a solid with cylindrical pores of uniform diameter into a wetting liquid, the liquid will be drawn into all the pores by capillary force and compress the gas until the gas pressure equals to the equilibrium pressure $P_{g}$ determined by $E q(2)$. Because there is no gas release during the intrusion process, the equilibrium volume of gas can be obtained by the relation $\mathrm{Pg}_{\mathrm{g}} \mathrm{V}=$ constant at constant temperature. As discussed above, the initial $P_{g}$ equals to the ambient pressure $P_{0}$, the equilibrium $P_{g}$ can be calculated from $\mathrm{Eq}(2)$ and the initial gas volume is the open porosity of the solid.

For solids with pores of varying diameter, however, the equilibrium pressures are different. Pores with smaller radii will have higher equilibrium pressures consistent with their higher capillary forces. Therefore, liquid intrusion into smaller pores can push the liquid and gas from larger pores causing greater penetration of the liquid. We call this phenomenon Differential Capillarity. Now the question is: under what conditions would gas release occur? 
Let us consider a simplified pore structure shown in Fig.2a, immersed in a wetting liquid under pressure $\mathrm{P}_{1}$. Before any intrusion occurs, the gas pressure inside the pores $\mathrm{Pg}_{\mathrm{g}}$ equals pressure in the liquid $P_{1}$ which is held constant under an ambient gas pressure. At $t=0$, the gas pressure $P_{g}=P_{l}$ is lower than the equilibrium pressure for either pore, therefore, the liquid will start to penetrate into both pores. As the liquid intrudes, the volume of gas becomes smaller and the gas pressure increases. When the gas pressure reaches $P_{2}=P_{1}+2 \gamma_{1 g} \cos \theta / r_{2}$, the interface in pore 2 attains mechanical equilibrium and stops to propagate (Fig.2b). However, the gas pressure $\mathrm{P}_{2}$ is still lower than the equilibrium pressure for pore 1 , so the capillary force draws more liquid into pore 1 increasing the gas pressure. This higher gas pressure will then tend to push the liquid outward from pore 2 (Fig.2c) producing a gas bubble that will attempt to reduce its curvature to balance the pressure $\mathrm{P}_{1}$ (Fig.2c). The minimum radius the interface can have is the radius of the pore $r_{2}$ corresponding to a pressure $\mathrm{P}_{\mathrm{c}}$. If $\mathrm{P}_{1}>\mathrm{P}_{\mathrm{c}}$, the gas bubble will then become unstable and presumably detach from the surface from buoyancy effects. Using Eq.2, the criterion for gas release can therefore be expressed as:

$$
P_{1}+2 \gamma_{l g} \cos \theta / r_{1}>P_{l}+2 \gamma_{l g} / r_{2}
$$

which reduces to a simple criterion for gas to be released:

$$
r_{1} / r_{2}<\cos \theta
$$

For a completely wetting or spreading system $\left(\theta=0^{\circ}\right)$, the liquid/gas interface inside pore 1 will always propagate until it fills with liquid. For a partially wetting system (where $0^{\circ}<\theta<90^{\circ}$ ), the interface propagation may continue and gas may release only when the difference in radius is large enough. If $\theta=60^{\circ}$, for example, $r_{1}$ must be smaller than half of 
$r_{2}$ in order that gas can escape, leading to the condition shown in Fig.3a. If this is not the case, very little penetration will occur as shown in Fig.3b.

For a tapered pore with diameters $r_{1}$ and $r_{2}\left(r_{1}<r_{2}\right)$ at its extremities, the liquid intrusion process is similar to the bi-size pore situation: the small side will fill with liquid and the other part of the pore will contain compressed gas (Fig.4). In this case, however, the curvature of liquid/gas interface, and hence its equilibrium pressure, is affected by the angle $\phi$ of the pore wall and becomes equal to $r_{i} / \cos (\theta+\phi)$, where $r_{i}$ is the pore radius at the point of contact, and $\mathrm{Eq}(8)$ reduces to

$$
r_{1} / r_{2}=\cos (\theta+\phi)
$$

True pore structures are, of course, much more complicated than the two cases we have analyzed. First of all, even if the pores are cylindrical, the cross section of the pores may be any shape far from a circle. Mortensen and Cornie ${ }^{[23]}$ have used the First Law of Thermodynamics to equate the work done in advancing the liquid/gas interface, $-\Delta \mathrm{P} . \Delta \mathrm{V}$, tc the total surface energy change $\left(\gamma_{s g}-\gamma_{s l}\right) S^{*}$

$$
\left(\gamma_{s g}-\gamma_{s l}\right) S^{*}=-\Delta P . \Delta V
$$

where $S^{*}$ is the wetted surface area per unit volume and $\Delta V$ is the intrusion volume. Combining Eq(1), (3) and (10) we obtain the effective radius of the pore:

or

$$
\begin{aligned}
& \mathrm{r}^{*}=2 \Delta \mathrm{V} / \mathrm{S}^{*} \\
& \mathrm{r}^{*}=\mathrm{B} / 2 \pi
\end{aligned}
$$


where $B$ is the perimeter of the pore. We can then express the gas release criterion using the perimeter instead of radii of the pores. $\mathrm{Eq}(8)$ can be rewritten as:

$$
\mathrm{B}_{1} / \mathrm{B}_{2}<\cos \theta
$$

Thus, using $\mathrm{Eq}(8)$ or (12), for a solid in which the radii or perimeters of open pores vary in a very narrow range, most of the pores will not satisfy the gas-releasing criterion for partially wetting liquids, but for wide radius distributions, most of the pores will satisfy the criterion and fill with liquid, if they do not form the "gas pockets" discussed below, or lead to partial penetration as shown in Fig.3a.

For non-wetting liquids, their surface energy always act against the gas bubble forming on the external surface of the solid and therefore prevents gas release. Following the above analysis, it can be seen that there will not be gas release in non-wetting situations, if gravity or buoyancy forces are negligible. Thus, in mercury intrusion porosimetry, the specimen is always evacuated before attempting to penetrate with mercury.

A second effect, called the "inkwell effect" in mercury-intrusion porosimetry, concerns the difficulty of intruding pores with small openings. For wetting liquids, an analogous effect shown in Fig.5 may be called a "gas-pocket" effect. Small pores are readily intruded, but large pockets may prevent intrusion beyond some point and become stabilized by the retained gas. Thus the degree of liquid intrusion may depend sensitively on the detailed pore morphology. For a wetting liquid, such large pockets may represent the dominant volume fraction of porosity. 


\section{EXPERIMENT}

Within the range of $20^{\circ} \mathrm{C} \sim 400^{\circ} \mathrm{C}$, both sodium and $\mathrm{U}-10 \mathrm{Zr}$ alloy can react with oxygen in very low oxygen partial pressures (less than $10^{-44} \mathrm{ppm}$ ) ${ }^{[24]}$. Such reactions will produce oxides that change $\gamma_{\mathrm{sl}}$ and $\gamma_{\mathrm{lg}}$. Therefore, commercial grade $\mathrm{Ar}$, was purified by an oxygen trap ${ }^{\neq}$and molecular sieve $e^{\#}$ during specimen preparation and sodium intrusion tests to minimize the oxidation of sodium and $\mathrm{U}-10 \mathrm{Zr}$ alloy with the gas phase. The partial pressure of oxygen in the purified $\mathrm{Ar}$ was measured at the exhaust at $400^{\circ} \mathrm{C}$ using a solid state oxygen sensorl to be $10^{-8} \mathrm{ppm}$. This appeared to permit reproducible results and negligible weight loss during the experiment ${ }^{*}$.

In producing the porous $\mathrm{U}-10 \mathrm{Zr}$ specimens, the method developed by $\mathrm{M}^{\mathrm{C}}$ Deavitt and Solomon ${ }^{[25]}$ was followed. First, pure uranium hydride $\mathrm{UH}_{3}$ and zirconium hydride $\mathrm{ZrH}_{2}$ powders were mixed by hand in an alumina mortar and pestle for about two minutes inside a purified argon atmosphere $\left(\mathrm{Po}_{2}<10^{-8} \mathrm{ppm}\right)$ glovebox in a weight ratio of $8.9: 1[26]$ (which gives the desired weight ratio $\mathrm{U}: \mathrm{Zr}=9: 1$ after decomposition of the hydrides). The powders were then dry-pressed in a double-action punch and die under a pressure $550 \mathrm{MPa}$ for 10 seconds to form cylindrical pellets with dimensions of $7.2 \mathrm{~mm}$ and $\sim 5.5 \mathrm{~mm}$ in diameter and height, respectively. The geometrical green density was $6.20 \mathrm{~g} / \mathrm{cm}^{3}$ or $57 \%$ T.D. The green body was then inserted into the sintering vessel and sealed within the glovebox to avoid exposure to the air before attaching to the sintering pressurization system ${ }^{[25]}$. The specimens were then heated up at a rate of $16^{\circ} \mathrm{C} / \mathrm{min}$ under rough vacuum.

$\neq$ Oxy Absorbent, Alltech Associates, Inc.

\# Grade 514GT 4A, Fisher Scientific

I Thermox 1A, Ametek Corp.

* Higher oxygen levels caused significant weight loss. 
The evolution of hydrogen during decomposition minimized back flow of air through the pump. After the hydrides had decomposed completely $\left(250^{\circ} \mathrm{C} \sim 500^{\circ} \mathrm{C}\right.$ for $\mathrm{UH}_{3}$ and $600^{\circ} \mathrm{C} \sim 900^{\circ} \mathrm{C}$ for $\left.\mathrm{ZrH}_{2}\right)^{[25]}$, the Ar pressure was increased to $250 \mathrm{psig}$ and the specimens were sintered at $1100^{\circ} \mathrm{C}$ for 10 minutes, and then the vessel was cooled to room temperature in about 15 hours to yield a geometric relative density of $70 \%$.

The immersion densities of the as-sintered specimens were determined using absolute ethyl alcohol. An electronic balance ${ }^{*}$ with sensitivity of $\pm 0.000005 \mathrm{~g}$ located outside the glovebox was used to measure the weights of the specimens before and after they were immersed into alcohol under vacuum. The pore-size distribution of an assintered specimen was obtained through mercury intrusion porosimetry\#. Specimens for microstructural analysis were sectioned with diamond, mounted in epoxy, and polished to $1 \mu \mathrm{m}$ diamond and examined using scanning electron microscopy.

To perform the sodium intrusion experiments, the sodium was contained in a stainless steel beaker inside a Hastalloy C-276 alloy pressure vessel [27], which was designed to be capable of withstanding high temperature and pressure up to $400^{\circ} \mathrm{C}$ and 2000 psig, respectively, Fig.6. A thermocouple was inserted into the sodium to measure its temperature during the tests. The specimen holder shown in Fig. 6 could be moved up and down through a Conax ${ }^{\dagger}$ fitting, without causing gas leakage into or out of the vessel which permitted specimen insertion and withdrawal from the molten sodium.

* Mettler H51AR, Mettler Instrument Corp.

\# Courtesy of Dr. D. Winslow, Purdue University

† Conax Buffaio Corp. 
Because of the rapid reaction of the porous specimen in air, all assembly operations were performed in the inert atmosphere glovebox. To assemble the system, the specimen was first weighed with an electronic balance ${ }^{*}$ of $\pm 0.0001 \mathrm{~g}$ sensitivity, placed in the specimen holder and inserted into the pressure vessel. The pressure vessel was then sealed, removed from the glovebox and connected to the purified argon supply as shown in Fig.6, and the lines were evacuated. The pressure inside the pressure vessel was controlled by feeding gas from the accumulator or evacuating with the mechanical vacuum pump. The pressure or vacuum inside the pressure vessel was continuously monitored by a strain gage pressure sensor ${ }^{\#}$ or a thermocouple gauge, respectively.

To perform the experiments, the pressure of Ar inside the vessel was first set at an initial pressure $\sim 20$ psig to prevent in-leaks. Heating was begun at a rate of $5^{\circ} \mathrm{C} / \mathrm{min}$, and at $100^{\circ} \mathrm{C}$ the pressure was adjusted to $\mathrm{P}_{\mathrm{O}}$ and the specimen was lowered into the molten sodium. It was important to immerse the specimen under non-wetting conditions to prevent "wicking" of the sodium and displacement of the gas during immersion itself. After that, the vessel was closed to the gas supply and vacuum pump to minimize contamination and, therefore, the pressure in the vessel increased with temperature until it reached the testing temperature of $\sim 400^{\circ} \mathrm{C}$ in about 40 minutes. The specimen was held at this temperature for 4 hours to allow wetting and intrusion. After intrusion, the hot plate was turned off and the vessel was allowed to air-cool to $\sim 100^{\circ} \mathrm{C}$ in about one hour, and the specimen was withdrawn from the liquid sodium and allowed to cool to room temperature. The intruded $\mathrm{Na}$ was assumed to come into mechanical equilibrium with the ambient gas pressure that existed just before freezing $\left(100^{\circ} \mathrm{C}\right)$.

\footnotetext{
* Mealer AJ100, Mettler Instrument Corp.

\# Sentra 280E, Sentra Systems Inc.
} 
After the intrusion experiment, the specimen was taken out of the holder in the glovebox. The excess sodium adhering to the surface was removed with a stainless steel spoon and the specimen was weighed. The amount of intruded sodium in the open pores was determined from the weight gain. To verify that some gas was retained, two specimens with high pressure entrapped gas were then re-heated up to the melting temperature of $\mathrm{Na}$ inside the glovebox to observe bubbles forming on the surface. Because the pressures of the entrapped gas were higher than ambient pressure in the glovebox, some molten sodium was extruded from the pores. After this sodium had also been removed, the specimens were re-weighed to determine the amount of extruded sodium.

Our initial experiments, using chemical grade sodium (Mallinckrodt Inc.), showed that, fully dense U-10Zr alloy from Argonne National Laboratory ANL (Chicago, IL) would lose $3 \%$ of its weight after 4 hours at $400^{\circ} \mathrm{C}$ in purified $\mathrm{Ar}$, and porous specimens showed a $1 \%$ weight loss instead of the expected weight gain due to sodium intrusion. Although the detailed mechanism is unknown, it is likely that the weight loss was caused by reactions between the impurities in the sodium and the alloy. Surface degradation was noted along with loss of material from the surface. (This degradation process could have important implications in safety, quality assurance, reprocessing and reactivity calculations.) To avoid this problem, reactor-grade sodium $\mathbb{\text { was }}$ used in subsequent intrusion tests. Some physical properties of sodium at different temperatures are listed in Table 1.

To confirm the chemical stability of the alloy in sodium and the testing environment as well as the technique of removing $\mathrm{Na}$ from the specimen surface, a fully-dense $\mathrm{U}-10 \mathrm{Zr}$ 
specimen from $\mathrm{ANL}$ was tested at $400^{\circ} \mathrm{C}$ and $20 \mathrm{psig}$ in the pressure vessel in the reactorgrade sodium. After 4 hours of testing the weight of the specimen was measured to be $1.4181 \mathrm{~g}$ compared to the initial weight of $1.4186 \mathrm{~g}$. This result showed that, although some residual sodium could be seen on the surface, after scraping the surface with the spoon, the weight was identical to the original weight within experimental error. Compared to the normal weight gain (above $1 \%$ ) from sodium intrusion, this weight loss is negligible. The result also implies that oxidation was negligible.

Several intrusion experiments were conducted under different temperature and pressure conditions. Two different testing temperatures, $150^{\circ} \mathrm{C}$ and $400^{\circ} \mathrm{C}$, were selected to examine intrusion behavior under wetting and non-wetting conditions. Pressure effects on intrusion were measured in a pressure range from $10 \mathrm{mmHg}$ to $1000 \mathrm{psig}$.

To virtually test the role of differential capillarity on intrusion behavior, identical size holes were drilled into specimens of fully-dense brass and fully-dense U-10Zr alloy from ANL. The geometry of the specimens and holes are showed in Fig.7. The brass specimen of $d=4.67 \mathrm{~mm}$ had seven holes of a uniform $0.8 \mathrm{~mm}$ diameter and $4.94 \mathrm{~mm}$ length. It was intruded by $99 \%$ dioctyl phthalate ${ }^{\dagger}$ at room temperature. Dioctyl phthalate was selected because of the reported well-defined wetting angle on brass of $2^{\circ[28]}$. The holes in the $U-10 \mathrm{Zr}$ alloy specimen of $\mathrm{d}=4.92 \mathrm{~mm}$ were found to be tapered with a maximum diameter of $0.90 \mathrm{~mm}$, a minimum diameter of $0.79 \mathrm{~mm}$, and a length of $4.74 \mathrm{~mm}$. (The unintentional tapering was apparently caused by "runout" of the carbide drills used, and was measured by inserting of drillrods closely varying diameter into the holes to various depths.) It was tested in sodium at $400^{\circ} \mathrm{C}$ exactly like the sintered specimens. The total

+ from Aldrich Chemical Company, Inc. 
pore geometric volumes were calculated to be $17.38 \mathrm{~mm}^{3}(21 \mathrm{vol} \%)$ and $15.96 \mathrm{~mm}^{3}$ (18vol\%) for brass and $\mathrm{U}-10 \mathrm{Zr}$ specimens, respectively. The weight changes before and after intrusion were measured and the volume percentages of intrusion over total hole volume were then calculated through the measured weight changes and the densities of dioctyl phthalate and sodium.

\section{RESULTS}

Porosities of the sintered $\mathrm{U}-10 \mathrm{Zr}$ specimens from immersion density and mercury intrusion measurements, listed in Table 2 , showed good agreement with each other. In the following analysis, we take $30 \mathrm{vol} \%$ as the open porosity of the sintered specimens. The original data obtained through mercury intrusion porosimetry, plotted in Fig.8, showed that the diameters of the pores were within the range of 0.4 to $3.6 \mu \mathrm{m}$, with an average diameter of $\sim 2.0 \mu \mathrm{m}$. Taking the derivative of Fig. 8 shows the pore volume distribution in Fig.9. SEM microscopy (Fig.10) shows that the pores (dark area) were fairly uniformly distributed inside the specimen, and that an impurity phase of $\sim 25 \mathrm{vol} \%$ was found which had been earlier identified ${ }^{[25]}$ as zirconium stabilized with $\mathrm{O}, \mathrm{N}$ and $\mathrm{C}$ impurities. For comparison, Fig. 11 shows the pore structure of an irradiated U-10Zrl at $\sim 30 \mathrm{vol} \%$ porosity.

The results of intrusion tests of the sintered $\mathrm{U}-10 \mathrm{Zr}$ alloy conducted at $150^{\circ} \mathrm{C}$ and $400^{\circ} \mathrm{C}$ under pressures of 20 psig to 800 psig are listed in Table 3 , where $\mathrm{P}_{0}$ represents the initial pressure at $100^{\circ} \mathrm{C} ; \mathrm{W}_{0}, \mathrm{~W}_{1}$ and $\Delta \mathrm{W}_{1} / \mathrm{W}_{0}$ are the specimen weights before and after intrusion and weight gain fraction, respectively. It is obvious that in these highly porous

I courtesy of Gerard Hofman, Argonne National Laboratory, Chicago, IL 
specimens, the weight changes due to sodium intrusion $(>1.5 \%)$ were much higher than that of due to measurement error (about $\pm 0.04 \%$ ); and weight changes under identical test conditions $\left(\mathrm{P}_{0}=20 \mathrm{psig}\right.$ and $\left.\mathrm{T}=400^{\circ} \mathrm{C}\right)$ were very reproducible.

The fractional intrusion volumes were also calculated and listed as $\Delta V_{1} / V_{0}$ in Table 3 , based on the densities of sodium and the alloy, open porosity of the specimens as well as the weight gains. The results of sodium extrusion are also listed in Table 3 , in which $\mathrm{W}_{2}, \Delta \mathrm{W}_{2} / \mathrm{W}_{0}$ and $\Delta \mathrm{V}_{2} / \mathrm{V}_{0}$ are the weight, \%weight gain and fractional penetration, respectively, after extrusion. For specimen $1 \mathrm{~W}$ tested at $\mathrm{P}_{\mathrm{O}}=100 \mathrm{psig}, 8.5 \%$ of the intruded sodium was extruded, and for specimen $1 \mathrm{Z}$ tested at $\mathrm{Po}=800 \mathrm{psig}, 65.6 \%$ was extruded, leaving the percentages of gas volume to total pore volume of $10.3 \%$ and $70.1 \%$, respectively.

Sodium wettability was examined through immersion tests at $150^{\circ} \mathrm{C}$ and $400^{\circ} \mathrm{C}$, with initial pressure $\mathrm{P}_{0}=20$ psig. After treating at $150^{\circ} \mathrm{C}$ for 4 hours in molten sodium, the alloy surface remained sodium-free and showed no evidence of sodium/alloy contact at this temperature. For specimens held at $400^{\circ} \mathrm{C}$ for 4 hours and then cooled down to room temperature, however, sodium completely covered and adhered to the entire surface, which indicated small contact angle. Thus, once the surface has been wetted, there is no evidence of de-wetting at lower temperature under the conditions investigated. The effect of initial pressure $P_{0}$ on sodium intrusion was examined under wetting conditions at $400^{\circ} \mathrm{C}$ within a range from 20 psig to 800 psig which is plotted in Fig. 7 from the data in Table 3.

The results of the intrusion tests for the specimens with drilled holes are listed in Table 4. The brass specimen was rapidly immersed in dioctyl phthalate to prevent wicking and exhibited a $0.00006 \mathrm{~g}$ weight gain that represents $0.06 \mathrm{~mm}^{3}$ volume of dioctyl phthalate 
intrusion. The $\mathrm{U}-10 \mathrm{Zr}$ alloy specimen exhibited a $0.0113 \mathrm{~g}$ weight gain in sodium or an intruded volume of $11.65 \mathrm{~mm}^{3}$.

\section{DISCUSSION}

\section{WETTING BEHAVIOR}

The results of sodium intrusion into sintered specimens at low pressure (Table 3 and Fig.12) show a significant influence of capillarity on intrusion. Under wetting conditions $\left(400^{\circ} \mathrm{C}\right)$, the porous specimens exhibited a $2.7 \%$ weight gain, whereas under non-wetting conditions $\left(150^{\circ} \mathrm{C}\right)$ virtually no weight change was expected or detected. The fractional intrusion can be calculated from open porosity and weight gain of the specimen and the densities of $\mathrm{U}-10 \mathrm{Zr}$ alloy and sodium. It is found that at $400^{\circ} \mathrm{C}$ and low $\mathrm{P}_{\mathrm{O}}$, virtually completely intrusion $(\sim 99 \%)$ occurred. Thus for $\mathrm{Na}$ penetration to occur in nuclear fuels wetting is clearly a prerequisite. The effects of sodium purity and fuel surface condition on wettability are not known.

\section{EFFECTS OF INITIAL PRESSURE ON INTRUSION}

As discussed above, the gas pressures within the pores at $100^{\circ} \mathrm{C}$ equal Po+ $\Delta \mathrm{P}$. According to $\mathrm{Eq}(2), \Delta \mathrm{P}$ depends on the surface energy $\gamma_{\mathrm{lg}}$, contact angle $\theta$ and the pore

size $r$. Using the assumed $\theta=10^{\circ}, \mathrm{r}=1 \mu \mathrm{m}$ for the sintered specimens, and $\gamma_{\mathrm{ig}}=0.210 \mathrm{~J} / \mathrm{m}^{2}$ for sodium at $100^{\circ} \mathrm{C}$, we can obtain $\Delta \mathrm{P}=60 \mathrm{psi}$ from $\mathrm{Eq}(2)$.

The lower curve in Fig.12, marked 0\% Gas Release, represents the effects of initial pressure on intrusion assuming no entrapped gas release from the pores. The relation 
between the weight gain and the initial pressure $P_{0}$ can be obtained by considering an unit volume of specimen. For $1 \mathrm{~cm}^{3}$ of the sintered specimen the volumes of solid alloy and the open pore are $\mathrm{V}_{\text {alloy }}=0.7 \mathrm{~cm}^{3}$ and $\mathrm{V}_{\text {pore }}=0.3 \mathrm{~cm}^{3}$. Because there is closed porosity inside the solid alloy (see Table 2), the "apparent" solid density is $16.00 \times 0.947=15.15 \mathrm{~g} / \mathrm{cm}^{3}$ and, therefore, its weight before intrusion is $W_{0}=10.60 \mathrm{~g}\left(0.7 \mathrm{~cm}^{3} \times 15.15 \mathrm{~g} / \mathrm{cm}^{3}\right)$. As discussed above, when the initial pressure is $P_{0}$, the equilibrium pressure will be $\mathrm{P}_{\mathrm{e}}=\left(\mathrm{P}_{0}+60\right)$ psi and the equilibrium volume of argon, $\mathrm{V}_{\mathrm{e}}$, can be obtained assuming $\mathrm{PV}=$ constant, or:

$$
\mathrm{V}_{\mathrm{e}}=\mathrm{P}_{0} \mathrm{~V}_{\text {pore }} /\left(\mathrm{P}_{0}+60\right)
$$

The intrusion volume and weight of sodium, $\mathrm{V}_{\mathrm{Na}}$ and $\mathrm{W}_{\mathrm{Na}}$, are:

$$
\begin{aligned}
& \mathrm{V}_{\mathrm{Na}}=\mathrm{V}_{\text {pore }}-\mathrm{V}_{\mathrm{e}}=60 \mathrm{~V}_{\text {pore }} /\left(\mathrm{P}_{0}+60\right)=18.0 /\left(\mathrm{P}_{0}+60\right), \mathrm{cm}^{3} \\
& \mathrm{~W}_{\mathrm{Na}}=\rho_{\mathrm{Na}} \cdot \mathrm{V}_{\mathrm{Na}}=0.97 \times 18.0 /\left(\mathrm{P}_{0}+60\right)=17.46 /\left(\mathrm{P}_{0}+60\right), \quad \mathrm{g}
\end{aligned}
$$

and the relation between the weight gain and $P_{0}$ is

$$
\text { Weight Gain }(\%)=100 \times \mathrm{W}_{\mathrm{Na}} / \mathrm{W}_{0}=164.7 /\left(\mathrm{P}_{0}+60\right)
$$

In the situation in which all the gas releases from the pores, the volume of intruded sodium will equal to the volume of open porosity and there will be an $100 \%$ penetration, as shown in the dashed line marked as $100 \%$ Gas-Release in Fig.12. Obviously, the initial pressure $P_{0}$ does not have any effect on intrusion when all the gas is released.

The solid points in Fig.12 represent the sodium intrusion results of sintered U-10Zr specimens at different temperatures and pressures. A decrease in penetration volume with pressure $\mathrm{P}_{0}$ is apparently only at the highest pressure of 800 psig although complete penetration is never achieved. 


\section{EXTRUSION BEHAVIOR}

After intrusion, one can calculate the percentages of pore volume occupied by the gas by assuming ideal gas behavior and no gas-release during the reheating and extrusion process. For specimen $1 \mathrm{~W}\left(\mathrm{P}_{0}=115 \mathrm{psia}\right)$, the pressures of entrapped gas before and after extrusion test were 175 psia $(115+60$ psia) and 75 psia (15+60 psia), respectively, and the gas volume after extrusion was measured as $10.3 \mathrm{vol} \%$ of the total pore volume; therefore, the volume percentage of entrapped gas before extrusion was only $4.4 \mathrm{vol} \%$. The same calculation procedure gives the volume percentage of entrapped gas in specimen $1 Z$ $\left(P_{0}=815 \mathrm{psia}\right)$ before extrusion as $6.0 \mathrm{vol} \%$. These results suggest that the retained gas volume after intrusion was apparently independent of initial pressure $\mathrm{P}_{0}$, and it was about $5.2 \mathrm{vol} \%$ for this particular material, liquid and testing condition.

The criterion for gas release, Eq.8, predicts that the penetrating liquid will occupy a pore of size $d$ and the gas will be released if $d / d_{\max }<\cos \theta$ is satisfied. The pore-size distribution measurement from mercury intrusion porosimetry showed that the maximum pore size was $d_{\max }=3.6 \mu \mathrm{m}$ in the sintered specimens. So in the sintered specimens the maximum size of the pore that allowed sodium intrusion, at which the contact angle is $10^{\circ} \mathrm{C}$, was

$$
\mathrm{d}^{*}=\mathrm{d}_{\max } \cos \theta=3.6 \times \cos 10^{\circ}=3.5 \mu \mathrm{m}
$$

From the pore-size distribution curve (see Fig.4), the volume of pores with sizes smaller than $3.5 \mu \mathrm{m}$ was $97.7 \%$ of the total volume which is in good agreement with the intrusion measurement and in fair agreement with the value of $5.2 \%$ of retained gas from the extrusion measurements. 


\section{MODEL EXPERIMENTS}

The results of the intrusion tests in fully-dense brass and $\mathrm{U}-10 \mathrm{Zr}$ specimens with drilled holes, listed in Table 4, also supports the Differential Capillarity model. At $20^{\circ} \mathrm{C}$, the density of dioctyl phthalate is $0.981 \mathrm{~g} / \mathrm{cm}^{3}$; its contact angle on brass and surface energy in air are $2^{\circ}$ and $0.0313 \mathrm{~J} / \mathrm{m}^{2}$, respectively[21]. Therefore from $\mathrm{Eq}(2)$, the pressure difference across dioctyl-phthalate/air interface inside pores of $0.80 \mathrm{~mm}$ diameter was a very small 0.023 psi. Because the diameters were constant in the brass specimen, the gasrelease criterion is not satisfied, and no gas release is predicted during the intrusion pre sess. The equilibrium gas volume can be calculated assuming ideal gas behavior. Thus for gas of $17.38 \mathrm{~mm}^{3}$ at an initial pressure of $14.70 \mathrm{psi}$, the equilibrium volume at a final pressure of $14.723 \mathrm{psi}$ was $17.35 \mathrm{~mm}^{3}$ and the volume of intruded dioctyl phthalate should be $0.03 \mathrm{~mm}^{3}$. This compares well with the measured value of $0.06 \mathrm{~mm}^{3}$.

For the tapered holes in the $\mathrm{U}-10 \mathrm{Zr}$ specimens, the pressure differences across the sodium/argon interface were, from $\mathrm{Eq}(2), 0.13 \mathrm{psi}$ and $0.12 \mathrm{psi}$ for $\mathrm{d}_{1}=0.79 \mathrm{~mm}$ and $\mathrm{d}_{2}=0.90 \mathrm{~mm}$, respectively. If no gas had been released from the holes, the volume of sodium intrusion in this specimen should have been only $0.16 \mathrm{~mm}^{3}$, based on the ideal gas behavior, rather than the measured $12.56 \mathrm{~mm}^{3}$. According to the gas release criterion for tapered holes given in $\mathrm{Eq}(9)$, the ratio of $d_{1} / d_{2}, 0.88$ for the tapered holes, was smaller than $\cos (\theta+\phi), 0.983$ for $\theta=10^{\circ}$ and $\phi=0.7^{\circ}$. Therefore the release criterion was satisfied, and the diameter of the cross section to which liquid sodium can propagate from the smaller opening, $\mathrm{d}_{\mathrm{i}}$, was $0.88 \mathrm{~mm}$, from $\mathrm{Eq}(9)$; and the total intrusion volume of sodium was $12.75 \mathrm{~mm}^{3}$ for this specimen, which is more accordance with the measured volume of $12.56 \mathrm{~mm}^{3}$. 
The intrusion experiments conducted at Po $<115$ psi showed essentially complete logging of the specimens with sodium. Using the pore size distribution, only $2.3 \mathrm{vol} \%$ of the pores would not satisfy the Differential Capillarity criterion, which is in reasonable agreement with the measurement of $4.9,2.0$ and $0.2 \mathrm{vol} \%$. However, the $800 \mathrm{psig}$ test showed an unexpected 44.6 vol\% of entrapped gas. In the subsequent extrusion test, if the entrapped gas had a pressure of 875 psia $(815+60$ psia), this gas should have expanded $520 \%$ when the pressure was reduced to 75 psia, forcing all of the sodium from the pores. However, the gas only expanded to 70.1 vol\%. If the criterion for gas release is independent of pressure as predicted, some other explanation must be found for the low apparent intrusion and extrusion. One possibility is that the high pressure gas extruded the solidified sodium after the ambient high pressure was reduced, or there was a pressure leak in the system during cooling. If this occurred, the small volume of retained gas $\sim 5 \mathrm{vol} \%$ would have expanded to $58 \mathrm{vol} \%$, which is closer to what was measured, and the subsequent extrusion would be negligible as measured. If this explanation is correct, then the results indicate almost complete sodium intrusion in all $\mathrm{U}-10 \mathrm{Zr}$ specimens. However, it should be pointed out that other specimen morphologies with gas pockets or other irregularities may not exhibit such complete intrusion.

There is no simple explanation for the large discrepancy between the results of the present experiments and those of Villarreal[4] which showed only small fractional penetration. The subsequent gas generation after the initial bubble interconnection and gas release should also have been released, since it is the differential pressures that cause the release. Also, the initial penetration of sodium should prevent resintering after gas release that might have trapped gas within the specimen. Even if one includes the "gap" sodium in Villarreal's measurements, there is still only small increase in total sodium penetration. Several possible explanations for the discrepancy might be (1) a large gas-pocket effect in the central region, or (2) a significant change in wetting behavior or pore structure as the 
fission product inventory increases, or (3) the build-up of the high density $\mathrm{Zr}$-rich zone which prevents sodium penetration.

\section{v. CONCLUSIONS}

The results indicate that under wetting conditions, sodium penetrates sinter porosity readily and virtually completely at low retained gas pressure. The differential capillarity mechanism proposed quantitatively explains the process of gas release from such specimens, although the maynitude of the release will depend on the detailed pore morphology. Less penetration was measured at high retained gas pressure, and less extrusion of sodium was observed when the ambient pressure was reduced suggesting an inadvertent loss in external pressure during the experiment.

\section{ACKNOWLEDGMENT}

The authors are indebted to Dr.Sean McDeavitt who originally suggested the possibility of Differential Capillarity.

\section{REFERENCES}

[1] Beck, N. Private communication, 1991

[2] Hofman, G. Private communication, 1991

[3] Hofman, G.L. and Walters, L.C. "Materials Science and Technology" vol.10 Nuclear Materials (edited by B.R.T. Frost), Chapter 1, Metallic Fuels. (in press)

[4] Villarreal, R. Memos to B. Pahe, Oct. 1987, Jan. 1988, Aug. 1988

[5] Hsu, F. and Solomon, A.A. Acta Metall. v31, n.3, pp453-464, 1983

[6] Delannay, F.; Froyen, L. and Deruyttere, A. J.Mat.Sci. v 22 ppl-16, 1987 
[7] Washburn, E.W.

Proc. Natl. Acad. Sci. U.S.

v7 pp115, 1921

[8] Young, $\mathrm{T}$.

Phil. Trans. R. Soc.

$\checkmark 95 \quad \mathrm{pp} 65, \quad 1805$

[9] Deshpande, M.S.; Desai, P.D. and Solomon, A.A. "High Temperature Science" vol.17, (The Humana Press Inc.) pp303-332, 1984

[1ii] Eustathopoulos, N. and Pique, D. Scripta Metall. v14 pp1291, 1980

[11] Guggenheim, E.A. Trans. Far. Soc. v41 pp150, 1945

[12] Dodds, N.E. and Henslee, S.P. Private communication

(1991)

[13] Clark, R.B and Kruger, O.L. BMI $1868 \quad$ ppA9-A15, 1969

[14] Bader, M. and Busse, C.A. J. Nuclear Materials v67 pp295-300, 1977

[15] Dokhov, M.P. Izvestiya Akademii Nauk SSSR Metally $\quad$ n.4 pp55, 1985

[16] Delannay, F., Froyen, L. and Deruyttere, A. J.Mat.Sci. v22 pp1, 1987

[17] Eustathopoulos, N. and Joud, J.C. "Current Topics in Material Science" vol.4, edited by E.Kaldis (North-Holland, Amsterdam) pp281, 1980

[18] Allen, B.C. "Liquid Metals: Chemistry and Physics" edited by S.Z. Beer (Dekker, New York) pp161, 1972

[19] Skapski, A.S. J. Chem. Phy. v16 pp869, 1948

[20] "CRC Handbook of Chem. and Phys." 63rd Ed. edited by R.C. Weast and M.J.

Astle. CRC Press, Inc. 1983

[21] Iakubov, I.T.; Khrapak, A.G.; Pogosov, V.V. and Trigger, S.A.

Solid State Communications v56 n.8 pp709-721, 1985

[22] Semlak, K.A. and Rhines, F.N. Trans. Met. Soc. AIME (June) pp325, 1958

[23] Mortensen, A. and Cornie, J.A. Metall. Trans. A v 18A pp1160, 1987

[24] Darken, L.S. and Gurry, R.W. "Physical Chemistry of Metals " McGraw Hill, New York, 1953

[25] McDeavitt, S.M. and Solomon, A.A. to be published

[26] Mueller, W.M., Blackledge, J.P., and Libowitz, G. G., "Metal Hydrides", Academic Press, pp405, 1968 
[27] Pragna, B. M.S. Thesis, Purdue University. Dec. 1987

[28] Fox, H.W.; Hare, E.F. and Zisman, W.A. J.Phys. Chem. v59 pp1097, 1950 
Table.1 Physical Properties of Sodium

\begin{tabular}{|c|c|c|c|c|}
\hline $\begin{array}{c}\text { Temp } \\
\left({ }^{\circ} \mathrm{C}\right)\end{array}$ & $\begin{array}{c}\text { Density } \\
(\mathrm{g} / \mathrm{cc})\end{array}$ & $\begin{array}{c}\text { Viscosity } \\
(\text { poise })\end{array}$ & $\begin{array}{c}\text { Vapor Pressure } \\
(\mathrm{mm} \mathrm{Hg})\end{array}$ & $\begin{array}{c}\text { Surface Energy } \\
(\mathrm{J} / \mathrm{m} \wedge 2)\end{array}$ \\
\hline 97.8 & 0.97 & & & 0.210 \\
\hline 100 & 0.927 & 0.705 & & \\
\hline 127 & & & $2.23 \mathrm{E}-6$ & \\
\hline 200 & 0.904 & 0.450 & & 0.021 \\
\hline 227 & & & 0.00115 & \\
\hline 300 & 0.882 & 0.345 & & 0.191 \\
\hline 327 & & & 0.0503 & \\
\hline 400 & 0.859 & 0.284 & & 0.179 \\
\hline 427 & & & 0.881 & \\
\hline 500 & 0.834 & 0.234 & & 0.167 \\
\hline 527 & & & 7.53 & \\
\hline 600 & 0.809 & 0.210 & & 0.154 \\
\hline 627 & & & 39.98 & \\
\hline
\end{tabular}

Table.2 Porosities of the Sintered U-10Zr Specimens

\begin{tabular}{|l|c|c|}
\hline & Open Porosity & Closed Porosity \\
\hline Immersion Method $^{\S}$ & $30.0 \%$ & $5.3 \%$ \\
\hline Mercury Intrusion & $28.1 \%$ & - \\
\hline
\end{tabular}

$\S$ theoretical density $(16.02 \mathrm{~g} / \mathrm{cc})$ was provided by Cerac Inc. 


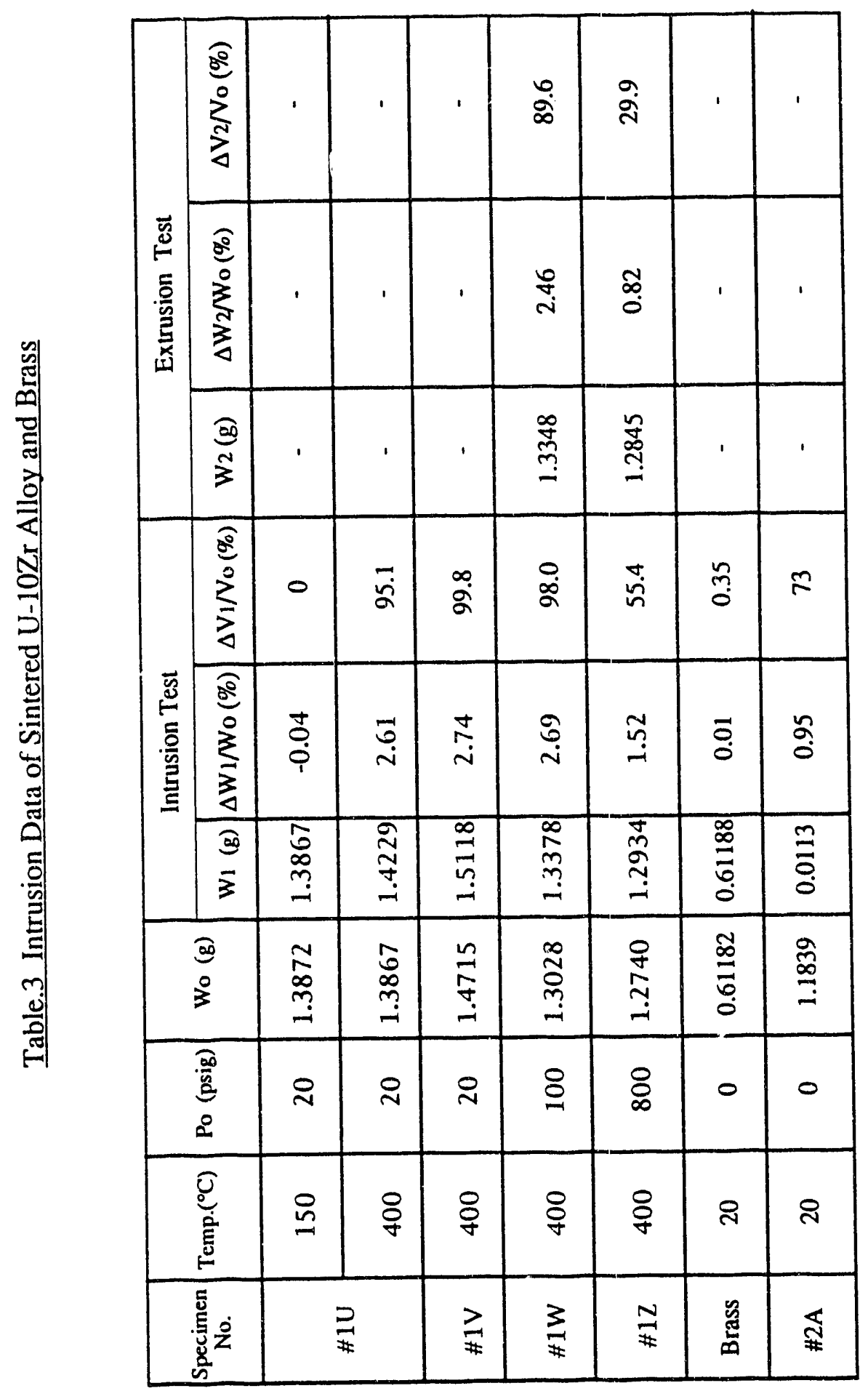




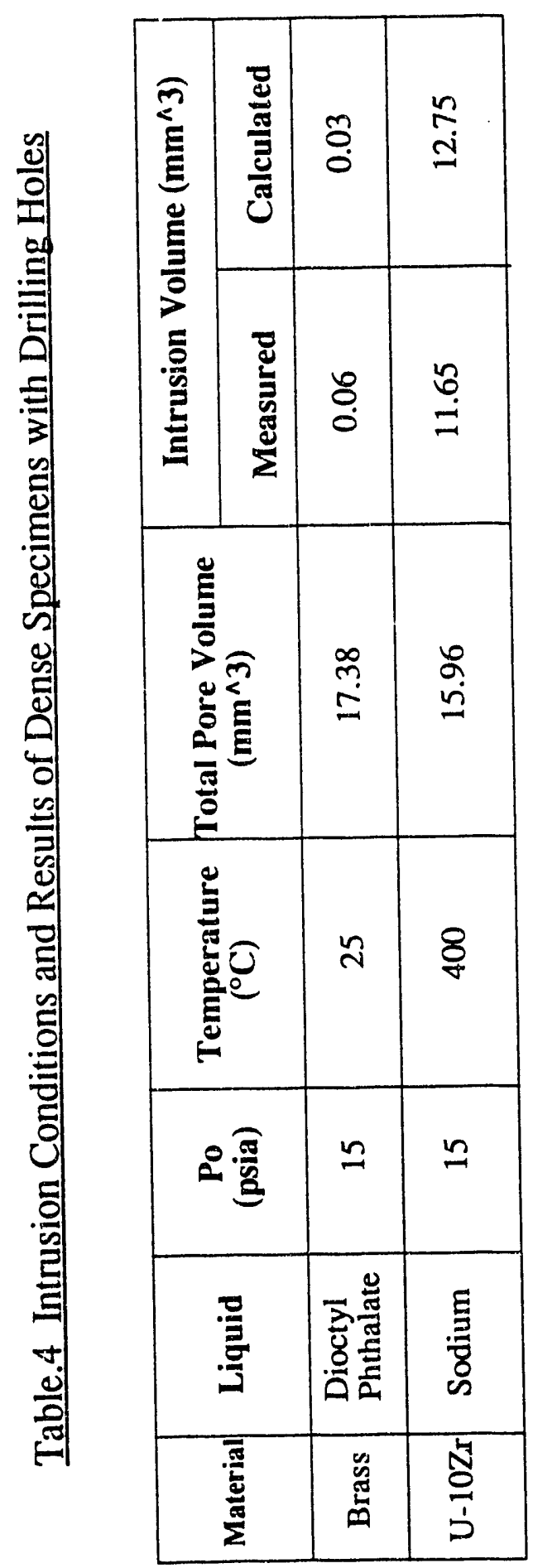




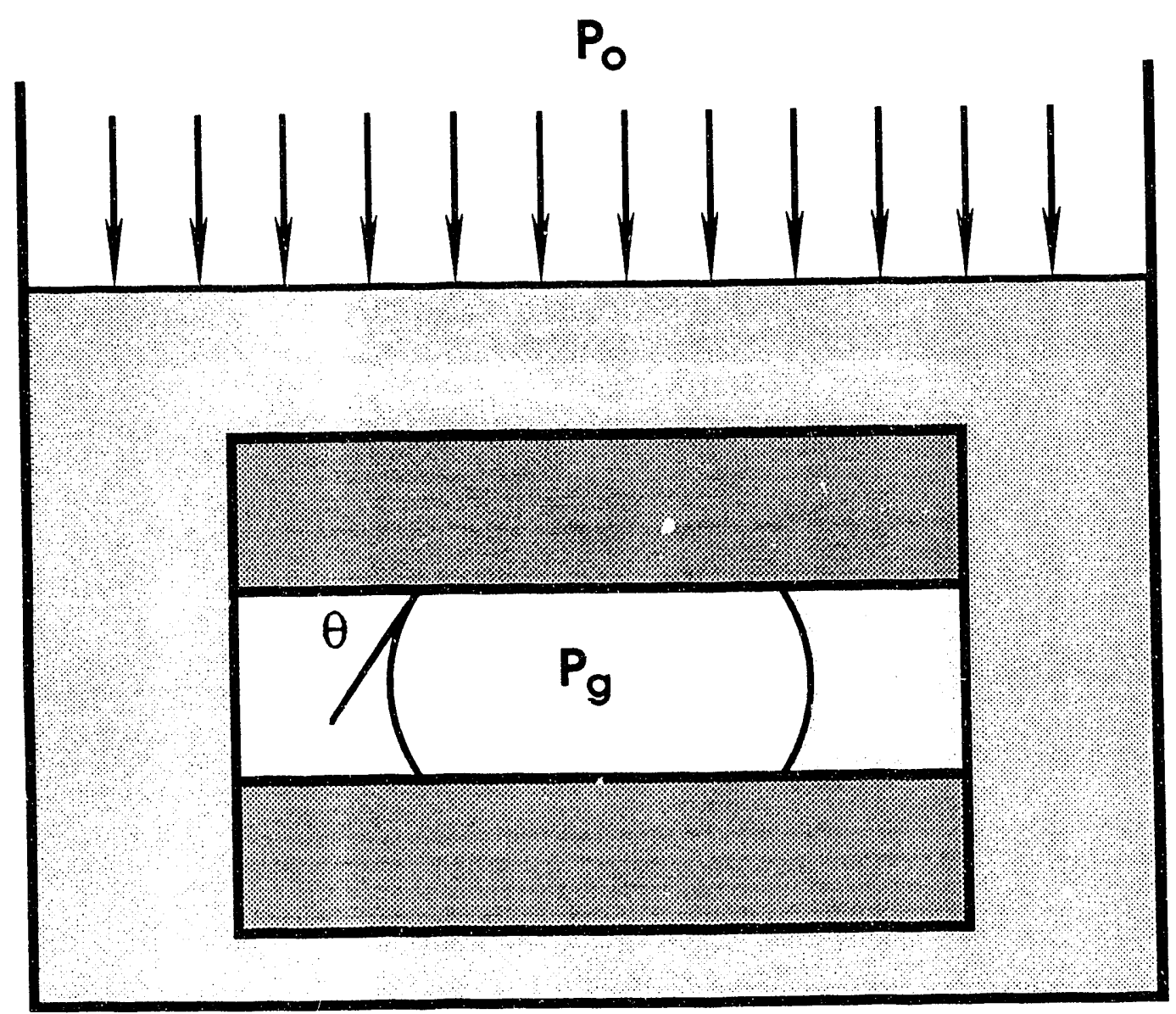

FIG.1 SHAPES OF GAS BUBBLE INSIDE THE PORES UNDER WETTING CONDITIONS 


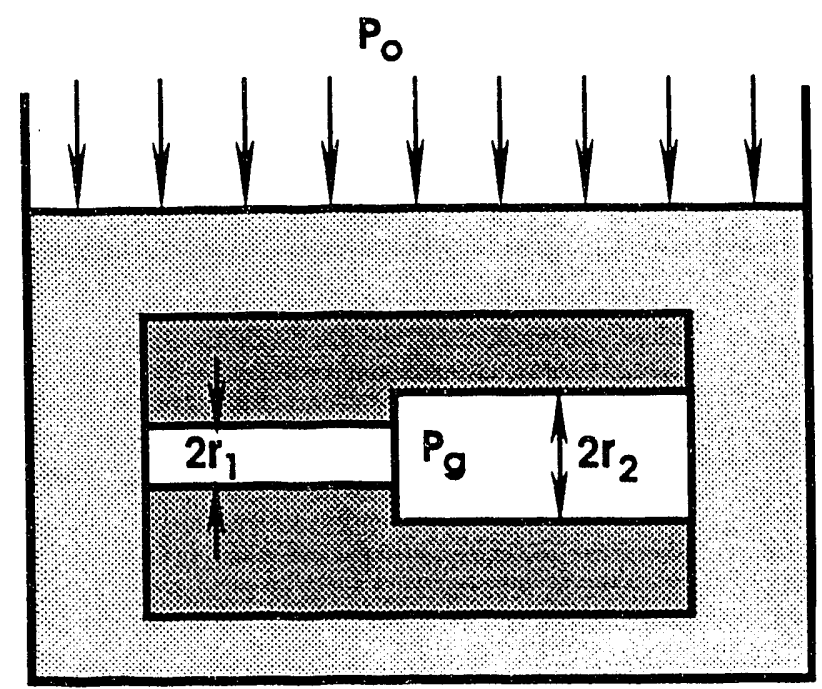

(a)

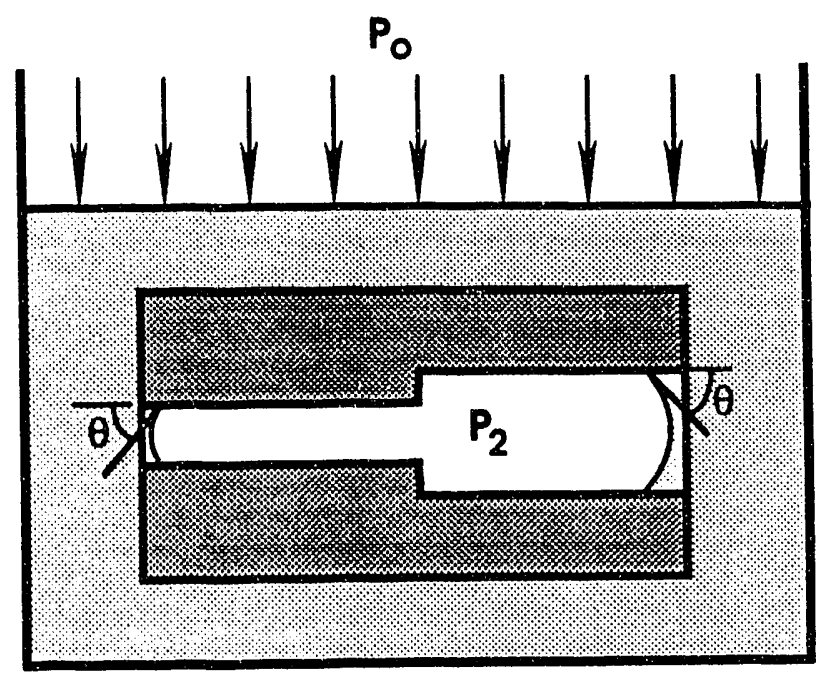

(b)

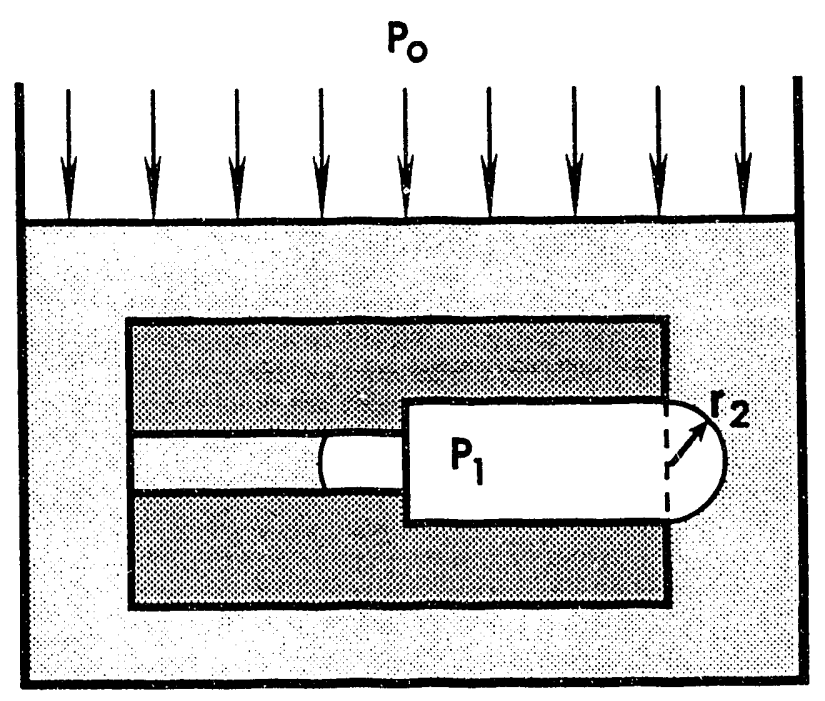

(c)

FIG.2 ILLUSTRATION OF LIQUID INTRUSION PROCESS. (A) AT $t=0$ WHERE $P_{g}=P_{0}$;

(B) AFTER INTRUSION OCCURS; (C) THE CRITICAL CONDITION FOR GAS RELEASE 

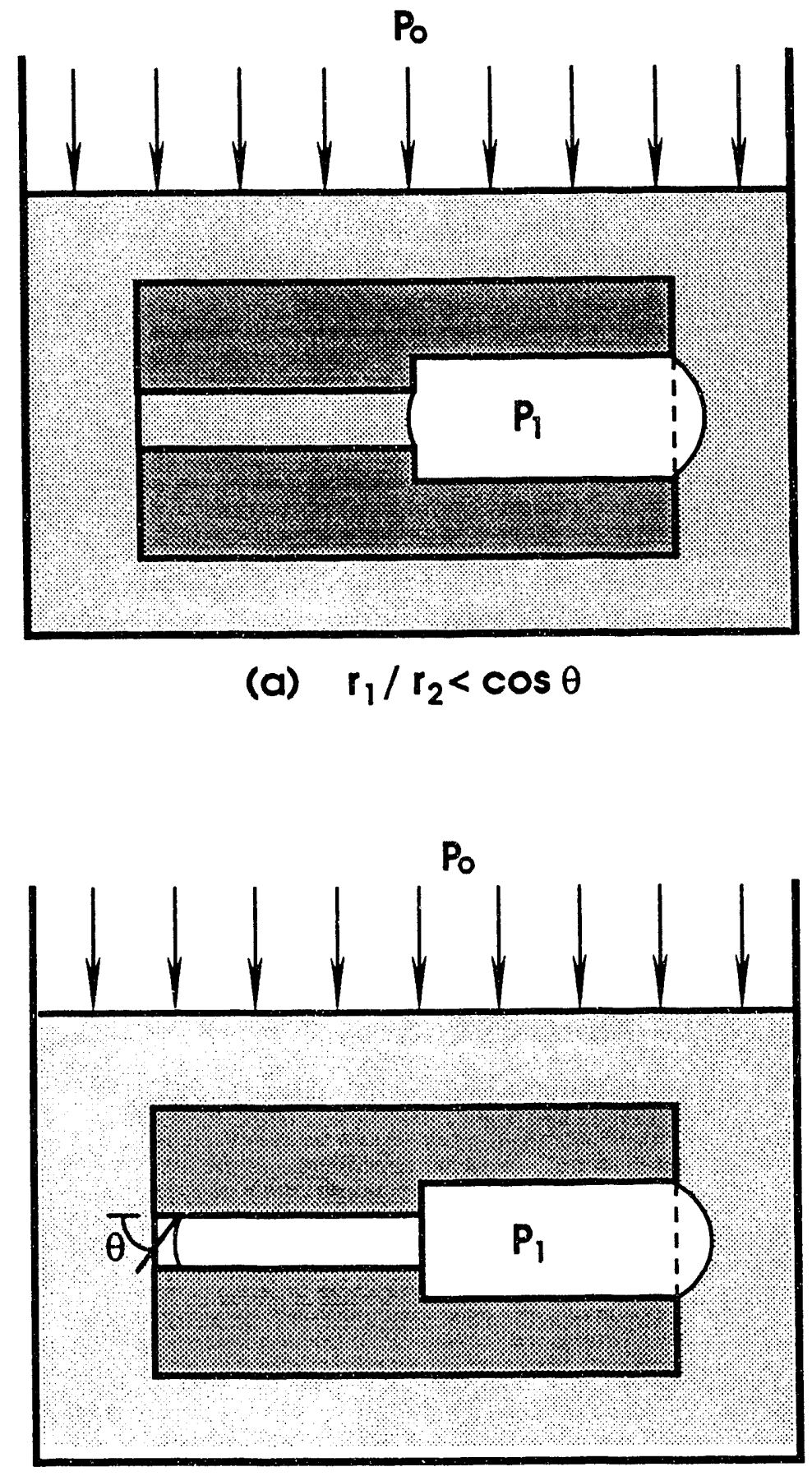

(b) $r_{1} / r_{2}>\cos \theta$

FIG.3 THE EFFECT OF $r_{1} / r_{2}$ RATIO ON LIQUID PENETRATION 


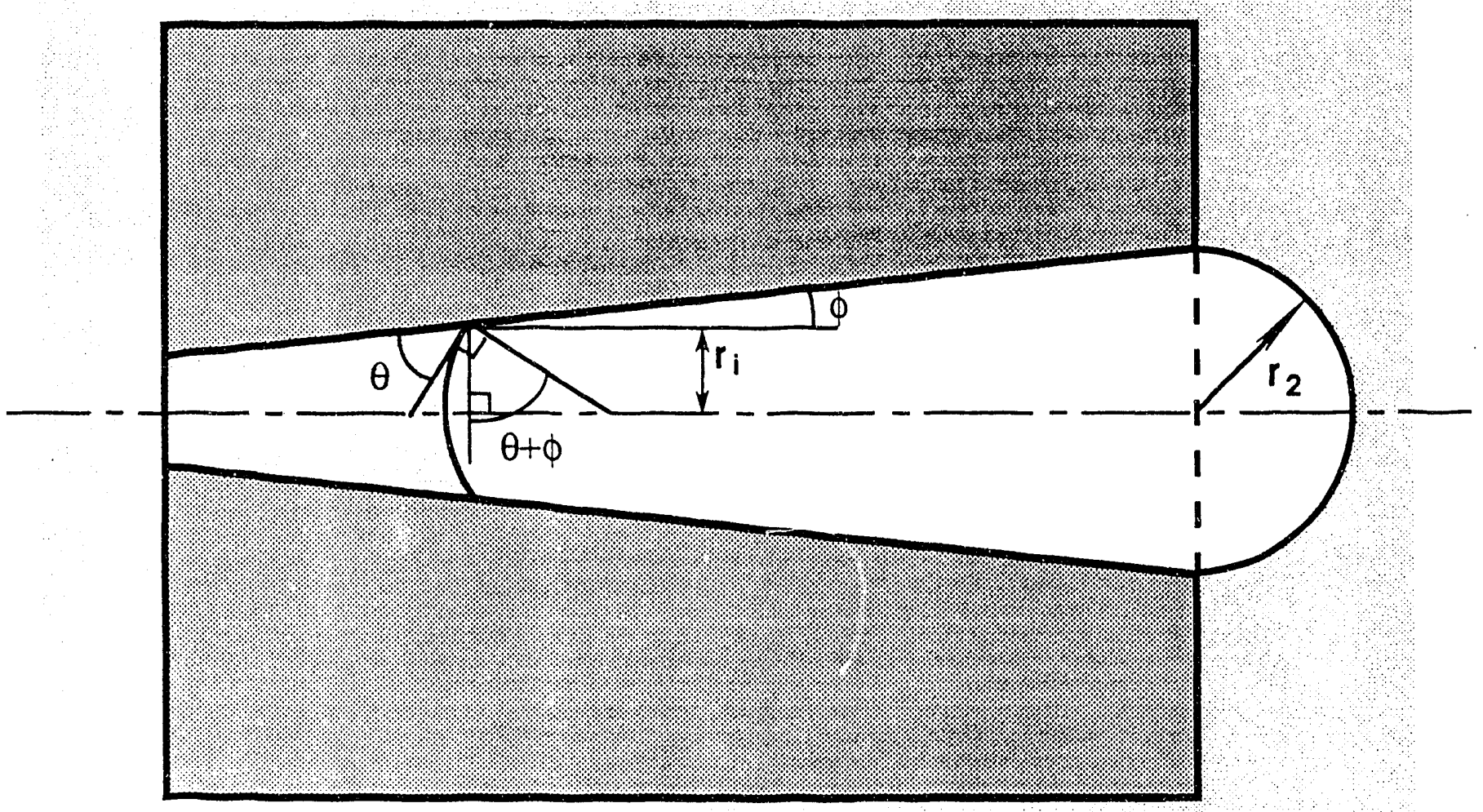

FIG.4 PENETRATION OF LIQUID INTO A TAPERED

PORE AT THE CRITICAL CONDITION 


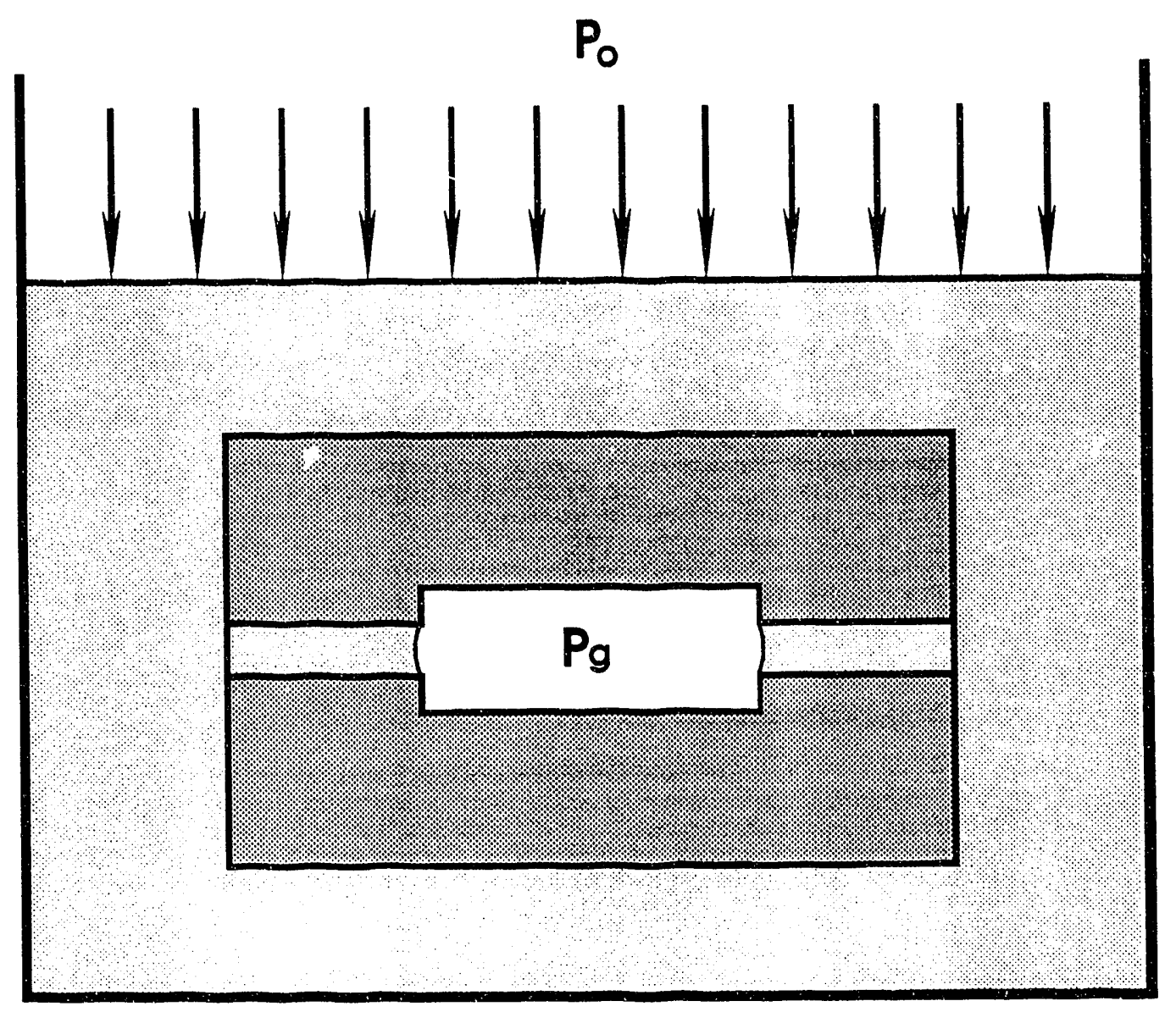

FIG.5 ILLUSTRATION OF THE GAS-POCKET EFFECT 


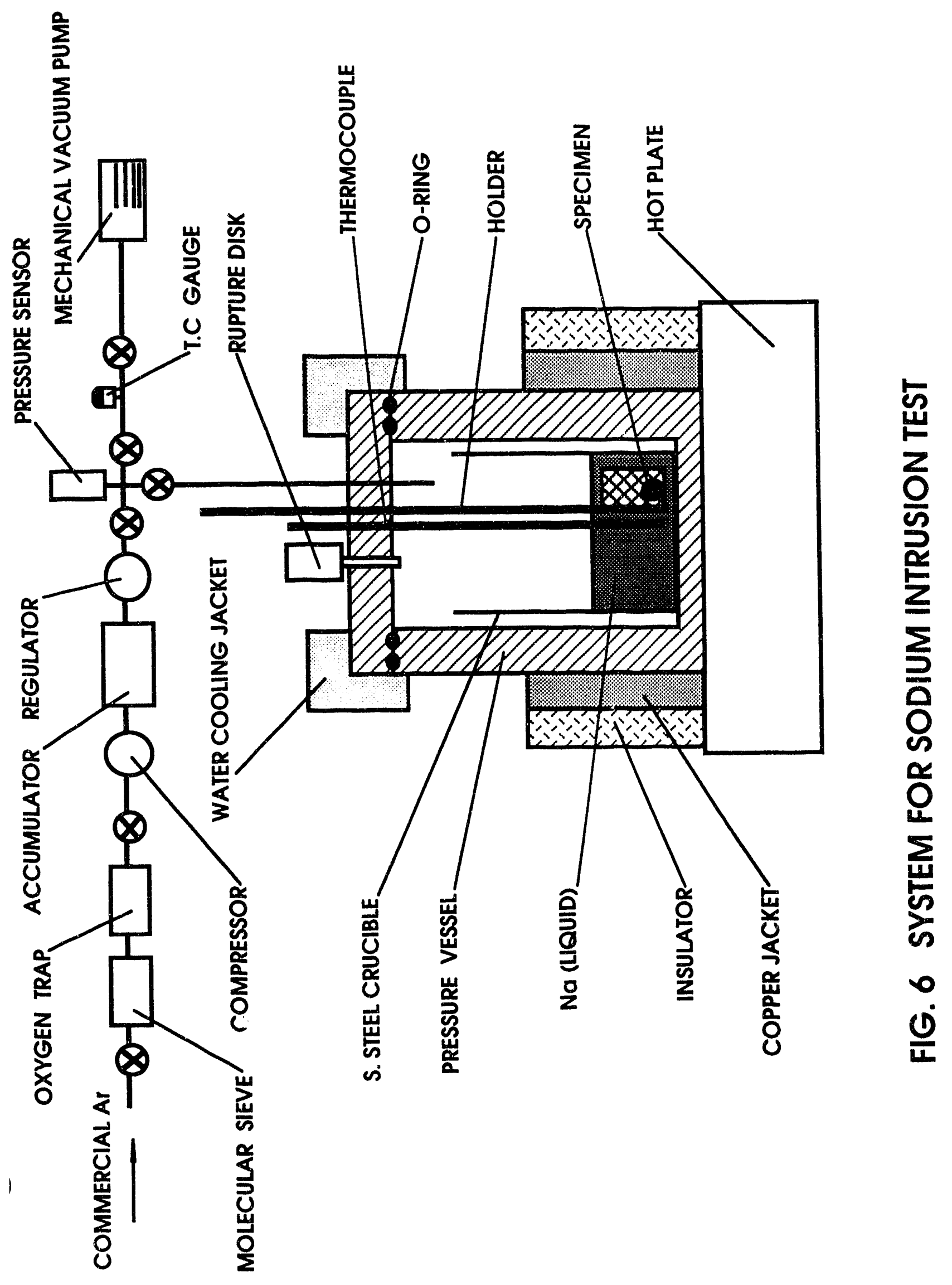




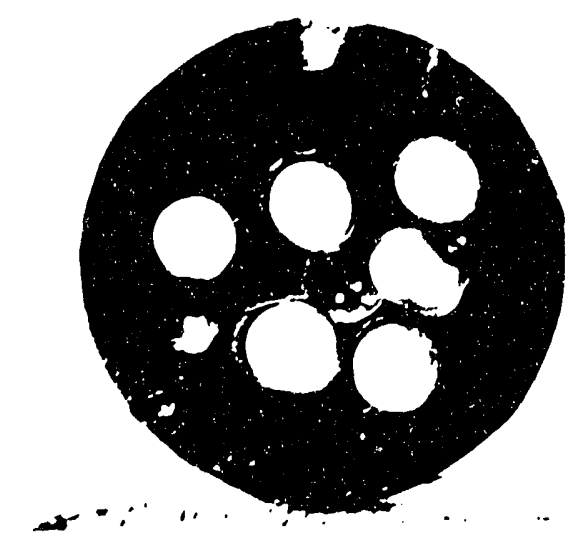

a) U-10Zr Alloy $(x 10)$

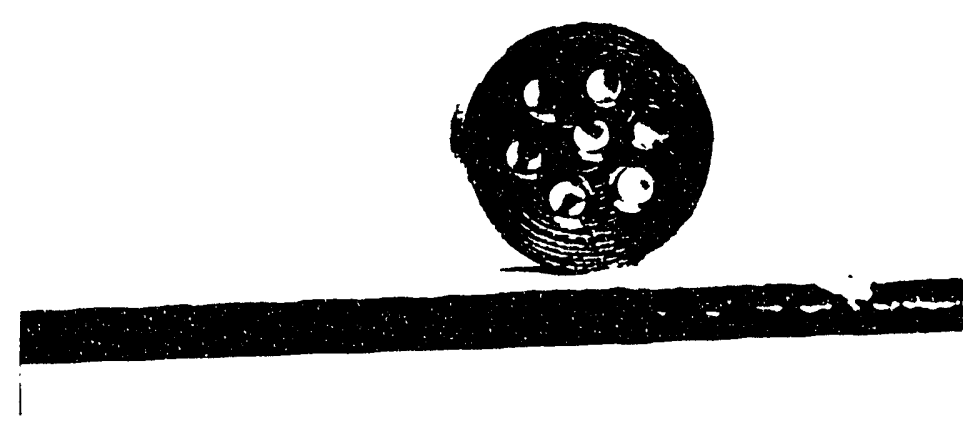

b) Brass (x5)

FIG.7 CROSS-SECTIONS OF SPECIMENS WITH DRILLED HOLES 


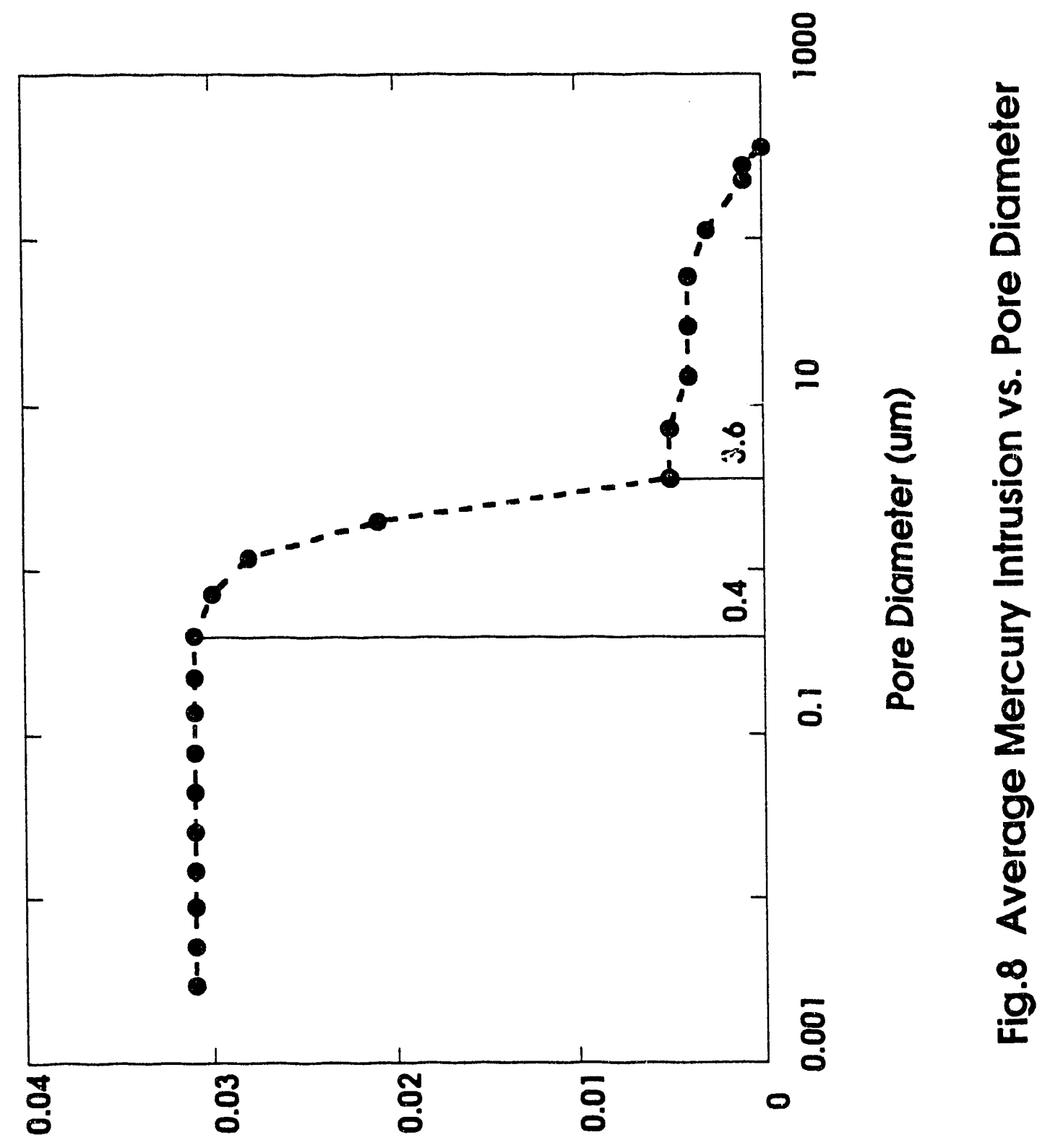

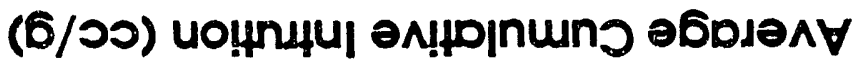




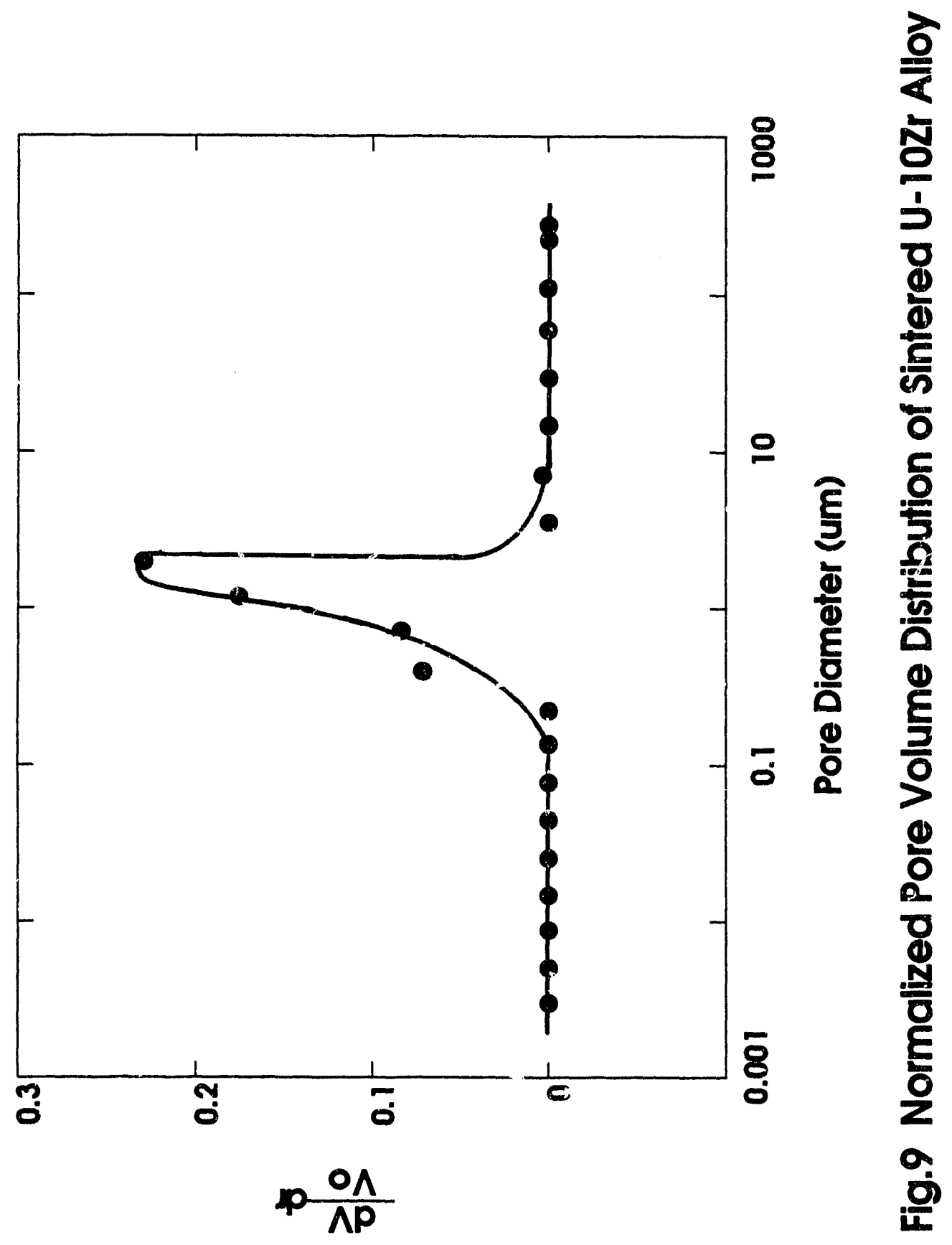




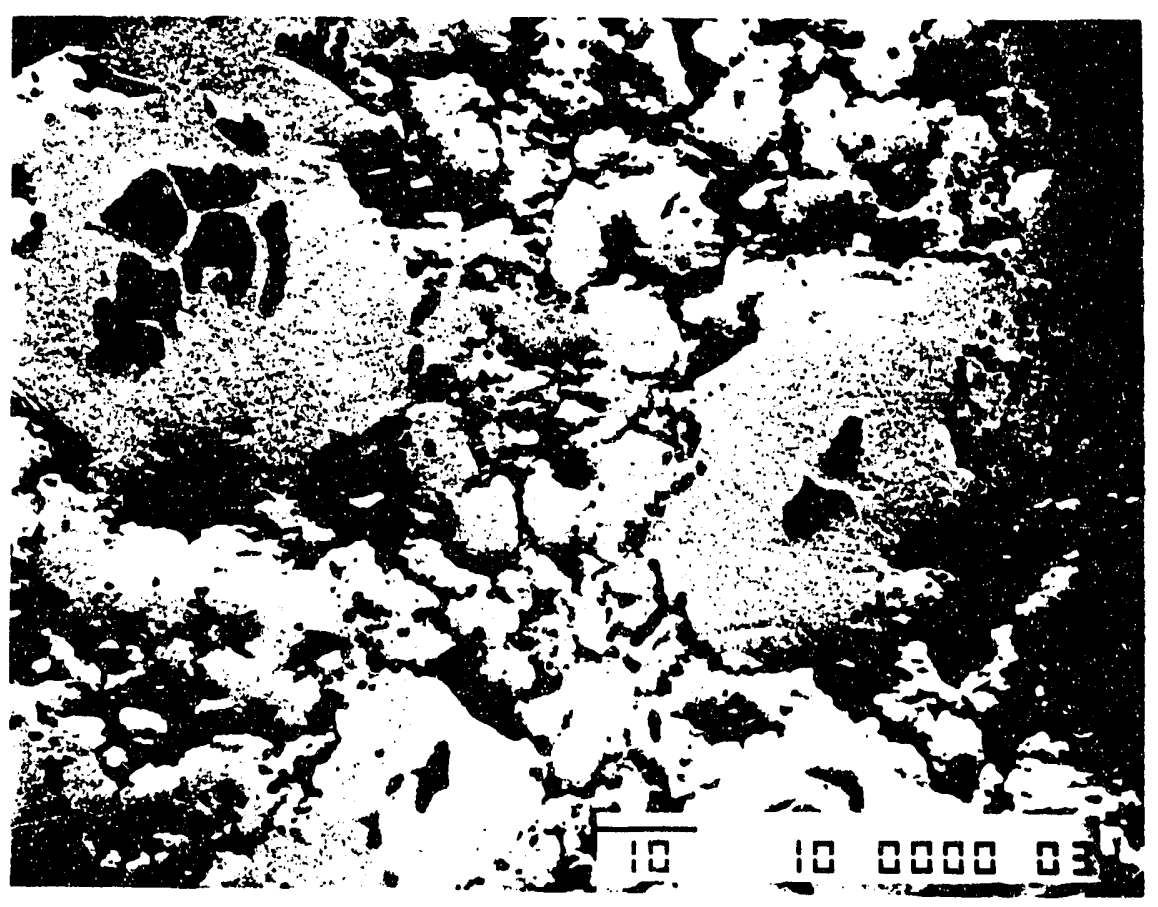

FIG.10 SEM MICROSCOPY OF SINTERED U-10Zr ALLOY 


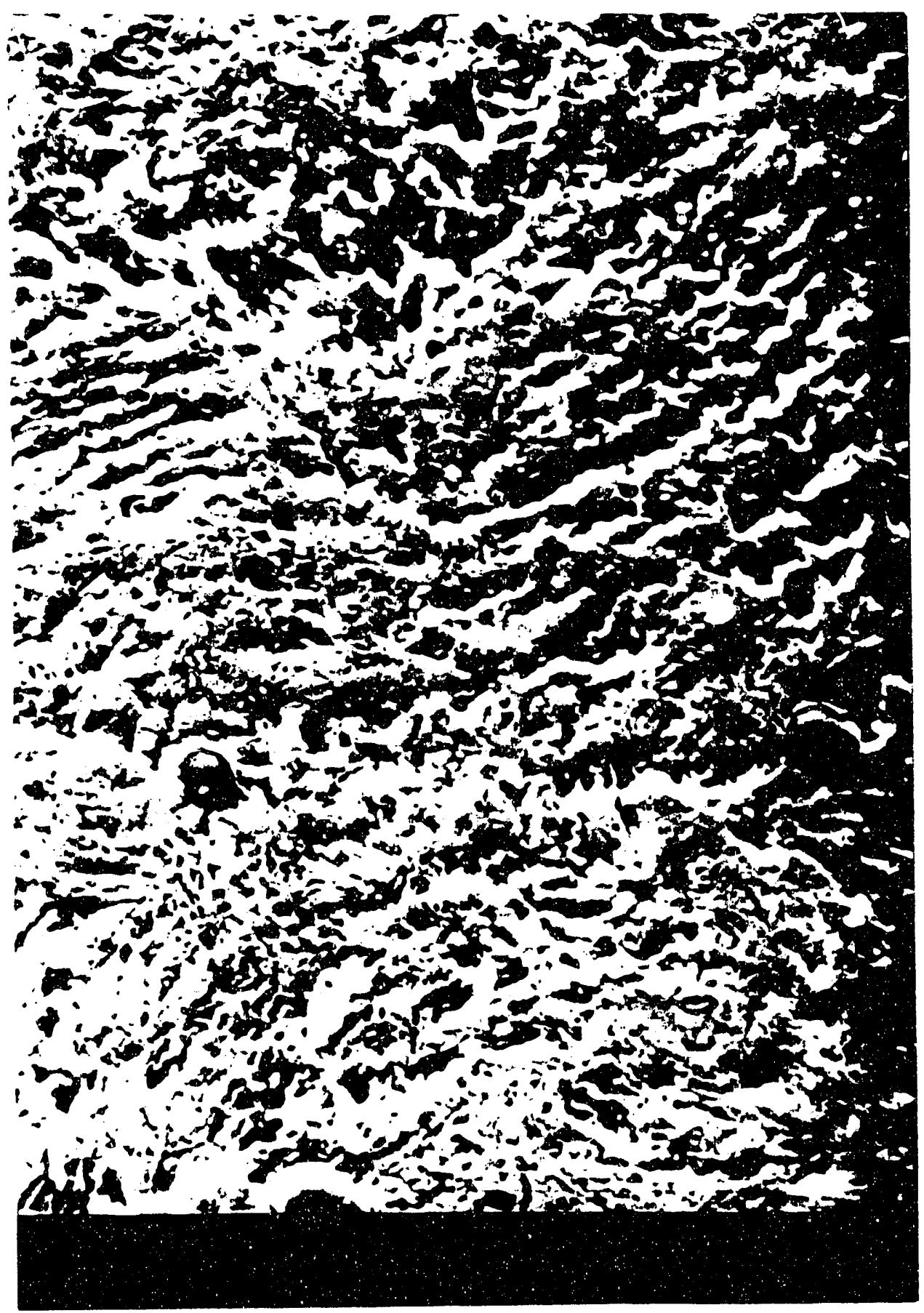

FIG.11 SEM MICROSCOPY OF AN IRRADIATED U-10Zr FUEL (Courtesy of Gerard Hofman, ANL) 


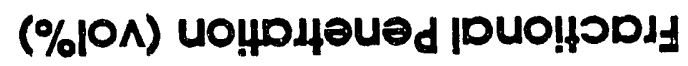

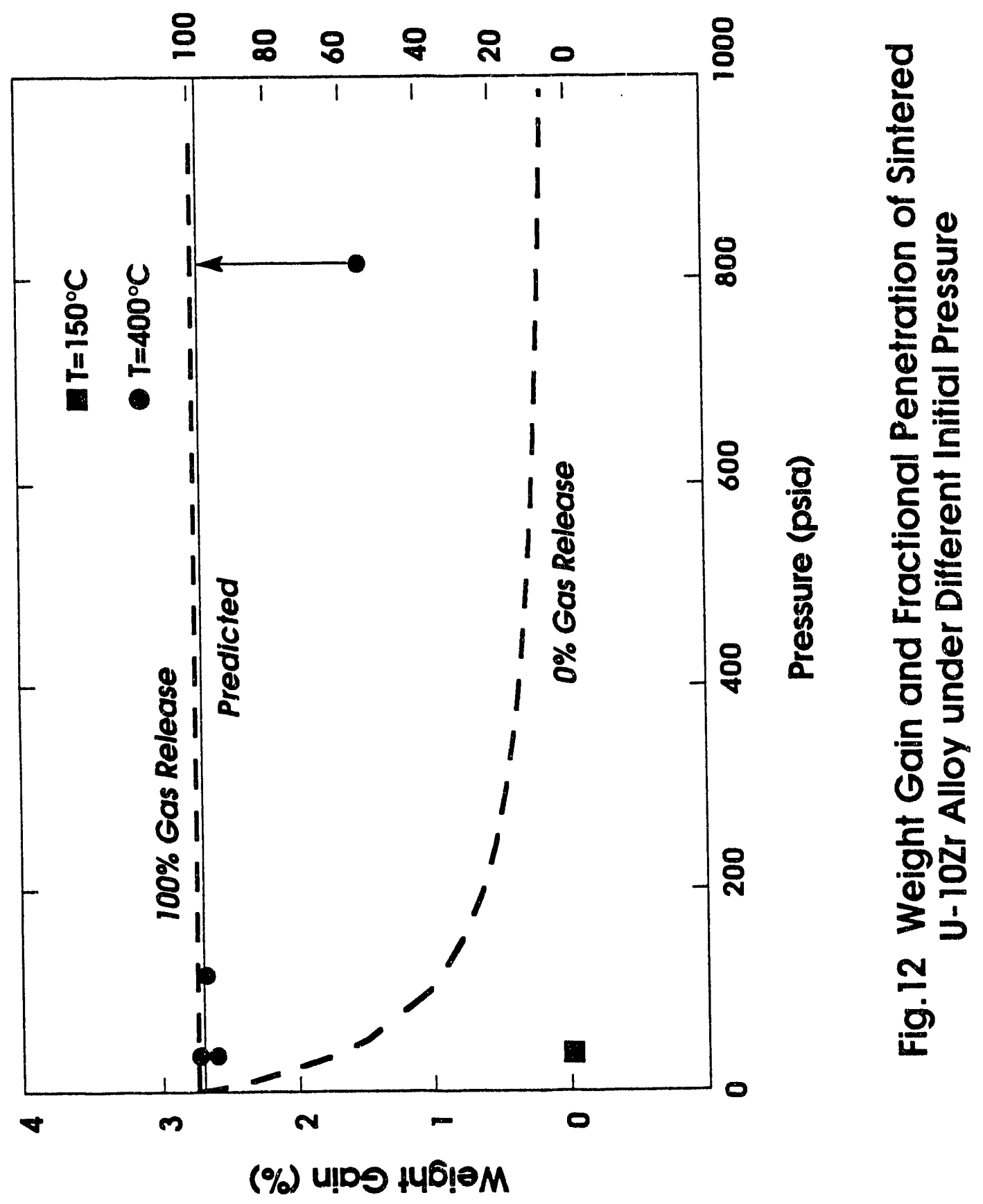




\section{APPENDIX D}

Interdiffusion Between U-Zr Fuel and Selected Fe-Ni-Cr Alloys 


\title{
Interdiffusion between U-Zr Fuel and Selected Fe-Ni-Cr Alloys
}

\author{
D. D. Keiser, Jr. and M. A. Dayananda \\ School of Materials Engineering \\ Purdue University, W. Lafayette, IN 47907
}

\begin{abstract}
As part of studies relevant to fuel-cladding compatibility in the Integral Fast Reactors, isothermal interdiffusion experiments were carried out at $700^{\circ} \mathrm{C}$ with solid-solid diffusion couples assembled with a U-23 at.\% $\mathrm{Zr}$ alloy fuel and a series of cladding alloys of selected compositions in the $\mathrm{Fe}-\mathrm{Ni}-\mathrm{Cr}$ system. Besides pure $\mathrm{Fe}$ and pure $\mathrm{Ni}$, the alloys included binary $\mathrm{Fe}-20.1 \mathrm{Cr}$, Ni-16.4 Cr, and Fe-10.1 Ni and a ternary Fe-16.4 Ni-9.4 Cr alloys (composition in at.\%). The diffusion structures developed in the various couples were examined metallographically and by SEM-EDS analysis. The development of diffusion layers and their variation with compositional changes of the cladding alloys are discussed in the light of phase diagrams, intermetallic formation, the relative diffusion behavior of the various elements and the experimental diffusion paths. From the composition profiles, average effective interdiffusion coefficients are determined for specific regions in the diffusion structures of selected diffusion couples. Intrinsic diffusion coefficients are also calculated at the composition of a marker plane in a $(\mathrm{U}, \mathrm{Zr}) \mathrm{Ni}_{2}$ phase layer.
\end{abstract}




\section{Introduction}

A new innovative nuclear reactor concept called the Integral Fast Reactor (IFR) which uses U-Pu-Zr metallic fuels with stainless steels as cladding alloys is being developed by Argonne National Laboratory [1]. The IFR exploits the good breeding performance, high burn-up potential, ease of fabrication, high thermal conductivity, and simple reprocessing characteristics of metallic fuels. At the reactor operating temperatures of $600^{\circ}$ to $650^{\circ} \mathrm{C}$, the metallic fuels have been shown to come into contact with the cladding [2]. This contact initiates interdiffusion between the fuel and the cladding and results in the development of diffusion structures that can adversely affect the structural integrity of the cladding alloy [3-8].

Early studies of fuel-cladding compatibility [9-12] with diffusion couples assembled with metal fuels and cladding alloys were unsatisfactory, as the couples suffered from poor bonding and oxide development. Such studies were carried out with cladding alloys such as stainless 304, 346, and Incoloy 800 and with U-5 wt.\% Fs and U-Pu-Fs fuels, where Fs represents fission product consisting of $2.4 \mathrm{Mo}, 1.9 \mathrm{Ru}, 0.3 \mathrm{Rh}, 0.2 \mathrm{Pd}, 0.1 \mathrm{Zr}, 0.01 \mathrm{Nb}$ (by wt.\%). Only limited diffusion studies have been reported for $\mathrm{U}-\mathrm{Pu}-\mathrm{Zr}$ alloys and cladding steels [8]. Hence, in order to assess the fuel-cladding compatibility for IFR fuels, it is essential to understand the relative interdiffusion behavior of the various elements in the fuel and cladding alloys and the type of intermetallic phases that can develop in fuel-cladding assemblies.

In this study, interdiffusion experiments were carried out at $700^{\circ} \mathrm{C}$ with a series of diffusion couples assembled with disks of a U-23 at.\% $\mathrm{Zr}$ alloy and disks of pure $\mathrm{Fe}$, pure $\mathrm{Ni}$, selected binary $\mathrm{Fe}-\mathrm{Ni}, \mathrm{Fe}-\mathrm{Cr}$, and $\mathrm{Ni}-\mathrm{Cr}$ alloys and an $\mathrm{Fe}-\mathrm{Ni}-\mathrm{Cr}$ ternary alloy. The binary U-23 at.\% $\mathrm{Zr}$ alloy corresponds to an actual fuel used in reactor and the compositions of the cladding alloys are based on those of the commercial stainless steels. Experimental diffusion structures and diffusion paths for all diffusion couples are presented and discussed in the light of the relative diffusion behavior of the various elements and the intermetallic phases formed in the couples. From the composition profiles, average effective interdiffusion coefficients for the 
For the description and representation of diffusion structure, experimental diffusion paths were generated from concentration profiles of $\mathrm{Fe}, \mathrm{Ni}, \mathrm{Cr}, \mathrm{U}$, and $\mathrm{Zr}$ as functions of distance for various diffusion couples. In multiphase regions only approximate average compositions could be determined. The diffusion path corresponds to the sequence of compositions developed within the diffusion zone of a solid-solid diffusion couple during isothermal diffusion. It is S-shaped when the compositions are plotted on a composition triangle and is independent of time since all concentration variables are considered to be functions of the Boltzmann parameter, $\lambda$, given by $x / \sqrt{t}$. For diffusion paths of couples with more than 3 components, the sum of the concentrations of $\mathrm{Fe}, \mathrm{Ni}$ and $\mathrm{Cr}$ is taken as one concentration variable. The diffusion path is especially useful for describing the development of various diffusion layers in the context of phase equilibria and isotherms.

\subsubsection{Couples $F(U-23 \mathrm{Zr})$ vs. Ni and $F(U-23 \mathrm{Zr})$ vs. Ni-16.4 Cr}

Diffusion structures developed for the $\mathrm{F}$ vs. $\mathrm{Ni}$ and $\mathrm{F}$ vs. $\mathrm{Ni}-16.4 \mathrm{Cr}$ couples are presented in Figures 1 and 2, respectively. The phases identified in the structures are similar to those expected on the basis of the binary phase diagrams. As can be seen in Fig. 1, the F vs, Ni couple exhibits single-phase layers of $\mathrm{UNi}_{5}, \mathrm{UNi}_{3-4}, \mathrm{U}_{5} \mathrm{Ni}_{7}$, and $(\mathrm{U}, \mathrm{Zr}) \mathrm{Ni}_{2}$. Adjacent to the $(\mathrm{U}, \mathrm{Zr}) \mathrm{Ni}_{2}$ are observed two contiguous two-phase layers; one contains $\mathrm{U}_{6} \mathrm{Ni}$ and $(\mathrm{Zr}, \mathrm{U})_{7} \mathrm{Ni}_{10}$ phases and the other $\mathrm{U}$ and $(\mathrm{Zr}, \mathrm{U})_{2} \mathrm{Ni}$ phases. The designations of the individual phases are essentially based on the approximate ratios of concentrations of the individual elements. The diffusion structure for the $\mathrm{F}$ vs. Ni-16.4 $\mathrm{Cr}$ couple shown in Fig. 2 differs slightly from that for the $\mathrm{F}$ vs. $\mathrm{Ni}$, as an additional $\left(\mathrm{Cr}+\mathrm{UNi}_{5}\right)$ two-phase layer appears on the alloy side of the diffusion structure.

The concentration profiles for the $\mathrm{F}$ vs. Ni-16.4 $\mathrm{Cr}$ couple are presented in Fig. 3 where the solid vertical lines represent boundaries between various phase layers or regions. The layers numbered 1-6 correspond to a $\left[\mathrm{Cr}+\mathrm{UNi}_{5}\right]$ two-phase layer, $\mathrm{UNi}_{5}, \mathrm{UNi}_{3-4}, \mathrm{U}_{5} \mathrm{Ni}_{7}$, and $(\mathrm{U}, \mathrm{Zr}) \mathrm{Ni}_{2}$ single-phase layers and a two-phase $\left[(\mathrm{U}, \mathrm{Zr}) \mathrm{Ni}_{2}+\mathrm{U}_{6} \mathrm{Ni}\right]$ layer, respectively. Most 
individual components have been calculated over selected regions of diffusion couples. Intrinsic diffusion coefficients have also been calculated for selected intermetallic phases.

\section{Experimental}

A series of diffusion couples was assembled with a U-23 at.\% $\mathrm{Zr}$ alloy fuel (designated F) bonded to pure $\mathrm{Fe}$, pure $\mathrm{Ni}$, Ni-16.4 Cr, Fe-10.1 Ni, Fe-20.1 Cr, and Fe-16.4 Ni-9.4 Cr alloys (compositions in at.\%). The binary and ternary alloys of the $\mathrm{Fe}-\mathrm{Ni}-\mathrm{Cr}$ system were prepared from pure $\mathrm{Fe}, \mathrm{Ni}$, and $\mathrm{Cr}$ by vacuum induction melting [13]. Charges were melted in alumina crucibles under argon atmosphere, and subsequently drawn up fused silica draw tubes, $10 \mathrm{~mm}$ in diameter. A steel chill was positioned inside the draw tube to act as the end of the mold. The alloy rods were sealed in quartz tubes under vacuum and then annealed at $1150^{\circ} \mathrm{C}$ for 7 days for homogenization. The U-23 at.\% Zr was prepared by Argonne National Laboratory with depleted $U$ by using conventional induction melting methods and casting into rods, $5 \mathrm{~mm}$ in diameter. A fuel rod furnished by $\mathrm{ANL}$ was homogenized at $900^{\circ} \mathrm{C}$ for 4 days.

Both fuel and cladding alloys were cut into slices about $0.5 \mathrm{~cm}$ thick. Their surfaces were metallographically polished through 0.05 micron alumina. During polishing, thickness measurements were made to ensure that both faces of the disks were flat and parallel to each other. Diffusion couples were assembled by sandwiching a disk of the U-23 at.\% Zr alloy between disks of two selected cladding alloys in a low-expansion Kovar steel jig, which consisted of two end plates, $1 / 8$ " thick $\times 7 / 8$ " in diameter, and three threaded Kovar steel rods. Kovar steel was chosen for the jig due to its low coefficient of thermal expansion $\left(5.27 \times 10^{-6}\right.$ in/in ${ }^{\circ} \mathrm{C}$ ). The assembled couples were placed in a quartz tube, 9 " long and $1 "$ in diameter. Each quartz tube was flushed several times with hydrogen, evacuated to a pressure of less than $10^{-5}$ torr and sealed to form a capsule about $6 "$ long.

All diffusion couples were annealed for 4 days at $700^{\circ} \mathrm{C}$ in a Lindberg heavy-duty threezone tube furnace. The temperature gradient over the length of the capsule was less than $1^{\circ} \mathrm{C}$ 
and the temperature controlled to $\pm 0.5^{\circ} \mathrm{C}$. After annealing, the capsules were allowed to cool in air outside the furnace.

The diffused couples were removed from the quartz capsules and mounted in a coldmount self-setting resin. Mounted couples were then cut with an Isomet cut-off wheel to expose sections parallel to the direction of diffusion. The exposed cross-section of each couple was metallographically polished through 0.05 micron alumina. The couples were analyzed by point-to-point counting techniques for concentration profiles and phase compositions with a JEOL 35CF scanning electron microscope equipped with a Tracor Northern Series II energy dispersive $\mathrm{X}$-ray analyzer. Intensities of $\mathrm{K}_{\alpha} \mathrm{X}$-radiations of $\mathrm{Fe}, \mathrm{Ni}$, and $\mathrm{Cr}$ identified at the energies of $6.403 \mathrm{KeV}, 7.477 \mathrm{KeV}$, and $5.414 \mathrm{KeV}$, respectively, of $\mathrm{Zr} \mathrm{L}_{\alpha} \mathrm{X}$-radiation at $2.042 \mathrm{KeV}$ and of $\mathrm{U} \mathrm{M}_{\alpha} \mathrm{X}$-radiation at $3.171 \mathrm{KeV}$ were collected, stored on floppy discs and converted into compositions with the aid of elemental standards and a ZAF correction program. Secondary electron micrographs were taken of diffusion structures developed in the various couples.

\section{Results}

\subsection{Diffusion structures and diffusion paths}

On the basis of the U-Ni, U-Fe, $\mathrm{Zr}-\mathrm{Fe}$, and $\mathrm{Zr}-\mathrm{Ni}$ phase diagrams [14], several intermetallic phases can form between $\mathrm{U}$ and $\mathrm{Fe}, \mathrm{U}$ and $\mathrm{Ni}, \mathrm{Zr}$ and $\mathrm{Fe}$, and $\mathrm{Zr}$ and $\mathrm{Ni}$, and these are listed in Table 1. In contrast to $\mathrm{Ni}$ and $\mathrm{Fe}, \mathrm{Cr}$ has some solubility in $\mathrm{U}$ (up to 4 at.\%) and does not form any intermetallic phase with $U$; only a single intermetallic compound is reported between $\mathrm{Zr}$ and $\mathrm{Cr}$. For the $\mathrm{U}-\mathrm{Zr}$ binary system, the intermetallic phase of interest is the $\delta$ phase, which appears as a precipitate in the as-received U-23 at.\% $\mathrm{Zr}$ fuel. Intermetallic designations for specific phases in the diffusion structure are based on the ratio of concentrations of $(\mathrm{U}+\mathrm{Zr})$ to that of $(\mathrm{Fe}+\mathrm{Ni}+\mathrm{Cr})$. The phases analyzed in the diffusion structures for each couple are presented in Table 2. 
single-phase layers are only a few microns wide, and hence concentration variations in such layers could not be determined. In layers 5 and 6 where $(\mathrm{U}, \mathrm{Zr}) \mathrm{Ni}_{2}$ phase appears, $\mathrm{U}$ manifests up-hill diffusion up its own concentration gradient, while $\mathrm{Zr}$ diffuses down its own concentration gradient. This observation implies that the activity of $\mathrm{U}$ is higher at higher $\mathrm{Zr}$ concentrations in the $(\mathrm{U}, \mathrm{Zr}) \mathrm{Ni}_{2}$ layer and that $\mathrm{Zr}$ can increase the activity of $\mathrm{U}$. This expectation agrees with the work of Pelton [15] who reported a positive deviation from Raoult's law for the U-Zr system.

Experimental diffusion paths drawn on the basis of concentration profiles for the $\mathrm{F}$ vs. $\mathrm{Ni}$ and F vs. Ni-16.4 Cr couples are presented in Fig. 4(a) and 4(b), respectively. The path segments crossing two-phase regions are represented by bold dashed lines, while path segments in single-phase regions are identified by solid lines. Thin dashed lines indicate schematic tielines for two-phase regions, and shaded areas represent approximate ranges of composition for single-phase regions. In Fig. 4(a) the path segment a-b passes through $\mathrm{UNi}_{5}, \mathrm{UNi}_{3-4}$, and $\mathrm{U}_{5} \mathrm{Ni}_{7}$ single-phase layers observed on the $\mathrm{Ni}$-side of the diffusion structure for the $\mathrm{F}$ vs. $\mathrm{Ni}$ couple. Segment c-d represents the variation in compositions for the $(\mathrm{U}, \mathrm{Zr}) \mathrm{Ni}_{2}$ single-phase layer. Path segment d-e covers the two-phase regions: $\left[\mathrm{U}_{6} \mathrm{Ni}+(\mathrm{U}, \mathrm{Zr}) \mathrm{Ni}_{2}\right]$, $\left[\mathrm{U}_{6} \mathrm{Ni}+(\mathrm{Zr}, \mathrm{U})_{7} \mathrm{Ni}_{10}\right],\left[\mathrm{U}+(\mathrm{Zr}, \mathrm{U})_{2} \mathrm{Ni}\right]$, and $[\mathrm{U}+\delta]$. The diffusion path in these regions crosses schematic tie-lines linking the approximate precipitate and matrix compositions.

The diffusion path presented in $4(\mathrm{~b})$ for the $\mathrm{F}$ vs. Ni-16.4 $\mathrm{Cr}$ couple is constructed on the composition triangle with the concentrations of $(\mathrm{Ni}+\mathrm{Cr})$ taken together as one variable. Thus, at any point within the composition triangle, the sum of the concentrations (atom fractions) of all the elements in the cladding alloy when added to the concentrations of $U$ and $Z \mathbf{r}$ is equal to one. Diffusion paths for couples involving more than 3 components can be still drawn on triangles and be compared for various couples. This procedure for the representation of diffusion paths is employed for all couples in this study. The path segment $a-b$ includes the two-phase layer $\left(\mathrm{Cr}+\mathrm{UNi}_{5}\right)$. This layer is a special feature which differentiates this couple from the F vs. Ni couple. This layer is denoted as layer 1 in Figs. 2(b) and 3. Except for the 
appearance of layer 1 , the concentration profiles, diffusion structures, and diffusion paths for the couples $\mathrm{F}$ vs. $\mathrm{Ni}$ and $\mathrm{F}$ vs. $\mathrm{Ni}-16.4 \mathrm{Cr}$ are quite similar.

\subsubsection{Couple $F(U-23 \mathrm{Zr})$ vs. Fe and $F(U-23 \mathrm{Zr})$ vs. $\mathrm{Fe}-20.1 \mathrm{Cr}$}

The diffusion structure for the couple $\mathrm{F}$ vs. Fe is presented in Fig. 5. The interdiffusion between the fuel alloy and $\mathrm{Fe}$ is quite limited. However, a $\mathrm{Zr}$ layer was identified along the $\mathrm{Fe} /$ fuel interface. This reflects the decomposition of the $\delta$ precipitates which have $\mathrm{Zr}$ concentrations in the range 66-78 at.\% and exist as part of the two-phase structure of the $\mathrm{U}-23$ at. $\% \mathrm{Zr}$ alloy. Adjacent to the $\mathrm{Zr}$ layer, there appears a region free of $\delta$ precipitates. Little Fe penetration into the fuel is observed and the overall size of the diffusion structure is small $(\approx 10-15 \mu \mathrm{m})$.

The diffusion structure for the F vs. Fe-20.1 $\mathrm{Cr}$ couple is presented in Fig. 6(a). It is $30 \mu \mathrm{m}$ in width which is slightly larger than the diffusion structure exhibited for the $\mathrm{F}$ vs. Fe couple. However, it is small compared to the width of diffusion structures developed for couples with Ni-containing alloys. The diffusion structure consists of a $\mathrm{U}(\mathrm{Fe}, \mathrm{Cr})_{2}$ phase layer, a $\mathrm{Zr}$ layer, and a two-phase region with $\mathrm{U}$ matrix and $\mathrm{Zr}$ precipitates. The concentration profiles for the couple are presented in Fig. 6(b).

In Fig. 4(c) is presented the experimental diffusion path for the $\mathrm{F}$ vs. Fe-20.1 $\mathrm{Cr}$ couple. The path bends toward the $\mathrm{Zr}$ corner of the ternary isotherm and differs from paths for the Ni-containing couples. Path segment a-c covers the single-phase layers of $\mathrm{U}(\mathrm{Fe}, \mathrm{Cr})_{2}$ and $\mathrm{Zr}(>97 \%)$, and segment $c-d$ covers the two-phase regions, $[\mathrm{U}+\mathrm{Zr}]$ and $[\mathrm{U}+\delta]$.

\subsubsection{Couples $F(U-23 \mathrm{Zr})$ vs. Fe-10.1 Ni and $F(U-23 \mathrm{Zr})$ vs. Fe-16.4 Ni-9.4 Cr}

The diffusion structures for the two couples, $\mathrm{F}$ vs. Fe-10.1 Ni and F vs. Fe-16.4 Ni-9.4 Cr, are presented in Fig. 7 and Fig. 8, respectively. The diffusion structure of F vs. Fe-10.1 Ni 
couple exhibits layers of $\mathrm{U}(\mathrm{Fe}, \mathrm{Ni})_{2}$ and $(\mathrm{Zr}, \mathrm{U})(\mathrm{Fe}, \mathrm{Ni})_{2}$ phases and of two-phase regions, one with $\mathrm{U}_{6}(\mathrm{Fe}, \mathrm{Ni})$ matrix and $\left(\mathrm{Zr}, \mathrm{U}_{2}(\mathrm{Fe}, \mathrm{Ni})\right.$ precipitates and the other with $\mathrm{U}$ matrix and $(\mathrm{Zr}, \mathrm{U})_{2}(\mathrm{Fe}, \mathrm{Ni})$ precipitates. The overall width of the diffusion structure is around $70 \mu \mathrm{m}$.

The $\mathrm{F}$ vs. Fe-16.4 Ni-9.4 $\mathrm{Cr}$ couple develops single-phase layers of $\mathrm{U}(\mathrm{Fe}, \mathrm{Ni}, \mathrm{Cr})_{2}$ and $(\mathrm{Zr}, \mathrm{U})(\mathrm{Fe}, \mathrm{Ni}, \mathrm{Cr})_{2}$ along with two-phase regions, one containing $\mathrm{U}_{6}(\mathrm{Fe}, \mathrm{Ni})$ matrix and $(\mathrm{Zr}, \mathrm{U})_{2}(\mathrm{Fe}, \mathrm{Ni})$ precipitates and the other $\mathrm{U}$ matrix with $(\mathrm{Zr}, \mathrm{U})_{2}(\mathrm{Fe}, \mathrm{Ni})$ precipitates. $\mathrm{A}(\mathrm{U}, \mathrm{Zr})_{9}(\mathrm{Fe}, \mathrm{Ni})$ phase appears on the fuel side of the diffusion structure. The widths of the diffusion zone of $\mathrm{Fe}$ and $\mathrm{Ni}$ are approximately 80 to $90 \mu \mathrm{m}$, while that of $\mathrm{Cr}$ is approximately $30 \mu \mathrm{m}$ toward the fuel.

An experimental diffusion path for couple F vs. Fe-10.1 Ni is presented in Fig. 9(a). Path segments b-c and d-e represent the single-phase layers of $U(F e, N i)_{2}$ and $(\mathrm{Zr}, \mathrm{U})(\mathrm{Fe}, \mathrm{Ni})_{2}$, respectively. Segment c-d represents the two-phase region $\left[\mathrm{U}(\mathrm{Fe}, \mathrm{Ni})_{2}+(\mathrm{Zr}, \mathrm{U})(\mathrm{Fe}, \mathrm{Ni})_{2}\right]$, while e-f covers the adjacent diffusion layers of $\left[\mathrm{U}_{6}(\mathrm{Fe}, \mathrm{Ni})+(\mathrm{Zr}, \mathrm{U})(\mathrm{Fe}, \mathrm{Ni})_{2}\right],\left[\mathrm{U}_{6}(\mathrm{Fe}, \mathrm{Ni})+\right.$ $\left.(\mathrm{Zr}, \mathrm{U})_{2}(\mathrm{Fe}, \mathrm{Ni})\right]$, and $\left[\mathrm{U}+(\mathrm{Zr}, \mathrm{U})_{2}(\mathrm{Fe}, \mathrm{Ni})\right]$.

The experimental diffusion path for the couple $\mathrm{F}$ vs. Fe-16.4 Ni-9.4 $\mathrm{Cr}$ is presented on a composition triangle in Fig. 9(b). The diffusion path segment a-b cuts across tie-lines through a two-phase region between the $\mathrm{U}(\mathrm{Fe}, \mathrm{Ni}, \mathrm{Cr})_{2}$ phase and the ternary terminal alloy. Segments b-c and d-e represent the single-phase layers of $\mathrm{U}(\mathrm{Fe}, \mathrm{Ni}, \mathrm{Cr})_{2}$ and $(\mathrm{Zr}, \mathrm{U})(\mathrm{Fe}, \mathrm{Ni}, \mathrm{Cr})_{2}$, respectively. Segment c-d represents the two-phase layer, $\left[\mathrm{U}(\mathrm{Fe}, \mathrm{Ni}, \mathrm{Cr})_{2}+(\mathrm{Zr}, \mathrm{U})(\mathrm{Fe}, \mathrm{Ni}, \mathrm{Cr})_{2}\right]$, and segment e-f cuts across two-phase regions of $\left[\mathrm{U}_{6}(\mathrm{Fe}, \mathrm{Ni})+(\mathrm{Zr}, \mathrm{U})(\mathrm{Fe}, \mathrm{Ni}, \mathrm{Cr})_{2}\right]$ and $\left[\mathrm{U}_{6}(\mathrm{Fe}, \mathrm{Ni})+(\mathrm{Zr}, \mathrm{U})_{2}(\mathrm{Fe}, \mathrm{Ni}, \mathrm{Cr})\right]$. The appearance of a three-phase region in this couple requires the diffusion path to pass through a three-phase triangle on the composition triangle, and this corresponds to path segment $\mathrm{f}-\mathrm{g}$. $(\mathrm{U}, \mathrm{Zr})_{9}(\mathrm{Fe}, \mathrm{Ni}), \mathrm{U}$ and $\delta$ are all observed in this three-phase region. 


\section{Interdiffusion}

Dayananda and Behnke [16] have presented an approach whereby effective interdiffusion coefficients and penetration depths for the individual components can be determined from the concentration profiles of a multicomponent diffusion couple. From this analysis, an average effective interdiffusion coefficient can be determined for each component over a range of concentrations selected in the diffusion zone. This analysis has been applied to the F vs. Ni16.4 $\mathrm{Cr}$ and $\mathrm{F}$ vs. Fe-20.1 Cr diffusion couples.

\subsubsection{Effective interdiffusion coefficients and penetration depths}

The Onsager's formalism of Fick's law for interdiffusion in an n-component system is expressed by [17]:

$$
\tilde{\mathrm{J}}=-\sum_{\mathrm{j}=1}^{\mathrm{n}-1} \tilde{\mathrm{D}}_{\mathrm{ij}}^{\mathrm{n}} \frac{\partial \mathrm{C}_{\mathrm{j}}}{\partial \mathrm{x}}
$$

where $\tilde{\mathrm{J}}_{\mathrm{i}}$ is the interdiffusion flux of component $\mathrm{i}$ on a laboratory-fixed frame and $\partial \mathrm{C}_{\mathrm{j}} / \partial \mathrm{x}$ is the concentration gradient of component $\mathrm{j}$. The $(n-1)^{2}$ interdiffusion coefficients, $\tilde{\mathrm{D}}_{\mathrm{ij}}^{\mathrm{n}}$, are defined as functions of composition, and the superscript $\mathrm{n}$ refers to the component taken as the dependent concentration variable. To determine $\tilde{\mathrm{D}}_{\mathrm{ij}}^{\mathrm{n}}$ 's from Eq. (1), it is necessary to employ independent diffusion couples with intersecting diffusion paths $[18,19]$ which is very difficult for systems with $n \geq 4$.

It is possible to calculate $\tilde{\mathrm{J}}_{\mathrm{i}}$ as a function of distance in a solid-solid diffusion couple directly from the concentration profiles without the need for the interdiffusion coefficients $[20,21]$. At time $t, \tilde{\mathrm{J}}_{\mathrm{i}}$ at any section $\mathrm{x}$ can be expressed by:

$$
\tilde{J}_{i}(x)=\frac{1}{2 t} \int_{C_{i}( \pm \infty)}^{C_{i}(x)}\left(x-x_{0}\right) d C_{i} \quad(i=1,2, \ldots, n)
$$

where $C_{i}(x)$ refers to the concentration of component $i$ at any position $x$ in the diffusion zone, 
and $C_{i}( \pm \infty)$ refers to the concentrations of component $i$ in the terminal alloys of the couple. $x_{0}$ refers to the Matano plane.

Integration of $\tilde{\mathrm{J}}_{\mathrm{i}}$ over $\mathrm{x}$ from $-\infty$ to $\mathrm{x}_{\mathrm{o}}$ yields the relation:

$$
\int_{-\infty}^{x_{0}} \tilde{J}_{i} d x=\frac{1}{2 t} \int_{C_{i}(-\infty)}^{C_{i}\left(x_{0}\right)}\left(x-x_{0}\right)^{2} d C_{i}
$$

where $C_{i}\left(x_{0}\right)$ refers to the concentration at $x_{0}$. Eq. (3) can be used to derive expressions for average effective interdiffusion coefficients for is dividual components over selected ranges of concentrations. $\tilde{\mathrm{J}}_{\mathfrak{i}}$ in Eq. (1) can be alternatively written as [16]:

$$
\tilde{\mathrm{J}}_{\mathrm{i}}=-\tilde{\mathrm{D}}_{\mathrm{i}}^{\text {eff }} \frac{\partial \mathrm{C}_{\mathrm{i}}}{\partial \mathrm{x}}
$$

where

$$
\tilde{D}_{i}^{\text {eff }}=\tilde{D}_{i i}^{n}+\frac{\sum_{j \neq i}^{n-1} \tilde{D}_{i j}^{n} \frac{\partial C_{j}}{\partial x}}{\frac{\partial C_{i}}{\partial x}} \quad(j \neq i)
$$

The second term containing the cross interdiffusion coefficients in Eq. (5) accounts for the diffusional interactions among the diffusing species. Substitution of Eq. (4) in Eq. (3) yields:

$$
\int_{C_{i}(-\infty)}^{C_{i}\left(x_{0}\right)} \tilde{D}_{i}^{\text {eff }} d C_{i}=\frac{1}{2 t} \int_{C_{i}(-\infty)}^{C_{i}\left(x_{0}\right)}\left(x-x_{0}\right)^{2} d C_{i}
$$

or

$$
\tilde{D}_{i_{,} L}^{\text {eff }}=\frac{\int_{i}^{C_{i}\left(x_{0}\right)}\left(x-x_{0}\right)^{2} d C_{i}}{2 t\left[C_{i}\left(x_{0}\right)-C_{i}(-\infty)\right]}
$$

where $\tilde{D}_{i, L}^{\text {eff }}$ is the average effective interdiffusion coefficient for component 1 over the concentration range $C_{i}(-\infty)$ to $C_{i}\left(x_{0}\right)$ on the left-hand side of she Matano plane. Similarly, an average effective interdiffusion coefficient $\tilde{D}_{i, R}^{\text {eff }}$ for component $i$ can be determined over the 
concentration range $C_{i}(+\infty)$ to $C_{i}\left(x_{0}\right)$ on the right-hand side of the Matano plane.

Root-mean-square (r.m.s.) penetration depths can be determined for component $i$ on either side of the Matano plane. The r.m.s. penetration depth $x_{i, L}$ to the left of the Matano plane can be calculated from [16]:

$$
x_{i, L}=\sqrt{2 \tilde{D}_{i, L}^{\text {eff }} t}
$$

A similar relation may ive employed to calculate $x_{i, R}$ and is given by

$$
x_{i, R}=\sqrt{2 \tilde{D}_{i, R}^{\text {eff }} t}
$$

The concentration profiles for the couples $r$ vs. $\mathrm{Ni}-16.4 \mathrm{Cr}$ and $\mathrm{F}$ vs. Fe-20.1 $\mathrm{Cr}$ were analyzed for average effective interdiffusion coefficients. For these couples, the location $\mathrm{x}_{0}$ of the Matano plane could be determined by performing a mass balance for $\mathrm{Cr}$ from the concentration profiles. The location of $x_{0}$ has been identified on the concentration profiles for the $\mathrm{F}$ vs. Ni-16.4 $\mathrm{Cr}$ and $\mathrm{F}$ vs. Fe-20.1 $\mathrm{Cr}$ couples shown in Figs. 3 and 6(b).

Equations (7) and (8) were employed to calculate the average effective interdiffusion coefficients and the effective penetration depths for the components for couples, F vs. $\mathrm{Ni}-16.4 \mathrm{Cr}$ and $\mathrm{F}$ vs. Fe-20.1 Cr. For each of the couples, the average effective interdiffusi coefficients, $\tilde{D}_{i, L}^{\text {eff }}$, over the concentration ranges of each component $i$ on the cladding side of the Matano plane were calculated on the basis of Eq. (7); these are reported in Table 3. Effective penetration depths for the components calculated from Eq. (8) are also included in Table 3.

\subsection{Intrinsic Diffusion}

Intrinsic diffusion fluxes, $\mathrm{J}_{\mathrm{i}}$, refer to atomic migration relative to the lattice-fixed or Kirkendall frame of reference. For component $i$ in an n-component system, $\mathrm{J}_{\mathrm{i}}$ is expressed by 


$$
\mathrm{J}_{\mathrm{i}}=-\sum_{\mathrm{j}=1}^{\mathrm{n}-1} \mathrm{D}_{\mathrm{ij}}^{\mathrm{n}} \frac{\partial \mathrm{C}_{\mathrm{j}}}{\partial \mathrm{x}} \quad(\mathrm{i}=1,2, \ldots, \mathrm{n})
$$

where $D_{i j}^{n}$ 's are the intrinsic diffusion coefficients.

From couples with inert markers, intrinsic diffusion coefficients can be determined at the marker plane from appropriate areas under the concentration profiles in binary alloys [22] and multicomponent alloys [23]. The cumulative intrinsic flux, $A_{i}$, of component i past a marker plane moving parabolically with time at a constant composition in a ternary couple is obtained by integrating Eq. (10) over t; thus,

$$
\begin{gathered}
A_{i}=\int_{0}^{t} J_{i} d t=-\int_{0}^{t} \sum_{j=1}^{2} D_{i j}^{3}\left[\frac{\partial C_{j}}{\partial x}\right] d t \\
A_{i}=-2 t\left[D_{11}^{3} \frac{\partial C_{1}}{\partial x}+D_{i 2}^{3} \frac{\partial C_{2}}{\partial x}\right]_{\text {marker plane }} \quad(i=1,2,3)
\end{gathered}
$$

where $D_{11}^{3}$ and $D_{i 2}^{3}$ are the intrinsic diffusion coefficients, and $C_{i}$ 's are functions of the Boltzmann parameter, $x / \sqrt{t} . A_{i}$ is graphically determined from appropriate areas under the composition profiles.

The inert markers placed at the original interface of the $\mathrm{F}$ vs. Ni-16.4 $\mathrm{Cr}$ couple are identified after diffusion at the plane $x_{m}$ within the $(\mathrm{U}, \mathrm{Zr}) \mathrm{Ni}_{2}$ phase in Fig. 3. On the basis of Eq. (12), values of selected intrinsic diffusion coefficients $\mathrm{D}_{\mathrm{NiZr}}^{\mathrm{U}}, \mathrm{D}_{\mathrm{Z}_{\mathrm{ZZ}}}^{\mathrm{Z}}$, and $\mathrm{D}_{\mathrm{UZ}}^{\mathrm{U}}$ have been calculated at the marker plane and are presented in Table 3.

\section{Discussion}

\section{4.. Phase Layers}

Diffusion layers that developed in the various couples consisted of intermetallic phases similar to those listed in Table 1 on the basis of binary phase diagrams. This similarity is 
reflected in the ratio of sum of $\mathrm{U}$ and $\mathrm{Zr}$ concentrations to that of $\mathrm{Fe}, \mathrm{Ni}$ and $\mathrm{Cr}$ for the various phases. In Table 2 the various phases identified in the couples are listed; it is apparent that similar types of intermetallic layers and regions are recognized in more than one couple. Alloys containing Ni develop more number of intermetallic phases with $\mathrm{U}$ and $\mathrm{Zr}$ than alloys without Ni. In general, the diffusion layers formed in the couples on the side of the cladding alloy correspond to those dictated by the interaction of $\mathrm{U}$ with $\mathrm{Ni}, \mathrm{Fe}$ and $\mathrm{Cr}$. The phases that are found on the fuel side of the couples correspond to the type of intermetallic phases that can form between $\mathrm{Zr}$ and $\mathrm{Fe}$, $\mathrm{Ni}$ and $\mathrm{Cr}$.

Several diffusion layers are observed for couples $\mathrm{F}$ vs. Ni and F vs. Ni-16.4 Cr. The layers include single-phase layers of $\mathrm{UNi}_{5}, \mathrm{UNi}_{3-4}, \mathrm{U}_{5} \mathrm{Ni}_{7}$, and $(\mathrm{U}, \mathrm{Zr}) \mathrm{Ni}_{2}$ and two-phase layers of $\left[(\mathrm{U}, \mathrm{Zr}) \mathrm{Ni}_{2}+\mathrm{U}_{6} \mathrm{Ni}\right],\left[\mathrm{U}_{6} \mathrm{Ni}+(\mathrm{Zr}, \mathrm{U})_{7} \mathrm{Ni}_{10}\right]$, and $\left[\mathrm{U}+(\mathrm{Zr}, \mathrm{U})_{2} \mathrm{Ni}\right]$. The main difference between the diffusion structures of the two couples lies in the development of a two-phase $\left(\mathrm{Cr}+\mathrm{UNi}_{5}\right)$ layer on the cladding alloy side of the diffusion structure for the $\mathrm{F}$ vs. Ni-16.4 Cr couple. As Ni diffuses out of the Ni-16.4 Cralloy, the alloy becomes more $\mathrm{Cr}$-rich and a two-phase laver containing a high $\mathrm{Cr}$ matrix and $\mathrm{UNi}_{5}$ precipitates develops.

The diffusion structure developed for the $\mathrm{F}$ vs. Ni couple is much more complicated than that reported for a binary U-Ni diffusion couple by Kimmel [24]. The binary couple developed $\mathrm{U}_{6} \mathrm{Ni}, \mathrm{UNi}_{5}$ and $\mathrm{U}_{7} \mathrm{Ni}_{9}$ phases. The ternary $\mathrm{F}$ vs. Ni couple shows not only the development of single-phase layers but also two-phase layers with phases containing $\mathrm{Zr}$, as identified in Fig. 1 .

The diffusion zone of couple $\mathrm{F}$ vs. Fe exhibits minimal interdiffusion and the addition of $\mathrm{Cr}$ and $\mathrm{Ni}$ to $\mathrm{Fe}$ increases the number of diffusion layers and the depth of interdiffusion. From the diffusion structure of couple F vs. Fe-20.1 $\mathrm{Cr}$ (Fig. 6a) it is apparent that $\mathrm{Cr}$ increases the depth of interdiffusion and the number of diffusion layers. In the absence of $\mathrm{Ni}, \mathrm{Cr}$ may affect the activity of $\mathrm{Zr}$ and cause the decomposition of $\delta$ precipitates, since a $\mathrm{Zr}$-rich phase (mostly $\mathrm{Zr}$ ), not observed in any other couple, forms as an intermediate layer adjacent to the $\mathrm{U}(\mathrm{Fe}, \mathrm{Cr})_{2}$ layer. The $\mathrm{Zr}$ layer may act as a barrier to interdiffusion. A comparison of the diffusion 
structures of couples $\mathrm{F}$ vs. Fe and F vs. Fe-10-1 Ni (Figs. 5 and 7) indicates that the presence of $\mathrm{Ni}$ in the cladding alloy results in an increase in the width of the diffusion structure and in the formation of several intermetallic phases.

From a comparison of the diffusion structures of $\mathrm{F}$ vs. Fe-10.1 Ni and F vs. Fe-16.4 Ni9.4 Cr couples, it is apparent that the phases in both couples are quite similar. This is consistent with the fact that $\mathrm{Cr}$ does not form any intermetallic phases with $\mathrm{U}$ and forms only one intermetallic phase with $\mathrm{Zr}$.

\subsection{Relative diffusion behavior of fuel and cladding elements}

The intrinsic diffusion coefficients for the $(\mathrm{U}, \mathrm{Zr}) \mathrm{Ni}_{2}$ phase reported in Table 3 give insight on the diffusion behavior of $\mathrm{U}$ and $\mathrm{Ni}$ as affected by the presence of $\mathrm{Zr}$. $\mathrm{D}_{\mathrm{UZ}}$, which is the cross intrinsic diffusion coefficient for $U$ is positive and indicates that when $U$ diffuses down a $\mathrm{Zr}$ gradient, the intrinsic diffusion flux of $U$ is increased. The negative value for the cross intrinsic diffusion coefficient, $\mathrm{D}_{\mathrm{Ni}}^{\mathrm{U}}$, implies that the diffusion flux of $\mathrm{Ni}$ gets reduced down a $\mathrm{Zr}$ gradient. The absolute values of these cross coefficients are over an order of magnitude greater than the main coefficient $\mathrm{D}_{\mathrm{Z} Z \mathrm{Zr}}$ and indicate that the diffusional interactions among the components cannot be ignored. The small $\mathrm{D}_{\mathrm{Z}_{\mathrm{Z}} \mathrm{Z}}^{\mathrm{implies}}$ small $\mathrm{Zr}$ intrinsic diffusion fluxes in the $(\mathrm{U}, \mathrm{Zr}) \mathrm{Ni}_{2}$ phase.

The average effective interdiffusion coefficients reported in Table 3 for the couple F vs. $\mathrm{Ni}-16.4 \mathrm{Cr}$ are for the diffusion structure covering the diffusion layers 1 through 5 to the left of $x_{0}$ in Fig. 3. These layers include the intermetallic phases between $U$ and $\mathrm{Ni}$ and the phase $(\mathrm{U}, \mathrm{Zr}) \mathrm{Ni}_{2}$. Since $\tilde{\mathrm{D}}_{\mathrm{U}, \mathrm{L}}^{\text {eff }}$ and $\tilde{\mathrm{D}}_{\mathrm{Ni}, \mathrm{L}}^{\text {eff }}$ are an order of magnitude larger than $\tilde{\mathrm{D}}_{\mathrm{Z}, \mathrm{L}}^{\text {eff }}, \mathrm{U}$ and $\mathrm{Ni}$ interdiffuse much faster than $\mathrm{Zr}$ and the effective penetration depths of $\mathrm{U}$ and Ni are 2-3 times larger than that of $\mathrm{Zr}$. The average effective interdiffusion coefficients for $\mathrm{U}, \mathrm{Fe}$ and $\mathrm{Cr}$ calculated from the couple $\mathrm{F}$ vs. Fe-20.1 $\mathrm{Cr}$ correspond to the phase $\mathrm{U}(\mathrm{Fe}, \mathrm{Cr})_{2}$ and are comparable to each other. However, they are 3 orders of magnitude smaller than those for the 
U-Ni intermetallic phases. Hence, $\mathrm{U}$ interdiffuses much faster in intermetallic phases containing Ni than those without it.

The interdiffusion behavior of the various elements can also be appreciated with the aid of diffusion paths in Figs. 4 and 9. The path segments a-b for the various couples lie almost parallel to the U-cladding alloy side of the composition triangles and indicate very low $\mathrm{Zr}$ concentration levels. This implies that the interdiffusion of $U$ with the cladding elements dominates the cladding alloy side of the couples. On the other hand, the diffusion path segments on the fuel side of the couples pass through one or more intermetallic phases typical of those that can form between $\mathrm{Zr}$ and $\mathrm{Fe}, \mathrm{Ni}$ and $\mathrm{Cr}$. For Ni-rich cladding alloys, the interaction of $\mathrm{Ni}$ with $\mathrm{U}$ and $\mathrm{Zr}$ dominates the diffusion structure, while for Fe-rich cladding alloys, the interaction of $\mathrm{Fe}$ with $\mathrm{U}$ and $\mathrm{Zr}$ appears to govern the diffusion layers.

\section{General Comments and Conclusions}

On the basis of the interdiffusion experiments carried out at $700^{\circ} \mathrm{C}$ with a U-23 at. $\% \mathrm{Zr}$ alloy fuel (F) bonded to pure $\mathrm{Fe}$, pure $\mathrm{Ni}$ and selected binary and ternary cladding alloys of the Fe-Ni-Cr system, the following comments and conclusions are made.

1. The diffusion layers that developed in the couples are consistent with the type of intermetallic phases expected between $\mathrm{U}$ and $\mathrm{Ni}, \mathrm{U}$ and $\mathrm{Fe}, \mathrm{Zr}$ and $\mathrm{Ni}$, and $\mathrm{Zr}$ and $\mathrm{Fe}$ depending on the cladding alloy composition.

2. For couples assembled with pure $\mathrm{Ni}$ or $\mathrm{Ni}-16.4 \mathrm{Cr}$ alloy, a large number of phases is observed and the diffusion layers include $\mathrm{UNi}_{5}, \mathrm{UNi}_{2}, \mathrm{U}_{5} \mathrm{Ni}_{7},(\mathrm{U}, \mathrm{Zr}) \mathrm{Ni}_{2}, \mathrm{U}_{6} \mathrm{Ni}$, $(\mathrm{Zr}, \mathrm{U})_{4} \mathrm{Ni}_{5}$ and $(\mathrm{Zr}, \mathrm{U})_{2} \mathrm{Ni}$ and $\mathrm{U}$-rich phases. $\mathrm{U}$ exhibits uphill diffusion in the $(\mathrm{U}, \mathrm{Zr}) \mathrm{Ni}_{2}$ phase where the cross intrinsic diffusion coefficient $\mathrm{D} U \mathrm{Ur}$ is positive and more than an order of magnitude larger than the main coefficient $\mathrm{D}_{\mathrm{ZrZ}}^{\mathrm{U}}$ for $\mathrm{Zr}$. Based on the average effective interdiffusion coefficients, the effective penetration depths of $\mathrm{Ni}, \mathrm{U}$ and 
$\mathrm{Zr}$ on the cladding alloy side of the $\mathrm{F}$ vs. Ni-16.4 $\mathrm{Cr}$ couple are approximately in the ratio of $3: 2: 1$.

3. Minimal interdiffusion is observed between the fuel and Fe. For the couple with $\mathrm{Fe}-20.1 \mathrm{Cr}$ alloy, diffusion layers of $\mathrm{U}(\mathrm{Fe}, \mathrm{Cr})_{2}$ and $\mathrm{Zr}$ develop in the diffusion zone. The average effective interdiffusion coefficients for $\mathrm{U}, \mathrm{Fe}$ and $\mathrm{Cr}$ in the $\mathrm{U}(\mathrm{Fe}, \mathrm{Cr})_{2}$ phase are comparable to one another and the effective penetration depths on the cladding alloy side of the couple are less than a couple of micrometers.

4. In the F vs. Fe-16.4 Ni-9.4 Cr couple, all the major intermetallic phases identified in the F vs. Fe-10.1 Ni and F vs. Fe-20.1 Cr couples are also observed without the $\mathrm{Zr}$-rich phase. These phases include $\mathrm{U}(\mathrm{Fe}, \mathrm{Ni}, \mathrm{Cr})_{2},(\mathrm{Zr}, \mathrm{U})(\mathrm{Fe}, \mathrm{Ni}, \mathrm{Cr})_{2}, \mathrm{U}_{6}(\mathrm{Fe}, \mathrm{Ni})$ and $(\mathrm{Zr}, \mathrm{U})_{2}(\mathrm{Fe}, \mathrm{Ni})$.

5. Diffusion structures developed in the various couples could be described by the aid of diffusion paths plotted on composition triangles with concentrations of $\mathrm{U}, \mathrm{Zr}$ and the sum of the concentrations of $\mathrm{Fe}, \mathrm{Ni}$ and $\mathrm{Cr}$ taken as concentration variables.

6. In general, the diffusion layers formed on the cladding alloy side of the couples are dictated by the interactions of $\mathrm{Ni}, \mathrm{Fe}$ and $\mathrm{Cr}$ with $\mathrm{U}$. The phases observed on the fuel side of the couples correspond to the type of intermetallic phases that can form between $\mathrm{Zr}$ and the elements in the cladding alloy.

\section{Acknowledgment}

This paper is based on a dissertation submitted by D. D. Keiser, Jr. to Purdue University in partial fulfillment of the requirements for the $\mathrm{Ph} . \mathrm{D}$. degree. The research was supported by the U. S. Department of Energy under contract DE-FG07-88ER12814. Additional support by the Argonne National Laboratory under the award No. 80000MOD1 is gratefully acknowledged. 


\section{References}

1. C. H. Till and Y. I. Chang, in: Proceedings of the American Power Conference (Chicago, IL, 1986) p. 688.

2. G. L. Hofman, Nucl. Tech. 47 (1980) 7.

3. R. E. Einziger and B. R. Seidel, Nucl. Tech. 50 (1980) 25.

4. B. R. Seidel, L. C. Walters and Y. I. Chang, J. Metall. 39 (1987) 10.

5. B. R. Seidel and L. C. Walters, Trans. of ASME 103 (1981) 612.

6. L. C. Walters and J. H. Kittle, Nucl. Tech. 48 (1980) 273.

7. C. E. Lahm, et al., Nucl. Engr. and Design 101 (1987) 25.

8. G. L. Hofman, et al., in: Proc. of the Int. Conf. on Reliable Fuels for Liquid Metal Reactors (Tucson, AZ, 1986) p. 4-121.

9. S. Thomas Zegler, et al., Compatibility of Uranium 5 w/o Fissium Alloy with Types 304L and 316 stainless Steel, Argonne National Laboratory, ANL-7596 (September 1969).

10. C. M. Walters, Interdiffusion Between Uranium 5 w/o Fissium Alloy and Type 304 Stainless Steel, Argonne National Laboratory, ANL-6816 (March 1964).

11. S. T. Zegler and C. M. Walters, Nucl. Mat. 13 (1967) 335.

12. J. H. Kittel, Layer Formation by Interdiffusion Between Some Reactor Construction Metals, Argonne National Laboratory, ANL-4937 (June 1949).

13. J. G. Duh, Ph.D. Thesis (Purdue University, 1983) p. 96.

14. Binary Alloy Phase Diagrams, ASM publication, Edited by T. B. Massalski, H. Okamoto, P. R. Subramanian, L. Kacprzak, (1990).

15. L. Leibowitz, et al., J. Nucl. Mater, 154 (1988) 145.

16. M. A. Dayananda and D. A. Behnke, Scripta Met. (1991) 2187.

17. L. Onsager, New York Acad. of Sciences 46 (1945) 241.

18. J. S. Kirkaldy, Can. J. Phys., 35 (1957) 435.

19. T. O. Ziebold and R. E. Ogilivie, TMS-AIME, 233 (1965) 1287.

20. M. A. Dayananda and C. W. Kim, Metall. Trans. 10A (1979) 1333.

21. M. A. Dayananda, Metall. Trans. 14A (1983) 1851.

22. T. Heumann, Z. Phys. Chem. 201 (1952) 168.

23. J. Philibert and A. G. Guy, Comptes Rendus 227 (1963) 2281.

24. G. Kimmel, et al., Trans. ASM 61 (1968) 703. 
Table 1. Possible intermetallic phases for various binary combinations from phase diagrams [14].

\begin{tabular}{|c|c|c|}
\hline & $\mathrm{U}$ & $\mathrm{Zr}$ \\
\hline $\mathrm{Fe}$ & $\mathrm{UFe}_{2}, \mathrm{U}_{6} \mathrm{Fe}$ & $\mathrm{ZrFe}_{3}, \mathrm{ZrFe}_{2}, \mathrm{Zr}_{3} \mathrm{Fe}, \mathrm{Zr}_{2} \mathrm{Fe}$ \\
\hline $\mathrm{Ni}$ & $\begin{array}{c}\mathrm{U}_{6} \mathrm{Ni} \mathrm{U}_{7} \mathrm{Ni}_{9}, \mathrm{U}_{5} \mathrm{Ni}_{7}, \\
\mathrm{UNi}_{2}, \mathrm{UNi}_{5}, \delta, \varepsilon\end{array}$ & $\begin{array}{c}\mathrm{Zr}_{2} \mathrm{Ni}, \mathrm{ZrNi}, \mathrm{ZrNi}_{3}, \mathrm{Zr}_{8} \mathrm{Ni}_{21}, \\
\mathrm{Zr}_{2} \mathrm{Ni}_{7}, \mathrm{ZrNi}_{5}, \mathrm{Zr}_{9} \mathrm{Ni}_{11}, \mathrm{Zr}_{7} \mathrm{Ni}_{10}\end{array}$ \\
\hline $\mathrm{Cr}$ & $\begin{array}{l}\text { solubility } \\
\text { of } \mathrm{Cr} \text { in U } \\
\text { (<4 at.\%) }\end{array}$ & $\mathrm{ZrCr}_{2}$ \\
\hline
\end{tabular}


Table 2. Phases identified in diffusion couples.

\begin{tabular}{|c|c|}
\hline Diffusion Couple & Phases $\ddagger$ \\
\hline F vs. Ni & $\begin{array}{l}\mathrm{UNi}_{5} *, \mathrm{UNi}_{3-4} * \mathrm{U}_{5} \mathrm{Ni}_{7} *,(\mathrm{U}, \mathrm{Zr}) \mathrm{Ni}_{2}, \mathrm{U}_{6} \mathrm{Ni}^{*},(\mathrm{Zr}, \mathrm{U})_{7} \mathrm{Ni}_{10}, \\
\left(\mathrm{Zr}, \mathrm{U}_{2} \mathrm{Ni}\right.\end{array}$ \\
\hline F vs. Fe & $\mathrm{Zr}$ \\
\hline F vs. Ni-16.4 Cr & $\begin{array}{l}\mathrm{UNi}_{5} *, \mathrm{UNi}_{3-4}{ }^{*}, \mathrm{U}_{5} \mathrm{Ni}_{7} *,(\mathrm{U}, \mathrm{Zr}) \mathrm{Ni}_{2}, \mathrm{U}_{6} \mathrm{Ni}^{*},\left(\mathrm{Zr}, \mathrm{U}_{7} \mathrm{Ni}_{10}\right. \\
(\mathrm{Zr}, \mathrm{U})_{2} \mathrm{Ni}, \mathrm{Cr}\end{array}$ \\
\hline F vs. Fe-20.1 Cr & $\mathrm{U}(\mathrm{Fe}, \mathrm{Cr})_{2}, \mathrm{Zr}$ \\
\hline F vs. Fe-10.1 Ni & $\mathrm{U}(\mathrm{Fe}, \mathrm{Ni})_{2}, \mathrm{U}_{6}(\mathrm{Fe}, \mathrm{Ni}),(\mathrm{Zr}, \mathrm{U})(\mathrm{Fe}, \mathrm{Ni})_{2}(\mathrm{Zr}, \mathrm{U})_{2}(\mathrm{Fe}, \mathrm{Ni})$ \\
\hline F vs. $\mathrm{Fe}-16.4 \mathrm{Ni}-9.4 \mathrm{Cr}$ & $\begin{array}{l}\mathrm{U}(\mathrm{Fe}, \mathrm{Ni}, \mathrm{Cr})_{2}, \mathrm{U}_{6}(\mathrm{Fe}, \mathrm{Ni}),(\mathrm{Zr}, \mathrm{U})(\mathrm{Fe}, \mathrm{Ni}, \mathrm{Cr})_{2},(\mathrm{Zr}, \mathrm{U})_{2}(\mathrm{Fe}, \mathrm{Ni}) \\
(\mathrm{U}, \mathrm{Zr})_{9}(\mathrm{Fe}, \mathrm{Ni})\end{array}$ \\
\hline
\end{tabular}

$\ddagger$ The intermetallic designations of the phases are based on the ratio of concentrations of $(\mathrm{U}+\mathrm{Zr})$ to that of $(\mathrm{Fe}+\mathrm{Ni}+\mathrm{Cr})$.

* In the phases with binary designations, the presence of negligibly small concentrations of $\mathrm{Zr}$ is ignored. 
Table 3. Average effective interdiffusion coefficients, intrinsic diffusion coefficients, and effective penetration depths for the $\mathrm{F}(\mathrm{U}-23 \mathrm{Zr})$ vs. Ni-16.4 $\mathrm{Cr}$ and $\mathrm{F}(\mathrm{U}-23 \mathrm{Zr})$ vs. $\mathrm{Fe}-20.1 \mathrm{Cr}$ couples annealed at $700^{\circ} \mathrm{C}$ for 4 days.

\begin{tabular}{|c|c|c|c|c|}
\hline Couple & $\left(\mathrm{x}_{\mathrm{m}}-\mathrm{x}_{\mathrm{o}}\right)$ & $\begin{array}{c}\text { Average Effective } \\
\text { Diffusion Coefficients } \\
\tilde{\mathrm{D}}_{\mathrm{i}, \mathrm{L}}^{\text {eff }}\left(\mathrm{cm}^{2} \mathrm{~s}^{-1}\right)\end{array}$ & $\begin{array}{c}\text { Effective } \\
\text { Penetration Depths } \\
\mathbf{x}_{\mathrm{i}, \mathrm{L}}(\mu \mathrm{m})\end{array}$ & $\begin{array}{c}\text { Intrinsic Diffusion } \\
\text { Coefficients for }(\mathrm{U}, \mathrm{Zr}) \mathrm{Ni}_{2} \\
\mathrm{D}_{\mathrm{ij}}^{\mathrm{U}}\left(\mathrm{cm}^{2} \mathrm{~s}^{-1}\right)\end{array}$ \\
\hline $\begin{array}{c}\text { F vs. } \\
\text { Ni-16.4 Cr }\end{array}$ & $9.2 \mu \mathrm{m}$ & $\begin{array}{l}\tilde{\mathrm{D}}_{\mathrm{U}, \mathrm{L}}^{\text {eff }}=8.21 \times 10^{-12} \\
\tilde{\mathrm{D}}_{\mathrm{Zr}, \mathrm{L}}^{\text {eff }}=1.74 \times 10^{-12} \\
\tilde{\mathrm{D}}_{\mathrm{Ni}, \mathrm{L}}^{\text {eff }}=1.73 \times 10^{-11}\end{array}$ & $\begin{array}{l}\mathrm{x}_{\mathrm{U}, \mathrm{L}}=23.8 \\
\mathrm{x}_{\mathrm{Zr,L}}=11.0 \\
\mathrm{x}_{\mathrm{Ni}, \mathrm{L}}=34.6\end{array}$ & $\begin{aligned} \mathrm{D}_{\mathrm{UZr}}^{\mathrm{U}} & =1.70 \times 10^{-11} \\
\mathrm{D}_{\mathrm{ZrZx}}^{\mathrm{U}} & =8.94 \times 10^{-13} \\
\mathrm{D}_{\mathrm{NiZr}} & =-5.29 \times 10^{-11}\end{aligned}$ \\
\hline $\begin{array}{c}\text { F vs } \\
\text { Fe-20.1 Cr }\end{array}$ & $1.4 \mu \mathrm{m}$ & $\begin{array}{l}\tilde{\mathrm{D}}_{\mathrm{U}, \mathrm{L}}^{\text {eff }}=4.10 \times 10^{-14} \\
\tilde{\mathrm{D}}_{\mathrm{Fe}, \mathrm{L}}^{\text {eff }}=5.33 \times 10^{-14} \\
\tilde{\mathrm{D}}_{\mathrm{Cr}, \mathrm{L}}^{\text {eff }}=1.57 \times 10^{-14}\end{array}$ & $\begin{array}{l}\mathrm{x}_{\mathrm{U}, \mathrm{L}}=1.7 \\
\mathrm{x}_{\mathrm{Fe}, \mathrm{L}}=1.9 \\
\mathrm{x}_{\mathrm{Cr}, \mathrm{L}}=1.0\end{array}$ & \\
\hline
\end{tabular}




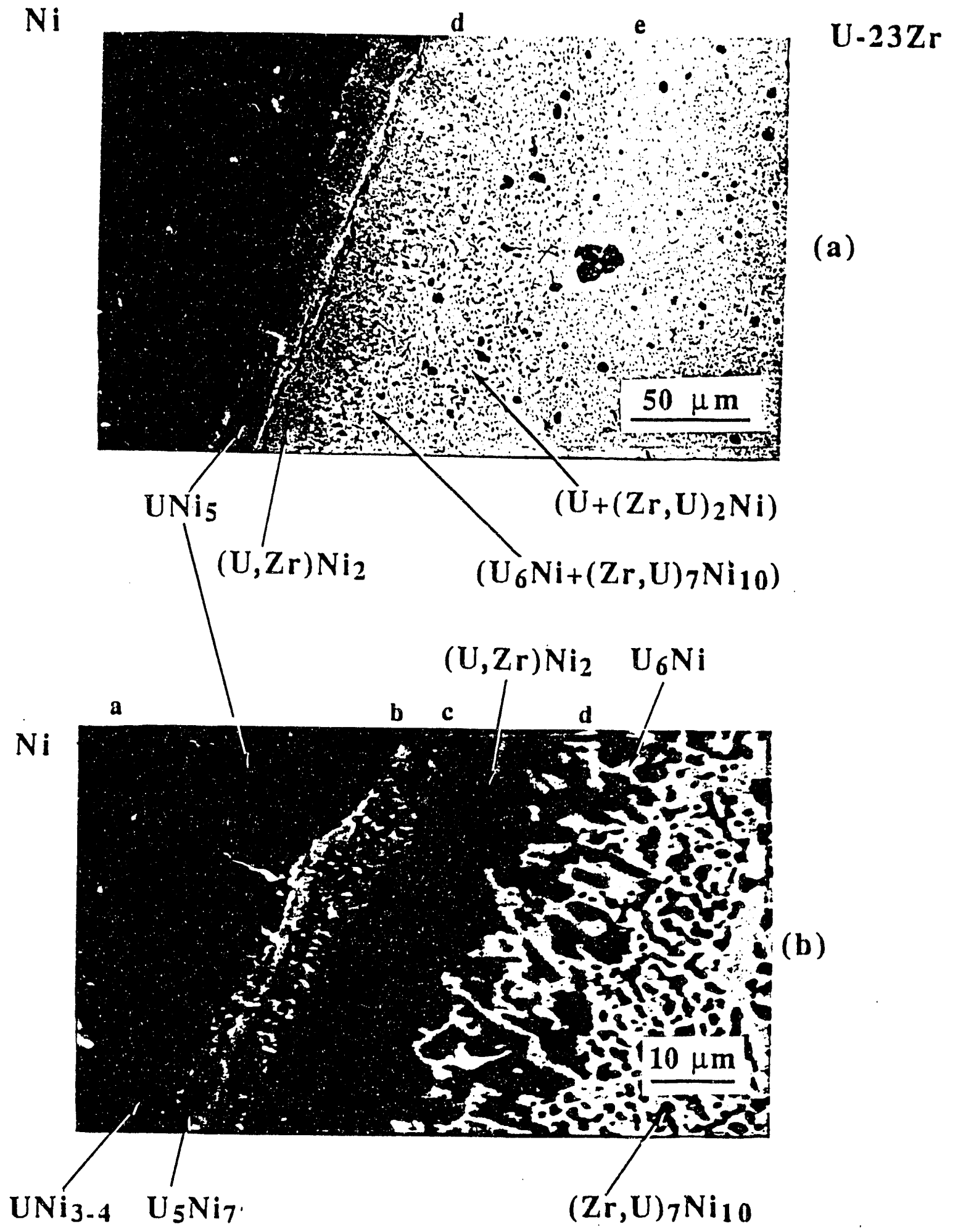

Figure 1. SEM micrographs showing several diffusion layers with intermetallic phases developed for the $\mathrm{F}\left(\mathrm{U}-23 \mathrm{Zr}\right.$ ) vs. Ni couple annealed at $700^{\circ} \mathrm{C}$ for 4 days; (a) and (b) are at two different magnifications. 

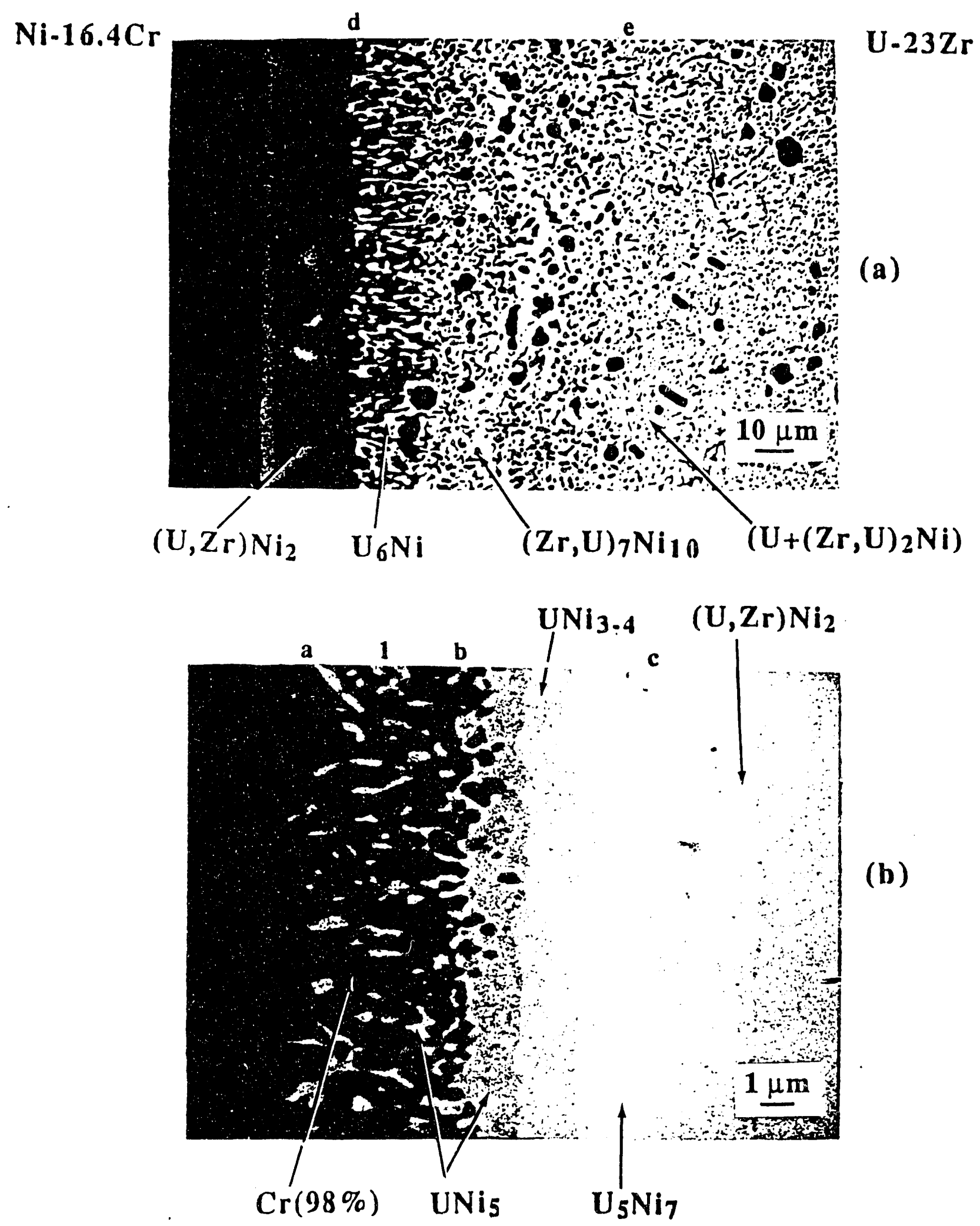

(b)

Figure 2. SEM micrographs showing the diffusion structure developed for the F(U-23Z $r$ ) vs. $\mathrm{A}(\mathrm{Ni}-16.4 \mathrm{Cr})$ couple on annealing at $700^{\circ} \mathrm{C}$ for 4 days; (a) and (b) are at two different magnifications. 


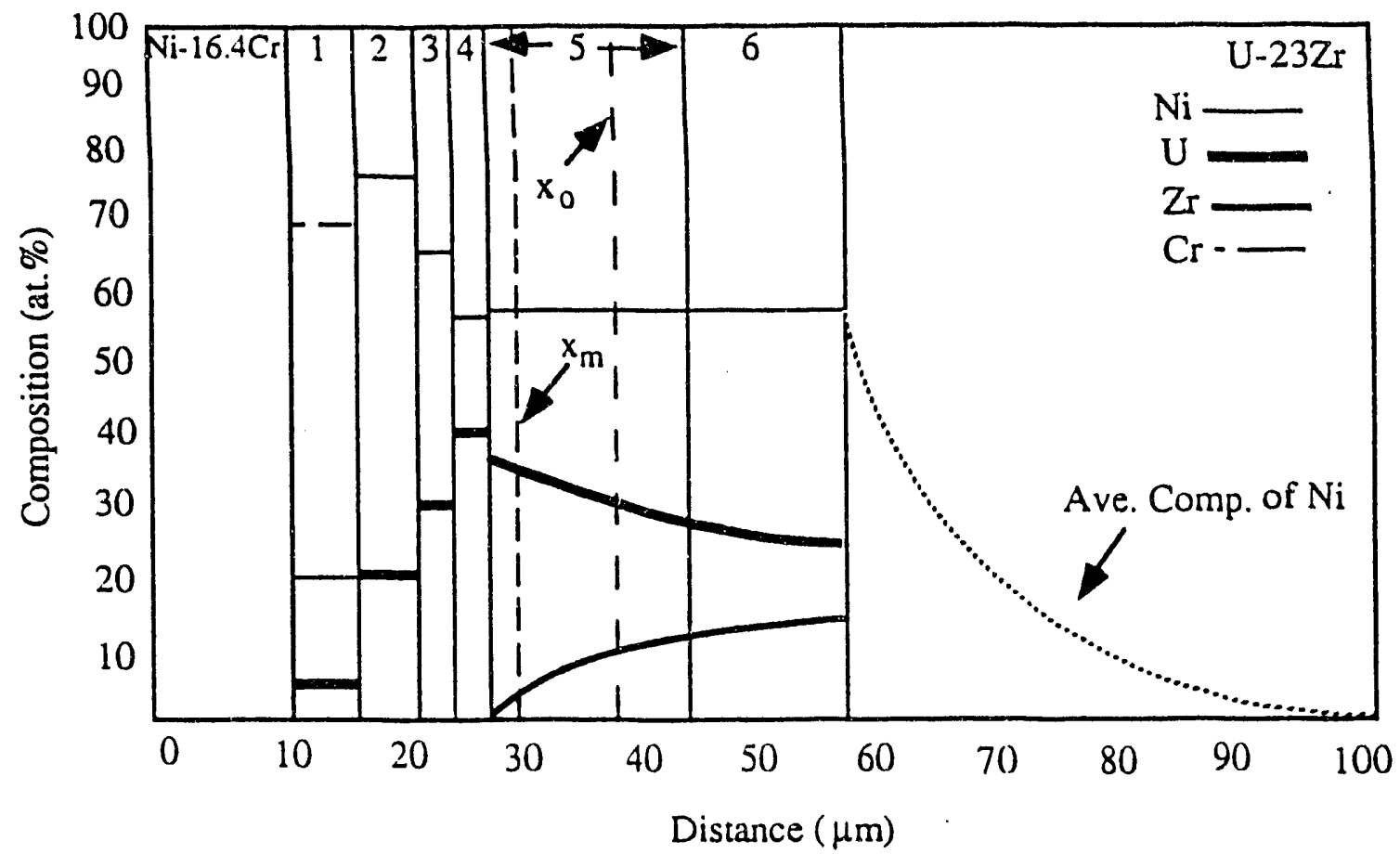

Figure 3. Concentration profiles of $\mathrm{Ni}, \mathrm{Cr}, \mathrm{U}$, and $\mathrm{Zr}$ for the $\mathrm{F}(\mathrm{U}-23 \mathrm{Zr})$ vs. $\mathrm{Ni}-16.4 \mathrm{Cr}$ coufle. Layers 1-6 represent: 1-( $\mathrm{Cr}+\mathrm{UNi} 5), 2-\mathrm{UNi}_{5}, 3-\mathrm{UNi}_{3-4}, 4-\mathrm{U}_{5} \mathrm{Ni}_{7}$, 5-(U, $\mathrm{Zr}) \mathrm{Ni}_{2}$, and $6-\left[(\mathrm{U}, \mathrm{Zr}) \mathrm{Ni}_{2}+\mathrm{U}_{6} \mathrm{Ni}\right] ; \mathrm{x}_{\mathrm{O}}$ and $\mathrm{x}_{\mathrm{m}}$ refer to the locations of the Matano plane and marker plane, respectively. 


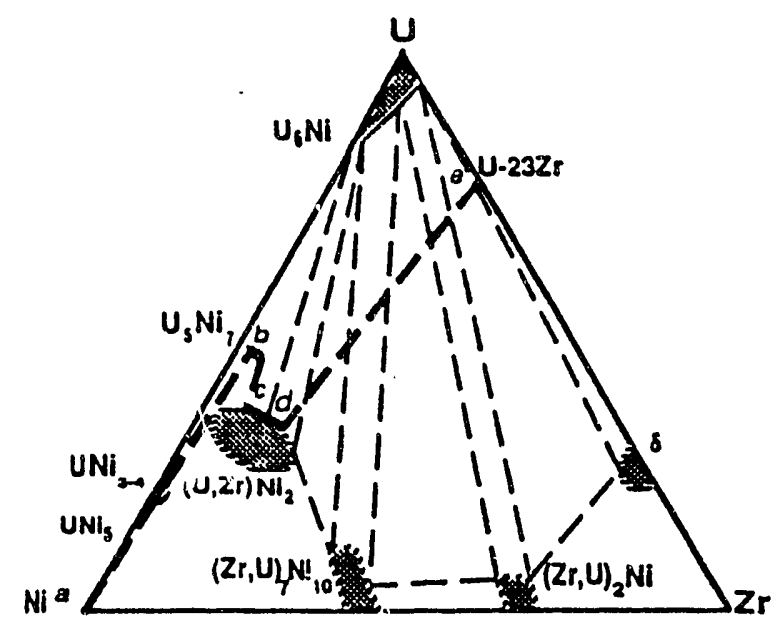

(a)

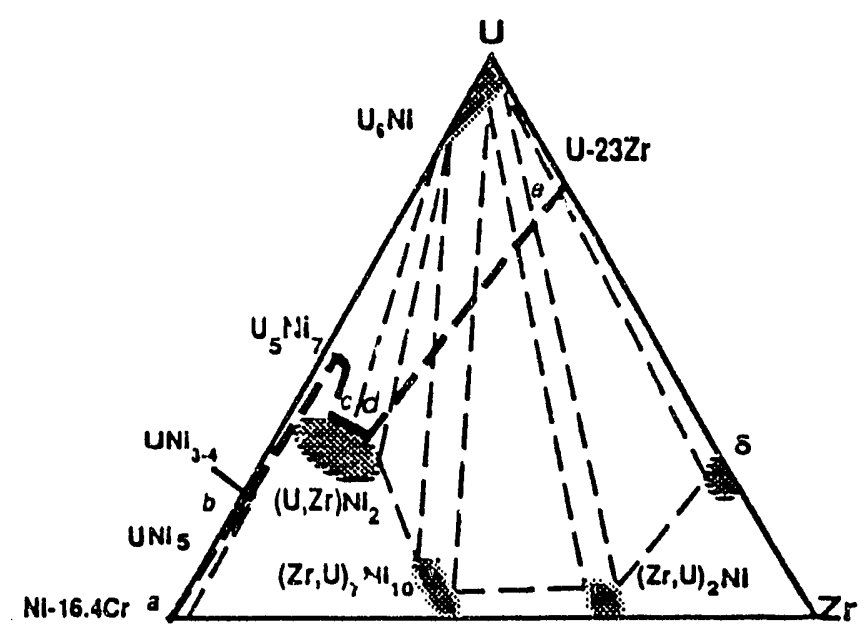

(b)

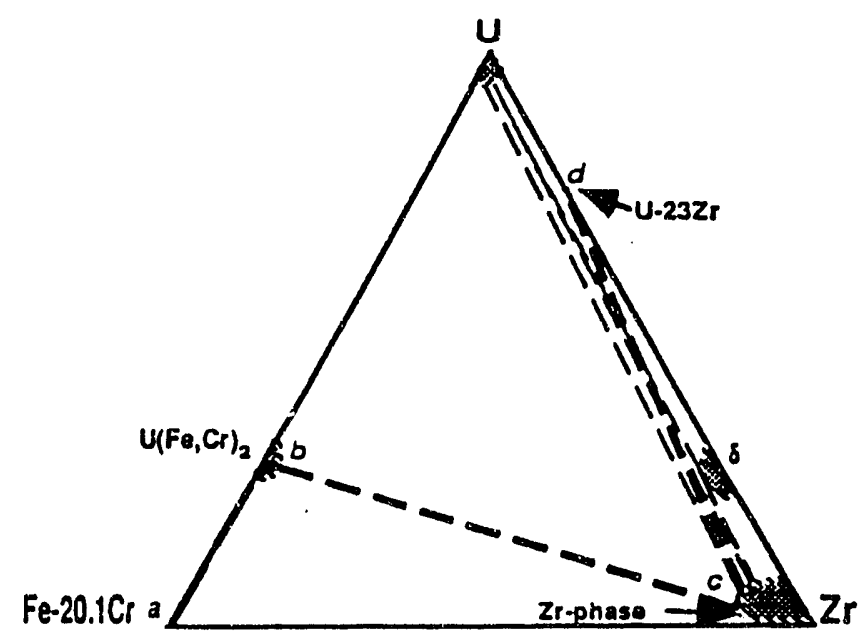

(c)

Figure 4. Experimental diffusion paths on composition triangles at $700^{\circ} \mathrm{C}$ for the couples (a) $\mathrm{F}$ vs. $\mathrm{Ni}$,

(b) $\mathrm{F}$ vs. $\mathrm{Ni}-16.4 \mathrm{Cr}$, and (c) $\mathrm{F}$ vs. Fe-20.1 Cr. Phase designations are based on relative ratios of concentrations and the tie-lines in two-phase regions are schematic. 


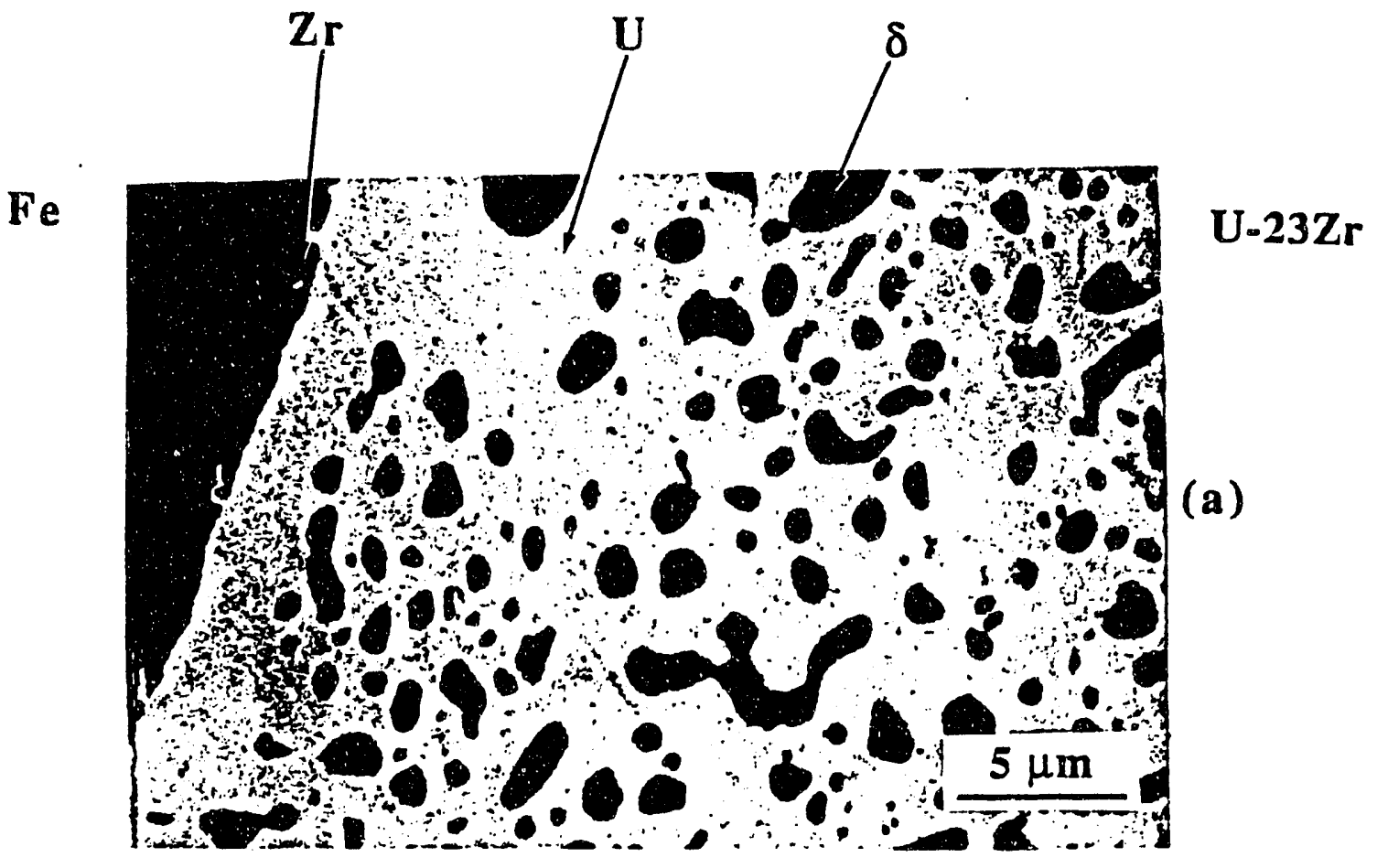

Figure 5. Diffusion structure for the $\mathrm{F}(\mathrm{U}-23 \mathrm{Zr})$ vs. Fe couple annealed at $700^{\circ} \mathrm{C}$ for 4 days. 

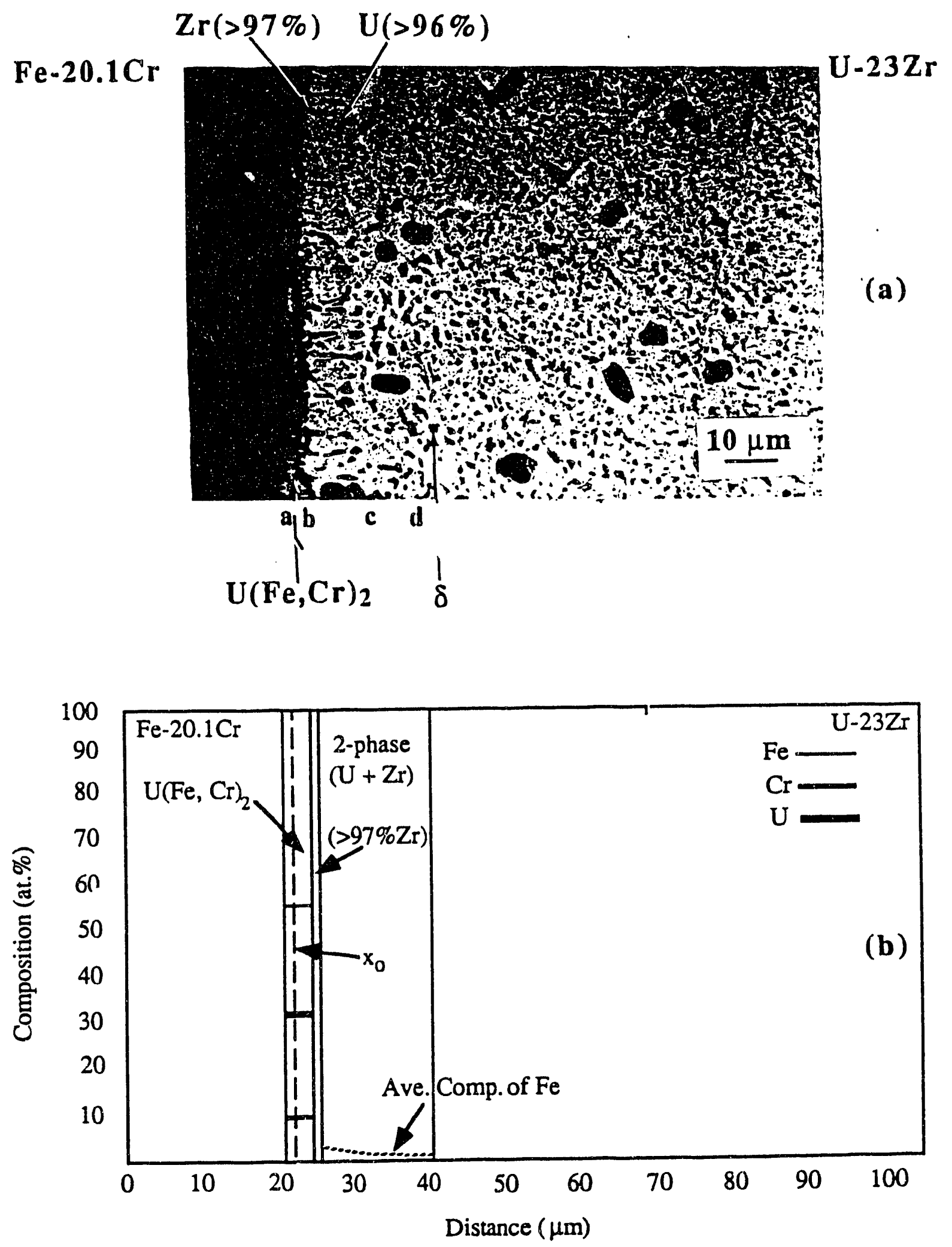

Figure 6. (a) Diffusion structure and (b) concentration profiles for the F(U-23Zr) vs. (Fe-20.1 Cr) couple annealed at $700^{\circ} \mathrm{C}$ for 4 days. 
$\mathrm{Fe}-10.1 \mathrm{Ni}$
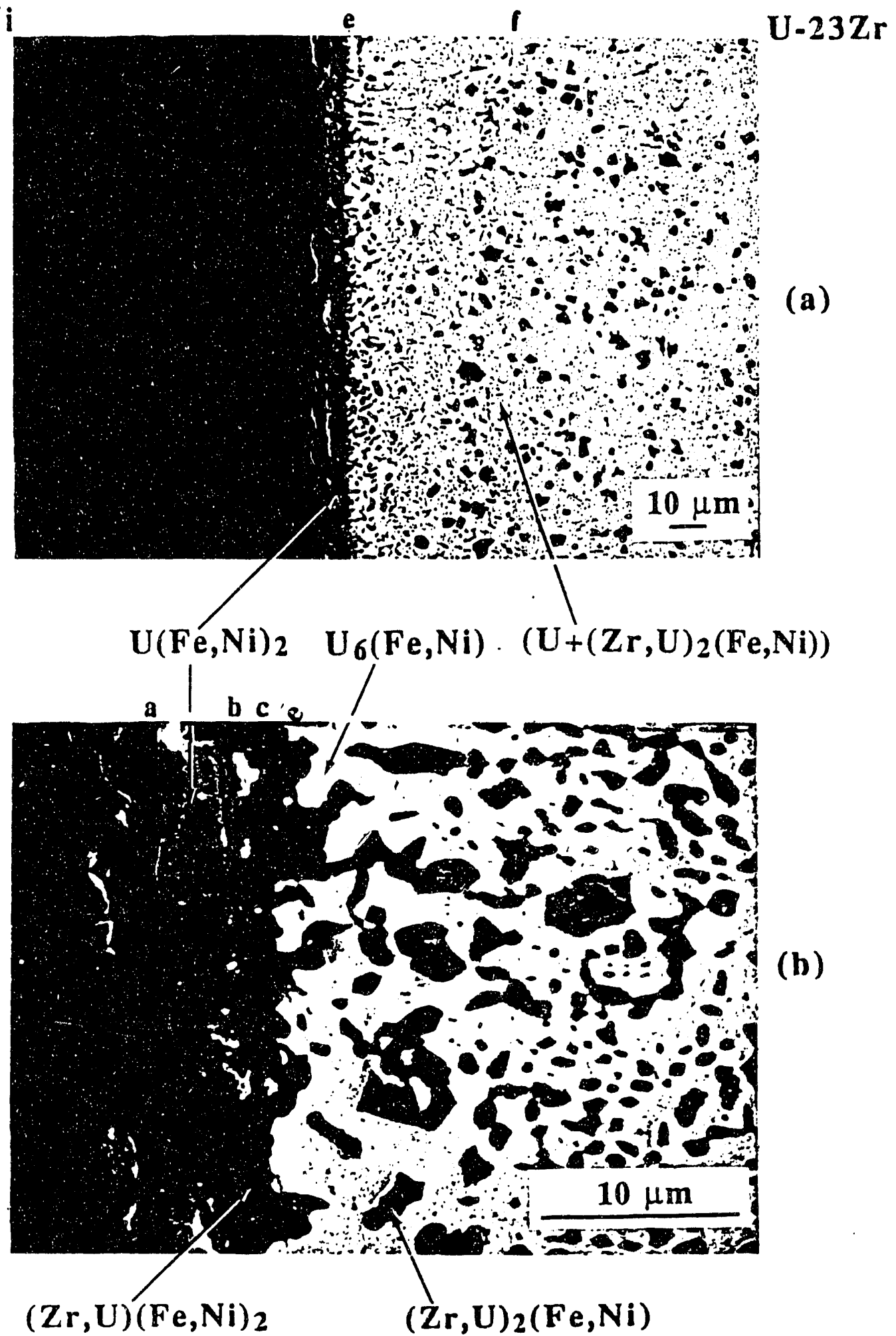

(b)

Figure 7. SEM micrographs showing the diffusion structure for the F(U-23Zr) vs. (Fe$10.1 \mathrm{Ni}$ ) couple annealed at $700^{\circ} \mathrm{C}$ for 4 days; (a) and (b) are at two different magnifications. 
$\mathrm{Fe}-16.4 \mathrm{Ni}-9.4 \mathrm{Cr}$

$(\mathrm{U}, \mathrm{Zr}) \boldsymbol{g}(\mathrm{Fe}, \mathrm{Ni})$

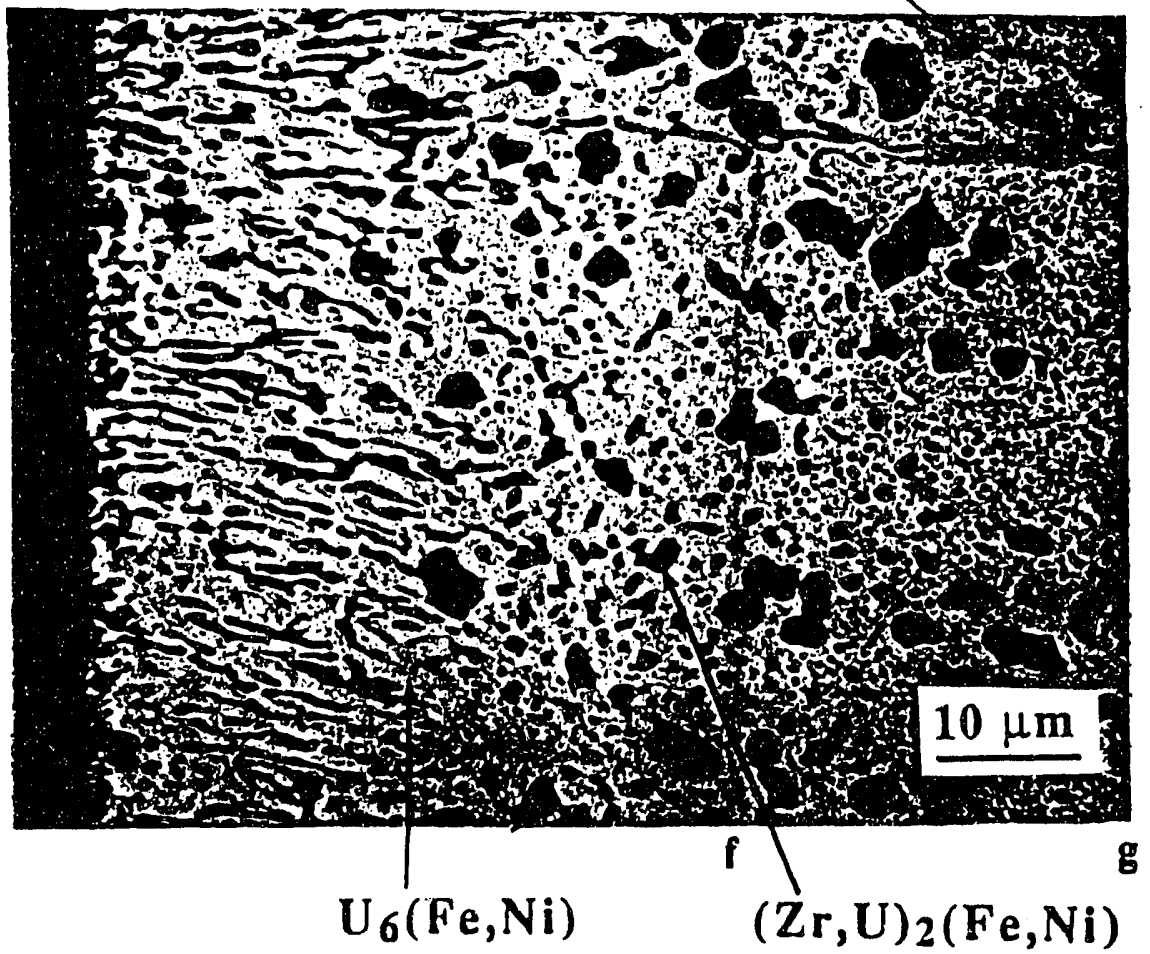

U-23Zr

(a)

a bc de

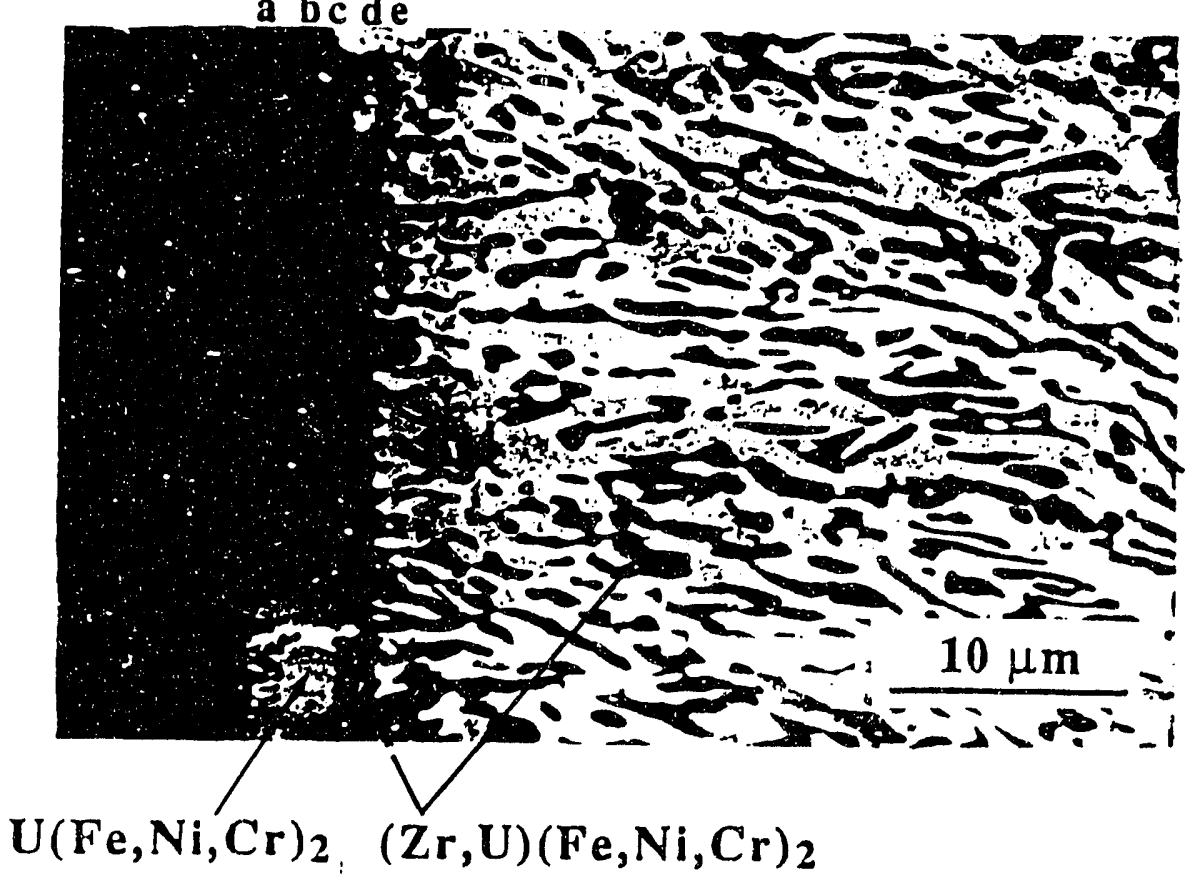

(b)

Figure 8. SEM micrographs showing the diffusion layers and intermetallic phases developed for the $\mathrm{F}(\mathrm{U}-23 \mathrm{Z} r$ ) vs. (Fe-16.4Ni-9.4Cr) couple annealed at $700^{\circ} \mathrm{C}$ for 4 days; (a) and (b) are at two different magnifications. 


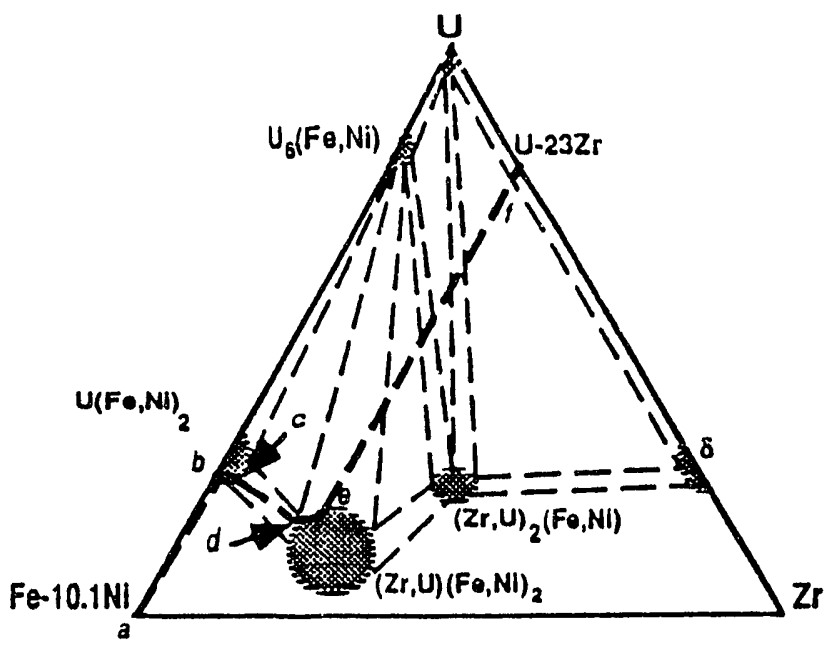

(a)

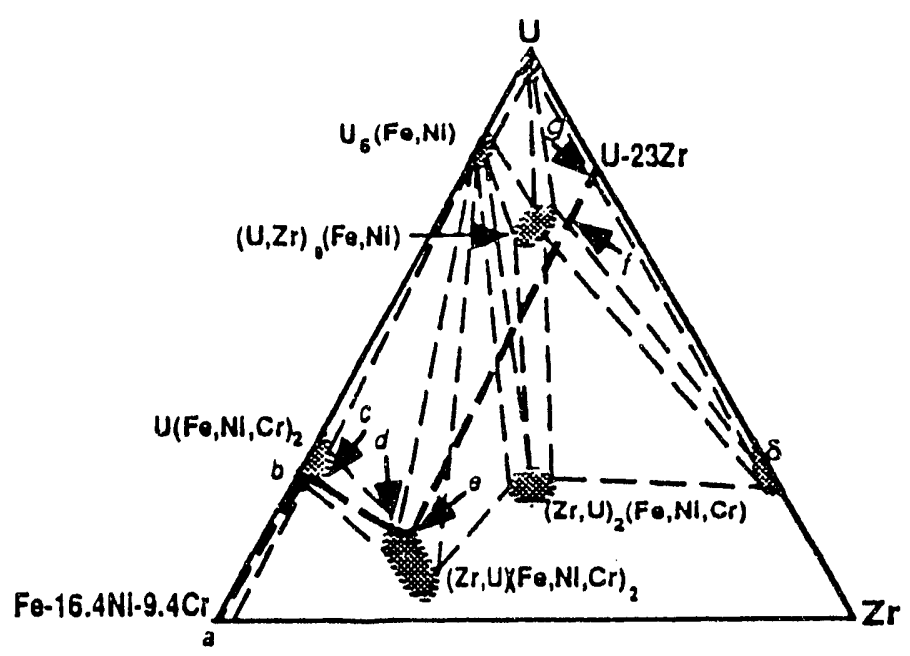

(b)

Figure 9. Experimental diffusion paths on composition triangles at $700^{\circ} \mathrm{C}$ for the couples (a) $\mathrm{F}$ vs. $\mathrm{Fe}-10.1 \mathrm{Ni}$ and (b) $\mathrm{F}$ vs. Fe-16.4Ni-9.4Cr. Phase designations are based on relative ratios of concentrations and the tie-lines in two-phase regions are schematic. 


\section{APPENDIX E}

Interdiffusion Between U-Zr Fuel vs. Selected Cladding Steels 


\title{
Interdiffusion Between U-Zr Fuel vs. Selected Cladding Steels
}

\author{
D. D. Keiser, Jr. and M. A. Dayananda \\ School of Materials Engineering \\ Purdue University, W. Lafayette, IN 47907
}

\begin{abstract}
To understand better fuel-cladding compatibility issues as affected by diffusion processes in the Integral Fast Reactors, interdiffusion studies were carried out at with solid-solid diffusion couples assembled with a U-23 at.\% Zr alloy and cladding steels, such as 316, D9, and HT9. All diffusion couples were annealed at $700^{\circ} \mathrm{C}$ and examined metallographically and by SEMEDS analysis for diffusion structure development. The development of diffusion layers in the couples for various cladding steels are compared and discussed in the light of the relative diffusion behavior of the individual elements, intermetallic formation and experimental diffusion paths. In the context of fuel-cladding compatibility, HT9 is considered superior to 316 and D9, as it developed the smallest diffusion zone with the fewest number of phases.
\end{abstract}




\section{Introduction}

The structural integrity of a fuel element is of paramount importance during operation of a nuclear reactor. During reactor operation with the metallic fuel elements used as part of Argonne National Laboratory's Integral Fast Reactor program, the fuel has been shown to come into contact with the cladding alloy between 0.5 and 1.0 at.\% burnup. Such contact between the fuel and cladding alloy results in interdiffusion [1-7] and in the development of strength reducing diffusion zones, which can cause a premature breach of a fuel element. In addition, low melting layers can form as a result of interdiffusion and affect the structural integrity of a fuel element. Therefore, to understand the compatibility of a fuel and the cladding alloy, it is important to understand diffusion behavior for various cladding steels.

In the recent paper [8] were presented results of interdiffusion studies with a set of diffusion couples assembled with a U-23 at.\% $\mathrm{Zr}$ fuel and $\mathrm{Fe}, \mathrm{Ni}$ and selected binary and ternary alloys of the Fe-Ni-Cr system. In this paper interdiffusion in couples assembled with the U-23 at.\% $\mathrm{Zr}$ fuel bonded to selected cladding steels namely $316 \mathrm{SS}$, HT9, and D9 is investigated. Diffusion structures and experimental diffusion paths for the couples are presented and the fuel-cladding compatibility is examined in the context of diffusion structure development for these couples. The interdiffusion behavior of the fuel with cladding steels is discussed in the light of the diffusion structures, diffusion paths, and the intermetallic phases as affected by variations in the composition of cladding alloys of the Fe-Ni-Cr system [8].

\section{Experimental}

The U-23 at.\% Zr fuel (designated F) as well as the cladding steels 316, HT9, D9 used in this investigation were provided by the Argonne National Laboratory. The compositions of the cladding steels are listed in Table I. The U-23 at.\% $\mathrm{Zr}$ alloy was prepared at the Argonne National Laboratory with depleted $U$ by using conventional induction melting methods and casting into rods, $5 \mathrm{~mm}$ in diameter. A fuel rod furnished by ANL was homogenized at $900^{\circ} \mathrm{C}$ 
for 4 days.

Both fuel and cladding steels were cut into disks about $0.5 \mathrm{~cm}$ thick. Their surfaces were metallographically polished through 0.05 micron alumina. Thickness measurements were made during polishing to ensure that both faces of the disks were flat and parallel to each other. Diffusion couples were assembled by sandwiching a disk of the $\mathrm{U}-\mathrm{Zr}$ at.\% $\mathrm{Zr}$ alloy between two disks of selected cladding steels. These "sandwiches" were clamped together in a (Kovar) jig which consisted of two end plates, 1/8" thick $\times 7 / 8 "$ in diameter, and three threaded Kovar rods. Kovar steel was chosen for the jig due to its low coefficient of thermal expansion (5.27 $\mathrm{x}$ $\left.10^{-6} \mathrm{in} / \mathrm{in}^{\circ} \mathrm{C}\right)$. The assembled couples were placed in a quartz tube, 9 " long and $1 "$ in diameter. Each quartz tube was flushed several times with hydrogen, evacuated to a pressure of less than $10^{-5}$ torr and sealed to form a capsule about $6 "$ long.

All diffusion couples were annealed for 4 days at $700^{\circ} \mathrm{C}$ in a Lindberg heavy-duty threezone tube furnace. The temperature gradient over the length of the capsule was less than $1^{\circ} \mathrm{C}$ and the temperature controlled to $\pm 0.5^{\circ} \mathrm{C}$. After annealing, the capsules were allowed to cool in air outside the furnace.

The diffused couples in the Kovar jigs were removed from the quartz capsules and mounted in cold-mount self-setting resin. Mounted couples were then cut with an Isomet cutoff wheel to expose sections parallel to the direction of diffusion. The exposed cross-section of each couple was metallographically polished through 0.05 micron alumina. The couples were analyzed by point-to-point counting techniques for concentration profiles and compositions of phases with a JEOL 35 CF scanning electron microscope equipped with a Tracor Northern Series II energy dispersive $\mathrm{X}$-ray analyzer. Intensities of $\mathrm{K}_{\alpha} \mathrm{x}$-radiations of $\mathrm{Fe}, \mathrm{Ni}$, and $\mathrm{Cr}$ identified at the energies of $6.403 \mathrm{KeV}, 7.477 \mathrm{KeV}$, and $5.414 \mathrm{KeV}$, respectively, of $\mathrm{Zr} \mathrm{L}_{\alpha} \mathrm{x}$ radiation at $2.042 \mathrm{KeV}$ and of $\mathrm{U} \mathrm{M}_{\alpha}$ x-radiation at $3.171 \mathrm{KeV}$ were collected and stored on floppy discs and converted into compositions with the aid of elemental standards and a ZAF correction program. Secondary electron micrographs were taken of diffusion structures 
developed in the various couples. Individual phases analyzed in the diffusion zones of the various diffusion couples are listed in Table 2 where intermetallic designations are used to represent the measured concentration ratios.

\section{Results}

The various phases identified in the diffusion structures of the 3 couples investigated in this study are listed in Table II. The intermetallic designations of the phases are based on the ratio of the $(\mathrm{U}+\mathrm{Zr})$ concentration to that of $(\mathrm{Fe}+\mathrm{Ni}+\mathrm{Cr})$. The details on the diffusion structures and their representation by experimental diffusion paths are presented below.

\section{A. Diffusion Structures}

The diffusion structure developed for the couple $\mathrm{F}(\mathrm{U}-23 \mathrm{Zr})$ vs. 316 is shown in Fig. 1 and is around $100 \mu \mathrm{m}$ wide. In multiphase layers, the phases which appear as the matrix are $U$ rich, while the precipitates are $\mathrm{Zr}$-rich. The primary single-phase layer for this couple is $\mathrm{U}(\mathrm{Fe}$, $\mathrm{Ni}, \mathrm{Cr})_{2}$. The other phases that appear in the diffusion structure include $(\mathrm{Zr}, \mathrm{U})(\mathrm{Fe}, \mathrm{Cr}, \mathrm{Ni})_{2-3}$, $(\mathrm{Zr}, \mathrm{U})_{2}(\mathrm{Fe}, \mathrm{Cr}, \mathrm{Ni}), \mathrm{U}_{6}(\mathrm{Fe}, \mathrm{Ni})$, and $(\mathrm{U}, \mathrm{Zr})_{9}(\mathrm{Fe}, \mathrm{Ni})$.

The diffusion structure for the couple $\mathrm{F}(\mathrm{U}-23 \mathrm{Zr})$ vs. D9 is presented in Fig. 2. It exceeds $175 \mu \mathrm{m}$ in width and contains phases with similar compositions ratios as those found in the $\mathrm{F}$ vs. 316 couple. These phases include: $\mathrm{U}_{6}(\mathrm{Fe}, \mathrm{Ni}), \mathrm{U}(\mathrm{Fe}, \mathrm{Ni}, \mathrm{Cr})_{2},(\mathrm{Zr}, \mathrm{U})(\mathrm{Fe}, \mathrm{Ni}, \mathrm{Cr})_{2},(\mathrm{Zr}$, $\mathrm{U}_{2}(\mathrm{Fe}, \mathrm{Cr}, \mathrm{Ni})$, and $\left.\mathrm{U}, \mathrm{Zr}\right)_{9}(\mathrm{Fe}, \mathrm{Ni}, \mathrm{Cr})$. A high $\mathrm{Zr}$ phase $(>80 \%)$ is observed in this couple along with a phase whose composition is similar to that of the $\sigma$ phase of the $\mathrm{Fe}-\mathrm{Cr}$ binary system. In a region adjacent to the high $\mathrm{Zr}$ phase, the $(\mathrm{Zr}, \mathrm{U})(\mathrm{Fe}, \mathrm{Ni}, \mathrm{Cr})_{2}$ precipitates exhibit high $\mathrm{Cr}$ concentrations $\left(\approx 35\right.$ at.\%). Comparatively, the $(\mathrm{Zr}, \mathrm{U})(\mathrm{Fe}, \mathrm{Ni}, \mathrm{Cr})_{2}$ phase in the $\mathrm{F}$ vs. 316 couple contains approximately 16 at.\% $\mathrm{Cr}$. For the $(\mathrm{Zr}, \mathrm{U})_{2}(\mathrm{Fe}, \mathrm{Cr}, \mathrm{Ni})$ precipitates, Fe concentrations increase and $\mathrm{Ni}$ concentrations decrease in the diffusion zone towards the fuelside of the diffusion structure, while the $U$ and $\mathrm{Zr}$ concentration levels stay relatively constant. 
The diffusion structure for the couple F vs. HT9 is approximately $30 \mu \mathrm{m}$ wide and is shown in Fig. 3. Phase layers of $\mathrm{UFe}_{2}$, and a $\mathrm{Zr}$-rich phase developed on the cladding-side of the diffusion structure. A two-phase region with a $\mathrm{U}$-rich matrix and $\mathrm{Zr}$-rich precipitate developed on the fuel side of the diffusion structure. Fe levels of 2-3 at.\% are apparent for around $90 \mu \mathrm{m}$ towards the fuel side of the diffusion structure, and a point-by-point analysis of the precipitates indicated that $\mathrm{Fe}$ is preferentially present in the precipitates as opposed to the matrix. The diffusion structure for this couple is much narrower and contains fewer diffusion layers and fewer phases than the F vs. 316 vs. D9 couples.

\section{B. Diffusion Paths}

For the description of diffusion structures of the multicomponent diffusion couples of this study with experimental diffusion paths on composition triangles, the sum of the concentrations of $\mathrm{Fe}, \mathrm{Ni}$ and $\mathrm{Cr}$ is taken as one concentration variable, while $\mathrm{U}$ and $\mathrm{Zr}$ represent the other two. Thus, at any point within the triangle, the sum of the concentrations (atom fractions) of the cladding elements $\mathrm{Fe}, \mathrm{Ni}$, or $\mathrm{Cr}$ when added to those of the elements $\mathrm{U}$ and $\mathrm{Zr}$ will equal one. A diffusion path constructed on this basis from the concentration profiles can be used to describe the diffusion structure and is helpful in comparing the diffusion structures of the various couples. The diffusion path segments crossing a two-phase region are represented by bold dashed lines, while bold solid lines show path segments in single-phase regions. Thin dashed lines indicate schematic tie-lines for two-phase regions, and shaded areas represent approximate ranges of composition for single-phase regions. This procedure for the representation of diffusion path is employed for all couples.

The diffusion path for the couple $\mathrm{F}(\mathrm{U}-23 \mathrm{Zr})$ vs. 316 is presented in Fig. 4(a). The path segment $\mathrm{a}-\mathrm{b}$ corresponds to the two-phase region with $\mathrm{U}(\mathrm{Fe}, \mathrm{Ni}, \mathrm{Cr})_{2}$ precipitates distributed in the $\mathrm{Fe}-\mathrm{Ni}-\mathrm{Cr}$ austenitic matrix. The various segments of the diffusion path are identified on the diffusion structure of the couple in Fig. 1. Segments b-c and d-e represent the single-phase layers $\mathrm{U}(\mathrm{Fe}, \mathrm{Ni}, \mathrm{Cr})_{2}$ and $(\mathrm{Zr}, \mathrm{U})(\mathrm{Fe}, \mathrm{Ni}, \mathrm{Cr})_{2}$, respectively. Segment $\mathrm{c}-\mathrm{d}$ represents the $[\mathrm{U}(\mathrm{Fe}$, 
$\left.\mathrm{Ni}, \mathrm{Cr})_{2}+(\mathrm{Zr}, \mathrm{U})(\mathrm{Fe}, \mathrm{Ni}, \mathrm{Cr})_{2}\right]$ two-phase layer. The diffusion path cuts across tie-lines in these regions which link the matrix and precipitate compositions. Path segment e-g crosses regions where two and three phases are present in the diffusion zone. Phases identified in these regions include: $\mathrm{U}_{6}(\mathrm{Fe}, \mathrm{Ni})$ and $\mathrm{U}$ which are matrices, and $(\mathrm{Zr}, \mathrm{U})(\mathrm{Fe}, \mathrm{Cr}, \mathrm{Ni})_{2-3}$, $(\mathrm{Zr}, \mathrm{U})_{2}(\mathrm{Fe}, \mathrm{Cr}, \mathrm{Ni})$ and $(\mathrm{U}, \mathrm{Zr})_{2}(\mathrm{Fe}, \mathrm{Ni})$ which appear as precipitates. Segment f-g represents the $\left[(\mathrm{U}, \mathrm{Zr})_{9}(\mathrm{Fe}, \mathrm{Ni})+\mathrm{U}+\delta\right]$ three-phase layer.

In Fig. 4(b) is presented the experimental diffusion path for the F vs. D9 couple. It is similar to the diffusion path observed for the F vs. 316 couple except that the path segment a-b extends closer to the $U$ comer of the composition triangle; this is because of the two and threephase layers that appear adjacent to the $\mathrm{U}(\mathrm{Fe}, \mathrm{Ni}, \mathrm{Cr})_{2}$ single-phase layer. These layers correspond to $\left[\mathrm{U}_{6}(\mathrm{Fe}, \mathrm{Ni})+\mathrm{Zr}(>80 \%)\right],\left[\mathrm{U}_{6}(\mathrm{Fe}, \mathrm{Ni})+\mathrm{Zr}(>80 \%)+(\mathrm{Zr}, \mathrm{U})(\mathrm{Fe}, \mathrm{Ni}, \mathrm{Cr})_{2}\right]$, and $\left[\mathrm{U}_{6}(\mathrm{Fe}, \mathrm{Ni})+(\mathrm{Zr}, \mathrm{U})(\mathrm{Fe}, \mathrm{Ni}, \mathrm{Cr})_{2}\right] . \mathrm{A}(\mathrm{U}, \mathrm{Zr})_{9}(\mathrm{Fe}, \mathrm{Ni})$ phase appears as a single-phase layer on the fuel side of the diffusion structure and it is represented by path segment $\mathrm{f}-\mathrm{g}$.

The experimental diffusion path for couple F vs. HT9 is presented in Fig. 4(c). The path extends closer towards the $\mathrm{Zr}$ corner of the triangle compared to the $\mathrm{F}$ vs. $\mathrm{D} 9$ and $\mathrm{F}$ vs. 316 diffusion couples. Path segment $b-c$ describes the single-phase layer $\mathrm{U}(\mathrm{Fe}, \mathrm{Cr})_{2}$ and segment d-e represents the $\mathrm{Zr}$-phase. e-f describes the two-phase layer where $\mathrm{U}$ is the matrix and $\mathrm{Zr}$ the precipitate.

\section{Discussion}

\section{A. On Diffusion Layers}

The intermetallic phases developed for the couples F vs. 316 and F vs. D9 as listed in Table II are very similar. The Ni bearing diffusion couples, F vs. 316 and F vs. D9, show very similar diffusion structures (Fig. 1 and 2) with comparable width (over $100 \mu \mathrm{m}$ ) and similar phases. The major difference between the two couples is the development of a $(\mathrm{U}, \mathrm{Zr})_{9}(\mathrm{Fe}, \mathrm{Ni})$ single-phase layer observed only in the F vs. D9 couple. The HT9 couple which contains 
negligibly small amounts of $\mathrm{Ni}$ has a diffusion structure (Fig. 3) that is different from these of the $\mathrm{F}$ vs. 316 and $\mathrm{F}$ vs. $\mathrm{D} 9$ couples. In the presence of very low concentration of $\mathrm{Ni}$, many metallic phases are not observed in the F vs. HT9 couple, which develops the smallest diffusion structure of all the couples assembled with cladding steels.

Even though $\mathrm{Fe}$ and Ni play the dominant role in the development of diffusion structures, $\mathrm{Cr}$ is crucial with regard to the development of $\mathrm{Zr}$ layers. From the diffusion structure for the $\mathrm{F}$ vs. HT9 couple where a $\mathrm{Zr}$ layer develops, $\mathrm{Cr}$ can be expected to affect the activity of $\mathrm{Zr}$ in the $\delta$ precipitates and cause them to become unstable and to yield a $\mathrm{Zr}$ layer. $\mathrm{The} \mathrm{Zr}$ layer may impede the interdiffusion of fuel and cladding elements. When $\mathrm{Cr}$ is in the presence of approximately 15 at.\% Ni, a large diffusion structure develops as is apparent for the $\mathrm{F}$ vs. D9 couple in Fig. 2. In this couple, $\mathrm{Cr}$ seems to affect the activity of $\mathrm{Zr}$ in $\mathrm{Zr}$-rich precipitates as was observed for the F vs. HT9 couple. A region of high-Zr precipitates is observed in the diffusion structure of the $\mathrm{F}$ vs. D9 couple near phase regions containing $(\mathrm{Zr}, \mathrm{U})(\mathrm{Fe}, \mathrm{Ni}, \mathrm{Cr})_{2}$ phases with relatively high $\mathrm{Cr}$ levels. The $(\mathrm{Zr}, \mathrm{U})(\mathrm{Fe}, \mathrm{Ni}, \mathrm{Cr})_{2}$ phase for the $\mathrm{F}$ vs. $\mathrm{D} 9$ couple has higher levels of $\mathrm{Cr}$ than the corresponding phase observed for other couples $(-35$ at.\% compared to 16 at.\%). In addition, from the cladding side of the $\mathrm{U}(\mathrm{Fe}, \mathrm{Ni}, \mathrm{Cr})_{2}$ layer towards the high- $\mathrm{Zr}$ precipitate side, $\mathrm{Cr}$ levels are observed to increase (from 12 to 22 at.\%). Therefore, as indicated for the F vs. HT9 couple, high Cr levels in the couple F vs. D9 are considered to give rise to the formation of high- $\mathrm{Zr}$ phases. The effect of $\mathrm{Cr}$ on the activity of $\mathrm{Zr}$ may cause the $(\mathrm{Zr}, \mathrm{U})(\mathrm{Fe}, \mathrm{Ni}, \mathrm{Cr})_{2}$ phase to decompose resulting in the formation of a high- $\mathrm{Zr}$ phase. This is similar to the decomposition of $\delta$ precipitates in the F vs. HT9 couple resulting in the formation of a high- $\mathrm{Zr}$ layer.

The differences in the diffusion layers of the various couples are reflected in their diffusion paths. The F vs. 316 and F vs. D9 diffusion couples have similar diffusion paths (Figs. 4(a) and 4(b)) that extend through the same types of phase layers. The diffusion structure for the $\mathrm{F}$ vs. $\mathrm{D} 9$ couple does not contain a well-defined $(\mathrm{Zr}, \mathrm{U})(\mathrm{Fe}, \mathrm{Ni}, \mathrm{Cr})_{2}$ single-phase layer like the F vs. 316 , and as a result the diffusion path for the F vs. D9 couple extends closer 
tov'ards the $U$ comer of the composition triangle. The diffusion path for the F vs. HT9 couple (Fig. 4(c)) differs from the diffusion paths for both the F vs. D9 and F vs. 316 couples. It extends cluser towards the $\mathrm{Zr}$-comer of the isotherm than any of the $\mathrm{Ni}$ bearing couples and includes only one intermediate phase layer. Therefore, the presence of 10 to 15 at.\% $\mathrm{Ni}$ appears to play a deciding role in determining the phase layers that form in the diffusion structure and hence in the development of diffusion paths.

\section{B. The interdiffusion behavior of $\mathrm{Fe}, \mathrm{Ni}$, and $\mathrm{Cr}$}

The results of interdinusion studies with a U-23 at.\% $\mathrm{Zr}$ fuel assembled with $\mathrm{Fe}, \mathrm{Ni}, \mathrm{Fe}-$ 20.1 Cr, Ni-16.4 Cr, Fe-10.1 Ni, and Fe-15.4 Ni-9.4 Cr were reported in a recent paper [8]. On the basis if this work, $\mathrm{Ni}$ is considered to play a major role in the interdiffusion of fuel and cladding components; $\mathrm{Ni}$ containing alloys are more susceptible to forming intermetallics phases with $\mathrm{U}$ and $\mathrm{Zr}$ than alloys without $\mathrm{Ni}$. In general, the diffusion layers formed on the cladding side of the couples are dictated by the $\mathrm{Ni}, \mathrm{Fe}$, and $\mathrm{Cr}$ interactions with $\mathrm{U}$, and the phases on the fuel side of the couple are influenced by the type of intermetallic phases that can form between $\mathrm{Zr}$ and the cladding elements. $\mathrm{Cr}$ influences the interdiffusion behavior by affecting the activities of $U$ and $Z r$ in the $\delta$ precipitates of the binary $U-Z r$ fuel resulting in the development of a Zr-rich layer, which can reduce interdiffusion of fuel and cladding elements. These observations are consistent with the types of phases observed in the diffusion structures of the couples in the present study.

Cladding steels have more elements available for interdiffusion than $\mathrm{Fe}, \mathrm{Ni}$, and $\mathrm{Cr}$. Yet, the diffusion structures and the types of intermetallics observed for the couples with cladding steels are essentially dictated by the interactions of $\mathrm{Fe}, \mathrm{Ni}$, and $\mathrm{Cr}$ with $\mathrm{U}$ and $\mathrm{Zr}$ and other elements appear to play a minor :ole. $U$ is a faster diffuser and the diffusion layers on the cladding side of the couples are dictated by $\mathrm{Fe}, \mathrm{Ni}$, and $\mathrm{Cr}$ interactions with $\mathrm{U}$. Phases on the fuel side of the couples are influenced by the type of intermetallics that can form between $\mathrm{Zr}$ and the cladding elements. As reported for the couples in [8], the diffusion layers that 
developed are consistent with the type of intermetallic phases identified between $\mathrm{U}$ and $\mathrm{Ni}, \mathrm{U}$ and $\mathrm{Fe}, \mathrm{Zr}$ and $\mathrm{Ni}$, and $\mathrm{Zr}$ and $\mathrm{Fe}$ on the basis of phase diagrams. Since $\mathrm{Cr}$ does not form intermetallics with $\mathrm{U}$ and $\mathrm{Zr}$, its role appears to be indirect in affecting $\mathrm{Zr}$ activity in high-Zr precipitates. Of all the cladding elements, $\mathrm{Fe}$ and $\mathrm{Ni}$ penetrate deepest into the fuel for all diffusion couples investigated in this study.

\section{Conclusions}

In the light of the relative diffusion behavior of the fuel and cladding elements and their roles in determining the intermetallic formation, HT9 is considered to be the most favorable choice for a cladding material in the context of fuel-cladding compatibility. HT9 has the lowest $\mathrm{Ni}$ concentration of all the cladding steels and forms the smallest diffusion structure with the fewest number of phases. It exhibits the smallest amount of interdiffusion between fuel and cladding elements possibly due to the formation of a $\mathrm{Zr}$-rich layer, and the number of observed phases is minimal relative to those observed for $\mathrm{Ni}$ bearing couples. Since $\mathrm{Fe}$ and $\mathrm{Ni}$ penetration into the fuel is appreciably smaller with HT9 than with D9 or 316 as the cladding steel, the formation of low melting phases or strength reducing structures is less likely with HT9. Hence, it is concluded that the structural integrity of the cladding can be maintained for a longer period of time during reactor operation with HT9 than with 316 or D9. The diffusion structures observed for the couples with the commercial cladding steels are consistent with those observed for couples with binary and ternary alloys of the Fe-Ni-Cr system.

\section{Acknowledgments}

This research was supported by the U. S. Department of Energy under contract DEFG07-88ER12814. Additional support by the Argonne National Laboratory under the award No. $80000 \mathrm{MOD} 1$ is gratefully acknowledged. 


\section{References}

1. G. L. Hofman, Nucl. Tech., 47 (1980) 7.

2. R. E. Einziger and B. R. Seidel, Nucl. Tech., 50 (1980) 25.

3. B. R. Seidel, L. C. Walters, and Y. I. Chang, J. Metall, 39 (1987) 10.

4. B. R. Siedel and L. C. Walters, Trans of ASME, 103 (1981) 612.

5. L. C. Walters and J. H. Kittel, Nucl. Tech., 48 (1980) 273.

6. C. E. Lahm, et a!., Nucl. Engr. and Design, 101 (1987) 25.

7. G. L. Hofman, et al., in: Proc. of the International Conference on Reliable Fuels for Liquid Metal Reactors, Tucson, AZ (1986) pp. 4-121.

8. D. D. Keiser, Jr. and M. A. Dayananda, J. Nucl. Mat., 1993 (in print). 
Table I. Typical compositions of cladding steels (at.\%) employed by ANL.

\begin{tabular}{|c|c|c|c|}
\hline & HT9 & D9 & 316 \\
\hline $\mathrm{Fe}$ & $\mathrm{Bal}$ & $\mathrm{Bal}$ & $\mathrm{Bal}$ \\
$\mathrm{Cr}$ & 12.02 & 13.45 & 16.30 \\
$\mathrm{Ni}$ & 0.57 & 15.61 & 10.50 \\
$\mathrm{Mo}$ & 1.03 & 1.65 & 2.11 \\
$\mathrm{Ti}$ & 0.002 & 0.32 & 0.0 \\
$\mathrm{~V}$ & 0.34 & $>0.01$ & 0.0 \\
$\mathrm{~W}$ & 0.51 & $>0.01$ & 0.0 \\
$\mathrm{Mn}$ & 0.50 & 2.05 & 1.47 \\
$\mathrm{Si}$ & 0.22 & 0.85 & 0.67 \\
$\mathrm{C}$ & 0.21 & 0.034 & 0.05 \\
$\mathrm{~N}$ & 0.0037 & 0.0051 & 0.0612 \\
$\mathrm{O}$ & 0.0058 & 0.0062 & 0.0075 \\
\hline
\end{tabular}


Table II. Phases identified in diffusion couples.

\begin{tabular}{|c|l|}
\hline Diffusion Couple & \multicolumn{1}{|c|}{ Phases* } \\
\hline F vs. 316 & $\mathrm{U}(\mathrm{Fe}, \mathrm{Ni}, \mathrm{Cr})_{2}, \mathrm{U}_{6}(, \mathrm{Fe}, \mathrm{Ni}),(\mathrm{Zr}, \mathrm{U})(\mathrm{Fe}, \mathrm{Ni}, \mathrm{Cr})_{2}(\mathrm{Zr}, \mathrm{U})_{2}(\mathrm{Fe}, \mathrm{Ni})$, \\
& $(\mathrm{U}, \mathrm{Zr})_{9}(\mathrm{Fe}, \mathrm{Ni})$ \\
& $\mathrm{U}(\mathrm{Fe}, \mathrm{Ni}, \mathrm{Cr})_{2}, \mathrm{U}_{6}(\mathrm{Fe}, \mathrm{Ni}),(\mathrm{Zr}, \mathrm{U})(\mathrm{Fe}, \mathrm{Ni}, \mathrm{Cr})_{2},(\mathrm{Zr}, \mathrm{U})_{2}(\mathrm{Fe}, \mathrm{Ni})$, \\
F vs. D9 & $(\mathrm{U}, \mathrm{Zr})_{9}(\mathrm{Fe}, \mathrm{Ni}), \mathrm{Zr}$-rich phase, $\sigma$ \\
& $\mathrm{U}(\mathrm{Fe}, \mathrm{Cr})_{2}, \mathrm{Zr}$-rich phase, $\sigma$ \\
\hline
\end{tabular}

*The intermetallic designations of the phases are based on the relative concentrations of the individual elements. 


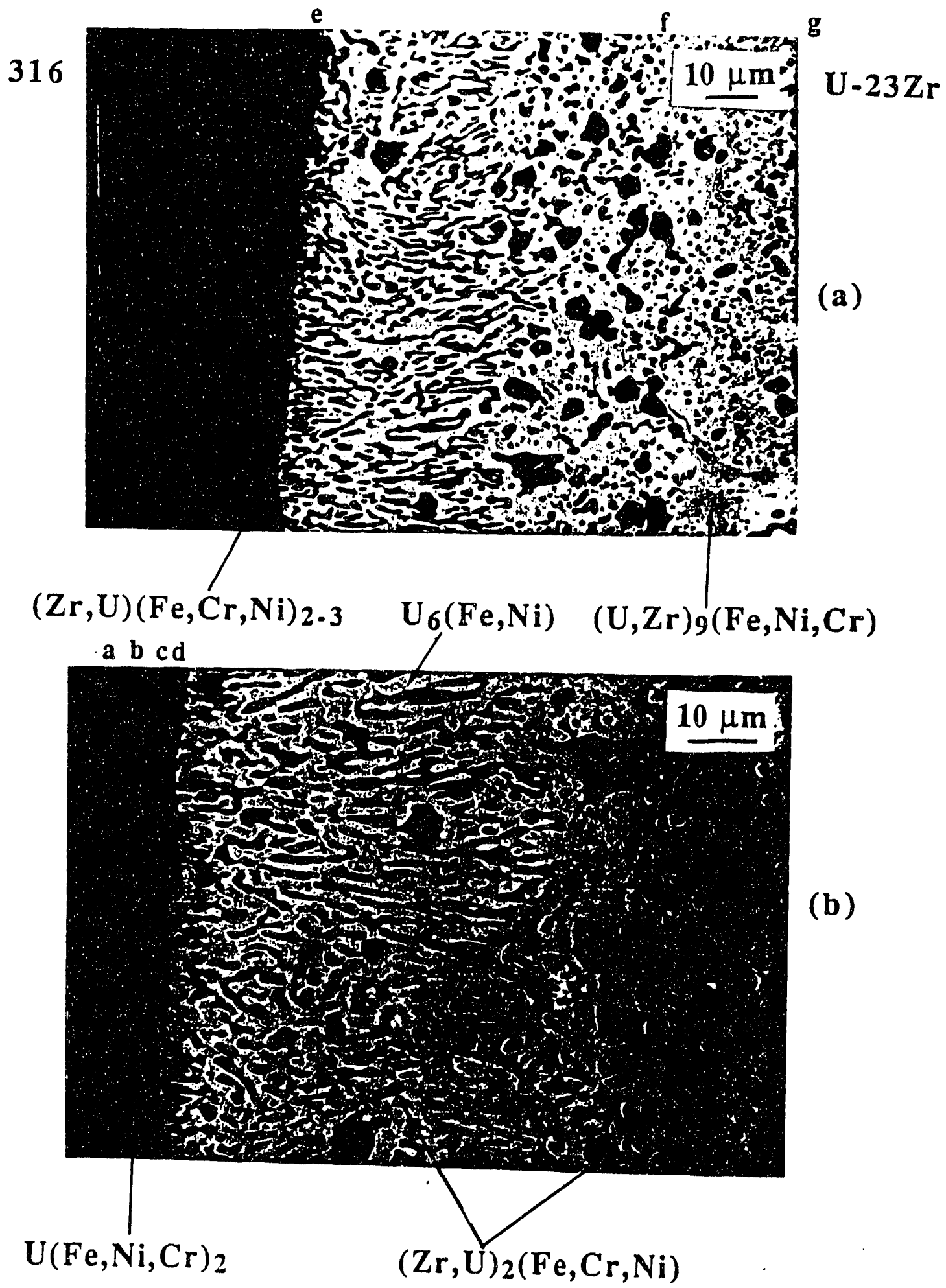

Fig. 1. SEM micrographs showing the diffusion layers and intermetallic phases developed for the $\mathrm{F}(\mathrm{U}-23 \mathrm{Zr})$ vs. 316 couple annealed at $700^{\circ} \mathrm{C}$ for 4 days; (a) and (b) are at two different magnifications. 


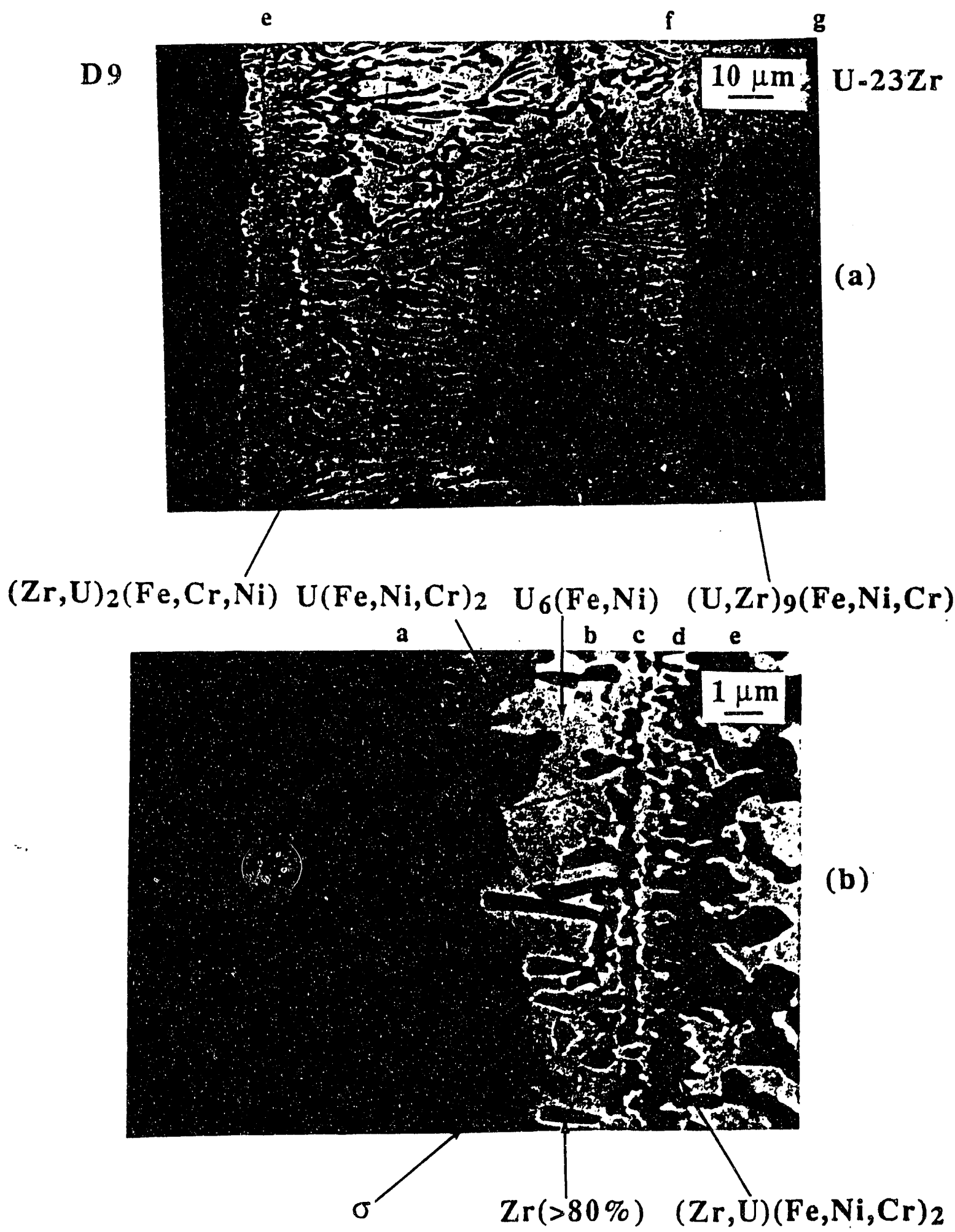

Fig. 2. SEM micrographs showing the diffusion layers and intermetallic phases developed for the $F(U-23 \mathrm{Zr})$ vs. $D 9$ couple annealed at $700^{\circ} \mathrm{C}$ for 4 days; (a) and (b) are at two different magnifications. 


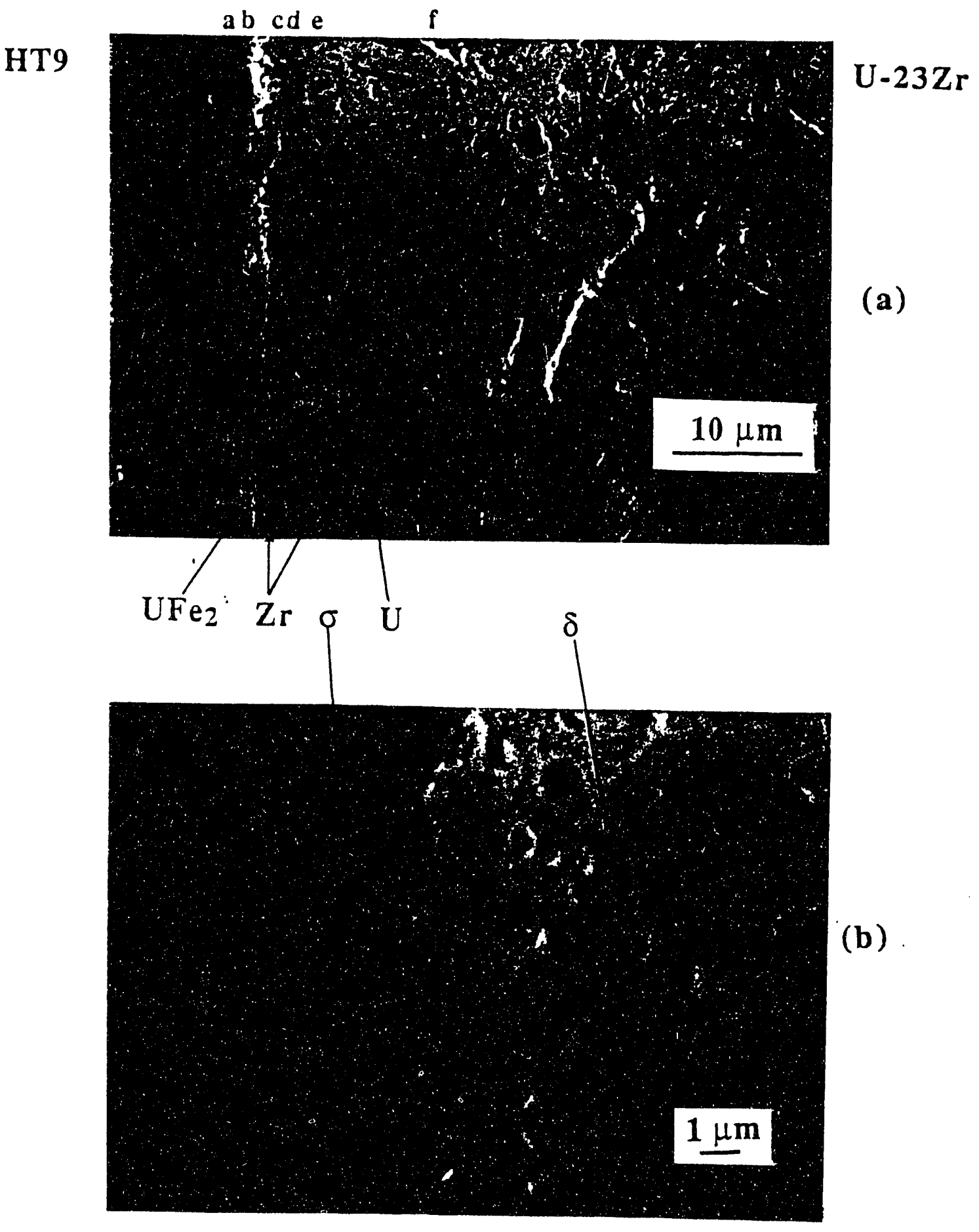

Fig. 3. SEM micrographs showing the diffusion layers and intermetallic phases developed for the $\mathrm{F}(\mathrm{U}-23 \mathrm{Zr})$ vs. HT9 couple annealed at $700^{\circ} \mathrm{C}$ for 4 days; (a) and (b) are at two different magnifications. 


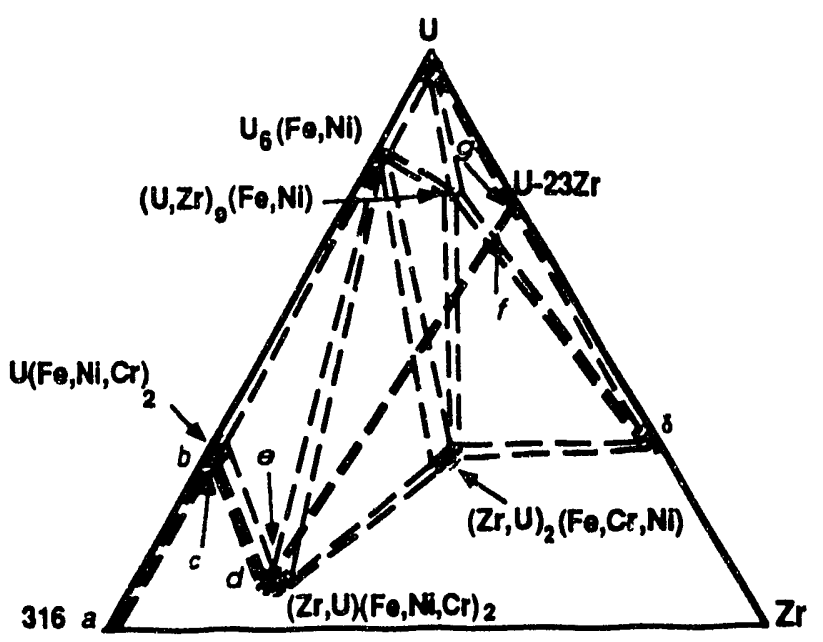

(a)

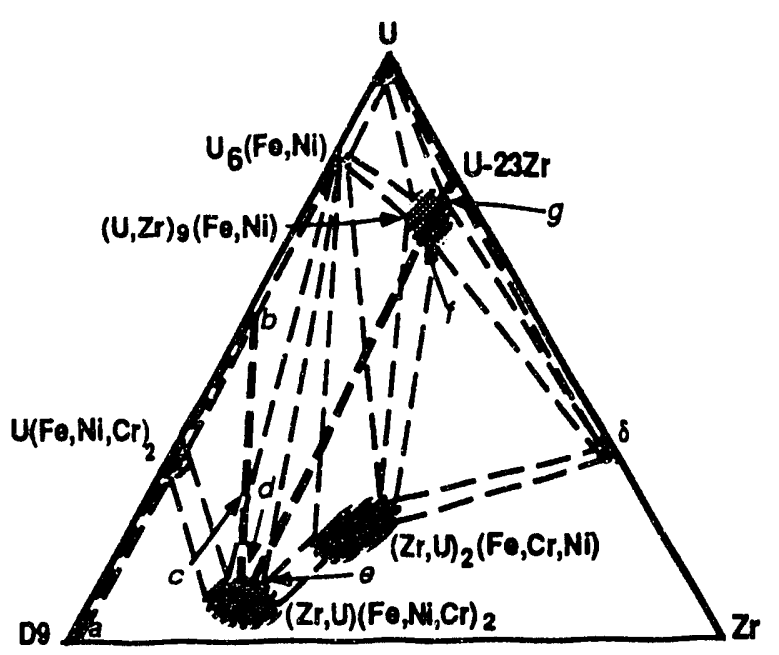

(b)

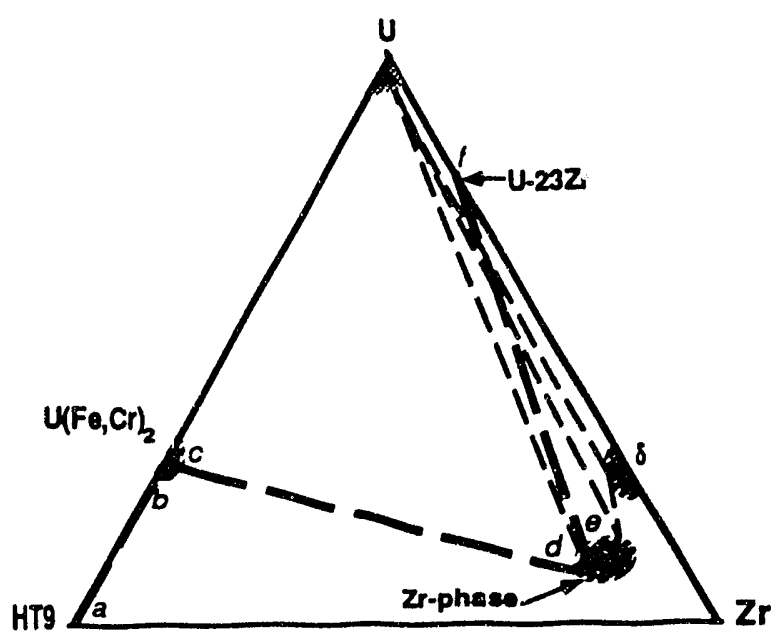

(c)

Figure 4. Experimental diffusion paths on composition triangles at $700^{\circ} \mathrm{C}$ for the couples (a) F vs. 316 , (b) F vs. D9, and (c) F vs. HT9. Diffusion layer designations are based on relative ratios of concentrations. The phase boundaries are approximate and schematic. 


\section{APPENDIX F}

Interdiffusion of Cerium in $\mathrm{Fe}$-Base Alloys with $\mathrm{Ni}$ or $\mathrm{Cr}$ 


\title{
INTERDIFFUSION OF CERIUM IN Fe-BASE ALLOYS WITH Ni OR Cr
}

\author{
P. C. Tortorici and M. A. Dayananda \\ Purdue University, W. Lafayette, IN 47907-1289, USA
}

\begin{abstract}
Isothermal interdiffusion studies relevant to lanthanide interactions with cladding alloys in the Integral Fast Reactor program were carried out at $425^{\circ} \mathrm{C}$ by employing solid-solid diffusion couples assembled with disks of $\mathrm{Ce}$ and disks of $\mathrm{Fe}, \mathrm{Ni}$, and $\mathrm{Fe}-10.1 \mathrm{Ni}$, and Fe-20.1 Cr, binary alloys (composition in at. \%). The diffusion structures and intermetallic layers which developed in the various couples during the diffusion anneal were metallographically examined and analyzed by SEM-EDS techniques for concentration profiles. Computer programs were developed to construct profiles of concentrations and to evaluate interdiffusion fluxes and effective interdiffusion coefficients for the individual components over selected regions of the diffusion zones of the various couples. Intrinsic diffusion data were calculated at marker planes in the $\mathrm{Ni}_{3} \mathrm{Ce}_{7}$ and $\mathrm{Fe}_{2} \mathrm{Ce}$ phases developed in the $\mathrm{Ni}$ vs. $\mathrm{Ce}$ and $\mathrm{Fe}$ vs. Ce couples, respectively. The intermetallic phases and diffusion layers observed in the various couples are discussed in the light of phase diagrams and experimental diffusion paths.
\end{abstract}




\section{Introduction}

The main features underlying the Integral Fast Reactor (IFR) concept which is being developed at Argonne National Laboratory include the use of U-Pu-Zr metallic fuel, liquid sodium cooling, a pool type reactor configuration, and the reprocessing of fuel [1]. The metallic U-Pu-Zr fuel offers high thermal conductivity, ease of fabrication, good irradiation behavior, high burn-up potential, among other benefits.

During irradiation, the U-Pu- $\mathrm{Zr}$ fuel swells and comes into contact with the stainless steel cladding enclosing the fuel element. Also during the irradiation process, a number of fission products including lanthanides (Ce, $\mathrm{La}, \mathrm{Pr}$ among others) are generated. The migration of the lanthanides through the fuel towards the fuel/clad interface can result in their chemical interaction with the stainless steel cladding materials. Such interactions can result in the formation of intermetallic phases and low melting eutectics, which adversely affect the structural integrity of the cladding alloy as a result of localized melting.

The extent of the interaction between the fuel containing lanthanides and cladding alloys is among the major issues that are currently being investigated in the context of fuel/clad compatibility and assessment of acceptable fuel/cladding combinations. In this study, interdiffusion experiments were carried out at $425^{\circ} \mathrm{C}$ with solid-solid diffusion couples assembled with disks of $\mathrm{Ce}$ and disks of $\mathrm{Fe}, \mathrm{Ni}$, and $\mathrm{Fe}-10.1 \mathrm{Ni}$, and $\mathrm{Fe}-20.1 \mathrm{Cr}$ binary alloys. The diffusion layers that developed in the various couples are examined for the identification of intermetallic phases, analyzed for average effective interdiffusion coefficients for the individual components, and described with the aid of phase diagrams and diffusion paths.

\section{Experimental Procedure}

$\mathrm{Ce}, \mathrm{Ni}$ and $\mathrm{Fe}$ (99.9\% pure) were obtained from Rhone-Poulenc Inc, Alpha Products Inc, and Goodfellow Inc., respectively. Binary alloys with compositions of $\mathrm{Fe}-10.1 \mathrm{Ni}$, and $\mathrm{Fe}-20.1$ $\mathrm{Cr}$ were fabricated at by vacuum induction melting [2]. Charges were melted in alumina 
crucibles under an argon atmosphere, and drawn up fused silica draw tubes, $10 \mathrm{~mm}$ in diameter. All alloys were homogenized at $1150^{\circ} \mathrm{C}$ for 7 days in an evacuated quartz capsule.

Diffusion disks, approximately $5 \mathrm{~mm}$ in diameter and $5 \mathrm{~mm}$ thick, were sectioned from $\mathrm{Ce}, \mathrm{Ni}, \mathrm{Fe}$ and various alloys. The disk surfaces were ground through 600 grit SiC paper to ensure parallel faces. The disks were metallographically polished through $1 \mu \mathrm{m}$ diamond paste in an Aldrich atmosbag with flowing helium (99.9\%). This procedure was employed to ensure that the surfaces were free from an oxide layer; the helium environment was especially required for cerium whose reactivity with air and water based solvents is severe. The polished disks were employed in assembling sandwich couples inside a Kovar steel jig consisting of two end plates and three threaded Kovar steel rods. The couples consisted of a Ce disk sandwiched by selected alloy disks, one on either side. Kovar steel ( $54 \mathrm{Fe}-29 \mathrm{Ni}-17 \mathrm{Co}$ at.\%) was chosen for the jig due to its low coefficient of thermal expansion.

The assembled couples were then placed in quartz capsules which were sealed at one end under a constant flow of helium gas. The capsule was then attached to a vacuum system, evacuated and backfilled with hydrogen gas several times. After a final evacuation, the capsule was sealed and annealed in a horizontal Lindberg three-zone tube furnace at $425^{\circ} \mathrm{C}$ for 4 days.

The annealed capsules were quenched in an ice water bath after the diffusion anneal. The couples with the Kovar jigs were removed and cold-mounted in a clear epoxy resin. The mounted couples were sectioned with an Isomet diamond saw to expose surfaces parallel to the diffusion direction. The exposed sections were then mechanically polished on 600 grit SiC paper and through $1 \mu \mathrm{m}$ diamond paste on a cloth wheel with dehydrated ethyl alcohol used as a lubricant in all steps.

The polished sample was immediately transferred to a JEOL 35CF scanning electron microscope (SEM), equipped with a Tracor Northern Series II energy dispersive X-ray analyzer. The couples were analyzed by point-to-point counting techniques for concentration profiles and phase identification. The intensities of $\mathrm{X}$-ray $\mathrm{K}_{\alpha}$ lines for $\mathrm{Fe}(6.403 \mathrm{keV}), \mathrm{Ni}(7.477 \mathrm{keV}), \mathrm{Cr}$ 
( $5.414 \mathrm{keV})$, and $\mathrm{L}_{\alpha}$ line for $\mathrm{Ce}(4.839 \mathrm{keV})$ were collected and stored on floppy disks, then converted into compositions with the aid of pure elemental standards and a ZAF correction program. Secondary electron micrographs were taken to record the diffusion structure and intermetallic layers developed in the various couples.

\section{Results}

\subsection{Diffusion structures and intermetallic phases}

The phase layers identified in the diffusion structures of the various couples in this study are listed in Table 1. The intermetallic designations of the phase layers in Table 1 are entirely based on compositional analysis by EDS ignoring the trace impurities such as $\mathrm{C}, \mathrm{O}$, and $\mathrm{N}$. The designation for a phase layer corresponds to the ratio of the Ce concentration to the sum of all the other elements analyzed in the layer and is not based on any intermetallic structural data. Based on the counting statistics, the uncertainty in the EDS analysis of the major elements Ce, $\mathrm{Fe}, \mathrm{Ni}$, and $\mathrm{Cr}$ is within \pm 0.5 at.\%. On the basis of the $\mathrm{Ni}$ vs. $\mathrm{Ce}$ and $\mathrm{Fe}$ vs $\mathrm{Ce}$ phase diagrams [3] presented in Figs 1(a) and 1(b), respectively, six possible intermetallic compounds are observed between $\mathrm{Ce}$ and $\mathrm{Ni}$, while only two can form between $\mathrm{Ce}$ and $\mathrm{Fe}$. $\mathrm{Ce}$ and $\mathrm{Cr}$ have negligible solubility in each other and form no intermetallic compounds [3].

\subsubsection{Binary Couples: Ni vs. Ce and Fe vs. Ce}

The diffusion structure and the concentration profile for the $\mathrm{Ni}$ vs. Ce couple are presented in Fig. 2(a) and 2(b), respectively. Two diffusion layers developed in this couple and correspond to $\mathrm{Ni}_{2} \mathrm{Ce}$ and $\mathrm{Ni}_{3} \mathrm{Ce}_{7}$ phases in the phase diagram in Fig. 1(a). The intermetallic designation of the phases are based on the approximate ratio of $\mathrm{Ni}$ concentration to that of $\mathrm{Ce}$. The approximate widths of the $\mathrm{Ni}_{2} \mathrm{Ce}$ and $\mathrm{Ni}_{3} \mathrm{Ce}_{7}$ layers are $10 \mu \mathrm{m}$ and $240 \mu \mathrm{m}$, respectively. The Matano plane for the couple determined on the basis of mass balance is identified at $x_{0}$ and a marker plane is identified at $\mathrm{x}_{\mathrm{m}}$ in the $\mathrm{Ni}_{3} \mathrm{Ce}_{7}$ phase. 
A secondary electron micrograph and the concentration profile for the Fe vs. Ce couple are presented in Fig. 3. Only one diffusion layer, approximately $20 \mu \mathrm{m}$ wide, develops as can be seen in Fig. 3(a); the layer corresponds to $\mathrm{Fe}_{2} \mathrm{Ce}$ phase on the basis of the phase diagram in Fig. 1(b). The width of the diffusion zone of the Fe vs. Ce couple is appreciably smaller than that of $\mathrm{Ni}$ vs. Ce couple. The interdiffusion of $\mathrm{Ni}$ in $\mathrm{Ce}$ is much more rapid than that of $\mathrm{Fe}$ in Ce. A marker plane is identified in the $\mathrm{Fe}_{2} \mathrm{Ce}$ phase in Fig. 3(b).

\subsubsection{Ternary Couples: $\mathrm{Fe}-10.1 \mathrm{Ni}$ vs. Ce, Fe-20.I Crvs. Ce}

In Fig. 4 (a) and 4(b) are presented the diffusion structure and the concentration profiles for the Fe-10.1 Ni vs. Ce couple. Two diffusion layers observed in the micrograph in Fig. 4(a) correspond to $(\mathrm{Fe}+\mathrm{Ni})_{2} \mathrm{Ce}$ and $(\mathrm{Ni}+\mathrm{Fe})_{3} \mathrm{Ce}_{7}$ phases. The width of the diffusion zone is of the order of $25 \mu \mathrm{m}$ and is similar to that observed for the Fe vs. Ce couple.

The diffusion structure and the concentration profiles for the Fe-20.1 $\mathrm{Cr}_{\mathrm{v}} \mathrm{vs} . \mathrm{C}_{\mathbf{v}}$ ternary couple are presented in Fig. 5. Two diffusion layers corresponding to $(\mathrm{Fe}+\mathrm{Cr})_{7} \mathrm{Ce}_{3}$ and $\mathrm{Fe}_{2} \mathrm{Ce}$ phases are observed in the diffusion $\mathrm{zr}$ ne whose width is approximately $20 \mu \mathrm{m}$. The $(\mathrm{Fe}+\mathrm{Cr})_{7} \mathrm{Ce}_{3}$ layer developed in the couple does not correspond to any phase on the binary Fe-Ce diagram. The layer identified as $\mathrm{Fe}_{2} \mathrm{Ce}$ has negligible amourts of $\mathrm{Cr}$, as can be seen from the $\mathrm{Cr}$ concentration profile in Fig. 5(b). In addition, $\mathrm{Cr}$ appears to build up in the $\mathrm{Fe}+$ $\mathrm{Cr})_{7} \mathrm{Ce}_{3}$ layer.

The diffusion paths for all the ternary couples are presented on compusition triangles in Fig. 6. The paths are S-shaped as required for solid-solid couples. The single phase layers developed in the various couples are identified by the shaded areas on the composition triangles. In Fig. 6(a) the dashed line segments, ab, cd and ef of the diffusion path for the Fe-10.1 Ni vs. $\mathrm{Ce}$ couple represent tie lines for two-phase equilibria at the interfaces between $\mathrm{Ce}$ and $(\mathrm{Ni}+\mathrm{Fe})_{3} \mathrm{Ce}_{7}$ phases, $(\mathrm{Ni}+\mathrm{Fe})_{3} \mathrm{Ce}_{7}$ and $(\mathrm{Fe}+\mathrm{Ni})_{2} \mathrm{Ce}$ phases, and $(\mathrm{Fe}+\mathrm{Ni})_{2} \mathrm{Ce}$ and $\mathrm{Fe}-10.1 \mathrm{Ni}$ phases, respectively. Similarly, the path segments, ab, cd and ef in Fig. 7(b) correspond to 
two-phase equilibria at the interfaces between $\mathrm{Ce}$ and $\mathrm{Fe}_{2} \mathrm{Ce}$ phases, $\mathrm{Fe}_{2} \mathrm{Ce}$ and $(\mathrm{Fe}+\mathrm{Cr})_{7} \mathrm{Ce}_{3}$ phases and $(\mathrm{Fe}+\mathrm{Cr})_{7} \mathrm{Ce}_{3}$ and $\mathrm{Fe}-20.1 \mathrm{Cr}$ phases, respectively.

\subsection{Average Effective Interdiffusion Coefficients}

On the basis of an analysis by Dayananda $[4,5]$, average effective interdiffusion coefficients and root-mean-square penetration depths can be determined for individual components in binary and multicomponent diffusion couples. This analysis is employed to calculate an effective interdiffusion coefficient for each component over selected ranges of concentrations in the diffusion zones of the diffusion couples investigated in this study.

On the basis of Onsager's formalism [6] of Fick's law, the interdiffusion flux $\tilde{\mathrm{J}}_{\mathbf{i}}$ of component $i$ in an n-component alloy is expressed by [4]:

$$
\tilde{\mathrm{J}}_{\mathrm{i}}=-\tilde{\mathrm{D}}_{\mathrm{i}}^{\text {eff }} \frac{\partial \mathrm{C}_{\mathrm{i}}}{\partial \mathrm{x}}
$$

where

$$
\tilde{D}_{i}^{\text {eff }}=\tilde{D}_{i i}^{n}+\sum_{j}^{n-1} \frac{\tilde{D}_{i j}^{n} \partial C_{j} / \partial x}{\partial C_{i} / \partial x}
$$

For component $\mathrm{i}, \tilde{\mathrm{D}}_{\mathrm{ii}}^{\mathrm{n}}$ is the main interdiffusion coefficient, and the second term in Eq. (2) incorporates cross i-...rdiffusion coefficients, $\tilde{\mathrm{D}}_{\mathrm{ij}}^{\mathrm{n}}$. For an isothermal diffusion couple assembled with two alloys of initial concentrations, $C_{i}^{+}$and $C_{i}^{-}$, and diffusion annealed for time $t$, the interdiffusion fluxes based on a laboratory fixed frame can be determined direcily from the concentration profiles on the basis of the relation $[7,8]$ :

$$
\tilde{J}_{i}=\frac{1}{2 t} \int_{C_{i}^{+} \text {or } C_{i}^{-}}^{C_{i}(x)}\left(x-x_{0}\right) d C_{i}
$$

where $x_{0}$ refers to the Matano plane. Upon integration of $\tilde{J}_{j}$ over $x$ from $+\infty$ to $x_{0}$, one derives the following relation [4]: 


$$
\int_{+\infty}^{x_{0}} \tilde{J}_{i} d x=-\frac{1}{2 t} \int_{C_{i}^{+}}^{x_{0}}\left(x-x_{0}\right)^{2} d C_{i}
$$

A substitution of Eq. (1) into Eq. (4) yields:

$$
\tilde{D}_{i, R}=\frac{1}{2 t} \frac{\int_{C_{i}^{+}}^{x_{0}}\left(x-x_{0}\right)^{2} d C_{i}}{\left[C_{i}^{0}-C_{i}^{+}\right]}
$$

where $C_{i}^{o}$ refers to the concentration at the Matano plane and $\tilde{D}_{i, R}$ is termed the average effective interdiffusion coefficient for component $i$ to the right of the Matano plane, over the range $C_{i}^{+}$to $C_{i}^{o}$. From Eq. (5) an effective penetration depth for component $i$ on the right-hand side of the Matano plane can be determined by:

$$
\overline{\mathbf{x}}_{\mathrm{i}, \mathrm{R}}=\sqrt{2 \tilde{\mathrm{D}}_{\mathrm{i}, \mathrm{R}} \mathrm{t}}
$$

where $x_{i, R}$ corresponds to the root-mean-square value of $\sqrt{\left(x-x_{0}\right)^{2}}$. A similar procedure can be applied to the concentration profile on the left-hand side of the Matano plane for the determination of an average effective interdiffusion coefficient, $\tilde{\mathrm{D}}_{\mathrm{i}, \mathrm{L}}$, and an effective penetration depth, $\bar{x}_{i, L}$. Effective interdiffasion coefficients and penetration depths for the individual components were evaluated over selected phase layers on either side of the Matano plane for the Ni vs. Ce, Fe vs. Ce, Fe-10.1 Ni vs. $\mathrm{Ce}$, and Fe-20.1 Cr vs. Ce couples and are reported in Table 2.

\subsection{Intrinsic Diffusion in $\mathrm{Ni}_{3} \mathrm{Ce}_{7}$ and $\mathrm{FC}_{2} \mathrm{Ce}$ Phases}

For the Ni vs. Ce and Fe vs. Ce binary diffusion couples, marker planes were identified after diffusion in the $\mathrm{Ni}_{3} \mathrm{Ce}_{7}$ and $\mathrm{Fe}_{2} \mathrm{Ce}$ phase layers, respectively, as indicated at $\mathrm{x}_{\mathrm{m}}$ in Figs. 2(b) and 3(b). The cumulative intrinsic flux, $A_{i}$, of component $i$ past a marker plane moving parabolically with time at a constant composition is obtained by integrating the intrinsic flux $J_{i}$ over time $\mathrm{t}$ [9]; thus, 


$$
\begin{aligned}
A_{i} & =\int_{0}^{i} J_{i} d x \\
& =-\left.2 t D_{i} \frac{\partial C_{i}}{\partial x}\right|_{x_{m}}
\end{aligned}
$$

where $D_{i}$ is the intrinsic diffusion coefficient for component $i . A_{i}$ is determined graphically from appropriate areas under the concentration profiles. For the ratio of cumulative intrinsic fluxes, Eq. (7) yields:

$$
\left|\frac{A_{1}}{A_{2}}\right|=\frac{D_{1}}{D_{2}}
$$

On the basis of Eq. (8), the ratio $\frac{D_{\mathrm{Ni}}}{\mathrm{D}_{\mathrm{Ce}}}$ of intrinsic diffusion coefficients in the $\mathrm{Ni}_{3} \mathrm{Ce}_{7}$ phase was determined to be 15 , while a value of 4 was obtained for the ratio of $\frac{D_{\mathrm{Fe}}}{\mathrm{D}_{\mathrm{Ce}}}$ for the $\mathrm{Fe}_{2} \mathrm{Ce}$ phase.

\section{Discussion}

\subsection{Phase Layer Development}

As reported in Table 1, the phase layers that developed in the binary Ni vs. Ce and Fe vs. Ce couples include only a few of the various intermetallic phases which can form on the basis of the binary phase diagrams in Fig. 1. Among the six possible intermetallic phases between $\mathrm{Ni}$ and $\mathrm{Ce}$, only two phases, $\mathrm{Ni}_{2} \mathrm{Ce}$ and $\mathrm{Ni}_{3} \mathrm{Ce}_{7}$, were observed in the $\mathrm{Ni}$ vs. Ce couple. The $\mathrm{Ni}_{3} \mathrm{Ce}_{7}$, phase is expected to form on the Ce side, as there exists some solubility of $\mathrm{Ni}$ in $\mathrm{Ce}$. The growth of the $\mathrm{Ni}_{3} \mathrm{Ce}_{7}$ phase occurs faster towards the $\mathrm{Ce}$ side than in the opposite direction towards the Ni side, as can be seen in Fig. 2(b) by the location of the Matano plane. This observation is consistent with the fact that Ni intrinsically diffuses nearly 16 times faster than $\mathrm{Ce}$ in the $\mathrm{Ni}_{3} \mathrm{Ce}_{7}$ phase, as calculated on the basis of Eq. (8). The small thickness of the $\mathrm{Ni}_{2} \mathrm{Ce}$ 
layer relative to that of $\mathrm{Ni}_{3} \mathrm{Ce}_{7}$ indicate that the velocities of $\mathrm{Ni} / \mathrm{Ni}_{2} \mathrm{Ce}$ and $\mathrm{Ni}_{2} \mathrm{Ce} / \mathrm{Ni}_{3} \mathrm{Ce} 7$ interfaces in the direction towards $\mathrm{Ni}$ are quite similar. Among the two phases, $\mathrm{Fe}_{17} \mathrm{Ce}_{2}$ and $\mathrm{Fe}_{2} \mathrm{Ce}$ that can form between $\mathrm{Fe}$ and $\mathrm{Ce}$ on the basis of the phase diagram in Fig. 1(b), only the $\mathrm{Fe}_{2} \mathrm{Ce}$ phase was observed as a thin layer in the $\mathrm{Fe}$ vs. Ce couple. Not all phases based on the phase diagram need to form in a multiphase diffusion couple, as the appearance of a phase in the diffusion zone is influenced by nucleation barriers, incubation time, and interdiffusion behavior in the adjacent phases [10].

From a comparison of the widths of the diffusion zones for the $\mathrm{Ni}$ vs. $\mathrm{Ce}$ and $\mathrm{Fe}$ vs. $\mathrm{Ce}$ binary couples, it is apparent that the interdiffusion of $\mathrm{Ni}$ with $\mathrm{Ce}$ is appreciably faster than that of $\mathrm{Fe}$ with $\mathrm{Ce}$. The phases, $\mathrm{Ni}_{3} \mathrm{Ce}_{7}$ and $\mathrm{Fe}_{2} \mathrm{Ce}$, formed in the two couples form eutectics with $\mathrm{Ce}$ at $477^{\circ} \mathrm{C}$ and $592^{\circ} \mathrm{C}$, respectively. In the context of lanthanide interactions with clad alloys, the formation of the $\mathrm{Ni}_{3} \mathrm{Ce}_{7}$ and $\mathrm{Fe}_{2} \mathrm{Ce}$ phases can be considered undesirable.

The layers of $(\mathrm{Fe}+\mathrm{Ni})_{2} \mathrm{Ce}$ and $(\mathrm{Ni}+\mathrm{Fe})_{3} \mathrm{Ce}_{7}$ intermetallics developed in the ternary $\mathrm{Fe}$ 10.1 $\mathrm{Ni}$ vs. Ce couple shown in Fig. 4 are comparable to the $\mathrm{Fe}_{2} \mathrm{Ce}$ and $\mathrm{Ni}_{3} \mathrm{Ce}_{7}$ phases identified in the binary couples. In the $(\mathrm{Fe}+\mathrm{Ni})_{2} \mathrm{Ce}$ phase, the $\mathrm{Ni}$ concentration is about 3 at.\%, while the concentration of $\mathrm{Fe}$ is about 3 at. $\%$ in the $(\mathrm{Ni}+\mathrm{Fe})_{3} \mathrm{Ce}_{7}$ phase. Hence, the compositions of these phases are quite close to $\mathrm{Fe}-\mathrm{Ce}$ and $\mathrm{Ni}-\mathrm{Ce}$ edges of the composition triangle as indicated on the diffusion path in Fig. 6(a). The important thing to note is that the presence of 10 at.\% $\mathrm{Ni}$ in the Fe-base terminal alloy of the couple is enough to cause the formation of a layer of $\mathrm{Ni}_{3} \mathrm{Ce}_{7}$, pe phase containing a few at.\% $\mathrm{Fe}$, although the thickness of the layer is quite limited as indicated in Table 1.

The ternary Fe-20.1 Cr vs. Ce couple which developed the layers of $(\mathrm{Fe}+\mathrm{Cr})_{7} \mathrm{Ce}_{3}$ and $\mathrm{Fe}_{2} \mathrm{Ce}$ as shown in Fig. 5 provides an insight into the effect of $\mathrm{Cr}$ addition to $\mathrm{Fe}$ on the development of diffusion structure. The $\mathrm{Fe}_{2} \mathrm{Ce}$ layer has little $\mathrm{Cr}$ and is similar to that developed for the Fe vs. Ce binary couple. This observation implies that $\mathrm{Cr}$ has little solubility in the $\mathrm{Fe}_{2} \mathrm{Ce}$ phase. On the other hand, the $(\mathrm{Fe}+\mathrm{Cr})_{7} \mathrm{Ce}_{3}$ phase has appreciable $\mathrm{Cr}$, as can be 
seen in Fig. 5(b) and Fig. 6(b). This is a new ternary phase not reported earlier, and there is no analogous binary $\mathrm{Fe}_{7} \mathrm{Ce}_{3}$ phase on the $\mathrm{Fe}$-Ce phase diagram.

\section{Interdiffusion Behavior of the Elements in Various Couples}

The relative interdiffusion behavior of the individual elements in the various couples can be appreciated from the average effective interdiffusion coefficients reported in Table 2 . $\tilde{\mathrm{D}}_{\mathrm{Ni}, \mathrm{R}}^{\mathrm{eff}}$ calculated for the diffusion zone on the right-hand-side of the Matano plane for the $\mathrm{Ni}$ vs $\mathrm{Ce}$ couple in Fig. 2(b) involves essentially the $\mathrm{Ni}_{3} \mathrm{Ce}_{7}$ phase and is larger than $\tilde{\mathrm{D}}_{\mathrm{Ni}, \mathrm{L}}^{\text {eff }}$ calculated for the left-hand-side which includes the $\mathrm{Ni}_{2} \mathrm{Ce}$ layer. Hence, the interdiffusion coefficient of $\mathrm{Ni}$ or $\mathrm{Ce}$ for the $\mathrm{Ni}_{3} \mathrm{Ce}_{7}$ phase is larger than that for the $\mathrm{Ni}_{2} \mathrm{Ce}$ phase. Similarly, $\tilde{\mathrm{D}}_{\mathrm{Ni}, \mathrm{R}}^{\text {eff }}$ for the $\mathrm{Fe}$ 10.1 $\mathrm{Ni}$ vs. Ce couple is large and is for the diffusion zone including the $(\mathrm{Ni}+\mathrm{Fe})_{3} \mathrm{Ce}_{7}$ phase, which is the ternary extension of the binary $\mathrm{Ni}_{3} \mathrm{Ce}_{7}$ phase. Lower values of average effective interdiffusion coefficients are observed specifically for Fe over the diffusion zones involving the $\mathrm{Fe}_{2} \mathrm{Ce}$ layer in the $\mathrm{Fe}$ vs. $\mathrm{Ce}$ and $\mathrm{Fe}-20.1 \mathrm{Cr}$ vs. Ce couples and the $(\mathrm{Ni}+\mathrm{Fe})_{3} \mathrm{Ce}_{7}$ layer in the $\mathrm{Fe}-10.1 \mathrm{Ni}$ vs. Ce couple. $\mathrm{Fe}$ interdiffusion in the $\left(\mathrm{Ni}+\mathrm{Fe}_{3}\right) \mathrm{Ce}_{7}$ layer is slower than that in the $(\mathrm{Fe}+\mathrm{Ni})_{2} \mathrm{Ce}$ layer where the interdiffusion behavior of $\mathrm{Ni}$ appears comparable to that of $\mathrm{Ce}$.

The interdiffusion of $\mathrm{Cr}$ in the $\mathrm{Fe}-20.1 \mathrm{Cr}$ vs. $\mathrm{Ce}$ couple is of special interest. As can be seen in Fig. 5(b), $\mathrm{Cr}$ concentration builds up in the $(\mathrm{Fe}+\mathrm{Cr})_{7} \mathrm{Ce}_{3}$ phase, while negligible $\mathrm{Cr}$ appears in the adjacent $\mathrm{Fe}_{2} \mathrm{Ce}$ phase. From the $\mathrm{Cr}$ concentration profile, the interdiffusion flux, $\tilde{\mathrm{J}}_{\mathrm{Cr}}$, can be calculated as a function of $\mathrm{x}$ on the basis of Eq. (3). The calculated $\tilde{\mathrm{J}}_{\mathrm{Cr}}$ is found to be negative and appreciable in magnitude in the $(\mathrm{Fe}+\mathrm{Cr})_{7} \mathrm{Ce}_{3}$ phase; on the other hand $\tilde{\mathrm{J}}_{\mathrm{Cr}}$ is negligibly small in the $\mathrm{Fe}_{2} \mathrm{Ce}$ layer. This observation implies that to the left of the $(\mathrm{Fe}+\mathrm{Cr})_{7} \mathrm{Ce}_{3} / \mathrm{Fe}_{2} \mathrm{Ce}$ interface $\mathrm{Cr}$ interdiffuses in the $(\mathrm{Fe}+\mathrm{Cr})_{7} \mathrm{Ce}_{3}$ phase in the direction towards the $\mathrm{Fe}-20.1 \mathrm{Cr}$ alloy, while the $\mathrm{Cr}$ flux towards the $\mathrm{Ce}$ side on the right-hand-side of the interface is negligible. Hence, $\mathrm{Cr}$ transfer across the Matano plane is negligible. $\mathrm{Cr}$ is considered to exhibit a flux reversal at the $(\mathrm{Fe}+\mathrm{Cr})_{7} \mathrm{Ce}_{3} / \mathrm{Fe}_{2} \mathrm{Ce}$ interface. Such flux reversals of a component have been reported for multicomponent diffusion couples within single phase 
layers or at interfaces [11] and have been discussed by Dayananda in the context of the phenomenon of zero-flux planes and flux reversals $[7,8]$. A negative effective interdiffusion coefficient $\tilde{D}_{C_{r}, L}^{\text {eff }}$ for $C r$ reported in Table 2 implies a back-flow and build-up of $\mathrm{Cr}$ in the diffusion zone on the left-hand-side of the Matano Plane.

In the present study, the major emphasis has been placed on the development of phase layers due to interdiffusion between $\mathrm{Ce}$ and the elements $\mathrm{Fe}, \mathrm{Ni}$ and $\mathrm{Cr}$. The presence of trace impurities such as $\mathrm{O}$ and $\mathrm{N}$ would be minimal because of the use of the atmosbag and the $\mathrm{He}$ environment employed in the assembly of diffusion couples. The active role of $\mathrm{O}$ and $\mathrm{N}$ in the development of diffusion structures is considered insignificant in the present study. Systematic assessment of the role of $\mathrm{O}$ and $\mathrm{N}$ on the interdiffusion process between $\mathrm{Ce}$ and $\mathrm{Fe}$-based alloys with $\mathrm{Ni}$ and $\mathrm{Cr}$ would be of interest in the context of exploring possible barriers that would prevent the development of undesirable low melting eutectic mixtures involving intermetallic layers such as $\mathrm{Ni}_{3} \mathrm{Ce}_{7}$ and $\mathrm{Fe}_{2} \mathrm{Ce}$.

\section{Conclusions}

The following are the main conclusions of this study on interdiffusion of $\mathrm{Ce}$ in $\mathrm{Ni}, \mathrm{Fe}$, Fe-10.1 Ni and Fe-20.1 Cr alloys carried out at $425^{\circ} \mathrm{C}$ for 4 days.

1. Only a few of the phases expected on the basis of the binary phase diagrams develop in the $\mathrm{Ni}$ vs. $\mathrm{Ce}$ and $\mathrm{Fe}$ vs. Ce diffusion couples. A large diffusion zone with layers of $\mathrm{Ni}_{2} \mathrm{Ce}$ and $\mathrm{Ni}_{3} \mathrm{Ce}_{7}$ intermetallics is observed in the $\mathrm{Ni}$ vs. Ce couple, while a thin layer of $\mathrm{Fe}_{2} \mathrm{Ce}$ phase forms in the Fe vs. Ce couple.

2. The intrinsic diffusion coefficient of $\mathrm{Ni}$ is 15 times larger than that of $\mathrm{Ce}$ in the $\mathrm{Ni}_{3} \mathrm{Ce}_{7}$ phase. Fe intrinsically diffuses 4 times as fast as $\mathrm{Ce}$ in the $\mathrm{Fe}_{2} \mathrm{Ce}$ phase.

3. The addition of 10 at.\% $\mathrm{Ni}$ to $\mathrm{Fe}$ is sufficient to form the ternary $(\mathrm{Ni}+\mathrm{Fe})_{3} \mathrm{Ce}_{7}$ phase analogous to the binary $\mathrm{Ni}_{3} \mathrm{Ce}_{7}$ phase. 
4. The presence of $\mathrm{Cr}$ in the Fe-20.1 Cr vs. Ce couple results in the formation of a ternary $(\mathrm{Fe}+\mathrm{Cr})_{7} \mathrm{Ce}_{3}$ phase not previously reported. In addition, $\mathrm{Cr}$ exhibits the phenomenon of flux reversal at the $(\mathrm{Fe}+\mathrm{Cr})_{7} \mathrm{Ce}_{3} / \mathrm{Fe}_{2} \mathrm{Ce}$ interface. The back-flow and build-up of $\mathrm{Cr}$ in the $(\mathrm{Fe}+\mathrm{Cr})_{7} \mathrm{Ce}_{3}$ layer yields a negative effective interdiffusion coefficient for $\mathrm{Cr}$ over the diffusion zone on the alloy side of the couple.

5. In the context of lanthanide/cladding interactions, the development of a large $\mathrm{Ni}_{3} \mathrm{Ce}_{7}$ type layer is undesirable, as it forms a low melting eutectic with $\mathrm{Ce}$ at $477^{\circ} \mathrm{C}$. Such phases can be avoided with Fe-base alloys containing little Ni. The Fe-20.1 $\mathrm{Cr}$ alloy is comparable to pure $\mathrm{Fe}$ in the formation of $\mathrm{Fe}_{2} \mathrm{Ce}$ layer which forms a eutectic with $\mathrm{Ce}$ at a higher temperature of $592^{\circ} \mathrm{C}$.

\section{Acknowledgments}

The support for this research was provided by the U. S. Department of Energy under contract DE-FG07-88ER12814 and by the Argonne National Laboratory under the award No. 80000MOD1 and is gratefully acknowledged. This paper is based on a dissertation submitted by P. C. Tortorici to Purdue University in partial fulfillment of the requirements for the M.S. degree in Metallurgical Engineering. Special thanks are given to M. C. Petri at Argonne National Laboratories for assistance with the experimental techniques and sample preparation.

\section{References}

1. C. H. Till and Y. I. Chang, Proc. of the American Power Conference 48 (1986) p. 688.

2. M. A. Dayananda and J. G. Duh, Diffusion and Defect Data, 39 (1985) 1.

3. T. B. Massalski [Ed], Binary Alloy Phase Diagrams (ASM International, Materials Park, OH 1986).

4. M. A. Dayananda and D. A. Behnke, Scripta Met., 25 (1991) 2187.

5. M. A. Dayananda: in Ordered Intermetallics-Physical Metallurgy and Mechanical Behavior, C. T. Liu et al. (eds), Kluwer Academic Publishers, (1992), p. 465.

6. L. Onsager, Annals New York Academy of Sciences, 46 (1945) 241.

7. M. A. Dayananda and C. W. Kim, Metall. Trans. A., 10A (1979) 1333. 
8. M. A. Dayananda and C. W. Kim, Metall. Trans. A., 14A (1983) 1851.

9. T. Heumann, Z. Phys. Chem., 201 (1958) 168.

10. J. Philibert, Atom Movements Diffusion and Mass Transport in Solid, Les Edition de Physique, France, (1991) p. 420.

11. M. A. Dayananda, Mater. Sci. and Eng., A121 (1989) 351. 


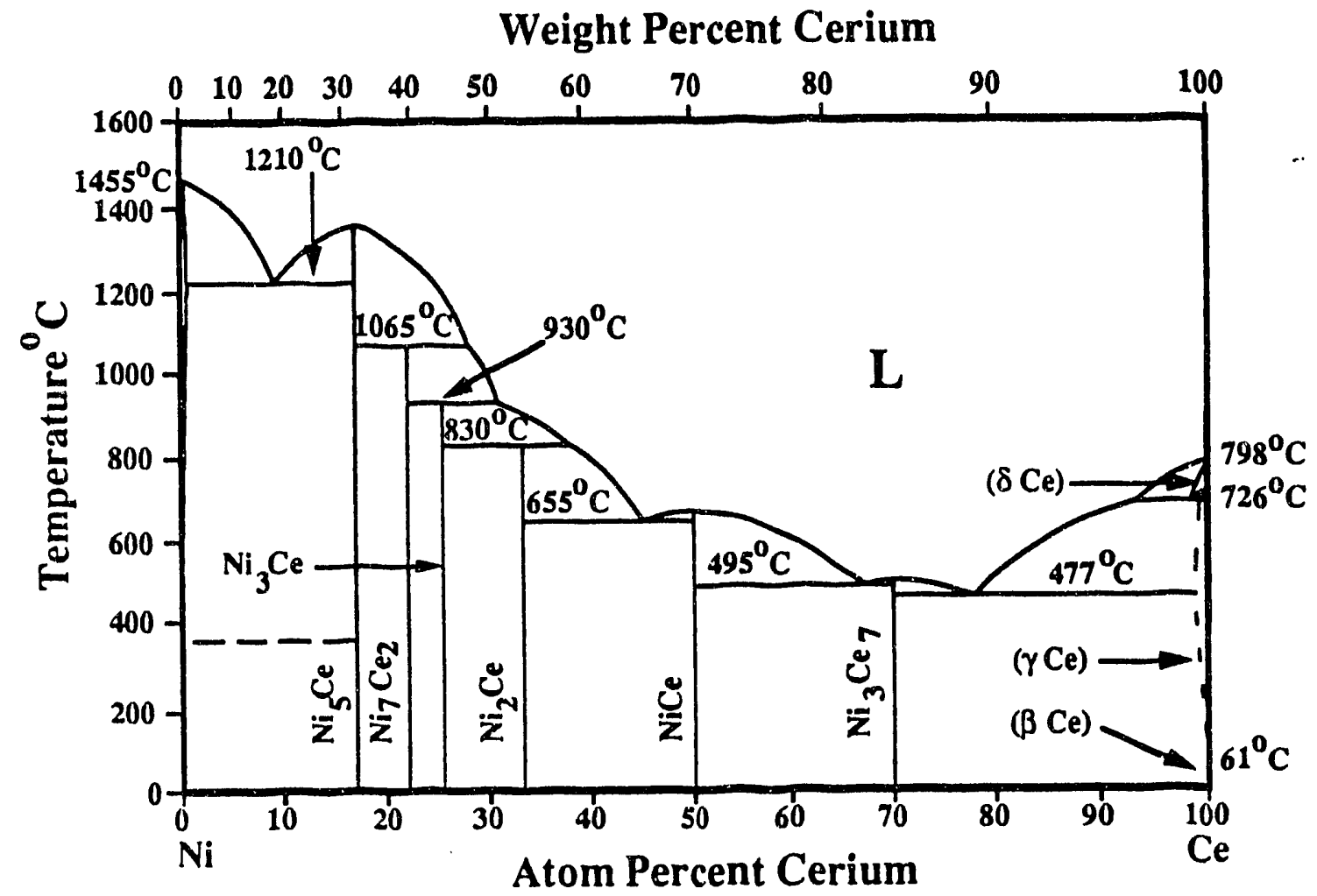

(a)

Weight Percent Cerium

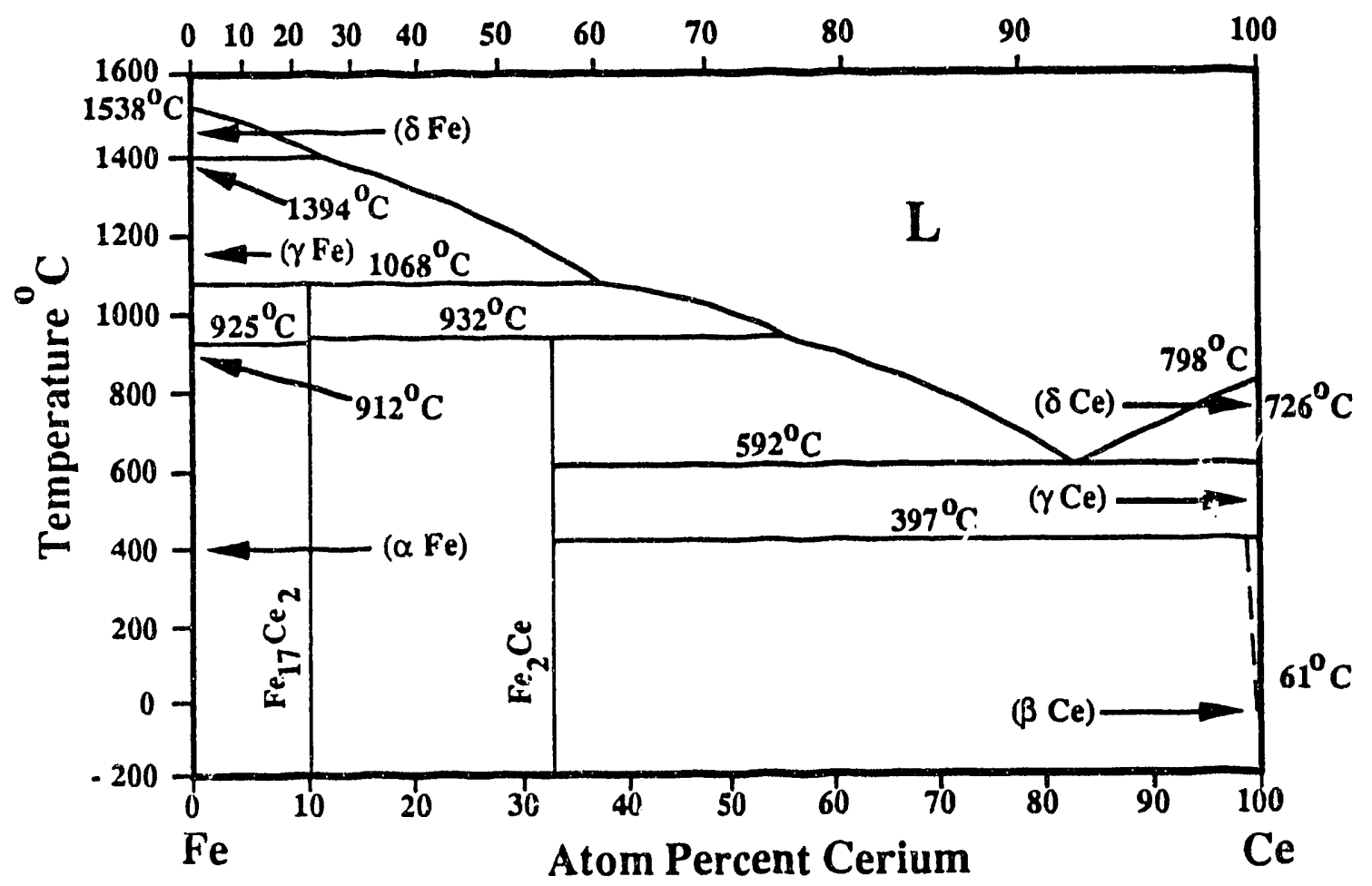

(b)

Figure 1. The phase diagrams for the (a) $\mathrm{Ni}$ vs. $\mathrm{Ce}$ and (b) $\mathrm{Fe}$ vs. $\mathrm{Ce}$ binary systems adapted from ref [3]. 


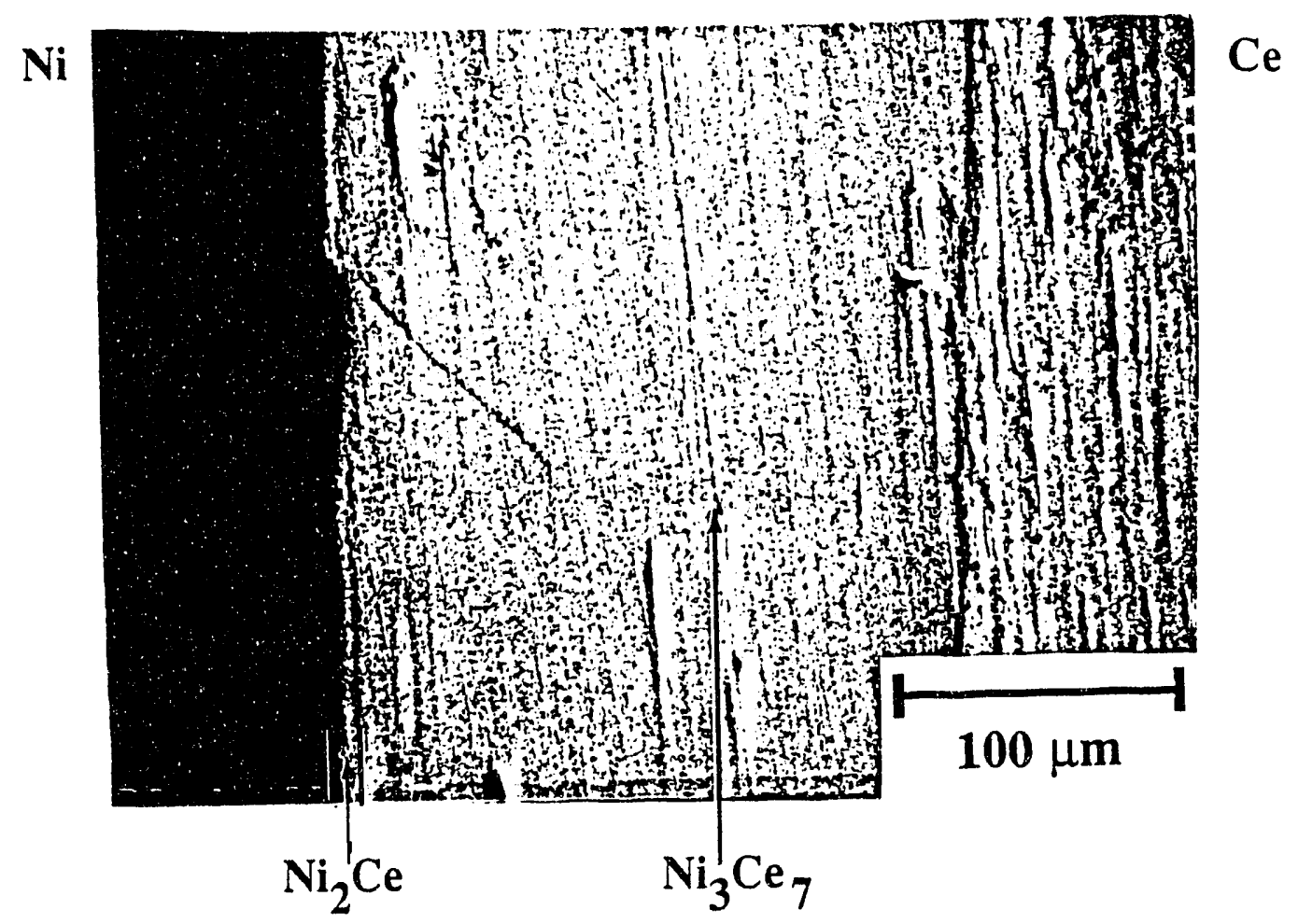

(a)

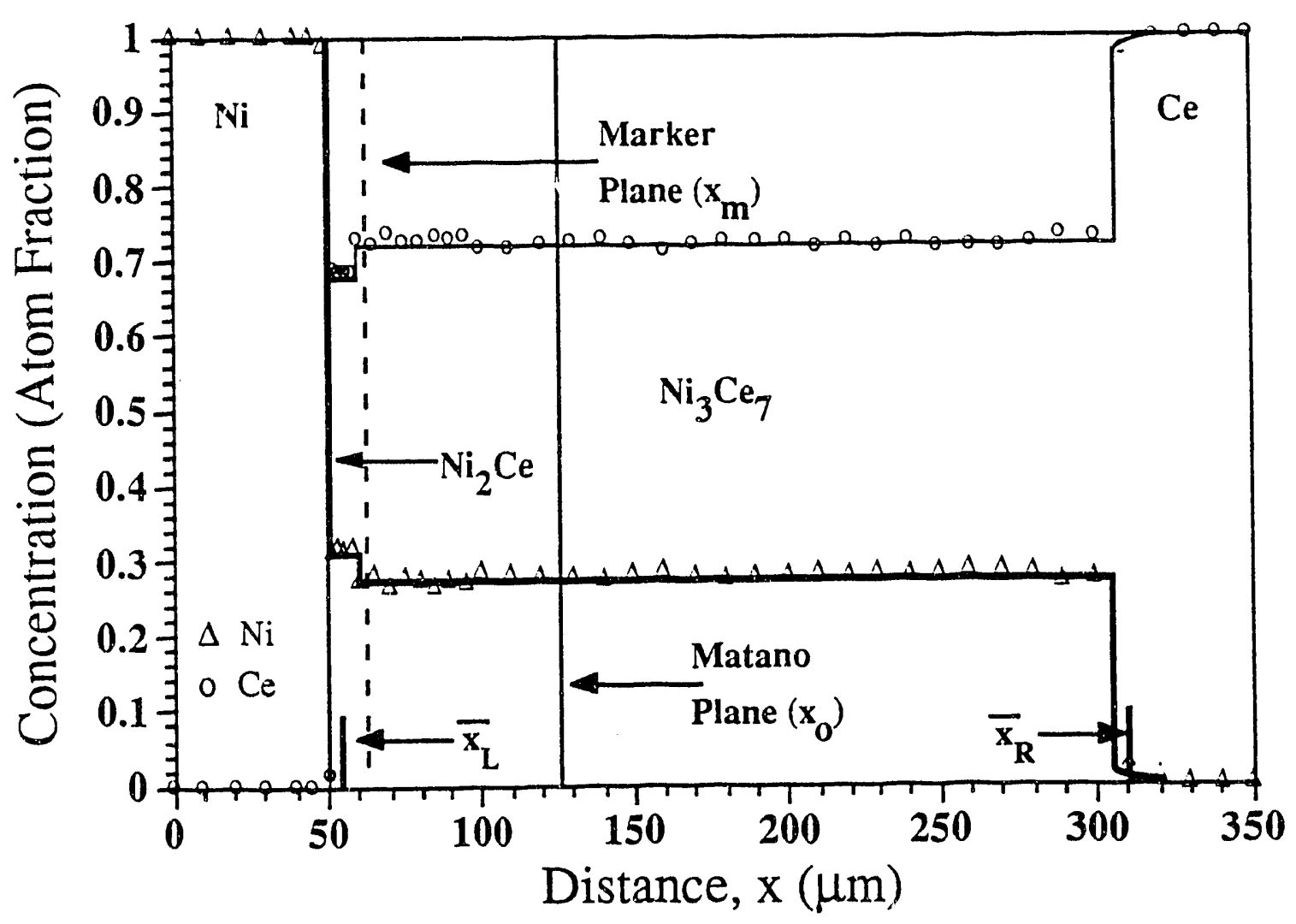

(b)

Figure 2 (a) Diffusion structure and (b) concentration profiles for the $\mathrm{Ni}$ vs. Ce couple annealed at $425^{\circ} \mathrm{C}$ for 4 days. $\mathrm{x}_{\mathrm{o}}$ and $\mathrm{x}_{\mathrm{m}}$ refer to the locations of the Matano plane and the marker plane, respectively. 


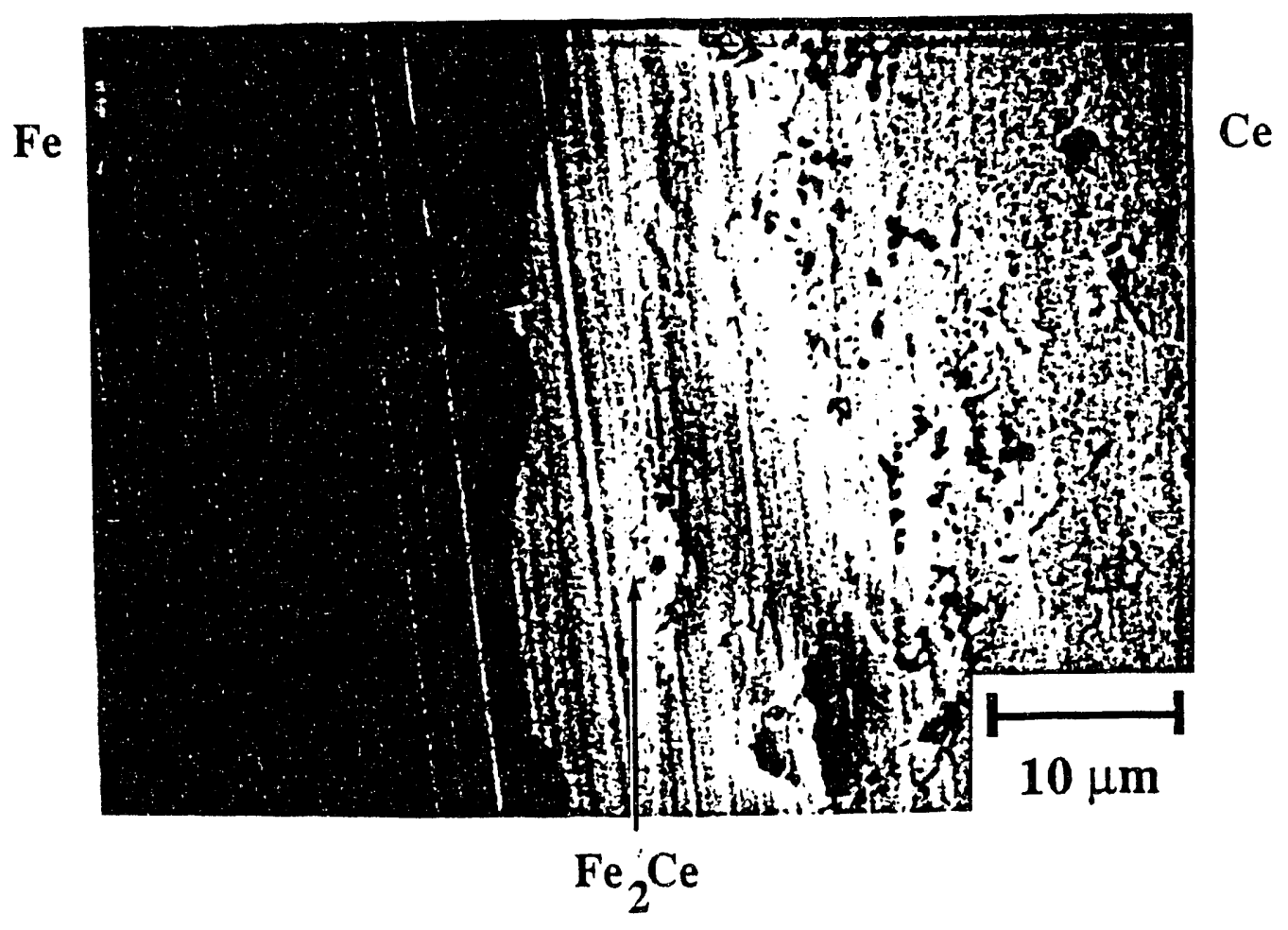

(a)

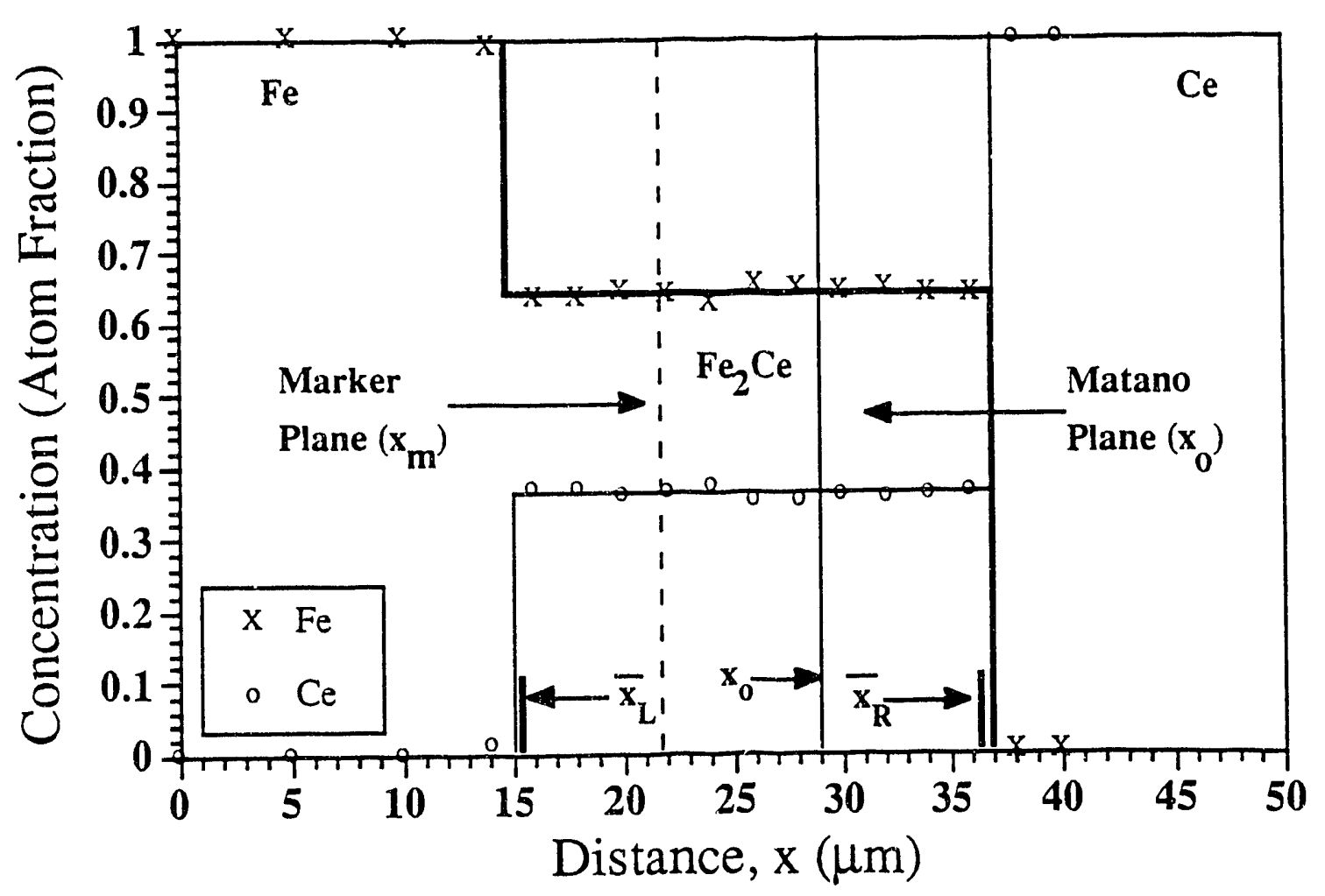

(b)

Figure 3 (a) Diffusion structure and (b) concentration profiles for the $\mathrm{Fe}$ vs. Ce couple annealed at $425^{\circ} \mathrm{C}$ for 4 days. $\mathrm{x}_{\mathrm{o}}$ and $\mathrm{x}_{\mathrm{m}}$ refer to the locations of the Matano plane and the marker plane, respectively. 


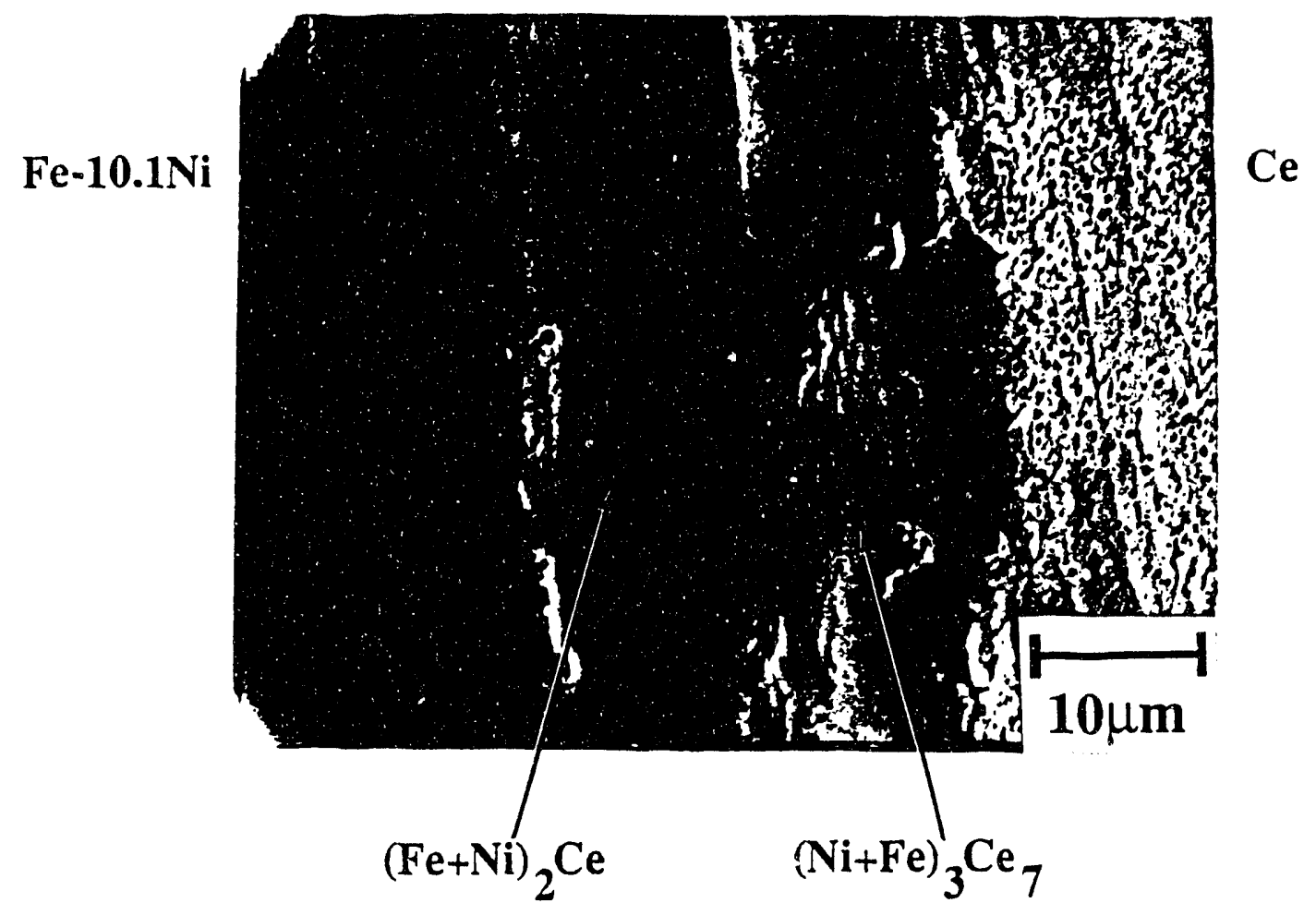

(a)

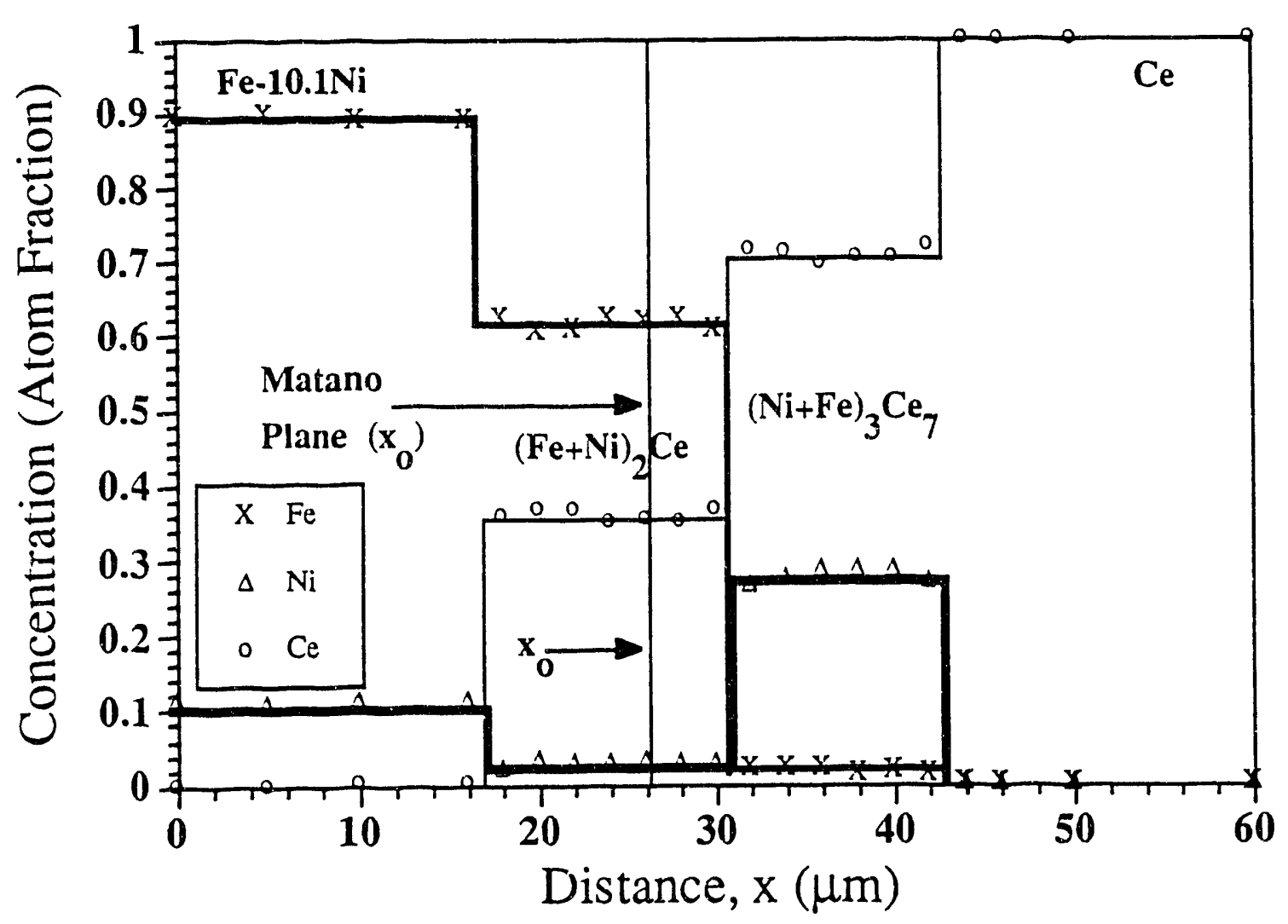

(b)

Figure 4 (a) Diffusion structure and (b) concentration profiles for the $\mathrm{Fe}-10.1 \mathrm{Ni}$ vs. Ce couple annealed at $425^{\circ} \mathrm{C}$ for 4 days. $\mathrm{x}_{\mathrm{o}}$ refers to the location of the Matano plane. 


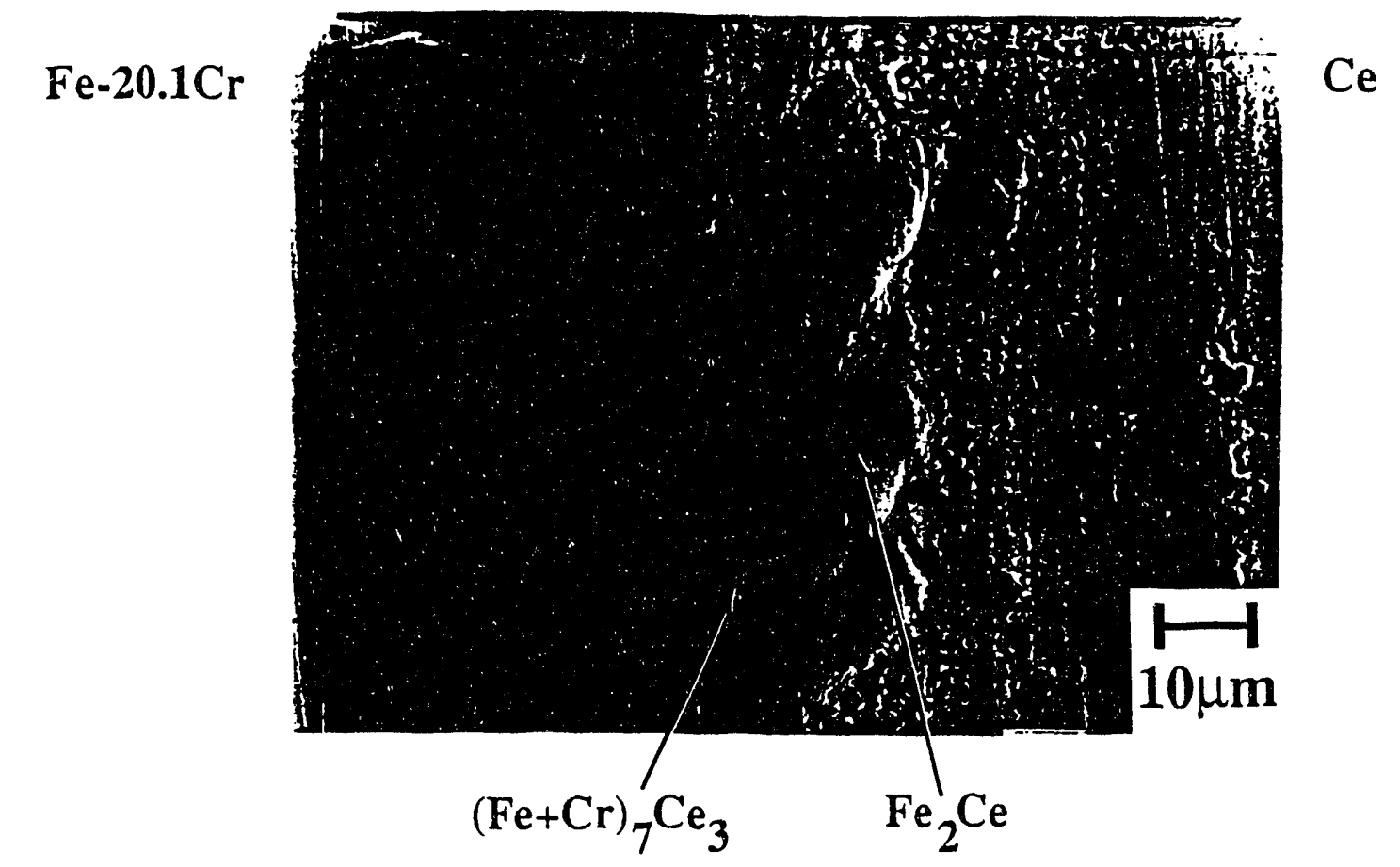

(a)

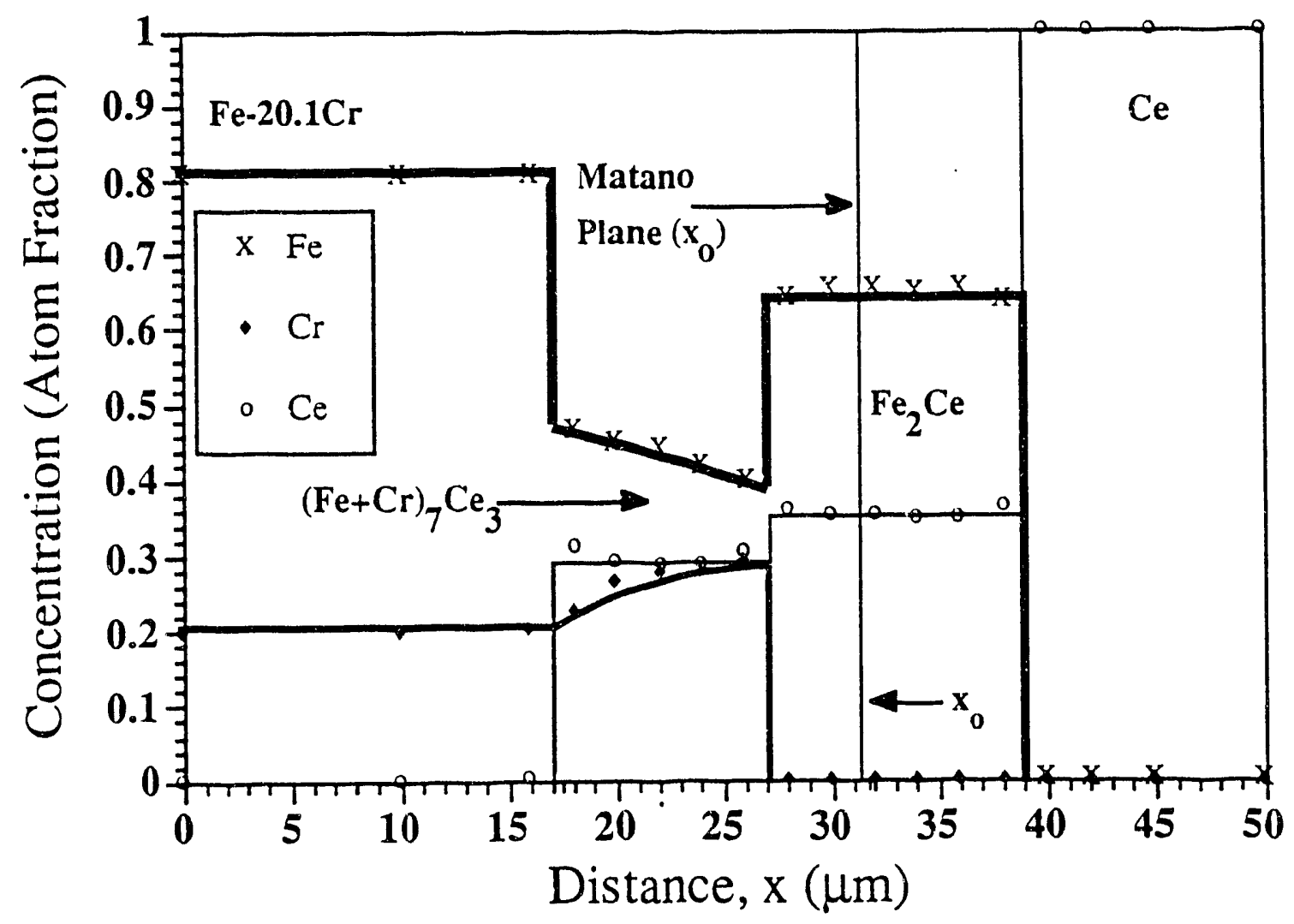

(b)

Figure 5

(a) Diffusion structure and (b) concentration profiles for the $\mathrm{Fe}-20.1 \mathrm{Cr}$ vs. Ce couple annealed at $425^{\circ} \mathrm{C}$ for 4 days. $\mathrm{x}_{\mathrm{o}}$ refers to the location of the Matano plane. 


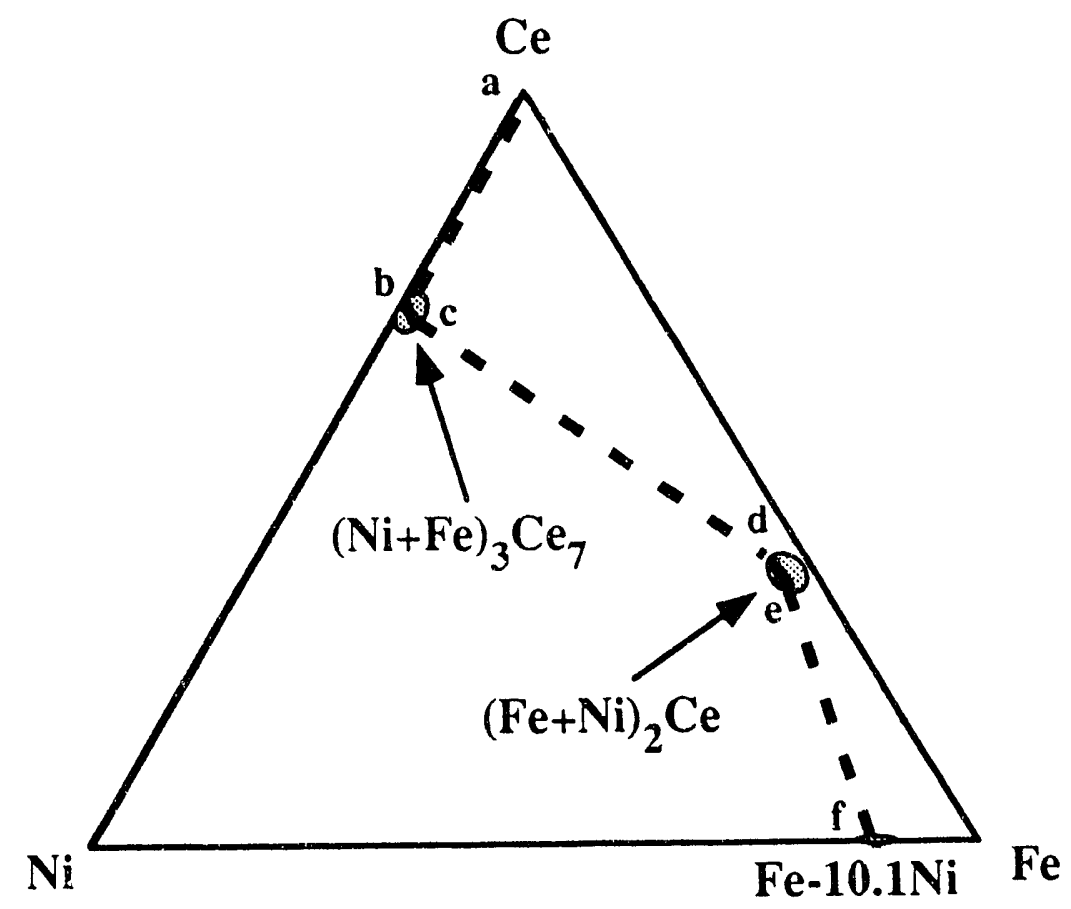

(a)

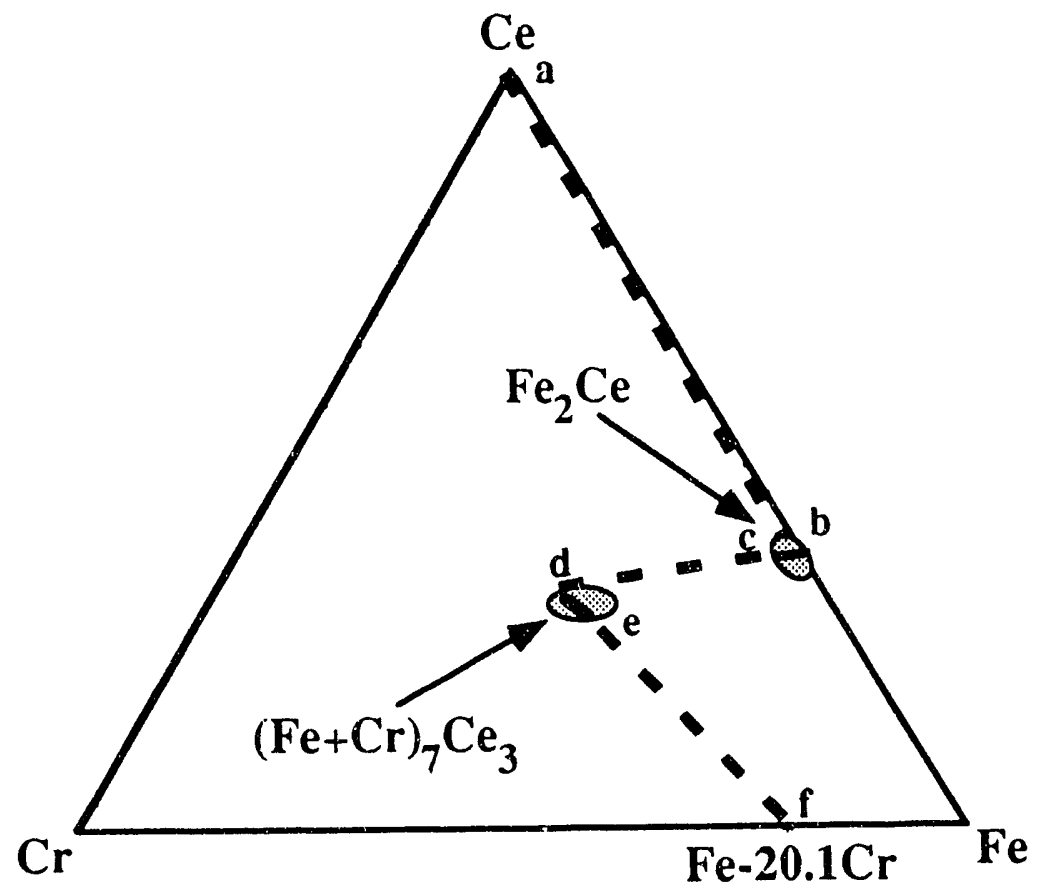

(b)

Figure 6 Experimental diffusion paths on composition triangles at $425^{\circ} \mathrm{C}$ for the couples (a) Fe-10.1Ni vs. Ce, and (b) Fe-20.1 Cr vs. Ce. The phase designations are based on ratios of concentrations. 
Table 2. Average effective interdiffusion coefficients and root-mean-square penetration depths for the various couples annealed at $425^{\circ} \mathrm{C}$ for 4 days.

\begin{tabular}{|c|c|c|c|c|}
\hline $\begin{array}{l}\text { Diffusion } \\
\text { Couple } \\
\text { Assembly }\end{array}$ & $\tilde{\mathrm{D}}_{\mathrm{i}, \mathrm{L}}^{\text {eff }}\left(\frac{\mathrm{m}^{2}}{\mathrm{sec}}\right)$ & $\tilde{\mathrm{D}}_{\mathrm{i}, \mathrm{R}}^{\mathrm{eff}}\left(\frac{\mathrm{m}^{2}}{\mathrm{sec}}\right)$ & $\bar{x}_{i, L}(\mu \mathrm{m})$ & $\bar{x}_{i, R}(\mu \mathrm{m})$ \\
\hline $\mathrm{Ni}$ vs. $\mathrm{Ce}$ & $\tilde{D}_{\mathrm{Ni} \alpha C_{e, L}}^{\text {eff }}=7.3 \times 10^{-15}$ & $\tilde{D}_{\mathrm{Ni} \text { or Ce, } \mathrm{R}}^{\text {eff }}=4.9 \times 10^{-14}$ & $\bar{x}_{\mathrm{Ni}, \mathrm{L}}=70.8$ & $\overline{\mathrm{x}}_{\mathrm{Ni}, \mathrm{R}}=184.8$ \\
\hline $\mathrm{Fe}$ vs. $\mathrm{Ce}$ & $\tilde{\mathrm{D}}_{\mathrm{Fe} \mathrm{or} \mathrm{Ce}, \mathrm{L}}^{\text {eff }}=2.7 \times 10^{-16}$ & $\tilde{\mathrm{D}}_{\mathrm{Fe} \text { or } \mathrm{C}_{e, \mathrm{R}}}^{\text {eff }}=8.4 \times 10^{-17}$ & $\bar{x}_{\mathrm{Fe}, \mathrm{L}}=13.7$ & $\overline{\mathrm{x}}_{\mathrm{Fe}, \mathrm{R}}=7.6$ \\
\hline$\underset{\mathrm{Ce}}{\mathrm{Fe}}$ & $\begin{array}{l}\tilde{D}_{\mathrm{Fe}, \mathrm{L}}^{\text {eff }}=1.4 \times 10^{-16} \\
\tilde{D}_{\mathrm{N}, \mathrm{L}}^{\text {eff }}=2.6 \times 10^{-16} \\
\tilde{\mathrm{D}}_{\mathrm{Ce}, \mathrm{L}}^{\text {eff }}=2.3 \times 10^{-16}\end{array}$ & $\begin{array}{l}\tilde{\mathrm{D}}_{\mathrm{Fe}, \mathrm{R}}^{\text {eff }}=3.4 \times 10^{-17} \\
\tilde{\mathrm{D}}_{\mathrm{Ni}, \mathrm{R}}^{\text {eff }}=2.9 \times 10^{-15} \\
\tilde{\mathrm{D}}_{\mathrm{Ce}, \mathrm{R}}^{\text {eff }}=1.3 \times 10^{-16}\end{array}$ & $\begin{array}{l}\overline{\mathrm{x}}_{\mathrm{Fe}, \mathrm{L}}=9.4 \\
\overline{\mathrm{x}}_{\mathrm{Ni}, \mathrm{L}}=13.0 \\
\overline{\mathrm{x}}_{\mathrm{Ce}, \mathrm{L}}=12.1\end{array}$ & $\begin{array}{l}\bar{x}_{\mathrm{Fe}, \mathrm{R}}=4.7 \\
\overline{\mathrm{x}}_{\mathrm{Ni}, \mathrm{R}}=9.6 \\
\overline{\mathrm{x}}_{\mathrm{Cc}, \mathrm{R}}=9.2\end{array}$ \\
\hline$\underset{\mathrm{Ce}}{\mathrm{Fe}-20.1 \mathrm{Cr}} \mathrm{vs}$ & $\begin{array}{l}\tilde{D}_{\mathrm{Fc}, \mathrm{L}}^{\text {eff }}=7.5 \times 10^{-16} \\
\tilde{D}_{\mathrm{Cr}, \mathrm{L}}^{\mathrm{eff}}=-6.9 \times 10^{-17} \\
\tilde{D}_{\mathrm{Ce}, \mathrm{L}}^{\mathrm{eff}}=2.9 \times 10^{-16}\end{array}$ & $\begin{array}{l}\tilde{D}_{\mathrm{Fe}, \mathrm{R}}^{\text {eff }}=8.1 \times 10^{-17} \\
\tilde{\mathrm{D}}_{\mathrm{Cr}, \mathrm{R}}^{\text {eff }}=-\cdots \\
\tilde{\mathrm{D}}_{\mathrm{Ce}, \mathrm{R}}^{\text {eff }}=7.7 \times 10^{-17}\end{array}$ & $\begin{aligned} \bar{x}_{\mathrm{Fe}, \mathrm{L}} & =22.7 \\
\overline{\mathrm{x}}_{\mathrm{Cr}, \mathrm{L}} & =6.9 \\
\overline{\mathrm{x}}_{\mathrm{Ce}, \mathrm{L}} & =14.0\end{aligned}$ & $\begin{array}{c}\overline{\mathrm{x}}_{\mathrm{Fe}, \mathrm{R}}=7.5 \\
\overline{\mathrm{x}}_{\mathrm{Cr}, \mathrm{R}}=0 \\
\overline{\mathrm{x}}_{\mathrm{Ce}, \mathrm{R}}=7.3\end{array}$ \\
\hline
\end{tabular}


Table 1. Phase layers and their thicknesses in the various couples annealed at $425^{\circ} \mathrm{C}$ for 4 days.

\begin{tabular}{|c|c|c|}
\hline Couple & Phases Observed * & $\begin{array}{c}\text { Layer Thickness } \\
(\mu \mathrm{m}) \\
\end{array}$ \\
\hline \multirow[t]{2}{*}{$\mathrm{Ni}$ vs. Ce } & $\mathrm{Ni}_{2} \mathrm{Ce}$ & 10 \\
\hline & $\mathrm{Ni}_{3} \mathrm{Ce}_{7}$ & 240 \\
\hline $\mathrm{Fe}$ vs. $\mathrm{Ce}$ & $\mathrm{Fe}_{2} \mathrm{Ce}$ & 20 \\
\hline \multirow[t]{2}{*}{$\mathrm{Fe}-10.1 \mathrm{Ni}$ vs. $\mathrm{Ce}$} & $(\mathrm{Fe}+\mathrm{Ni})_{2} \mathrm{Ce}$ & 10 \\
\hline & $(\mathrm{Ni}+\mathrm{Fe})_{3} \mathrm{Ce}_{7}$ & 10 \\
\hline \multirow[t]{2}{*}{$\mathrm{Fe}-20.1 \mathrm{Cr}$ vs. $\mathrm{Ce}$} & $(\mathrm{Fe}+\mathrm{Cr})_{7} \mathrm{Ce}_{3}$ & 10 \\
\hline & $\mathrm{Fe}_{2} \mathrm{Ce}$ & 10 \\
\hline
\end{tabular}

* The designation of a phase layer is based on the ratio of concentration of $\mathrm{Ce}$ to the sum of the concentrations of the other elements present in the phase layer. 

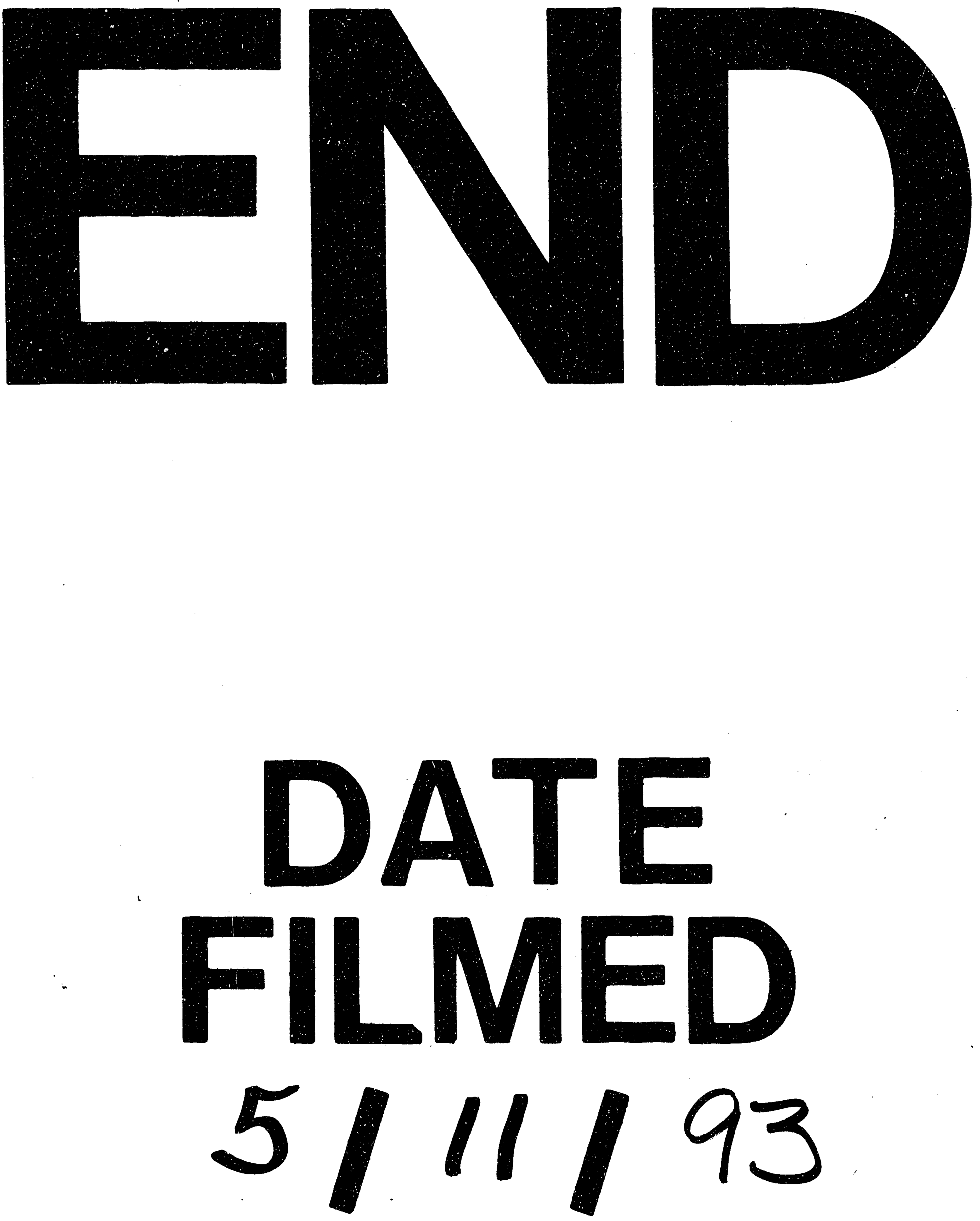

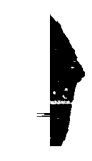


